\title{
ENERGY MODELLING AND FIELD TESTING OF NATURAL GAS ABSORPTION HEAT PUMP SYSTEM IN COLD CLIMATE - CANADA
}

\author{
by \\ Kajen Ethirveerasingham \\ Bachelor of Engineering (Mechanical Engineering) \\ Ryerson University, Toronto, 2016
}

A Thesis

Presented to Ryerson University

In partial fulfillment of the

Requirements for the degree of

MASTER OF APPLIED SCIENCE

In the program of

Mechanical Engineering

Toronto, Ontario, Canada, 2018

(C) Kajen Ethirveerasingham, 2018 


\section{Author's Declaration}

I hereby declare that I am the sole author of this thesis. This is a true copy of the thesis, including any required final revisions, as accepted by my examiners.

I authorize Ryerson University to lend this thesis to other institutions or individuals for the purpose of scholarly research.

I further authorize Ryerson University to reproduce this thesis by photocopying or by other means, in total or in part, at the request of other institutions or individuals for the purpose of scholarly research.

I understand that my thesis may be made electronically available to the public. 


\title{
ENERGY MODELLING AND FIELD TESTING OF NATURAL GAS ABSORPTION HEAT PUMP SYSTEM IN COLD CLIMATE - CANADA
}

\author{
Kajen Ethirveerasingham \\ Master of Applied Science \\ Mechanical Engineering \\ Ryerson University, Toronto, Ontario, Canada, 2018
}

\begin{abstract}
The feasibility of a Natural Gas Absorption Heat Pump (GAHP) was investigated through the use of a technology screening tool developed in Excel and TRNSYS simulations that used experimentally evaluated performance curves using 50\% propylene glycol (PG)/water solution. The Excel tool was used for cost and greenhouse gas (GHG) reductions analysis and indicated that the GAHP was cost effective compared to an Air-Source Heat Pump (ASHP) in locations where the primary heating fuel was natural gas and had significantly lower GHG emissions compared to a $90 \%$ efficient natural gas furnace. During the heating season, it was found that the system only had more than $100 \%$ heating Gas Utilization Efficiency (GUE) at $-1.5^{\circ} \mathrm{C}$ or above and would go as low at $66 \%$ GUE at nominal flow and return temperatures. Part load performance was analyzed using experimental data and implemented in a TRNSYS model. The TRNSYS model shows significant losses from part load performance and 50\% PG/water derating for both heating and cooling season due to excessive cycling.
\end{abstract}




\section{Acknowledgements}

This thesis would not have been possible without the kind support of my supervisor, Dr. Alan Fung. Dr. Fung has guided and encouraged me to go beyond what I thought to be my potential. Only through his support was I able to take on and finish this great task. Without Dr. Fung, I would not have had the opportunities to grow and learn as much as I did, and I am immensely grateful.

I would like to thank my trusted fellow project partner, Altamash Ahmad Baig for all the support and guidance he had provided over the course of this project. I am immensely grateful for the all the time he had taken to teach and help me with my tasks.

I would also like to show my gratitude to the Sustainable Technologies Evaluation Program (STEP) staff for all that they had done to make this project possible. I wish to give my gratitude to especially Aidan Brookson and Erik Janssen for all the time they have invested in not only in this project but for also guiding me and supporting me in my tasks to complete this research. I would also like to thank Gil Amdurski, Ricardo Brown, David Nixon, Svend De Bruyn and Leigh St. Hilaire for all their help in the design and implementation of the project at the Archetype Sustainable Houses.

I wish to also give recognition and thanks to the undergraduate students who had assisted with the experimental data collection for this project and for all the work they've contributed. I would like to thank Kevin Kai Ye, Ahmad Mhanna and Monica Brands for all their hard work and enthusiasm.

I would like to also acknowledge the support provided by Union Gas Limited, Enbridge Gas, Natural Science and Engineering Research Council (NSERC), of Canada, Ontario Center of Excellence (OCE), Toronto and Region Conservation Authority (TRCA) and of course Ryerson University for all the support in this project.

I'd like to give my final thanks to my immensely supportive family, who have encouraged me in all my endeavors in mt studies and have always trusted and believed in my potential. I would especially like to thank mother, whose support has helped greatly throughout my academic career. 


\section{Table of Contents}

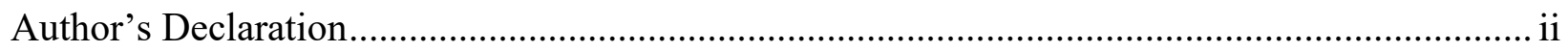

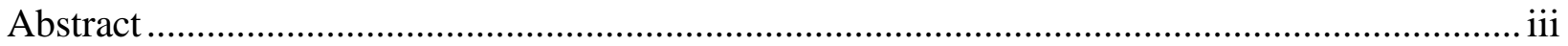

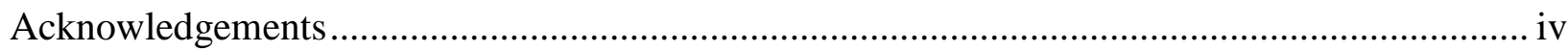

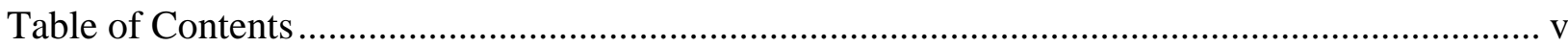

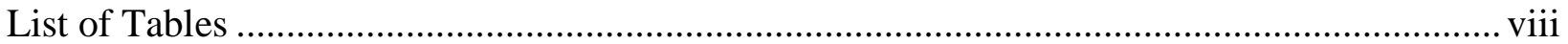

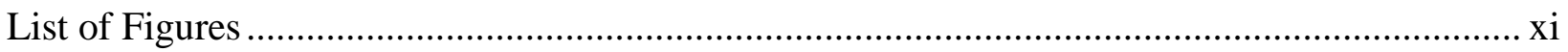

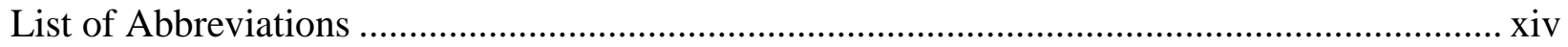

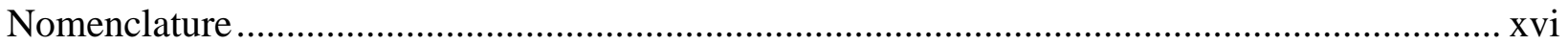

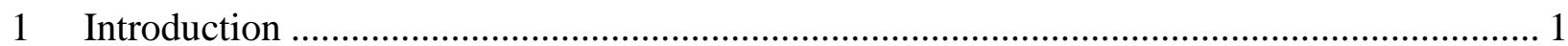

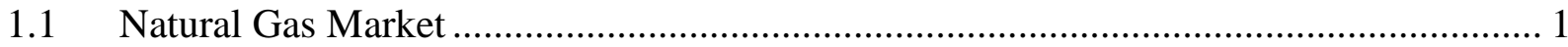

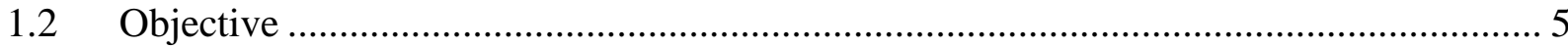

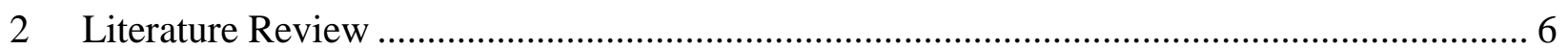

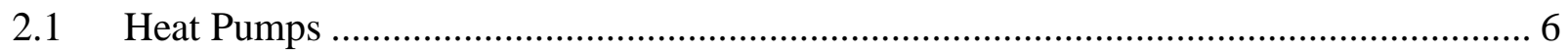

2.1.1 Air-Source and Ground-Source Heat Pumps .......................................................... 6

2.1.2 Absorption Heat Pumps ................................................................................ 7

2.2 System Optimization and Control ......................................................................... 17

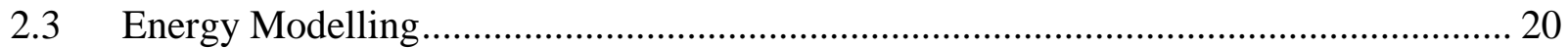

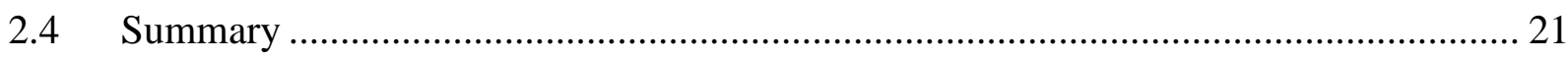

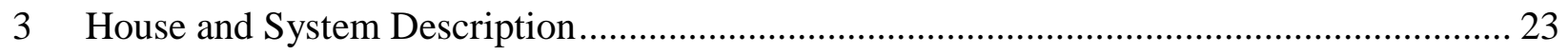

3.1 Construction Summary …………………………….............................................. 25

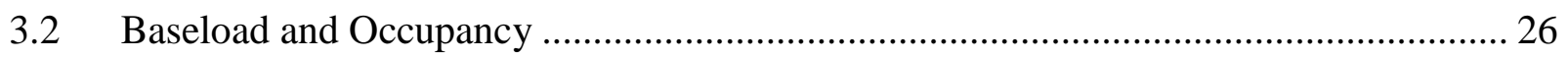

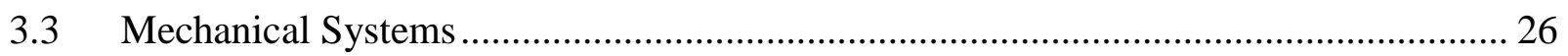

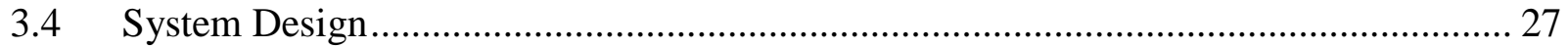

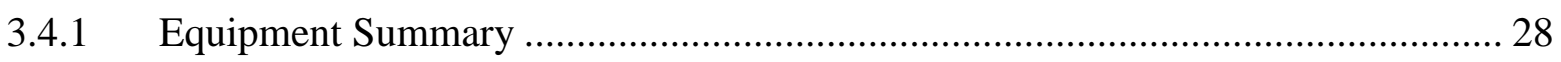

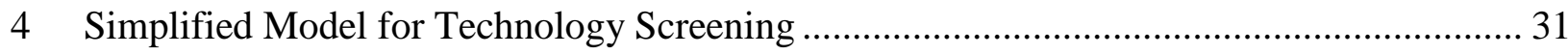

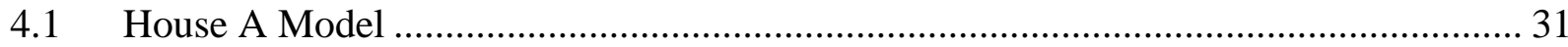

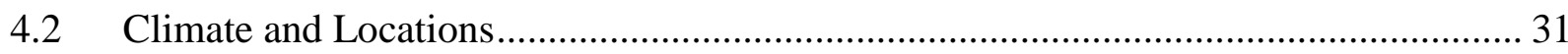

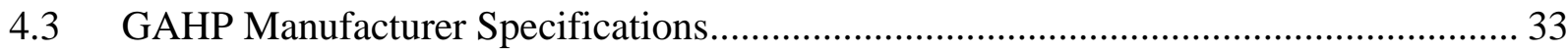

4.4 Simplified Excel Model .................................................................................... 35 


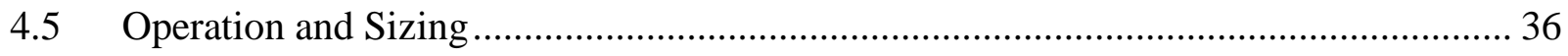

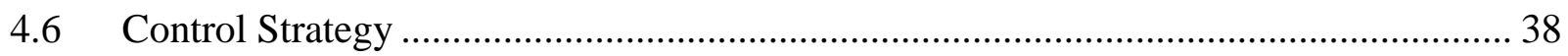

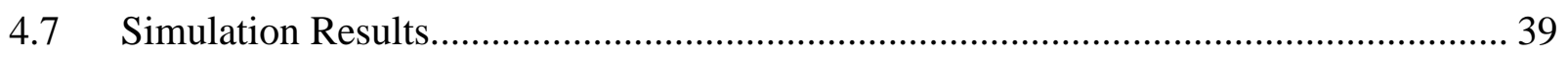

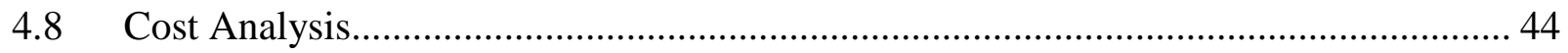

4.8.1 Marginal Cost for Natural Gas and Electricity ........................................................ 44

4.8.2 Simple Cost Analysis ....................................................................................... 44

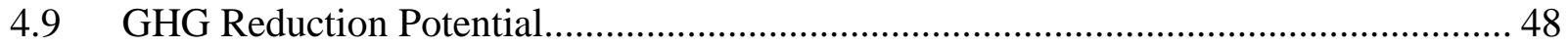

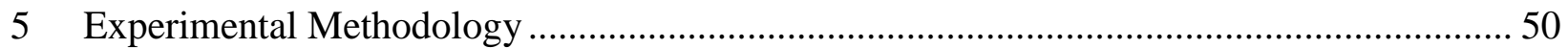

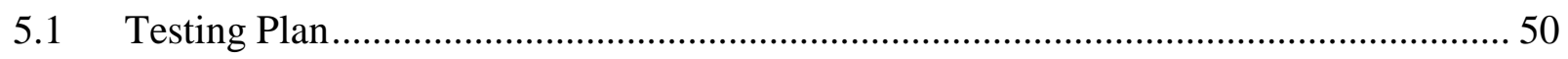

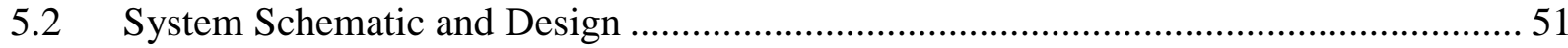

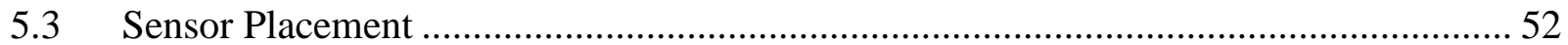

5.4 Data Acquisition System (DAQ) and Monitoring..................................................... 53

5.5 Sensor Calibration and Validation ......................................................................... 53

5.5.1 Fluid Temperature Measurements ......................................................................... 53

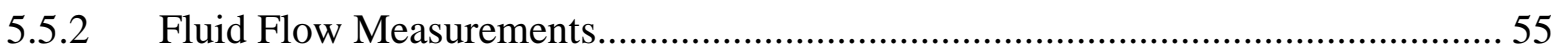

5.5.3 Ambient Outdoor Temperature and Relative Humidity …….................................... 55

5.5.4 Natural Gas Meter Verification .......................................................................... 57

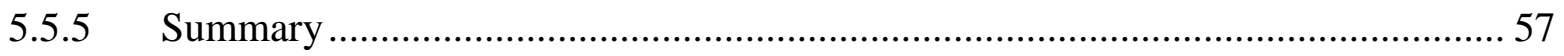

5.6 Steady State Data Collection and Analysis ............................................................... 59

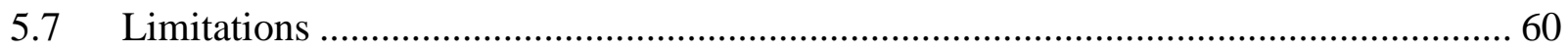

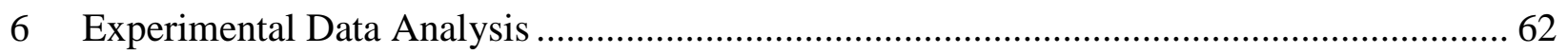

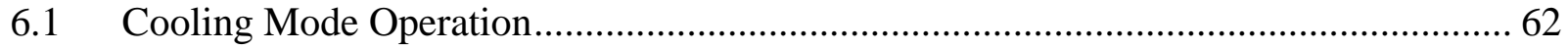

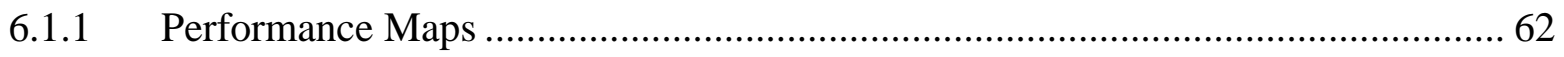

6.1.2 Gas Utilization Efficiency (GUE) of GAHP ..................................................... 67

6.1.3 Power Consumption .............................................................................................. 70

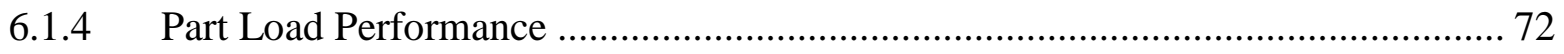

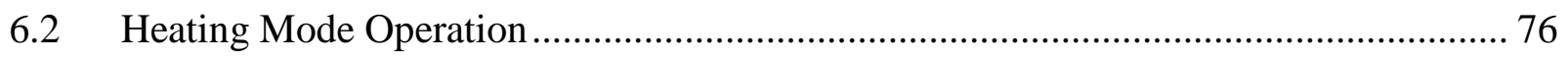

6.2.1 Performance Maps ......................................................................................... 76

6.2.2 Gas Utilization Efficiency (GUE) of GAHP ………………………............. 82

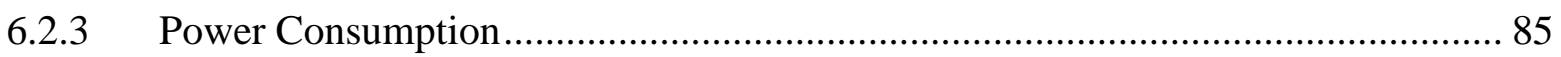

6.2.4 Cycling and Part Load Performance …………….................................................. 87 


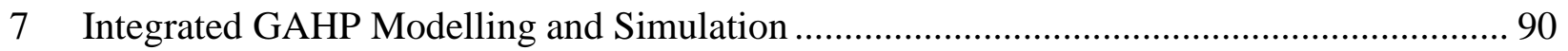

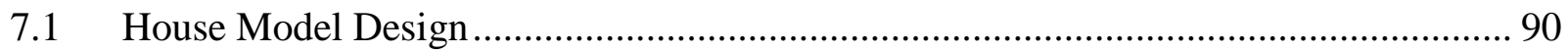

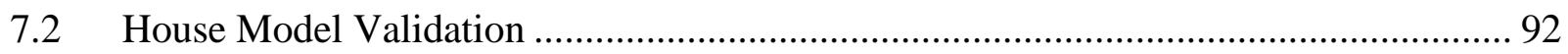

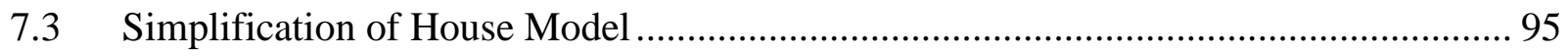

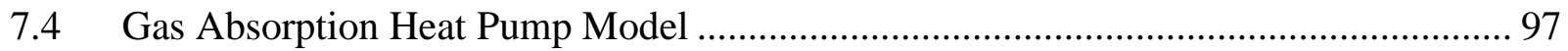

7.4.1 Part Load Performance Modelling .......................................................................... 98

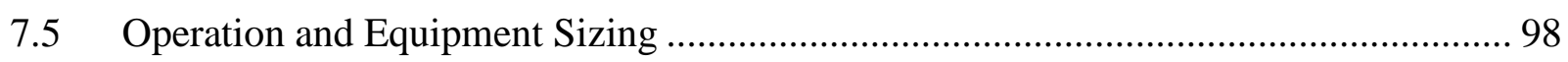

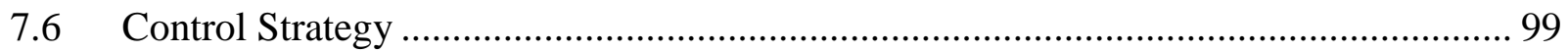

7.7 System Parameters and Effects …………………................................................. 100

8 TRNSYS Simulation Results and Analysis.................................................................. 102

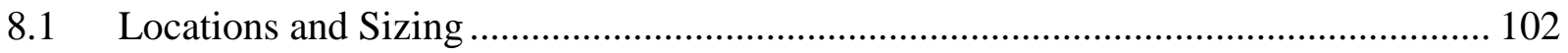

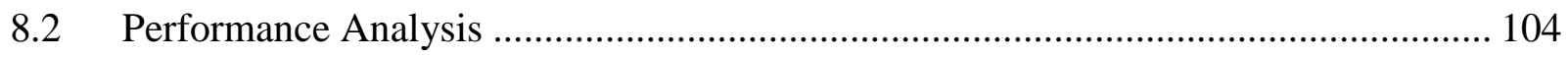

8.3 Operational Cost Comparison with Forced Air Furnace............................................... 109

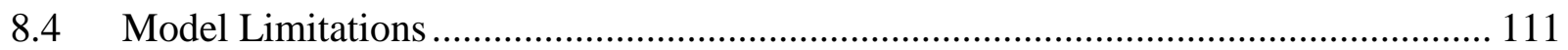

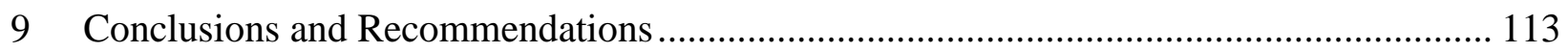

9.1 Simplified Screening Model.............................................................................. 113

9.2 Experimental Performance Evaluation.................................................................... 115

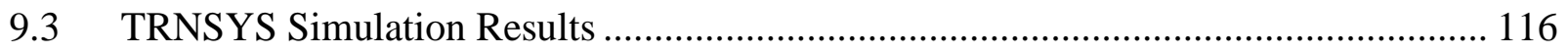

9.4 Future work and Recommendations.................................................................... 117

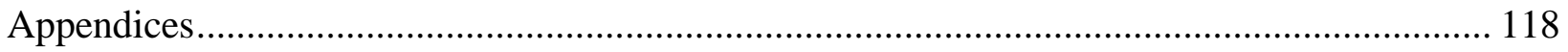

Appendix A - Marginal Cost Breakdown for Natural Gas and Electricity ............................. 118

Appendix B - 50\% PG/Water Solution Thermal Properties ................................................... 120

Appendix C - Sample GAHP Heating and Cooling Cycles .................................................. 122

Appendix D - Uncertainty Analysis ................................................................................... 124

Appendix E - MATLAB Scripts ..................................................................................... 126

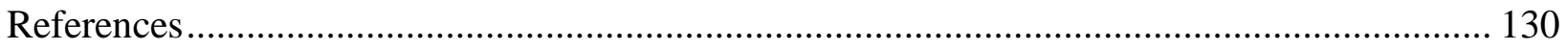




\section{List of Tables}

Table 1.1: Heating fuel usage fraction for each province for varying fuel types in 2011 (Statistics Canada, 2011). 3

Table 2.1: Requirements for effective refrigerant and absorber fluids for safe and effective operation (Murphy \& Phillips, 1984) ............................................................................ 8

Table 3.1: Summary of structural features of Archetype Sustainable Houses (Zhang et al., 2011)

Table 3.2: Summary of air volume and floor area of Archetype Sustainable Houses ................. 25

Table 3.3: Summary of internal gain in each Archetype Sustainable House (Safa et al., 2015c) 26

Table 3.4: House A equipment summary (Zhang et al., 2011) .............................................. 28

Table 3.5: House B equipment summary (Zhang et al., 2011) .............................................. 29

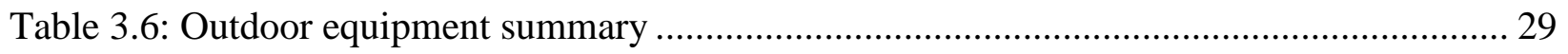

Table 4.1: Summary of maximum and minimum ambient temperatures and HDD and CDD for different Canadian cities.......................................................................................... 33

Table 4.2: Summary of start and end times for heating and cooling season for different Canadian

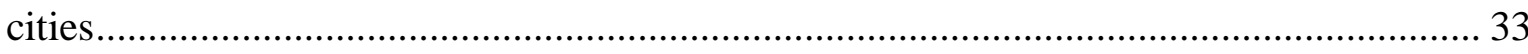

Table 4.3: Heating and cooling peak demands and annual demands for select Canadian cities .. 36

Table 4.4: GAHP heating performance summary from simplified model for various Canadian

cities with $50 \% \mathrm{PG} /$ water as the primary working fluid ............................................. 40

Table 4.5: GAHP heating performance summary from simplified model for various Canadian cities with water as the primary working fluid ........................................................... 41

Table 4.6: GAHP cooling performance summary from simplified model for various Canadian cities with $50 \%$ PG/water as the primary working fluid .............................................. 42

Table 4.7: GAHP cooling performance summary from simplified model for various Canadian cities with water as the primary working fluid ......................................................... 43

Table 4.8: Average marginal gas and electricity prices for various Canadian cities .................. 44

Table 4.9: ASHP thermal energy output and electricity consumption for both heating and cooling season for various Canadian cities (Safa et al., 2015c) ............................................... 45

Table 4.10: Total electricity and natural gas consumption of ASHP and GAHP for various

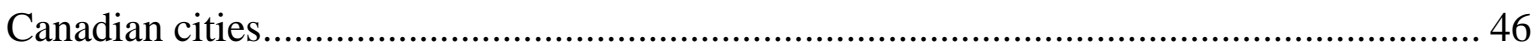

Table 4.11: Total annual operational costs for ASHP and GAHP for various Canadian cities.... 46

Table 4.12: Natural gas energy consumption of $90 \%$ efficient forced air furnace for House A for

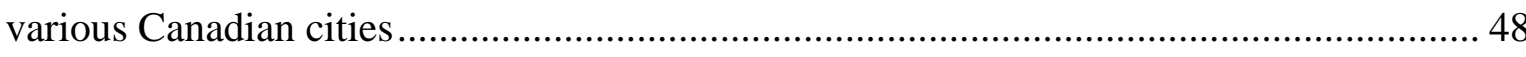

Table 4.13: GHG emissions reduction through reduced natural gas consumption of GAHP using $50 \%$ PG/water compared to $90 \%$ efficient forced air furnace in various Canadian cities .. 49 
Table 5.1: Return temperature and flow rate conditions used for developing experimental performance map for GAHP ........................................................................ 51

Table 5.2: Calibration and validation methods for various sensor/measurement types ............. 53

Table 5.3: Calibration equations of RTDs used in experimental evaluation of GAHP .............. 54

Table 5.4: Summary of sensor locations, operational ranges and accuracies ........................... 58

Table 6.1: Experimental cooling performance curves for varying flow rates at a fixed return

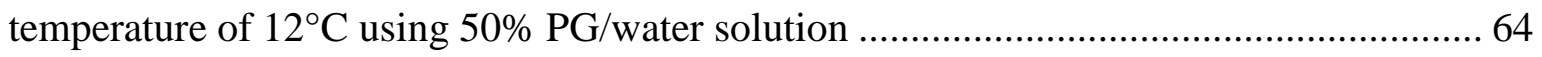

Table 6.2: Maximum and minimum experimental cooling GUE values of varying flow for a fixed return temperature of $12^{\circ} \mathrm{C}$ for $50 \% \mathrm{PG} /$ water solution....................................... 68

Table 6.3: Maximum and minimum manufacturer cooling GUE values for a working fluid of water at a flow rate of $12.8 \mathrm{GPM}$ for varying return temperatures ................................. 70

Table 6.4: Average electric power consumption of GAHP and circulation pumps at varying flow

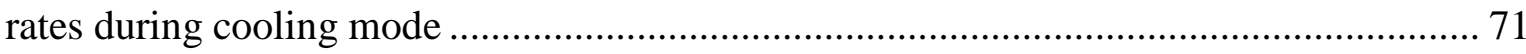

Table 6.5: Maximum and minimum experimental cooling COP values of varying flow for a fixed return temperature of $12^{\circ} \mathrm{C}$ for $50 \% \mathrm{PG}$ /water solution ............................................. 72

Table 6.6: Average cycling parameters evaluated for part-load performance mapping during cooling mode operation of GAHP ..................................................................... 73

Table 6.7: Experimental heating performance curves for varying return temperatures at a fixed flow rate of 13.4 GPM using 50\% PG/water solution............................................... 79

Table 6.8: Maximum and minimum experimental heating capacity values of varying return temperatures at a flow rate of 13.4 GPM for $50 \%$ PG/water solution .............................. 80

Table 6.9: Maximum and minimum experimental heating GUE values of varying return temperatures at a flow rate of $13.4 \mathrm{GPM}$ for $50 \% \mathrm{PG}$ /water solution ........................... 82

Table 6.10: Maximum and minimum manufacturer heating GUE values for a working fluid of water at a flow rate of 13.4 GPM for varying return temperatures ............................... 83

Table 6.11: Average electric power consumption of GAHP and circulation pumps at varying

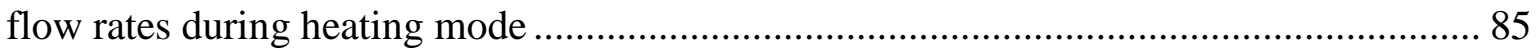

Table 6.12: Maximum and minimum experimental heating COP values of varying return temperatures at a flow rate of $13.4 \mathrm{GPM}$ for $50 \% \mathrm{PG} /$ water solution .............................. 86

Table 6.13: Average cycling parameters evaluated for part-load performance mapping during

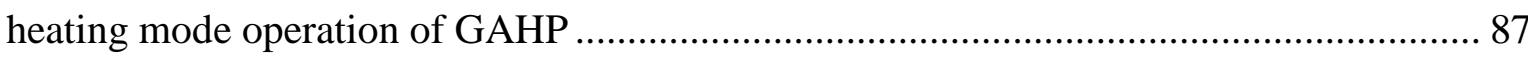

Table 7.1: Peak heating and cooling demand of each house of validated house models compared to combined house model.

Table 7.2: Annual heating and cooling demand of each house of validated house models compared to combined house model

Table 7.3: Peak heating and cooling demand for each floor of each house in combined house model 
Table 7.4: Heating and cooling ratio for each floor for both houses with respect to total heating or cooling energy input into each house .............................................................. 96

Table 8.1: Heating and cooling peak demands and annual demands for combined house model in

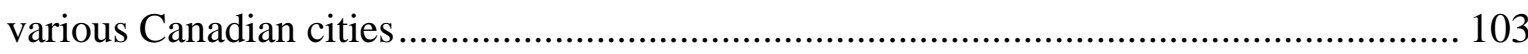

Table 8.2: GAHP heating performance simulation results for various Canadian cities with part

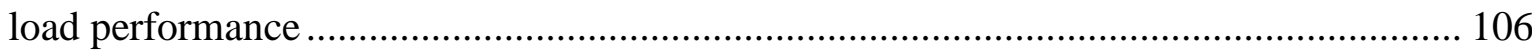

Table 8.3: GAHP cooling performance simulation results for various Canadian cities with part

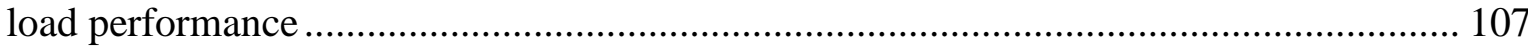

Table 8.4: GAHP heating performance simulation results for various Canadian cities with no part

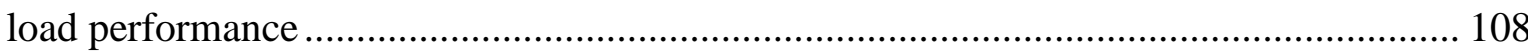

Table 8.5: GAHP cooling performance simulation results for various Canadian cities with no part load performance

Table 8.6: Annual thermal demand and respective natural gas consumption for 2 cases of forced air furnaces with different efficiencies in various Canadian cities.

Table 8.7: Operational cost comparison of GAHP during heating season and forced air furnace with efficiency of $85 \%$ in various Canadian cities

Table 8.8: Operational cost comparison of GAHP during heating season and forced air furnace with efficiency of $90 \%$ in various Canadian cities 110

Table 8.9: Operational cost comparison of GAHP during heating season and forced air furnace with efficiency of $95 \%$ in various Canadian cities 


\section{List of Figures}

Figure 1.1: Average electricity prices for the period of April 2015 (NRC, 2016) ........................ 2

Figure 1.2: Relative natural gas usage for each province in Canada for 2012 (NRC, 2016) ......... 2

Figure 1.3: Relative electricity usage for each province in Canada for 2012 (NRC, 2016) ........... 3

Figure 1.4: Primary heating system in Canadians homes in 2011 (Statistics Canada, 2011) ......... 4

Figure 2.1: Diagram of basic vapor compression cycle in compression-based heat pump systems

(Wu, 2009) 6

Figure 2.2: Schematic of Absorption Heat Pump where Ammonia Water is the working fluid

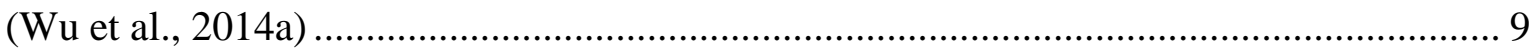

Figure 2.3:Schematic diagram of single-effect AHP cycle (Wang \& Infante Ferreira, 2017) ..... 11

Figure 2.4: Single-effect AHP cycle in a ln P- (-1/T) (Wang \& Infante Ferreira, 2017) ............. 12

Figure 3.1: North-east side of Archetype Sustainable Houses, House B is seen on far left ......... 24

Figure 3.2: North-west side of Archetype Sustainable Houses, House A is seen on far right ..... 24

Figure 3.3: Robur AR-GAHP unit installed on east wall of House B ......................................... 27

Figure 4.1: Ambient outdoor temperature profile for Toronto (Klein, 2010) ……...................... 32

Figure 4.2: Heating GAHP performance curves for water and 50\% PG/water with a return temperature of $40^{\circ} \mathrm{C}$ at $13.4 \mathrm{GPM}$............................................................................... 35

Figure 4.3: Cooling GAHP performance curves for water and 50\% PG/water with a return

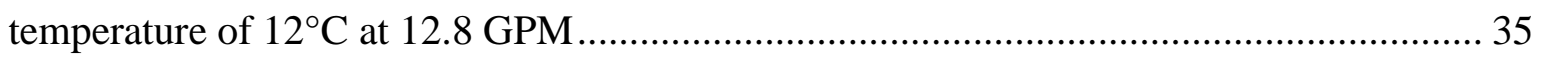

Figure 4.4: Flow diagram of the control strategy used in simplified model................................ 39

Figure 5.1: Complete combined house HVAC schematic for GAHP experimental evaluation ... 52

Figure 5.2: Comparison of Vaisala measured outdoor temperature against Lufft weather station

over two week period (TRCA, 2018) ........................................................................ 56

Figure 5.3: Comparison of Vaisala measured relative humidity against Lufft weather station over

two week period (TRCA, 2018) …………………………......................................... 57

Figure 6.1: Experimental cooling capacity with respect to ambient outdoor temperature for a return temperature of $12^{\circ} \mathrm{C}$ for varying flow rates using 50\% PG/water .......................... 63

Figure 6.2: Experimental cooling capacity of GAHP with respect to ambient outdoor temperatures for varying return temperatures at a flow rate of 12.6 GPM using 50\% PG/water..... 64

Figure 6.3: Manufacturer cooling performance curves for a working fluid of water for varying return temperatures at $12.8 \mathrm{GPM}$

Figure 6.4: Experimental cooling capacity of GAHP with respect to ambient outdoor temperatures for varying return temperatures at a flow rate of 12.1 GPM using 50\%

$\mathrm{PG} /$ water 66 
Figure 6.5: Experimental cooling capacity of GAHP with respect to ambient outdoor temperatures for varying return temperatures at a flow rate of 10.1 GPM using 50\% PG/water....

Figure 6.6: Experimental cooling GUE with respect to ambient outdoor temperature for a return temperature of $12^{\circ} \mathrm{C}$ for varying flow rates using $50 \% \mathrm{PG} /$ water with gas input of $28.7 \mathrm{~kW}$

Figure 6.7: Manufacturer cooling GUE for a working fluid of water for varying return temperatures at $12.8 \mathrm{GPM}$ with gas input of $28 \mathrm{~kW}$

Figure 6.8: Experimental cooling COP with respect to ambient outdoor temperature for a return temperature of $12^{\circ} \mathrm{C}$ for varying flow rates using $50 \% \mathrm{PG} /$ water.

Figure 6.9: Experimental cycling factor of GAHP during cooling mode operation with respect to the duration of an entire cycle 74

Figure 6.10: Experimental cooling mode cycle factor with respect to time for average GAHP start-up period, first 6 minutes. 76

Figure 6.11:Experimental heating capacity with respect to ambient outdoor temperature for a return temperature of $40^{\circ} \mathrm{C}$ for varying flow rates using $50 \% \mathrm{PG} /$ water 77

Figure 6.12: Manufacturer heating performance curves for a working fluid of water for varying return temperatures at $13.4 \mathrm{GPM}$

Figure 6.13: Experimental heating capacity of GAHP with respect to ambient outdoor temperatures for varying return temperatures at a flow rate of 13.4 GPM using 50\% PG/water.

Figure 6.14: Experimental heating capacity of GAHP with respect to ambient outdoor temperatures for varying return temperatures at a flow rate of 14.8 GPM using 50\% PG/water

Figure 6.15: Experimental heating capacity of GAHP with respect to ambient outdoor temperatures for varying return temperatures at a flow rate of 10.1 GPM using 50\% PG/water

Figure 6.16: Experimental heating GUE of GAHP with respect to ambient outdoor temperatures for varying return temperatures at a flow rate of 13.4 GPM using 50\% PG/water with gas input of $28.7 \mathrm{~kW}$

Figure 6.17: Manufacturer heating GUE for a working fluid of water for varying return temperatures at 13.4 GPM with gas input of $28 \mathrm{~kW}$

Figure 6.18: Experimental heating COP of GAHP with respect to ambient outdoor temperatures for varying return temperatures at a flow rate of 13.4 GPM using 50\% PG/water. 86

Figure 6.19: Experimental cycling factor of GAHP during heating mode operation with respect to the duration of an entire cycle 
Figure 6.20: Experimental heating mode cycle factor with respect to time for average GAHP start-up period, first 8 minutes........................................................................................ 89

Figure 7.1: South facing side of TRNSYS 3D ASH model, House A on left and House B on right 91

Figure 7.2: North facing side of TRNSYS 3D ASH model, House A on right and House B on left .

Figure 7.3: House A annual energy demand profile for identical setpoints and season durations used in validated model. 93

Figure 7.4: House B annual energy demand profile for identical setpoints and season durations used in validated model

Figure 7.5: Combined house model annual energy demand profile for identical setpoints and season durations used in validated model

Figure 8.1: TRNSYS simulation GAHP output profile for heating and cooling season in the city of Toronto 105 


\section{List of Abbreviations}

AHP

AHU

ARI

$\mathrm{ASH}$

ASHP

ASHRAE

BTU

CDD

COP

DAQ

DHW

DX

EHP

FS

GAHP

GAX

GEHP

GHG

GHP

GPM

GRG

GSHP

GUE

HDD

HHV

HVAC

IESO

IL
Absorption Heat Pump

Air Handling Unit

Air Conditioning and Refrigeration Institute

Archetype Sustainable Houses

Air-Source Heat Pump

American Society of Heating, Refrigerating and Air-

Conditioning Engineers

British Thermal Unit

Cooling Degree Day

Coefficient of Performance

Data Acquisition System

Domestic Hot Water

Direct Expansion

Electric Heat Pump

Full Scale

Gas Absorption Heat Pump

Generator-Absorber Heat Exchanger

Gas Engine Heat Pump

Greenhouse Gas

Gas-Driven Heat Pump

Gallons per Minute

Generalized Reduced Gradient

Ground-Source Heat Pump

Gas Utilization Efficiency

Heating Degree Day

Higher Heating Value

Heating, ventilation, and air conditioning

Independent Electricity System Operator

Ionic Liquid 


$\begin{array}{ll}\text { kW } & \text { Kilowatt } \\ \text { kWh } & \text { Kilowatt hour } \\ \text { LEED } & \text { Leadership in Energy and Environment Design } \\ \text { LNG } & \text { Liquid Natural Gas } \\ \text { LPM } & \text { Liters per Minute } \\ \text { MBH } & \text { Thousand BTUs per Hour } \\ \text { OAHP } & \text { Open Absorption Heat Pump } \\ \text { PER } & \text { Primary Energy Ratio } \\ \text { PG } & \text { Propylene Glycol } \\ \text { PV } & \text { Photovoltaic } \\ \text { RMSE } & \text { Root Mean Sum Error } \\ \text { RNG } & \text { Renewable Natural Gas } \\ \text { RTD } & \text { Resistance Temperature Detector } \\ \text { SHX } & \text { Solution Heat Exchanger } \\ \text { STEP } & \text { Sustainable Technologies Evaluation Program } \\ \text { TES } & \text { Thermal Energy Storage } \\ \text { TRCA } & \text { Toronto and Region Conservation Authority } \\ & \end{array}$




\section{Nomenclature}

$\begin{array}{ll}C_{p} & \text { Specific heat capacity }(\mathrm{kJ} / \mathrm{kg} \cdot \mathrm{K}) \\ \dot{E} & \text { GAHP natural gas input energy }(\mathrm{kW}) \\ F_{c y c} & \text { GAHP cycling factor } \\ \dot{m} & \text { Primary fluid mass flow rate }(\mathrm{kg} / \mathrm{s}) \\ N & \text { Number of days } \\ \dot{Q} & \text { Heat transfer rate }(\mathrm{kW}) \\ T & \text { Temperature }\left({ }^{\circ} \mathrm{C}\right) \\ \bar{T}_{l} & \text { Daily average temperature }\left({ }^{\circ} \mathrm{C}\right) \\ T_{r e f} & \text { Reference temperature }\left({ }^{\circ} \mathrm{C}\right) \\ \Delta T & \text { Temperature difference }\left({ }^{\circ} \mathrm{C}\right) \\ t & \text { Time (minutes) }\end{array}$

Greek symbols:

$\begin{array}{ll}\rho & \text { Primary fluid density }\left(\mathrm{kg} / \mathrm{m}^{3}\right) \\ \eta & \text { Cycle efficiency }\end{array}$

Subscripts:

Cooling GAHP cooling mode operation

Heating GAHP heating mode operation

Overall Average over entire cycle time

$P G /$ water $\quad 50 \%$ Propylene glycol and water solution

SS Steady state operation

Startup GAHP start up period 


\section{Introduction}

Natural Gas-fired Absorption Heat Pumps (GAHPs) are able to deliver space conditioning and water heating at a higher level of efficiency and lower operating cost than traditional natural gas heating equipment. In comparison with electric heat pumps, GAHP technology has many potential merits, such as more stable thermal outputs in cold weather conditions, higher primary energy conversion efficiency, reduced peak electric demand and lower operating costs. GAHPs are ideal to be used as a transitional technology since their operational costs are lower than electric heat pumps due to the difference in electricity and natural gas prices, and GHG emissions are still reduced due to reduced gas consumption relative to traditional natural gas heating equipment such as forced air furnaces.

A recent examination of residential heat pump systems in Ontario by the Independent Electricity Systems Operator (IESO) has found that electric heat pump technologies will benefit homes that already use electricity as the primary heating source through reduced operational cost and energy use, while less so for homeowners that use natural gas as the primary heating fuel (IESO, 2017). They have also considered that natural gas prices must increase by more than $50 \%$ for electric heat pumps such as Air-Source Heat Pumps (ASHP) to be viable alternatives (IESO, 2017). What the IESO examination report did not consider however, is that transitional natural gas driven technologies such as GAHPs can offer a middle ground, in terms of costs and emission reduction, between ASHP and conventional heating systems such as furnaces and boilers.

\subsection{Natural Gas Market}

Understanding the market for such a technology is crucial in understanding its applications and its key strengths. Currently, the primary objective of advances in heat pump technology is to minimize the energy consumption, which as a result, is expected to reduce energy cost and GHG emissions. However, the most efficient technologies on the market that address these goals that are widely available are electrically powered, ASHP and Ground-Source Heat Pump (GSHP) (Wu, 2009). Heat pumps that only use electricity are a very appealing option, especially so when the electricity used, is produced using energy sources that are either renewable or have minimal to zero GHG emissions such as solar, wind, hydro and nuclear power. Figure 1.1 shows average electricity prices in April 2015 of various provinces in Canada. It can be seen that Ontario has one 
of the highest prices for electricity with an average of 16.40 cents/kWh according to Natural Resources Canada (NRC, 2016).

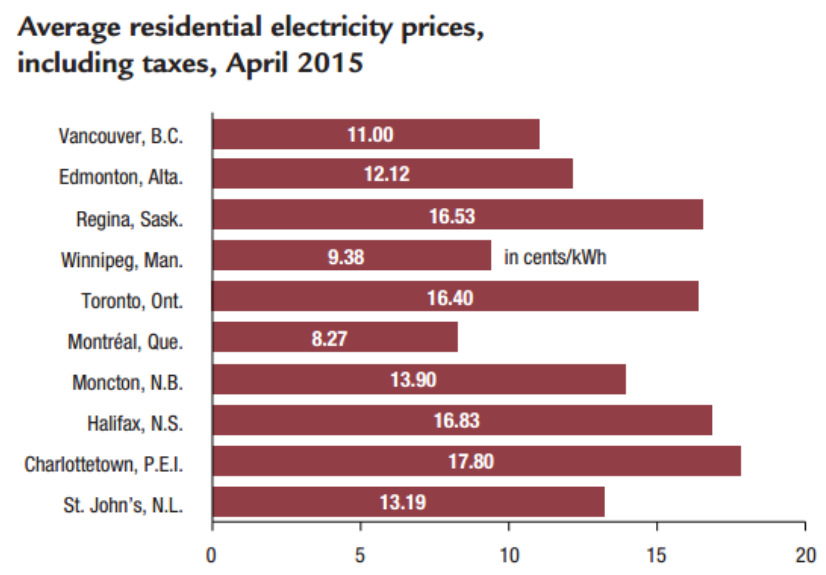

Figure 1.1: Average electricity prices for the period of April 2015 (NRC, 2016)

From Figure 1.2, it can be seen that Ontario, along with Alberta, use the most natural gas of all provinces in 2012. In addition, a total of $26.2 \%$ of natural gas use is estimated to be for residential use, second only to industrial use at 52.8\% (NRC, 2016).

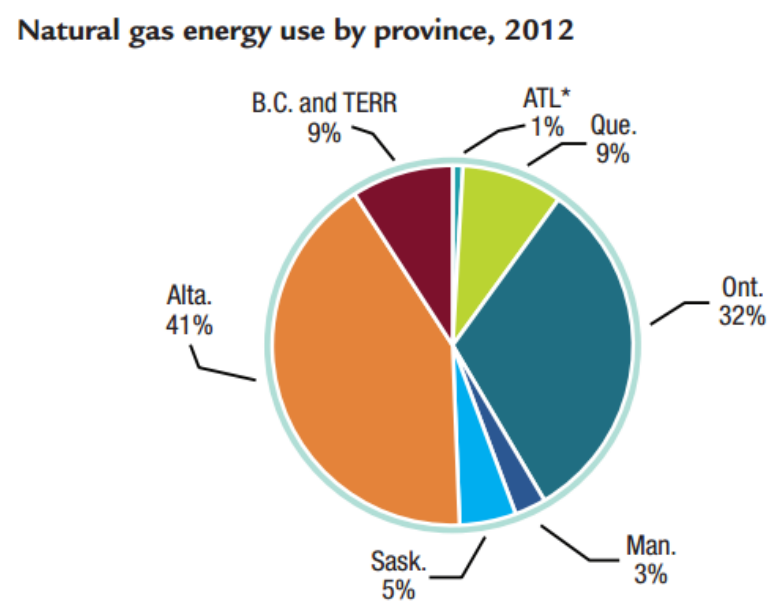

* Atlantic provinces.

Figure 1.2: Relative natural gas usage for each province in Canada for 2012 (NRC, 2016)

Compared to electricity usage for all provinces, Figure 1.3 shows that Ontario has less share but is still a large consumer. 


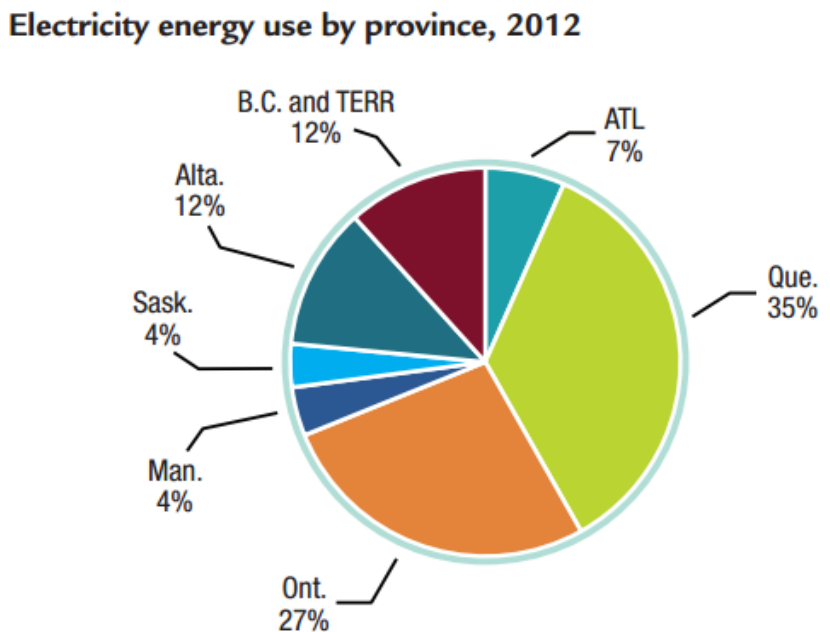

Figure 1.3: Relative electricity usage for each province in Canada for 2012 (NRC, 2016)

Statistics Canada found that in a household energy usage study, Ontario's primary heating fuel in 2011 was natural gas at 76\%, and where natural gas is the main heating fuel for $50 \%$ of Canada (Statistics Canada, 2011). Table 1.1 shows that electricity usage as a heating fuel is minimal in Ontario at 14\%, but a more significant $39 \%$ for Canada as a whole (Statistics Canada, 2011).

Table 1.1: Heating fuel usage fraction for each province for varying fuel types in 2011 (Statistics Canada, 2011)

\begin{tabular}{|l|c|c|c|c|c|}
\hline \multicolumn{1}{|c|}{ Source } & $\begin{array}{c}\text { Electricity } \\
(\boldsymbol{\%})\end{array}$ & $\begin{array}{c}\text { Natural } \\
\text { Gas (\%) }\end{array}$ & $\begin{array}{c}\text { Oil } \\
(\boldsymbol{\%})\end{array}$ & $\begin{array}{c}\text { Wood and Wood } \\
\text { Pellets (\%) }\end{array}$ & $\begin{array}{c}\text { Propane } \\
(\boldsymbol{\%})\end{array}$ \\
\hline Canada & 39 & 50 & 7 & 6 & 1 \\
\hline $\begin{array}{l}\text { Newfoundland and } \\
\text { Labrador }\end{array}$ & 71 & N/A & 21 & 22 & N/A \\
\hline $\begin{array}{l}\text { Prince Edward } \\
\text { Island }\end{array}$ & N/A & N/A & 76 & 32 & N/A \\
\hline Nova Scotia & 29 & N/A & 54 & 26 & N/A \\
\hline New Brunswick & 66 & N/A & 13 & 23 & N/A \\
\hline Quebec & 85 & 3 & 8 & 7 & N/A \\
\hline Ontario & 14 & 76 & 5 & 3 & 2 \\
\hline Manitoba & 37 & 61 & N/A & N/A & N/A \\
\hline Saskatchewan & 11 & 87 & N/A & N/A & N/A \\
\hline Alberta & 9 & 91 & N/A & N/A & N/A \\
\hline British Columbia & 39 & 55 & 3 & 5 & N/A \\
\hline
\end{tabular}


Natural gas has a majority share as the primary heating fuel in many provinces, with existing infrastructure and distribution systems. IESO, who have recommended the use of electric heat pumps such as the ASHP, have raised concerns for market penetration noting operation costs are far too high when the more affordable natural gas option is available (IESO, 2017). In addition, Ontario's recent Climate Change Action Plan, with the support of the Canadian Gas Association, has stated plans to introduce cleaner renewable natural gas (RNG) by increasing the fraction of RNG that is distributed through utilities for 2020, which will increase the appeal of natural gas even further (Ministry of the Environment and Climate Change, 2016; CGA, 2014). RNG is produced from organic waste from farms, forests, landfills and water treatments plants, where gas is captured, cleaned and injected into the pipelines. (CGA, 2014) This will be realized by the numerous RNG projects that have already been underway since 2010 (CGA, 2014).

Currently, most heating systems in Canada are forced air furnaces, which have greatly improved in efficiency over the decades, but still hold a higher market share for space heating. Figure 1.4 shows that furnaces were found to be the main heating system for $57 \%$ of all Canadian homes in 2011, which shows a great opportunity for GAHP penetration where existing infrastructure can be used, and efficiency of the system can be improved beyond 100\% (Statistics Canada, 2011).

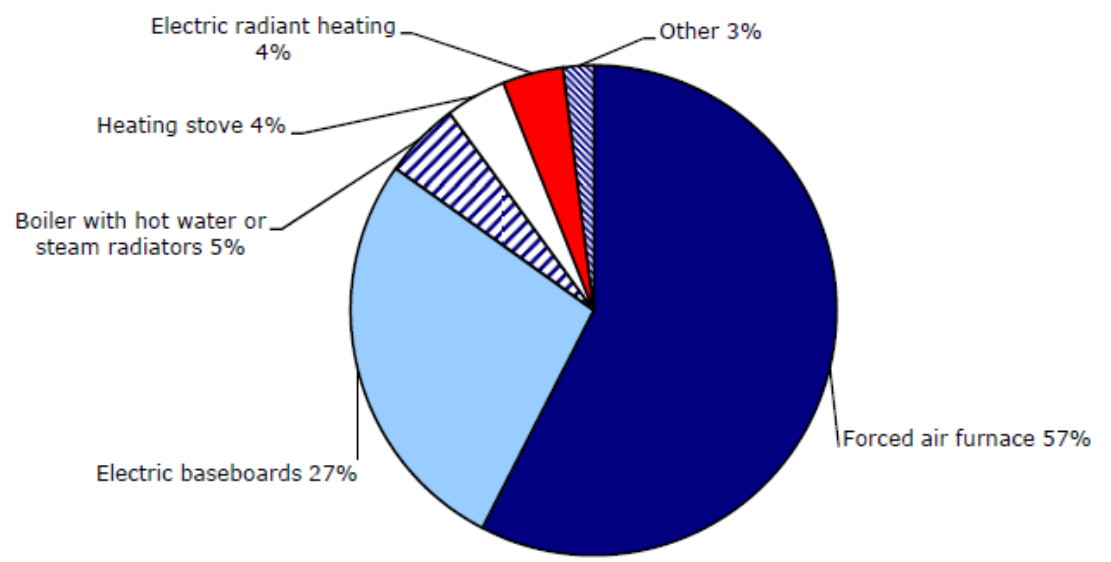

Figure 1.4: Primary heating system in Canadians homes in 2011 (Statistics Canada, 2011)

Although natural gas is one of the cleaner fossil fuel alternatives, it will still contribute significant emissions. For this reason, it is not expected to be a permanent solution, but instead a transitional solution. At least until efficient technologies become more widely available and electricity prices become more affordable for the common homeowner. IESO has suggested that 
the Ministry of Energy implement more incentives for more efficient heat pump systems and to increase the penetration of systems such as ASHP and GSHP through educational programs and stronger policies (IESO, 2017). However, a 20-year outlook developed by engineering firm Navigant has shown that natural gas will still have a significant demand in 2035, although demand will reduce relative to the current demand (Navigant Consulting, 2016). Unless natural gas prices increase more than $50 \%$ its current value relative to electricity prices, natural gas heating systems will remain the more affordable option (IESO, 2017). Carbon

\subsection{Objective}

Recognizing the potential utilization of this technology in Ontario, our research group and industry partners plan to investigate and quantify the true techno-economic benefits of GAHPs for the province. To achieve these project goals, an in-depth field performance monitoring and analysis was conducted. This was done at the Toronto and Region Conservation Authority's (TRCA) Sustainable Archetype House located in Vaughan, Ontario, Canada and was implemented to supply the heating and cooling needs of two attached Archetype Sustainable Houses (ASH) throughout the year. The research objective is to analyze the potential Greenhouse Gas (GHG) emissions reductions, energy and cost savings along with identifying efficient control strategies. This will be done through modelling of the GAHP in the Archetype Sustainable Houses using TRNSYS 17. The houses will be fitted with a unique mechanical system to accommodate the GAHP to reduce cycling with the addition of several buffer tanks and a flat plate heat exchanger by storing and transferring thermal energy to extend the period of the cycles of the heat pump. Experimental evaluation of the GAHP in the Canadian climate is carried out.

From the data collected from the monitoring of the GAHP, parametric curves will be used to develop a TRNSYS model that will use weather files for various cities across Canada, and perform similar analyses as stated above. With the model, key performance parameters such as Coefficient of Performance (COP) and heating and cooling capacity variance with respect to outdoor air temperature changes, GHG emissions, and the cyclic characteristics will be analyzed. Work will be done to analyze the potential savings and GHG savings by considering the differences in performance of a single GAHP system during heating and cooling seasons. The data will be collected for both heating and cooling and covers both heat and cooling seasons. 


\section{Literature Review}

\subsection{Heat Pumps}

Heat pumps are a fairly mature technology that have gained traction around the world for various climates. Most heat pumps commonly run on vapor compression cycles, where heat from one source is upgraded and directed to the space that requires the heating and vice versa for cooling. A general vapor compression cycle can be seen in Figure 2.1. Heat pumps are systems that are widely used in residential, commercial and industrial applications due to the ability to be driven by different energy sources. The feasibility of the heat pumps however, vary from situation to situation.

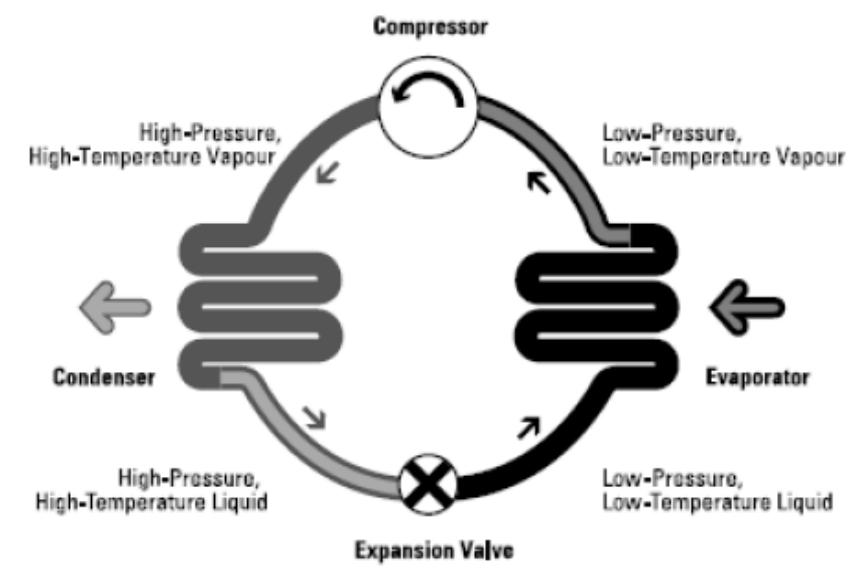

Figure 2.1: Diagram of basic vapor compression cycle in compression-based heat pump systems $(W u, 2009)$

\subsubsection{Air-Source and Ground-Source Heat Pumps}

To understand the benefits of the GAHP, the competing counterparts must be understood as well. In the field of heat pumps for HVAC applications, two of the most studied and efficient heat pumps systems available are the GSHP and the ASHP. Both are heralded as the most promising new energy efficient technologies in the fight against climate change (Wu, 2009). The only fuel that these heat pumps require is electricity, and due to this, the Greenhouse Gas (GHG) emissions of these systems is very minimal, depending solely on how clean the energy used to produce the electricity was. To judge the performance of heat pumps, the most common performance parameter used is the COP. 
ASHPs that have been tested in the cold Canadian climate, by (Safa et al., 2015a), were found to have a seasonal heating COP of 3.23 and a seasonal cooling COP of 5.27. However, taking into consideration the indoor air circulating fan, the COP values had dropped considerably with a heating COP of 2.1 and cooling COP of 3.5. COP decreased significantly during lower outdoor temperatures (below $-19^{\circ} \mathrm{C}$ ) without having any supplementary heating or additional supporting systems. This is an issue that is not shared with the performance of the GSHP. This is due to the fact that the ground has a fairly consistent moderate temperature throughout the year. However, the GSHP has higher circulation pump power consumption compared to the ASHP but consumes less compressor power due to milder source temperatures (Safa et al, 2015c). As a result, cold climate ASHP and GSHP had comparable seasonal heating and cooling performance in typical Toronto climate (Safa et al., 2015c).

There are, however, limitations to these technologies that have withheld them from gaining larger market shares. These issues are strongly related to costs and implementation. The greatest cost for the GSHPs is the initial cost, for the system as well as installation, which is most cost effective during the early stages of construction (Wu, 2009). The ASHP excels through lower initial cost and faster pay back and only has marginally higher operating costs due to similar seasonal COP compared to GSHP, showing to be quite feasible (Safa et al., 2015c).

\subsubsection{Absorption Heat Pumps}

A technology that is not commonly considered when considering HVAC applications for residential homes is the Absorption Heat Pump (AHP). The AHP uses a process more complicated than that of the typical heat pump. However, it has the potential to be highly efficient and have a lower carbon footprint.

The concept of the absorption heat pump is derived from the idea of using two-phase solutions at specific temperatures and pressures, the refrigerant will separate from the combined solution in order to collect and release thermal energy to be absorbed by the absorbent to cool and repeat the cycle (Srikhirin et al., 2000). There are many solutions that are used to operate absorption heat pumps, the most commonly used solutions are $\mathrm{H}_{2} \mathrm{O}-\mathrm{LiBr}$ and $\mathrm{NH}_{3}-\mathrm{H}_{2} \mathrm{O}$ (as refrigerants-absorbent pairs) (Srikhirin et al., 2000; Wu et al., 2014). The former has higher performance usually when compared to the latter but has certain limitations. The most effective refrigerant-absorbent combination for cold climates is $\mathrm{NH}_{3}-\mathrm{H}_{2} \mathrm{O}$. This is because $\mathrm{H}_{2} \mathrm{O}$ (in the case 
of $\mathrm{H}_{2} \mathrm{O}-\mathrm{LiBr}$ ) as the refrigerant cannot be used in subfreezing scenarios, reducing its feasibility. Further limitations of the $\mathrm{H}_{2} \mathrm{O}-\mathrm{LiBr}$ solution is that it must be contained in a high vacuum and is prone to crystallization, increasing its operation and maintenance costs (Wu et al., 2014a). For this reason, ammonia-based refrigerants are most common in cold climate regions and are most commonly used in residential applications (Wu et al., 2014a). Although $\mathrm{NH}_{3}-\mathrm{H}_{2} \mathrm{O}$ also has its own limitations, mainly that it requires a rectifier to maintain purity of the refrigerant and performance of the system. Different combinations of refrigerant and absorbent solution exist and are in use, mainly which are variations that contain either $\mathrm{NH}_{3}$ or $\mathrm{LiBr}$ but are far less common than the two listed above. Different combinations are selected solely for the ability as refrigerants, but also their ability to mix with an absorbent, which is why most common solutions are made up of fairly simple compounds (Srikhirin et al., 2000; Wu et al., 2014a). Nonetheless, the use of these refrigerants instead of the more toxic counterparts that are used in ASHP and GSHP are more beneficial for the environment and will cause less damage if a leak were to occur ( $\mathrm{Wu}, 2009)$. Table 2.1 shows a list of requirements for effective refrigerant-absorber combinations that should be considered for AHP systems.

Table 2.1: Requirements for effective refrigerant and absorber fluids for safe and effective operation (Murphy \& Phillips, 1984)

\begin{tabular}{|l|l|}
\hline Refrigerant & Absorber \\
\hline High latent heat & Low volatility \\
\hline $\begin{array}{l}\text { Operating } \\
\text { Pressure }\end{array}$ & Stability \\
\hline Stability & Compatibility \\
\hline High solubility & Low viscosity \\
\hline Compatibility & Low toxicity \\
\hline Low toxicity & Non-flammable \\
\cline { 1 - 1 } Non-flammable & \\
\hline
\end{tabular}

The basic cycle of an AHP is similar to that of a normal heat pump, but with one main difference. The difference between the systems is that instead of using a compressor to pump the solution back to the generator, an absorber unit is used where the refrigerant is absorbed, then pumped back using significantly less power (Srikhirin et al., 2000). This results in a reduced consumption of electricity and fewer mechanical parts to service since the solution in the absorber can be moved with a simple low power pump instead of a higher power compressor. However, 
typical AHPs use many other components to increase the efficiency and capacity of the system, especially for cold climates. To satisfy higher demands, AHPs, similar to regular heat pumps, can also work in up to three stages to improve the quality of the thermal energy being output (Karamangil et al., 2010). One core benefit of this AHP system is that in addition to the reduced power consumption, it also contains the potential to provide water heating. Since the absorber requires a coolant to maintain low temperature and increase the concentration of the solution, it provides a source of DHW, this can be seen in Figure 2.2, which represents the absorption cycle for $\mathrm{NH}_{3}-\mathrm{H}_{2} \mathrm{O}$ (Wu et al., 2012a). In Figure 2.2, the coolant water can be seen to flow through both the absorber and condenser units to gain useful thermal energy, which can be used for either DHW or radiant space heating (Wu et al., 2012b). There have been many developments in designing a more efficient system with the addition of such technologies as a generator-absorber heat exchanger (GAX), low pressure boosters (between evaporator and absorber) and high pressure boosters (between generator and condenser) which are employed in order to increase the capacity of heat able to be retained by the refrigerant but also to maximize the amount of useful energy collected from the cycle (Wu et al., 2014b; Aprile et al., 2016).

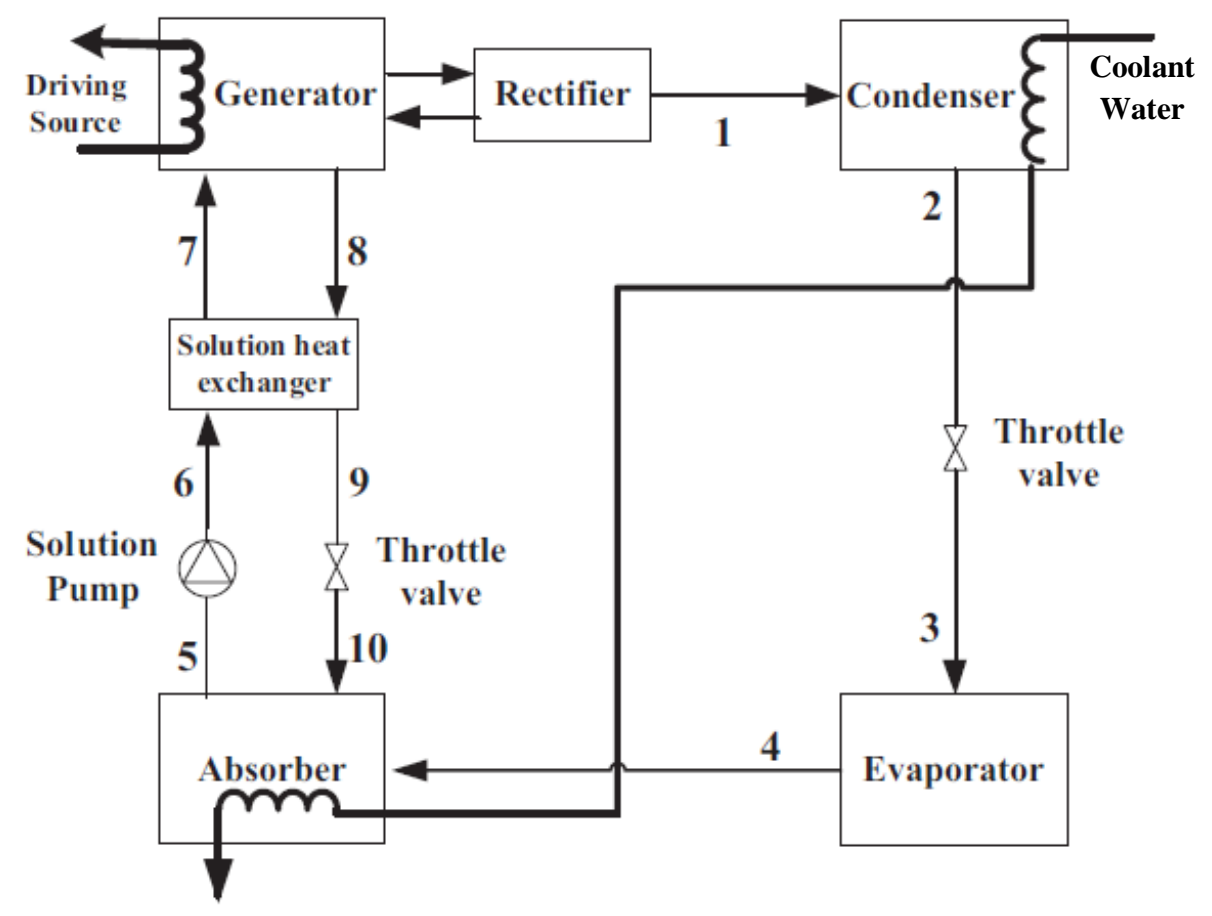

Figure 2.2: Schematic of Absorption Heat Pump where Ammonia Water is the working fluid (Wu et al., 2014a) 


\subsubsection{Fundamentals}

Understanding the fundamentals of a basic single effect AHP can offer insight into the simplicity of the thermodynamic cycles and performance of the system. There are four basic components of the AHP system: the generator, condenser, evaporator, and absorber. The generator is simply where the heat that drives the absorption cycle is introduced. Waste heat is commonly used as the driving source, but energy sources such as solar and liquid fuels are also widely adopted Grossman, 1991; Aprile et al., 2016; Ayadi et al., 2012). In the generator, the strong refrigerantabsorbent solution is heated to the point where the refrigerant is converted into vapor and maintained at high pressure into the condenser, where it is cooled into a liquid state resulting in useful heat extracted from the system. A unit known as a rectifier is commonly found between the generator and condenser. The purpose of the rectifier is to cool down any absorbent vapor that accompanies the refrigerant. The absorbent (e.g., water) would have a higher saturation temperature then the refrigerant (e.g., $\mathrm{NH}_{3}$ ) and would be condensed as to allow only the refrigerant vapor to flow forward in the cycle. The weak refrigerant solution (high absorbent content) would then be sent back to the generator where it is either heated again or passed through the solution heat exchanger (SHX). The rectifier unit can be seen in the schematic in Figure 2.2. In the condenser, once the pure refrigerant is cooled to a liquid state, it is passed through a throttle valve into the evaporator. In this evaporator, pure refrigerant at low pressure absorbs heat (i.e., producing a cooling effect) and passes the refrigerant vapor over to the absorber. Weak solution present in the absorber will absorb the pure refrigerant vapor forming a strong solution. This process of the refrigerant being absorbed by the absorbent results in an exothermic reaction that releases heat (i.e., heating effect). This strong solution is pumped back into the generator where the cycle can be repeated. It is common to have a solution heat exchanger between the generator and absorber (GAX) to improve system efficiency where heated weak solution is used to preheat the stronger solution moving into the generator (Wang \& Infante Ferreira, 2017). The schematic in Figure 2.3 shows these same processes with each major unit abbreviated, excluding the rectifier which is used mainly in $\mathrm{NH}_{3}-\mathrm{H}_{2} \mathrm{O}$ solution pairs (Wang \& Infante Ferreira, 2017). 


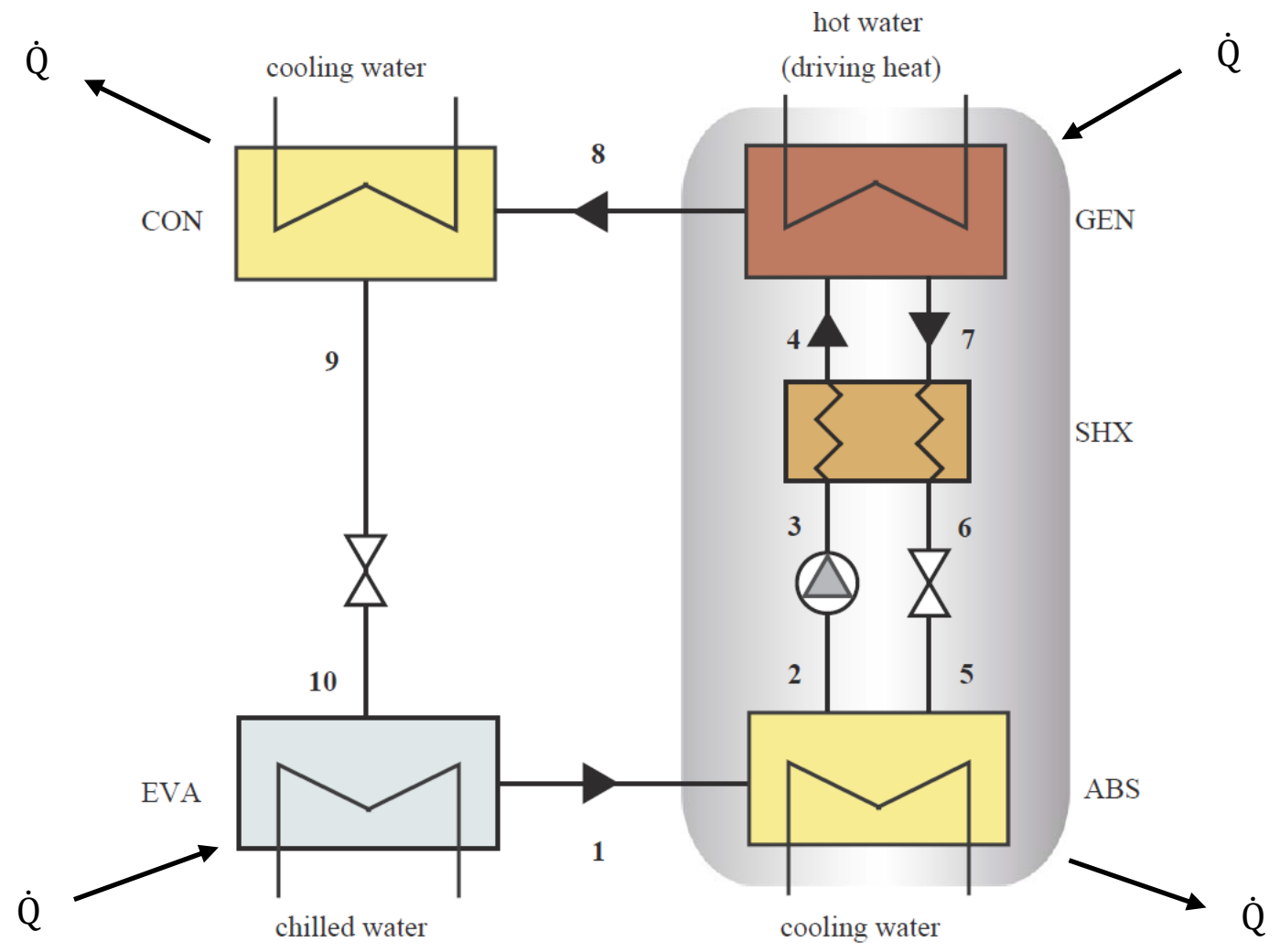

Figure 2.3:Schematic diagram of single-effect AHP cycle (Wang \& Infante Ferreira, 2017)

Figure 2.4 presents a thermodynamic cycle of the single effect AHP system seen in Figure 2.3, highlighting the main points of heat transfer in a simplified P-T diagram. As it can be seen, in both the condenser unit and absorber unit, useful heating effect is produced, where at the evaporator unit, useful cooling effect is produced. This enables the AHP system to behave as a heat pump capable of both heating and cooling applications. 


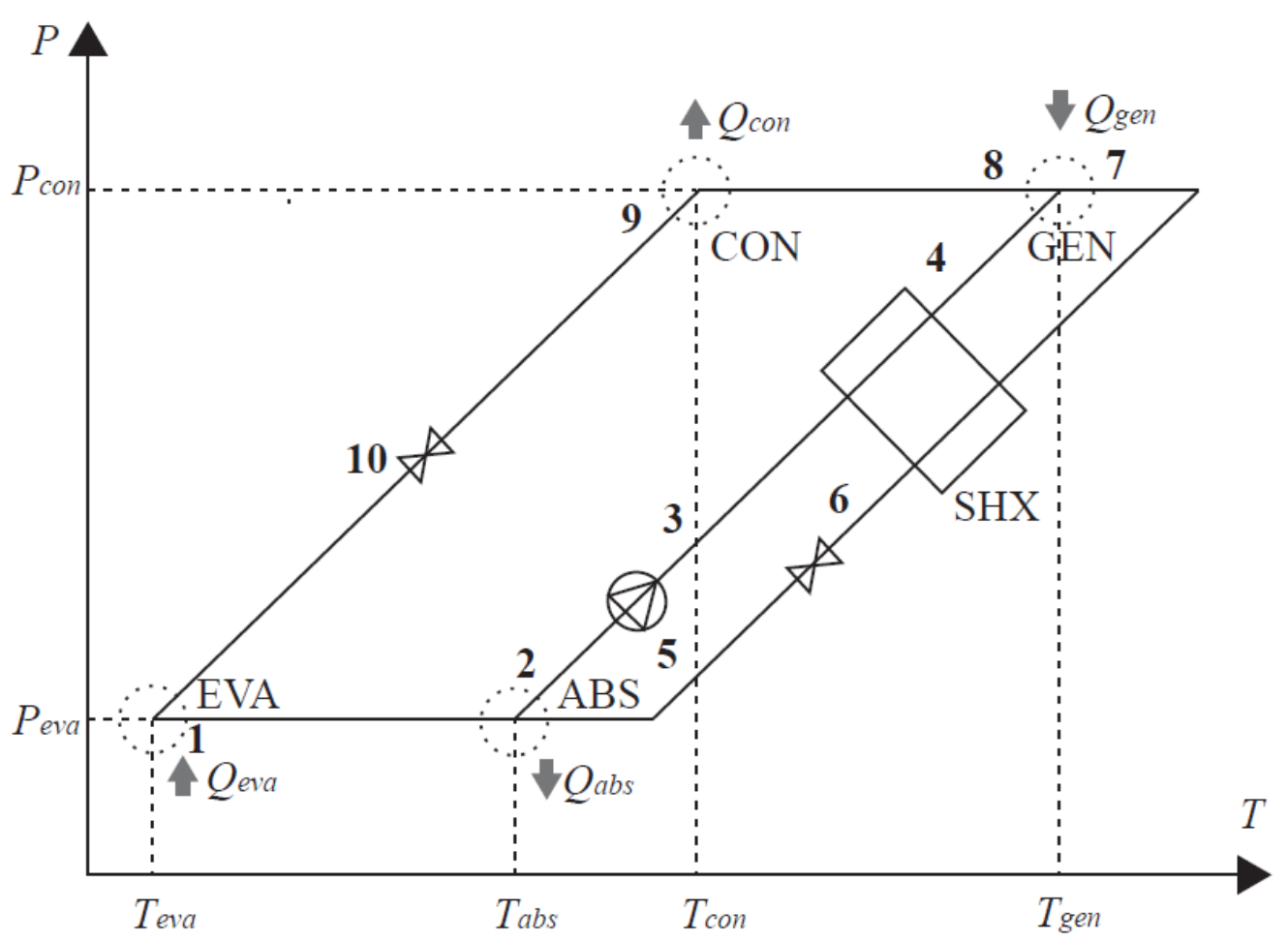

Figure 2.4: Single-effect AHP cycle in a ln P- (-1/T) (Wang \& Infante Ferreira, 2017)

\subsubsection{Different AHP Configurations}

Most studies done on AHP have been specifically for the case of cooling where either waste heat or solar energy is utilized to provide the energy source to operate the AHP (Grossman, 1991; Ikeuchi et al., 1985; Nakanishi et al., 1981; Eicker \& Pietruschka, 2009).

One study, (Bakhtiari et al., 2011), performed simulation and experimental work using a single stage $\mathrm{H}_{2} \mathrm{O}-\mathrm{LiBr}$ absorption chiller of $14 \mathrm{~kW}$ and investigated the COP and its relationship with 5 parameters. These parameters were generator flow rate, generator inlet temperature, cooling water flow rate, cooling water temperature, and chilled water temperature. For the specific AHP used, the COP was quite low having values as low as 0.2 and reaching maximums of 0.77 . It was found that as all the evaluated parameters in the study increased, apart from the cooling water temperature, the $\mathrm{COP}$ increased. The results showed that there was a large range of efficiency of the system depending on these few select parameters.

Another study, (Eicker \& Pietruschka, 2009), that designed and tested the performance of a solar powered absorption chiller in an office building found that control strategy had a significant impact when the system was running on part loads. Thermal storage was needed to improve the 
system thermal efficiency, and with appropriate control, the COP that resulted ranged from 0.67 to 0.76 at a solar fraction of about $80 \%$. Previous studies have found that high solar fractions were needed, above $50 \%$, to provide adequate chilling at reasonable cost relative to other higher performing technologies (Mendes et al., 1998).

Numerous other studies have been done with absorption systems designed to provide cooling to various systems that are solar driven but tend to achieve low COP values that have a wide range when tested under real conditions. A numerical model by (Thomas \& Andre, 2012) has shown COP values for solar driven absorption systems to be about 0.67 at a set point temperature of $24^{\circ} \mathrm{C}$ and 0.7 at a set point of $26^{\circ} \mathrm{C}$. This shows a more idealistic value as real system studies have demonstrated lower performance due to factors difficult to account for in simulations. One similar chiller (Thomas \& Andre, 2012) was experimentally tested with a reduced cooling capacity and found a COP value of 0.53 from 3 months of testing data (Rosiek \& Batlles, 2009). A different chiller studied by another group that was monitored found to have a monthly COP of 0.3 to 0.41 (Marc et al., 2010). Separate studies (Ayadi et al., 2012) found that monthly COP was reduced from nominal to 0.53 to 0.62 . Studies have also been done for solar driven adsorption systems, which are similar to absorption systems but use a solid adsorbent instead of liquid absorbent, have shown similar performances and share similar operation and optimization issues due to solar thermal efficiency (Fan et al., 2007). Modelling of solar adsorption systems have also demonstrated a COP range of approximately 0.3 to 0.5 , showing consistent performance for solar sorption technologies (Januševičius et al., 2015). These studies consistently found that part load performance reduced the thermal COP and systems must be sized more appropriately to avoid such cases.

For a more reliable source of energy that is affordable relative to electricity, natural gas is also used for cooling applications using the GAHP. One group in Beijing, China used a more uncommon approach of using an Open-cycle Absorption Heat Pump (OAHP) designed to recover waste heat from flue gases. This system is evaluated against two more common heat recovery systems, and Electric Heat Pump (EHP) and AHP with a gas boiler. To account for the condensing flue gases, a condensing boiler was used where an indirect heat exchanger and direct contact heat exchanger is used to maximize the potential heat transfer to the system. The OAHP system is designed that the flue gas will go directly into the absorber, where the solution will absorb the 
water vapor to increase the solution temperature but reduce the concentration. This is the main difference of the open-cycle which maximizes the potential to use the latent heat from the flue gases. The results of the study showed that the OAHP system had improved the efficiency by $11 \%$ compared to the base case, EHP, while only $1.5 \%$ when compared to the AHP. Both systems however, are very cost effective in Beijing when the gas $\left(\$ / \mathrm{m}^{3}\right)$ to electricity $(\$ / \mathrm{kWh})$ price ratio was below 5.5 and this ratio would need to have a value of 8 or above to prove otherwise (Wei et al., 2015).

A research group in Ohio (Priedeman \& Garrabrant, 2001) experimentally tested the performance of a residential sized gas-fired absorption chiller with GAX. The capacity of the tested heat pump was $17.5 \mathrm{~kW}$ (5 refrigeration tons). The cooling COP was found to be 0.68 when tested under steady-state operating conditions in ambient conditions. The monitoring system was quite thorough and was done using a breadboard system using T-type thermocouples, electronic mass flow meters and pressure transducers. Gas was measured using periodic measurements from the local gas utility. Steady state was assumed to be achieved when the system was run for 30 minutes as standard rating conditions defined by the Air Conditioning and Refrigeration Institute (ARI). Thorough monitoring was done for every core component in the absorption heat pump process to identify locations of weakness. The tests were carried out in nearly full capacity, and as such, part load inefficiencies were minimized. Unable to achieve the goal of obtaining a COP value of 0.7, it was found that the primary issues were the burner-generator efficiency that was not up to design specifications, large pressure drops, and low heat recovery efficiency.

Another research group (Garimella et al., 2016) developed and demonstrated a compact microscale prototype of a single effect $\mathrm{NH}_{3}-\mathrm{H}_{2} \mathrm{O}$ absorption chiller that has a $3.5 \mathrm{~kW}$ nominal cooling capacity. The system is gas driven and uses two monolithic blocks to provide the heat and mass transfer, which was found to have higher heat transfer coefficients in comparison to conventional systems assisting in reducing system size. Semi-autonomous controls were designed to allow for stand-alone operation. The system was run over varying operation conditions and compared to existing system models. The monitoring was done at a breadboard test facility and an initial test without the control system achieved a cycle COP of 0.53 . However, when a prototype packaged unit was developed with the semi-autonomous control system, the cycle COP was evaluated to be 0.47 . When scaling the system up, it was noted that refinements in the vapor- 
generation unit and reducing thermal losses was required to increase performance compared to the microscale proof-of-concept.

Many cases exist for AHP for cooling, to provide heating however, a reliable, common source is needed especially during the winter. One such source that is commonly investigated is natural gas due to its ease of access and existing infrastructure as the primary heating fuel. Typically, residential and light commercial buildings use furnaces or boilers, especially so if existing infrastructure exists and the options are available. Furnaces and boilers are nearing their limits in how much more efficient they can become, and to achieve higher efficiencies, new technologies must be explored (Murphy \& Phillips, 1984; Colosimo, 1987). With high electricity prices, natural gas is an option that is still a major primary heating fuel with a strong hold on the market. Natural Gas-driven Heat Pumps (GHP) are one alternative to the usage of ASHP and GSHP. Natural gas being a cheap, abundant resource with the potential to be renewable makes it a viable option worth investigating. In the case of GHPs, there are two commonly used heat pump types, Gas Engine Heat Pumps (GEHP) and Gas Absorption Heat Pumps (GAHP). GEHP systems have literature that shows that they have fairly high performance as a gas driven heat pump with Primary Energy Ratio (PER) ranging from 1.0 to 1.5 for cooling and 1.3 to 1.6 for heating (Rosato et al., 2013). They are also capable of better part load performance due to the ability to control the fuel consumption of the engines for varying demand (Sanaye \& Chahartaghi, 2010; Qin et al., 2009). GAHPs serve similar purpose but delivered through a system that uses a fundamentally different thermodynamic cycle, which comes both with consequences and benefits.

Studies on GAHP that have investigated both heating and cooling modes are few. Typically, $15 \%$ more primary energy is consumed when compared to a similar capacity Electric Heat Pump (EHP) during cooling season (Dieckmann et al., 2005). However, during heating mode, primary energy consumption can be reduced $40 \%$ compared to conventional systems such as furnaces and boilers (Dieckmann et al., 2005).

One research group in Montreal (Kummert \& Bernier, 2008) studied the performance of a combined photovoltaic-geothermal gas-fired absorption heat pump. The GAHP that was studied was a commercially available single effect ammonia-water unit with a nominal heating capacity of $35 \mathrm{~kW}$ and cooling capacity of $13.5 \mathrm{~kW}$. This system is coupled with a vertical geothermal heat exchanger (GHX) used to help store energy for space cooling or heating in separate tanks offering 
simultaneous heating and cooling options. The photovoltaic (PV) system is used with a battery storage to run the HVAC system, where the main power consumption is through the fan coil unit. This system was modelled using TRNSYS with standard component libraries. From the study, it was found that the cooling COP ranged from 0.4 to 0.63 and decreases with an increase in temperature difference of the evaporator and condenser. The heating COP for heating however, ranged from 1.17 to 1.4 and increased when the difference of evaporator and condenser temperature decreased. When the COP was corrected for part load operation however, the heating and cooling COPs were found to be 1.12 and 0.55 respectively. The yearly COP, accounting for hours of operation in each mode however, was calculated to be 0.94 , which is adequate but not competitive when compared to electric systems. It is noted that full load operations may have improved the performance, so measures should be taken to size the system correctly.

One group in Italy (Fumagalli et al., 2016) monitored and performance tested several GAHP systems in public buildings over a three-year project. A monitoring system based on specific performance parameters was developed and a performance assessment was carried out. The main performance indicator was to estimate for the Primary Energy Ratio (PER) (which is the ratio of useful energy output over the total energy input) in addition to analyzing the external conditions, working conditions, features of operating mode, duration and frequency of cycles, management of pumps and operation time. It was found that circulation pumps were a large source of energy consumption that has the potential for better optimization and that cycling was a key issue in running efficiently. The system was tested for different boundaries, where solving for the PER would give a more global understanding of the efficiency of the system. Understandably, as the boundaries of the GAHP system increased to other components of the system such as circulating pumps and fan coil units, the PER was reduced, however the reduction was not too significant. However, the PER changed dramatically depending on the location, as a school campus may have a PER of approximately 1.2, but a middle school was found to have a PER of about 0.3 . This shows that the effectiveness of the system largely depends on the management and design of the system that the GAHP is implemented in and that adequate optimization is required to obtain reasonable energy savings.

A report, (Phillips, 1990), on the development of high efficiency GAHPs for residential and light commercial use to accomplish COP values on 1.6 and 0.7 for heating and cooling 
respectively. The primary technological advances that were investigated to accomplish these goals were higher efficiency cycling, increasing flue efficiency and better fluids. The study investigated and found that fan-assisted combustion systems coupled with condensing heat exchangers reduced losses due to flue and insulation up to $10 \%$. The reports evaluated six different GAHP cycles with an $\mathrm{NH}_{3}-\mathrm{H}_{2} \mathrm{O}$ pair and found that the most preferable cycle had included a GAX. From the study, five cycles tested obtained a cooling COP in the range of 1.0 to 1.1 and a heating COP in the range of 2.0 and 2.1, with room for further improvement. With the addition of the GAX, the system was found to offer significant energy savings for residential heating and cooling, making it more competitive and marketable. Recommendations are made to consider ternary fluid combinations such as $\mathrm{NH}_{3}-\mathrm{LiBr}-\mathrm{H}_{2} \mathrm{O}$ and compensate with better construction to prevent corrosion. Another recommendation that was made was to reduce cost and maintenance of GAX cycle and methods to operate the GAHP with condensing flue gases.

\subsection{System Optimization and Control}

Building system design is a crucial aspect in understanding the performance of a heat pump. Understanding the cause and effect that thermal mass or building control systems can sometimes be the defining characteristic between a well-designed and efficient system and a poorly designed system. Literature on optimization of the HVAC system to maximize the performance of the GAHP is limited but provides key insights into operation and cost effectiveness.

Studies have been done, (Ciganda et al., 2015), to highlight common issues that occur in GAHPs and their application in real situations. One study that was done in Berlin, Germany highlighted these issues while also suggesting methods for improvement. This research group investigated improvement measures for GAHPs by studying systems implemented in three different applications. These systems were designed to provide space heating for a public swimming pool (4 GAHPs), a kindergarten (1 GAHP), and for a residential care home for the disabled (6 GAHPs). The analysis found that there were three main areas that had the potential for improvement: reduction of electrical energy consumption, reducing short cycling, and operating the heat pump with lower temperature lifts. To improve electrical energy consumption, redundant fans totalling $7.2 \mathrm{~kW}$ were removed in one case, and better controls were implemented. For short cycling, the two issues that were observed was poor control as a result of using the default control systems that did not account for thermal storage components such as buffer tanks, and flow rates 
that were less than nominal, causing the primary fluid to exceed set point temperatures too soon. Both these issues were to be resolved by using more suitable pumps and designing a control strategy that considered all core aspects of the HVAC system to moderate the cycling. In an attempt to reduce the temperature lift, issues that were found were that more GAHP systems were operating at a time than actually required and the monitoring and control system was poorly designed due to incorrect sensor placement. Both of these issues were solved through correcting sensor placement and control algorithms. Removing supply fans showed an increase in PER by $15 \%$ in the public pool case. Minimizing the number of operating GAHPs for the residential home reduced short cycling and went from producing an average heating capacity of $16 \mathrm{~kW}$ to the nominal $40 \mathrm{~kW}$ through the reduction of short cycling. The PER of the care home had also increased from 0.95 to 1.10 and cycle times improved from 30 cycles per hour to cycles lasting from 30 minutes to 2 hours. Part load inefficiencies still existed however, although reduced, preventive measures for part load issues must be addressed in the early design stages. Overall, affordable solutions to the system and adjustments to the control strategy resulted in energy cost savings of approximately $10 \%$. The potential for improvement is greater during the initial design stage and shows that GAHPs can offer a more efficient solution only if designed correctly.

Similar to the previous group's findings (Ciganda et al., 2015), separate studies have found that electricity consumption, cycling and control strategy is a common issue among GAHP operation (Fumagalli et al., 2016). A recommendation that is common among absorption heat pump systems, including gas-fired systems, is the incorporation of a GAX in the cycle (Kang et al., 2000; Garimella et al., 2016; Phillips, 1990; Velázquez \& Best, 2002). The GAX cycles have consistently shown to boost the COP values and offer energy and cost saving potential (Priedeman \& Garrabrant, 2001; Velázquez \& Best, 2002; Engler et al., 1997). However, a GAX cycle alone will not maximize the potential of the GAHP system, reduction of part load and maximizing time that the GAHP operates at full load is crucial in preventing unnecessary losses that reduce the efficiency of the overall system (Velázquez \& Best, 2002).

For this reason, thermal storage must be utilized to increase the load by increasing thermal mass, while also providing a buffer to improve cycling time. Reviews of thermal energy storage (TES) suggests that significant savings can be realized when utilized for storage of waste or excess heat energy (Dincer, 2002). In the case of the GAHP, to maintain long cycle times, the excess heat 
must be created deliberately and stored as short cycling will be far more detrimental overall compared to running cycles for the sole reason of charging TES tanks. Thermal mass of the building should also be taken into account in its effects on energy demand and its contribution to buffering the conditioned spaces of a building. Multi-tank TES systems are also an alternative that may be implemented, as it will not only provide a large volume of thermal mass but reduce the stratifications within tanks by promoting mixing and maintaining a uniform temperature through the tanks, which along with proper control systems, may help extend cycle times (Cruickshank \& Harrison, 2008).

One other solution that should be strongly considered is sizing correctly, as literature has shown that oversized systems limit greatly how much performances improvements can be made (Kummert \& Bernier, 2008; Kummert et al., 2007). Understanding these concepts is to realize that developing a sufficient monitoring system is crucial for efficient operation and minimizing losses in the system. The need for proper monitoring systems is recommended in several experimentation studies as a core component in running a cost effective and energy saving system (Fumagalli et al., 2016; Ciganda et al., 2015). It should also be noted that studies have found that taking a more active role in the control of solution mass flow within the system and having the capability to adjust and monitor systems that are more typically inaccessible, can improve part load performance (Aprile et al., 2016). However, the extent of this control and its cost effectiveness must be analyzed.

In addition to these optimization methods, modifying the refrigerant-absorbent fluid pairings may also be a viable option. Currently, one of the common pairings available is $\mathrm{NH}_{3}-\mathrm{H}_{2} \mathrm{O}$. A study was done to investigate the use of ionic liquids (IL) as an absorbent to improve the COP of AHP systems (Wang \& Infante Ferreira, 2017). In this case, the absorbent $\mathrm{H}_{2} \mathrm{O}$ was replaced with an $\mathrm{IL}$ in an $\mathrm{NH}_{3}-\mathrm{H}_{2} \mathrm{O}$ pairing and was found to have heating $\mathrm{COP}$ values ranging from 1.70 - 1.79 for four different $\mathrm{NH}_{3}$-IL pairing. All the IL pairs showed to have higher performance than the typical $\mathrm{NH}_{3}-\mathrm{H}_{2} \mathrm{O}$ solution pair. Using IL liquid pairing was also evaluated to have significant energy and economic savings when produced on an industrial scale. This novel concept can further improve the absorption cycle efficiency with minimal modification. 
Apart from system optimization, the location of where the system will be in use must also be considered to evaluate performance. In this project, a GAHP is being tested in the Canadian climate. Considerations must be made to account for any limitations, mainly the freezing outdoor temperatures in the winter. Due to the nature of a GAHP being an outdoor unit, the fluid in the primary loop that carries the heating or cooling effect from the GAHP into the conditioned spaces must be able to resist freezing. Using fluids such as propylene glycol/water solutions can combat these limitations. Toronto commonly has temperatures that approach $-25^{\circ} \mathrm{C}$ and below during the winter seasons. For these low temperatures, solutions such as $50 \%$ propylene glycol/water solutions are most effective, which have a freezing point of $-33.5^{\circ} \mathrm{C}$ (ASHRAE, 2009). However, the use of this fluid also has its draw backs, primarily the loss of heat transfer potential due to changes in specific heat, thermal conductivity, density and viscosity. This result in an approximate overall heat transfer factor of 0.878 for $50 \%$ PG/water, which translates to approximately a $12 \%$ loss in capacity theoretically of the AHP system (Robur Corporation, 2017). This significant loss of performance due to the required use of this primary loop fluid must be accounted for in the design of evaluation of an AHP system in cold climate.

\subsection{Energy Modelling}

In the energy modelling of AHP systems, first order models tend to be far too complex and are only required when studying the effects of different components within a system. Parametric studies are more common when experimental data collection and thorough controlled monitoring is an option. Most first order models in the literature study very detailed systems and the interactions of binary fluid mixtures and novel heat exchanger designs (Karamangil et al., 2010; Bakhtiari et al., 2011; Wei, Yuan et al., 2015; Rameshkumar et al., 2009). This is required as there is limited development in AHP models and current models, such as Type 107 in TRNSYS are noted to be less than accurate while also being limited in scope (Thomas \& Andre, 2012). These models are usually developed using FORTRAN or Absorption Simulation (ABSIM) software (Aprile et al., 2016; Eicker \& Pietruschka, 2009; Engler et al., 1997; Toppi, Aprile et al., 2016; Lostec et al., 2013). Although TRNSYS has its limitations, for larger scope systems, parametric models offer sufficient understanding that can be applied to various situations with reasonable certainty. For the modelling of AHP systems in TRNSYS, literature has showed that TRNSYS has merit and preference in performance studies (Thomas \& Andre, 2012; Kummert \& Bernier, 2008; 
Qu et al., 2010; Casals, 2006; Wang et al., 2015; Yu et al., 2014; Macia et al., 2013). TRNSYS studies have also been done using varying AHP operating conditions and building types using meteorological data from different climate regions (Mateus \& Oliviera, 2009). However, it should be noted that most AHP literature that uses TRNSYS as the primary modelling software only do so for cooling seasons or for absorption chillers. A primary benefit of using TRNSYS is also the ability to provide accurate solar radiation modelling for PV assisted AHP systems, which is not required for the GAHP system but will still offer the potential for future optimizations using solar energy to increase performance of the system (Thomas \& Andre, 2012; Maciaet al., 2013; Mateus \& Oliviera, 2009). There is currently no defined type in the TRNSYS libraries that will directly model a GAHP that will be able to provide both space heating and cooling and DHW heating, and as such must be developed on a case by case basis (Klein, 2010). In addition to developing a new TRNSYS GAHP model, the Archetype House currently has validated models of previously tested ASHP and GSHP systems and house models that can be used to make consistent comparisons on energy and cost savings with GAHP systems (Safa et al., 2015a; Safa et al., 2015b).

\subsection{Summary}

Through the literature investigated, it is clear that research in GAHP performance and optimization exists but is limited. Studies have shown methods of optimization through adjusting control strategies but changes to the HVAC system itself are rarely investigated. There is limited work on comparing how effectiveness of the GAHP systems are changed depending on the entire system. This offers the opportunity to investigate how different technologies can be coupled with a GAHP to improve the performance and cost effectiveness, while still remaining reliable. A thorough monitoring system is repeatedly suggested to have accurate performance testing and control. To be able to test a GAHP system in a controlled environment such as the Archetype Houses offers the possibility to study causes and effects of the system in a much higher detail than systems already fitted in commercial buildings where monitoring is limited. Understanding that sizing has limited the performance in much of the published literature, the ability to develop an HVAC system to account for such details is crucial and can be done in the early design and installation stages. With limited literature in GAHP systems being employed for both heating and cooling systems, to be able to monitor a system for a full year, one will be able to identify any net benefits or losses and a more holistic control strategy. In addition, AHP systems have limited 
model information in software such as TRNSYS open to the public. By developing and providing access to a model that can be easily incorporated with varying building system designs and having the opportunity to further optimize the system will help AHP systems become a serious consideration to home builders and owners. 


\section{House and System Description}

The Archetype Sustainable Houses (ASH) are a set of highly efficient semi-detached houses that are used to promote sustainable technologies for residential buildings. These houses were built for the Toronto and Region Conservation Authority and are located at the Living City Campus in Kortright Center located in Vaughan, Ontario, Canada. The ASH was one of the earliest Canadian houses to achieve LEED Platinum Certification for residential homes (Dembo et al., 2010). These houses have also been certified by EnergyStar and R2000 programs (Dembo et al., 2010). TRCA have used the ASH to develop an extensive list of sustainable projects that have been used to promote research, awareness, education and training in the green building industry.

Both houses can be seen in Figure 3.1 and 3.2. These houses are referred to as House A and House B and each was designed with a specific purpose in mind. House A was designed to showcase widely available sustainable technologies and the best practices used to implement them. While House B primarily showcases more experimental sustainable technologies that continue to reach technological maturity and are expected to be used in the near future. Both houses are fully equipped with a detailed data acquisition (DAQ) system, with more than 300 sensors collecting information at 5-second interval or less, to monitor multiple sustainable technology systems and they overall effects on the performances on both houses (Zhang et al., 2011). These houses are both designed in accordance to ASHRAE Standards 90.1. 


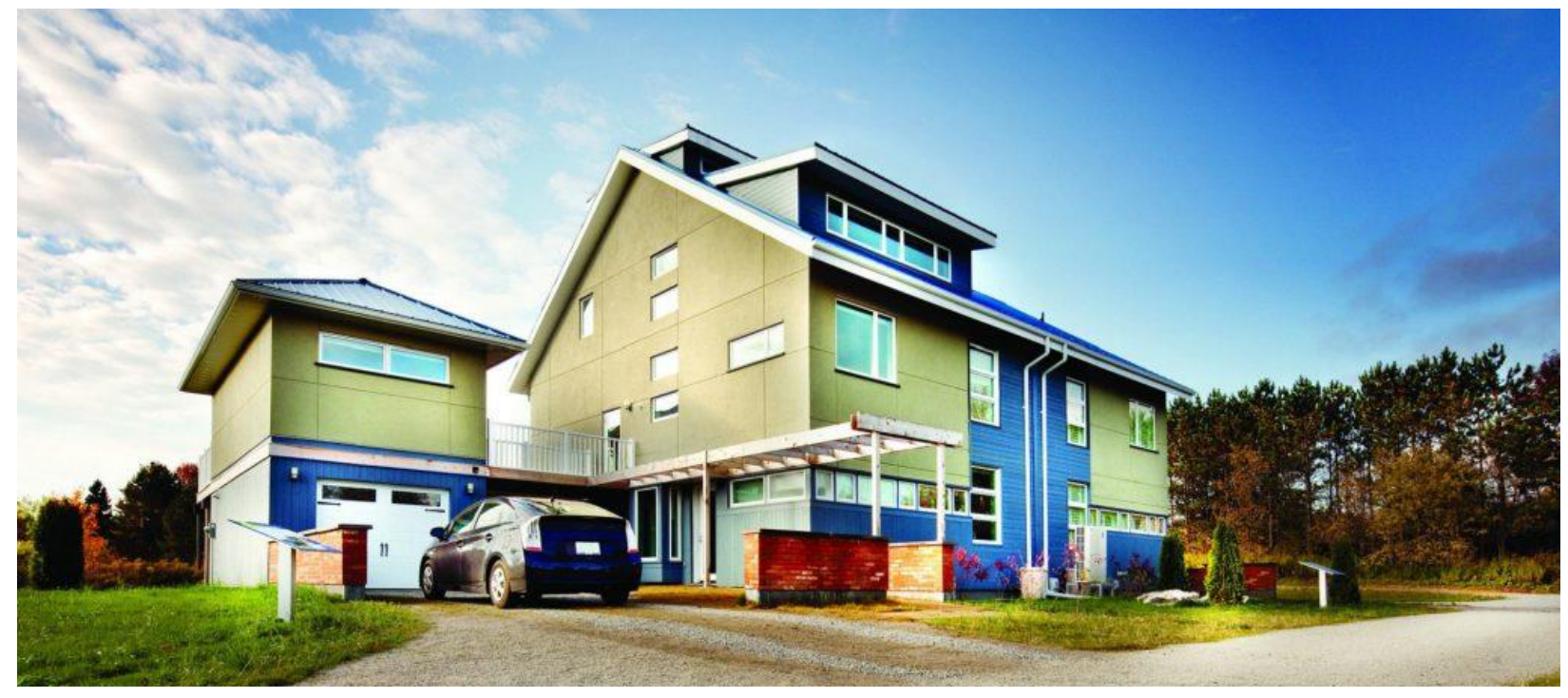

Figure 3.1: North-east side of Archetype Sustainable Houses, House B is seen on far left

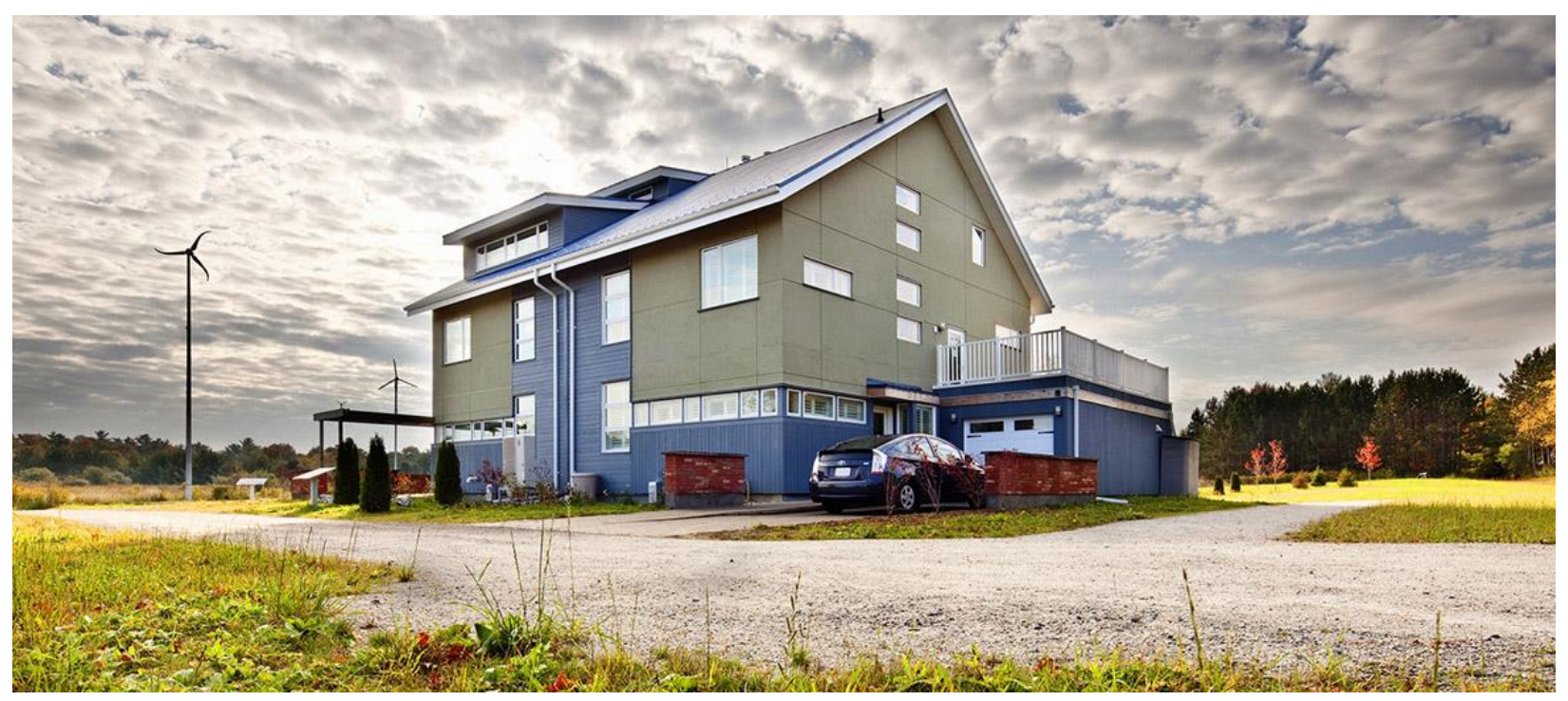

Figure 3.2: North-west side of Archetype Sustainable Houses, House A is seen on far right

The ASHs were chosen as the test site due to high control over the evaluation process through a monitoring system that had been thoroughly developed. In these houses, there are staff that work on weekdays, contributing to real life occupancy conditions during experimentation. For this study, the GAHP system was used to provide both space heating and cooling to both houses simultaneously. As a result, a unified design was developed where the individual HVAC systems of each house were connected to the GAHP primary loop. Each house is equipped with DHW tanks that are integrated with the main HVAC system, but for this study only space heating and cooling is investigated in detail. 


\subsection{Construction Summary}

House A and House B have highly energy efficient construction at the time of development and have lower energy use than typical homes. A summary of the construction details can be found in Tables 3.1 and 3.2. House B has a notable unique construction in the sense that it has an atrium that extends from the first and second floor. As a result, the zone representing the first floor has a larger volume, while the zone representing the second floor has lower volume along with lower floor space.

Table 3.1: Summary of structural features of Archetype Sustainable Houses (Zhang et al., 2011)

\begin{tabular}{|c|c|c|}
\hline Primary Feature & House A & House B \\
\hline Below Grade Wall Insulation & $\begin{array}{l}\text { RSI 3.54 (R20) using Durisol } \\
\text { Blocks }\end{array}$ & $\begin{array}{l}\text { RSI 3.54 (R20) using Durisol } \\
\text { Blocks }\end{array}$ \\
\hline Above Grade Wall Insulation & $\begin{array}{l}\text { RSI 5.31(R30) using Roxul } \\
\text { Batt Fibre and 3" Styrofoam }\end{array}$ & $\begin{array}{l}\text { RSI } 5.31 \text { (R30) using Heat- } \\
\text { Lock Soya Polyurethane } \\
\text { Foam and Lcyene spray foam }\end{array}$ \\
\hline Basement Slab & RSI 1.76 (R10) & RSI 1.76 (R10) \\
\hline Roof & $\begin{array}{l}\text { RSI } 7 \text { (R40) using } \\
\text { Structurally Insulated Panels } \\
\text { (SIPs) }\end{array}$ & $\begin{array}{l}\text { RSI } 7 \text { (R40) using } \\
\text { Structurally Insulated Panels } \\
\text { (SIPs) }\end{array}$ \\
\hline Windows & $\begin{array}{l}2.19 \mathrm{~W} / \mathrm{m}^{2} \cdot \mathrm{K}\left(0.39 \mathrm{Btu} / \mathrm{ft}^{2} \cdot \mathrm{F}\right) \\
\text { using double glazed, low "E", } \\
\text { fiberglass frame }\end{array}$ & $\begin{array}{l}1.59 \mathrm{~W} / \mathrm{m}^{2} \cdot \mathrm{K}\left(0.28 \mathrm{Btu} / \mathrm{ft}^{2} . \mathrm{F}\right) \\
\text { using triple glazed, low "E", } \\
\text { argon filled, aluminum-clad } \\
\text { wood frame }\end{array}$ \\
\hline
\end{tabular}

Table 3.2: Summary of air volume and floor area of Archetype Sustainable Houses

\begin{tabular}{|l|c|c|c|c|}
\hline \multirow{2}{*}{ Thermal Zone } & \multicolumn{2}{|c|}{ House A } & \multicolumn{2}{c|}{ House B } \\
\cline { 2 - 5 } & Floor Area $\left(\mathbf{m}^{\mathbf{2}}\right)$ & Volume $\left.\mathbf{( m}^{\mathbf{3}}\right)$ & Floor Area $\left(\mathbf{m}^{\mathbf{3}}\right)$ & Volume $\left.\mathbf{( m}^{\mathbf{3}}\right)$ \\
\hline Basement & 82.7 & 204.7 & 83.3 & 206.2 \\
\hline First Floor & 82.7 & 257.2 & 83.3 & 322.8 \\
\hline Second Floor & 82.7 & 206.8 & 44.6 & 111.6 \\
\hline Third Floor & 82.7 & 228.6 & 83.3 & 331.4 \\
\hline Total & 330.8 & 897.4 & 294.5 & 972.0 \\
\hline
\end{tabular}




\subsection{Baseload and Occupancy}

Since this study will only evaluate the thermal performance of the HVAC system, only thermal gains will be included in the system, which will be representative of the baseload. Previous studies on various equipment tested in the ASHs shows that for the internal gains/baseload of the house, only 3 items were considered: interior lighting, major appliances and miscellaneous loads. In Table 3.3, the breakdown of the internal gains in the home can be seen. As for occupancy, values used are similar to previous studies as well, using a 4-person family, 2 of which are adults and the other 2 children. The internal gain due to occupancy is $2.4 \mathrm{kWh} /$ day of sensible heat gain. These values are used in previously validated ASH models (Safa et al., 2015c).

Table 3.3: Summary of internal gain in each Archetype Sustainable House (Safa et al., 2015c)

\begin{tabular}{|l|c|c|c|}
\hline \multicolumn{1}{|c|}{ Item } & $\mathbf{k W h} / \mathbf{d a y}$ & Annual kWh & $\mathbf{k J / h r}$ \\
\hline Interior Lighting & 3 & 1095 & 450 \\
\hline Major Appliances & 6 & 2190 & 900 \\
\hline Miscellaneous Loads & 3 & 1095 & 450 \\
\hline
\end{tabular}

\subsection{Mechanical Systems}

Since House A was designed to present current best practices, the mechanical system that it is equipped with is one that is most commonly used in residential homes. House A uses a force air HVAC system to provide both its heating and cooling needs, with the exception of having a radiant floor heating system for the basement during heating season. The primary heating and cooling unit in House A was the air-to-air two stage variable cold climate ASHP along with a Direct Expansion (DX) coil Air Handling Unit (AHU) to deliver the space heating and cooling needs. House A uses its AHU to deliver heating and cooling to the entire house as a single zone. House B however, uses a hydronic HVAC system for heating and cooling needs. House B was equipped with a horizontalloop coupled GSHP with a supplementary desuperheater for DHW heating. House B uses a radiant floor heating system for all floors of the home, but for cooling season uses a multizone AHU to provide the cooling. House B as a result, has a high level of temperature control of each zone (floor) in the home. For this study however, the primary units used in both houses for heating and cooling, the ASHP and GSHP, were replaced with a single GAHP unit to provide both heating and cooling needs, with optional DHW heating. The GAHP unit being evaluated is a Robur GAHP- 
AR. According to the manufacturer specifications, it provides a nominal heating and cooling capacity of $35 \mathrm{~kW}$ and $17 \mathrm{~kW}$, respectively. This capacity however, far exceeds the total peak loads for both heating and cooling for both houses combined, and as a result a dump coil is used in the experimental evaluation to help the GAHP unit reach nominal capacity to achieve steady state operation. Figure 3.3 shows the GAHP unit installed outdoors.

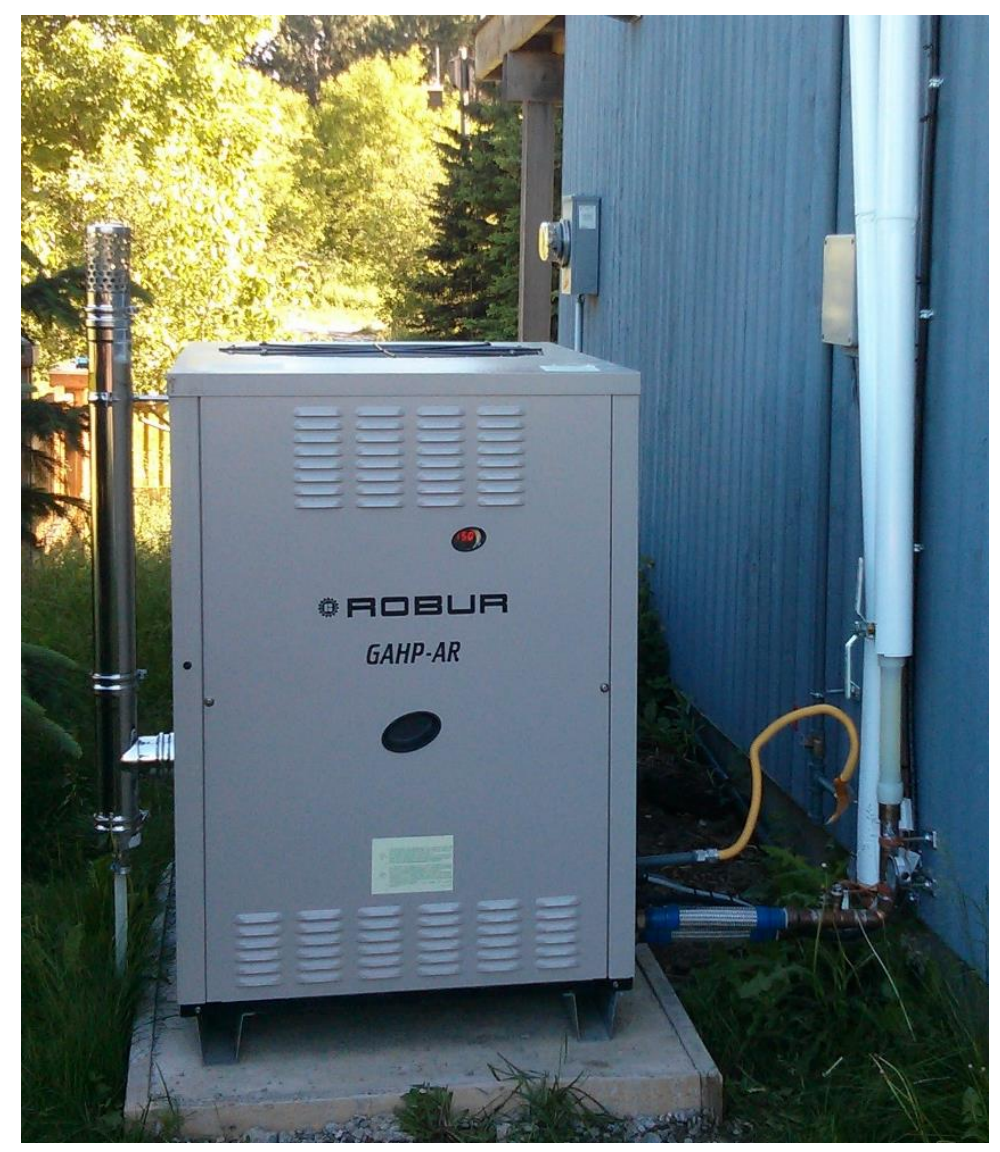

Figure 3.3: Robur AR-GAHP unit installed on east wall of House B

\subsection{System Design}

For the design of the HVAC system in this project, both houses needed to be combined into one system. Since it was clear that the GAHP was oversized for both houses, measures also had to be made to implement strategies that would improve the steady state performance of the system. Several thermal storage tanks were available in House B to be used as a buffer and to help maintain longer cycles as recommended through literature. With the addition of a couple of dump coils, the nominal capacity of the GAHP is achievable, with the added potential to have extended cycles. These dump coils dumped the excess energy into the ambient outdoor environment. 
The GAHP however, is an outdoor unit which exposes it and any piping connected to it to the ambient environment. Since Canadian winter results in temperatures far below freezing, the primary heat transfer fluid used must be resistant to freezing for temperatures below $-25^{\circ} \mathrm{C}$. For this reason, $50 \%$ propylene glycol (PG) was used, which has a freezing point of $-33.5^{\circ} \mathrm{C}$ according to ASHRAE Fundamentals Handbook (ASHRAE, 2009). A single primary loop that provided for both House A and B would have been most effective, but due to limitations on feasibility and minimizing the change to the current HVAC and monitoring systems, it could not be done. Instead, there are two hydronic loops used in the system. The first primary loop, which is connected to the GAHP, is exposed to outdoor conditions and therefore required a PG/water solution. Due to expense and maintenance, the volume of PG/water solution would be too great for the thermal storage tanks. Therefore, the second hydronic loop contains only water, where a flat plate heat exchanger transfers thermal energy from the PG/water solution in the primary loop to the secondary loop. The primary loop supplies energy to both House A and the heat dump coils placed outside of the house, while the secondary loop provides energy to House B, which also includes the thermal storage tanks. House B has an additional load due to the inlaw suite, which is a small office space. Refer to Section 5.2 for further details on the system schematic.

\subsubsection{Equipment Summary}

Table 3.4: House A equipment summary (Zhang et al., 2011)

\begin{tabular}{|c|c|c|}
\hline Item & $\begin{array}{c}\text { Model } \\
\text { Number }\end{array}$ & Specifications \\
\hline $\begin{array}{l}\text { House A Air } \\
\text { Handling Unit } \\
\text { (AHU) }\end{array}$ & $\begin{array}{l}\text { Mitsubishi } \\
\text { Electric: } \\
\text { PKA- } \\
\text { A36KA(L) }\end{array}$ & $\begin{array}{l}\text { Multi Speed Fan: } \\
\text { Airflow (Dry): 705-810-920 CFM } \\
\text { Airflow (Wet): 635-730-830 CFM }\end{array}$ \\
\hline $\begin{array}{l}\text { House A } \\
\text { Upgraded Air } \\
\text { Handling Unit } \\
\text { (AHU) Coil }\end{array}$ & $\begin{array}{l}\text { Ecologix } \\
\text { CW1320-03 }\end{array}$ & $\begin{array}{l}800 \mathrm{CFM}(376 \mathrm{~L} / \mathrm{s}), \text { Heating: } 11.7 \mathrm{~kW}(39.8 \mathrm{MBH}) \text { at } \\
60^{\circ} \mathrm{C}\left(140^{\circ} \mathrm{F}\right) \\
\text { Cooling: } 6.65 \mathrm{~kW}(22.7 \mathrm{MBH}) \text { at } 7^{\circ} \mathrm{C}\left(45^{\circ} \mathrm{F}\right)\end{array}$ \\
\hline $\begin{array}{l}\text { Heat Recovery } \\
\text { Ventilation } \\
\text { (HRV) System }\end{array}$ & $\begin{array}{l}\text { VanEE: High } \\
\text { Efficiency } \\
\text { Series-3000 } \\
\text { HE }\end{array}$ & $\begin{array}{l}\text { Heat Exchanger Surface Area: } 17.1 \mathrm{~m}^{2}\left(184 \mathrm{ft}^{2}\right) \\
\text { Type: Counter-flow } \\
\text { Core Material: Polypropylene } \\
\text { Performance: } 80 \% \text { sensible recovery efficiency at } 55 \mathrm{~L} / \mathrm{s} \\
(117 \mathrm{CFM}) \text { with } 0^{\circ} \mathrm{C}\left(32^{\circ} \mathrm{F}\right) \text { ambient air temperature }\end{array}$ \\
\hline
\end{tabular}


Table 3.5: House B equipment summary (Zhang et al., 2011)

\begin{tabular}{|c|c|c|}
\hline Item & $\begin{array}{c}\text { Model } \\
\text { Number }\end{array}$ & Specifications \\
\hline $\begin{array}{l}\text { House B Air } \\
\text { Handling Unit } \\
\text { (AHU) }\end{array}$ & $\begin{array}{l}\text { Ecologix } \\
\text { Heating } \\
\text { Technologies } \\
\text { Inc.: C3-06 }\end{array}$ & $\begin{array}{l}\text { Multi Speed Fan, Multi-Zone Air Distribution } \\
\text { Cooling Capacity: } 5.27 \text { to } 12.3 \mathrm{~kW} \\
\text { Heating Capacity: } 16.73 \mathrm{~kW}(57.48 \mathrm{MBH}) \text { at } 800 \mathrm{CFM} \\
\text { and } 180^{\circ} \mathrm{F} \text { Operation Temperature }\end{array}$ \\
\hline $\begin{array}{l}\text { Energy Recovery } \\
\text { Ventilation } \\
\text { System (ERV) }\end{array}$ & $\begin{array}{l}\text { VanEE: Gold } \\
\text { Series Series- } \\
2001 \text { ERV }\end{array}$ & $\begin{array}{l}\text { Heat Exchange Surface Area: } 14.51 \mathrm{~m}^{2}\left(156 \mathrm{ft}^{2}\right) \\
\text { Type: Cross-flow } \\
\text { Core Material: Enthalpic Transfer Media } \\
\text { Performance: } 69 \% \text { sensible recovery efficiency at } 52 \mathrm{~L} / \mathrm{s} \\
(110 \mathrm{CFM}) \text { at } 0^{\circ} \mathrm{C} \text { ambient air temperature } \\
45 \% \text { latent recovery efficiency at } 52 \mathrm{~L} / \mathrm{s}(110 \mathrm{CFM}) \text { at } \\
0^{\circ} \mathrm{C} \text { ambient air temperature }\end{array}$ \\
\hline $\begin{array}{l}\text { Flat Plate Heat } \\
\text { Exchanger }\end{array}$ & $\begin{array}{l}\text { SWEP: } \\
\text { B10TX20 }\end{array}$ & $\begin{array}{l}20 \text { Plate, Heat Load: } 13.40 \mathrm{~kW}(45.7 \mathrm{MBH}) \\
\text { Heat Transfer Area: } 0.558 \mathrm{~m}^{2}\left(6 \mathrm{ft}^{2}\right)\end{array}$ \\
\hline Buffer Tank 1 & $\begin{array}{l}\text { GSW Water } \\
\text { Heating: } \\
\text { CST-80 } \\
\end{array}$ & 270 L (71 US Gallon) Capacity \\
\hline Buffer Tank 2 & $\begin{array}{l}\text { Viessmann: } \\
\text { VITOCELL- } \\
\text { B } 100 \\
\end{array}$ & 300 L (79 US Gallon) Capacity \\
\hline Buffer Tank 3 & $\begin{array}{l}\text { Viessmann: } \\
\text { VITOCELL- } \\
\text { B } 100 \\
\end{array}$ & 300 L (79 US Gallon) Capacity \\
\hline
\end{tabular}

Table 3.6: Outdoor equipment summary

\begin{tabular}{|c|c|c|}
\hline Item & Model Number & Specifications \\
\hline $\begin{array}{l}\text { Gas Absorption } \\
\text { Heat Pump } \\
\text { (GAHP) Unit }\end{array}$ & $\begin{array}{l}\text { Robur GAHP- } \\
\text { AR }\end{array}$ & $\begin{array}{l}\text { Heating Mode: } 35 \mathrm{~kW}(120.4 \mathrm{MBH}) \text { Heating } \\
\text { Capacity at DB } 7^{\circ} \mathrm{C}\left(44.6^{\circ} \mathrm{F}\right) \text { with Outlet } \\
\text { Temperature at } 50^{\circ} \mathrm{C}\left(122^{\circ} \mathrm{F}\right) \\
\text { Water Flow Rate Range: } 6.2-22 \mathrm{GPM}(23.6-83.6 \\
\text { LPM }) \text {, GUE: } 126 \% \\
\text { Cooling Mode: } 17 \mathrm{~kW}(57.7 \mathrm{MBH}) \text { Cooling Capacity } \\
\text { at } 35^{\circ} \mathrm{C}\left(95^{\circ} \mathrm{F}\right) \text { with Outlet Temperature } 7^{\circ} \mathrm{C}\left(44.6^{\circ} \mathrm{F}\right) \\
\text { Water Flow Rate Range: } 11-14.1 \mathrm{GPM}(41.8-53.6 \\
\text { LPM), GUE: } 60 \% \\
\text { Rated Gas Input (HHV): } 95.5 \mathrm{MBH}(28 \mathrm{~kW}) \\
\text { Refrigerant-Absorbent Pair: } \mathrm{NH}_{3}-\mathrm{H}_{2} \mathrm{O}\end{array}$ \\
\hline
\end{tabular}




\begin{tabular}{|l|l|l|}
\hline Heat Dump Load 1 & Modine: & $\begin{array}{l}\text { Horizontal Delivery } \\
\text { Core Type: Single Serpentine } \\
\text { HSB108S01 }\end{array}$ \\
& & $\begin{array}{l}31.65 \mathrm{~kW}(108 \mathrm{MBH}) \text { Heating Capacity } \\
\text { Heating Capacity: } 108 \mathrm{MBH} \text { with } 2 \mathrm{lb} \text { steam, } 60^{\circ} \mathrm{F} \\
\text { entering air at 2010 CFM }\end{array}$ \\
\hline Heat Dump Load 2 & Modine: & $\begin{array}{l}\text { Horizontal Delivery } \\
\text { Core Type: Double Serpentine } \\
\text { Heating Capacity: } 193 \mathrm{MBH} \text { with } 2 \mathrm{lb} \text { steam, } 60^{\circ} \mathrm{F} \\
\text { entering air at } 2900 \mathrm{CFM}\end{array}$ \\
\hline
\end{tabular}




\section{Simplified Model for Technology Screening}

To investigate the feasibility of the GAHP system to be implemented in Canada, a technology screening tool was developed using Excel. This simplified model is designed to have the GAHP deliver the required amount of thermal energy, i.e., meeting exactly the heating and cooling demand, for any building, given the demand profile. This model is intended to give a rough estimate of expected GAHP performance using manufacturer performance data, originally based on a primary fluid of water but corrected for the use of a PG/water solution using a provided correction factor.

\subsection{House A Model}

Previous studies done at the ASH have resulted in the development of various models for both Houses A and B. For the specific software known as TRNSYS, both House A and B models were developed to evaluate the performance of an ASHP and GSHP. TRNSYS is a software that is capable of exporting building energy demand profiles for models designed using the TRNBuild, which is included with the TRNSYS software package. House A is one building that has been previously developed and validated using TRNSYS with experimental data obtained from the ASH monitoring systems (Safa et al., 2012a).

House A was used to test the performance of an ASHP system which used electricity as its primary fuel. Using this house model in TRNSYS, an energy demand profile is generated. The heating and cooling season temperature setpoint is $22^{\circ} \mathrm{C}$ and $24^{\circ} \mathrm{C}$, respectively.

\subsection{Climate and Locations}

Location plays a large part in how effective a system can be due to socioeconomic and climatic factors unique to each area. Various locations will have different fuel pricings as well as initiatives and incentives to help subsidize technologies. For this screening study, various Canadian cities will be studied to distinguish best use locations.

The House A model was originally validated using Metropolitan Toronto TM2 weather data. The ambient outdoor temperature profile can be seen in Figure 4.1. The highest and lowest temperatures in this profile are $33.91{ }^{\circ} \mathrm{C}$ and $-22.31^{\circ} \mathrm{C}$, respectively. These weather files are typically averaged over several decades and use past climatic data. 


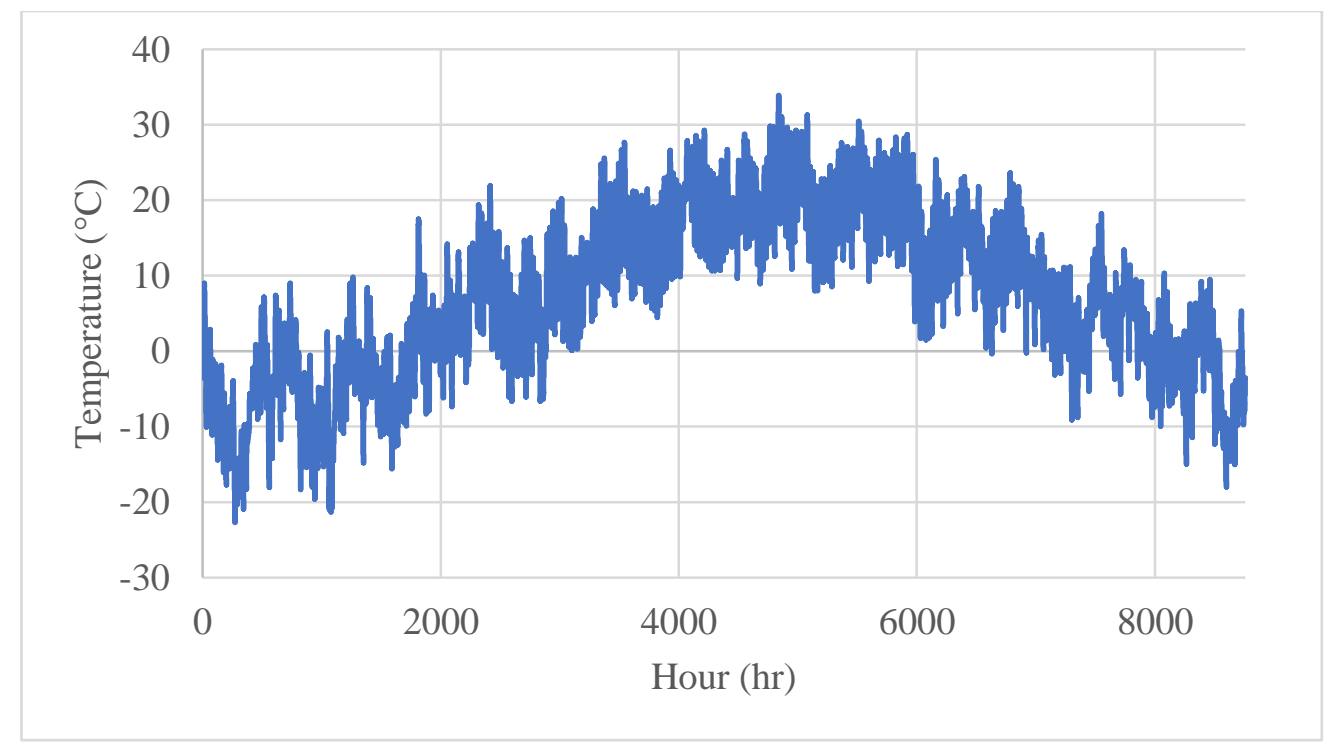

Figure 4.1: Ambient outdoor temperature profile for Toronto (Klein, 2010)

For these simulations however, each region had different heating and cooling season durations and start and end periods. This is done as different climates would inherently have shorter or longer heating or cooling seasons depending on location. A location with a milder climate would have a shorter duration for the heating season than one with a harsher cold climate. This is better visualized by understanding the difference in climates by using a standard reference. This is done using annual heating degree days (HDD) and cooling degree days (CDD) using a reference temperature of $18.3^{\circ} \mathrm{C}\left(65^{\circ} \mathrm{F}\right)$ (ASHRAE, 2009). The ambient outdoor temperatures profiles used to solve for the HDD and CDD for the various cities were taken from TM2 weather files provided in TRNSYS 17 (Klein, 2010). Table 4.1 lists a summary of the 5 Canadian cities that will be simulated with the annual HDD and CDD. HDD and CDD were solved using the following equations provided through the ASHRAE Fundamentals Handbook (ASHRAE, 2009).

$\begin{array}{lr}H D D=\sum_{i=1}^{N}\left(T_{\text {ref }}-\bar{T}_{l}\right) & \text { Equation } 4.1 \\ C D D=\sum_{i=1}^{N}\left(\bar{T}_{l}-T_{\text {ref }}\right) & \text { Equation } 4.2\end{array}$

Where:

$N$ : is the number of days, 365 for the case of annual HDD or CDD

$\bar{T}_{l}:$ is the daily average temperature 
$T_{r e f}:$ is the reference temperature for $\mathrm{HDD}$ and $\mathrm{CDD}, 18.3^{\circ} \mathrm{C}\left(65^{\circ} \mathrm{F}\right)$ is used in both cases

Table 4.1: Summary of maximum and minimum ambient temperatures and HDD and CDD for different Canadian cities

\begin{tabular}{|l|c|c|c|c|}
\hline \multicolumn{1}{|c|}{ Location } & $\begin{array}{c}\text { Max Temperature } \\
\left({ }^{\circ} \mathbf{C}\right)\end{array}$ & $\begin{array}{c}\text { Min Temperature } \\
\left({ }^{\circ} \mathbf{C}\right)\end{array}$ & $\begin{array}{c}\text { HDD* } \\
\left({ }^{\circ} \mathbf{C}-D a y\right)\end{array}$ & $\begin{array}{c}\text { CDD* } \\
\left({ }^{\circ} \mathbf{C}-D a y\right)\end{array}$ \\
\hline Toronto, ON & 33.91 & -22.73 & 4135 & 207 \\
\hline Montreal, QC & 32.24 & -25.11 & 4500 & 263 \\
\hline Halifax, NS & 28.15 & -20.67 & 4304 & 37 \\
\hline Edmonton, AB & 29.51 & -30.66 & 5543 & 127 \\
\hline Vancouver, BC & 26.33 & -5.80 & 3051 & 19 \\
\hline
\end{tabular}

*Reference Temperature of $18.3^{\circ} \mathrm{C}\left(65^{\circ} \mathrm{F}\right)$ used.

These cities will be used to perform a sensitivity analysis to estimate the feasibility of the GAHP system in different regions. For each city, the TRNSYS House A model was analyzed to find the optimal start and end times of cooling and heating season. This was done by finding the hour where significant cooling was required during the transition from spring to summer, and when cooling was no longer required during the transition from fall to winter. Table 4.2 shows the start and end hours of each season, along with the duration of heating or cooling season.

Table 4.2: Summary of start and end times for heating and cooling season for different Canadian cities

\begin{tabular}{|l|c|c|c|c|}
\hline Location & $\begin{array}{c}\text { Cooling Season } \\
\text { Start Time } \\
\text { (hour) }\end{array}$ & $\begin{array}{c}\text { Heating Season } \\
\text { Start Time } \\
\text { (hour) }\end{array}$ & $\begin{array}{c}\text { Cooling Season } \\
\text { Duration } \\
\text { (hours)* }\end{array}$ & $\begin{array}{c}\text { Heating Season } \\
\text { Duration } \\
\text { (hours)** }\end{array}$ \\
\hline Toronto & 3345 & 6025 & 2680 & 6080 \\
\hline Montreal & 3320 & 6060 & 2740 & 6020 \\
\hline Edmonton & 3900 & 6050 & 2150 & 6610 \\
\hline Vancouver & 4040 & 6025 & 1985 & 6775 \\
\hline Halifax & 4060 & 6000 & 1940 & 6820 \\
\hline
\end{tabular}

*Cooling Season Duration is solved using: (Heating Season Start Time - Cooling Season Start Time) **Heating Season Duration is solved using: (8760 - Cooling Season Duration)

\subsection{GAHP Manufacturer Specifications}

The GAHP system developed by Robur is designed to operate using a primary fluid of water to deliver the heating and cooling needs of buildings. Although it is a small commercial unit, it can be sized for multiple homes. When the primary fluid is water, the nominal heating and cooling 
capacity is $35 \mathrm{~kW}$ and $17 \mathrm{~kW}$, respectively. However, due to freezing outdoor temperatures commonly seen during the heating season in Canada, water is not a feasible primary fluid to be exposed to these outdoor temperatures. As a result, a PG/water solution is required. For the case of Toronto especially, a 50\% PG/water solution is required due to having a freezing point of $-33.5^{\circ} \mathrm{C}$. This solution is needed for all cities being simulated with the exception of Vancouver. Due to Vancouver mild temperatures, a 30\% PG/water solution would be most practical, with a freezing point of $-12.7^{\circ} \mathrm{C}$ (ASHRAE, 2009). Due to the nature of the PG/water solution however, some heat transfer capability is lost with higher concentrations. The correction factor approximation for $50 \% \mathrm{PG} /$ water is 0.878 , while the correction factor for a $30 \%$ solution is 0.96 (Robur Corporation, 2017). This is a significant difference in heat transfer potential. For the case of Vancouver, the 30\% PG/water solution would be most optimal, however for the sake of consistency when comparing the performance in these different regions, all models will use the 50\% PG/water solution. Further details on the varies PG/water heat transfer factors can be found in Appendix B.

Due to using a 50\% PG/water solution, the nominal capacity of the GAHP is corrected to $30.7 \mathrm{~kW}$ and $14.9 \mathrm{~kW}$ for both heating and cooling capacity, respectively. This translates roughly to a $12 \%$ reduction in capacity of the system. Figure 4.2 and 4.3 shows the manufacturer performance data in both the original capacities when using water, and when corrected for the use of a PG/water solution. The manufacturer data is described using a $3^{\text {rd }}$ order and $2^{\text {nd }}$ order polynomial fit for heating and cooling mode respectively. The respective equations describing the curves are presented above (working fluid of water) and below (working fluid 50\% PG/water) the in Figures 4.2 and 4.3. The trendlines observed from these performance curves will be used to describe the GAHP performance in the simplified model of the system in the House A model. 


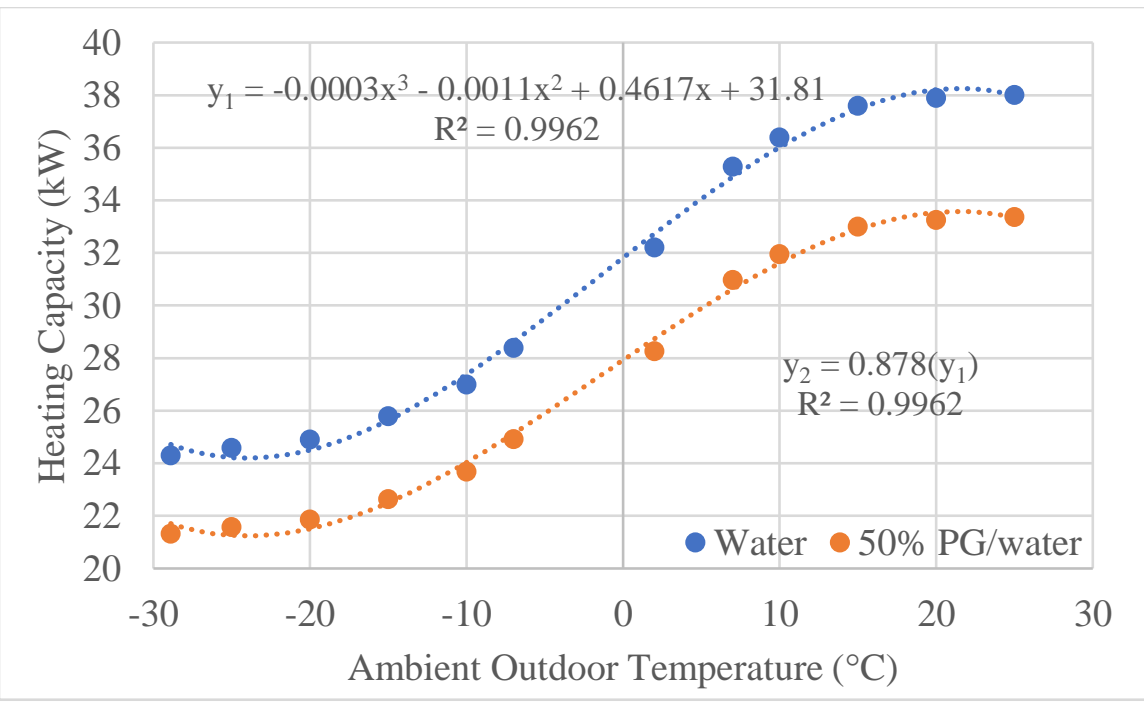

Figure 4.2: Heating GAHP performance curves for water and 50\% PG/water with a return temperature of $40^{\circ} \mathrm{C}$ at $13.4 \mathrm{GPM}$

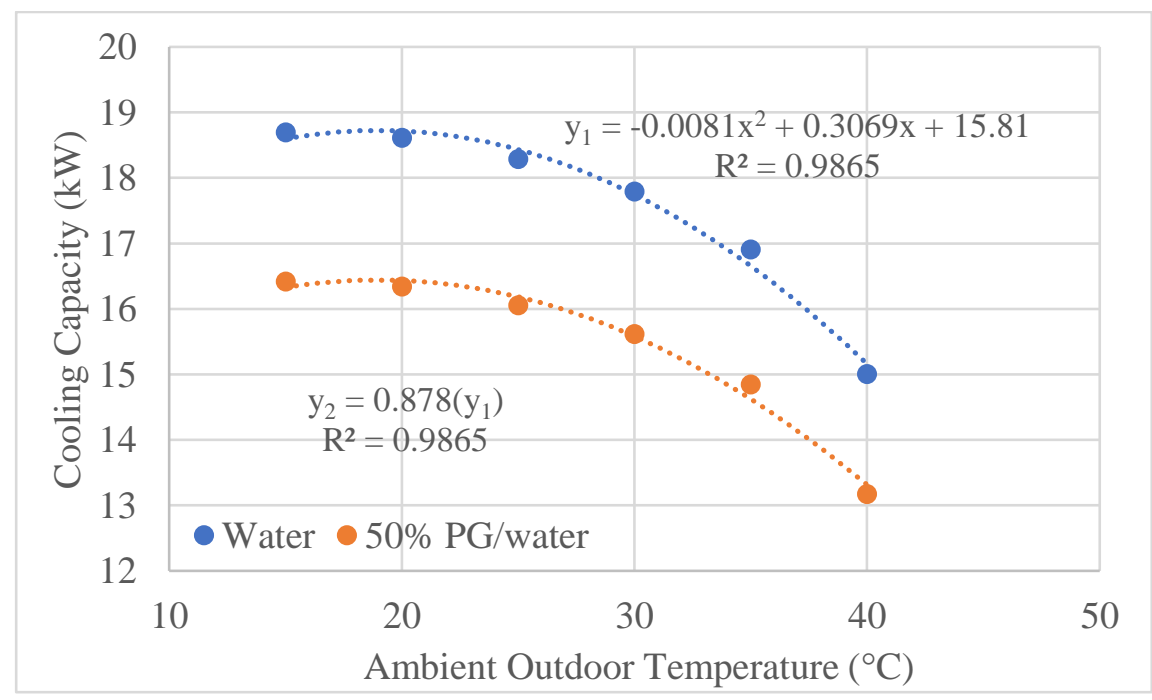

Figure 4.3: Cooling GAHP performance curves for water and 50\% PG/water with a return temperature of $12^{\circ} \mathrm{C}$ at $12.8 \mathrm{GPM}$

Polynomial fits are used to describe the correlation of the manufacturer capacity points with the ambient outdoor temperatures. For each plot, the $\mathrm{R}^{2}$ values were near unity.

\subsection{Simplified Excel Model}

The model used for this study was developed using Microsoft Excel. For each city, a House A energy demand profile was generated using TRNSYS. Each of these demand profiles are generated at 5-minute time intervals. This is due to the nature of how the GAHP operates. The 
GAHP control signal is dependant on the temperature of the return temperature of the primary working fluid. If the time step was for a long period, such as an hour, the GAHP would continue operating for a full hour, which will result in the primary fluid heating up or cooling down to a temperature far from reasonable to meet demand that does not exist. Using a time-step such as 1 minute or less would provide a more detailed simulation and maintain the temperature of the primary fluid at more realistic values. However, to minimize resources needed for computation, a 5-minute time step is used as a compromise. A small time step is especially necessary to effectively model the GAHP control strategy. The model is solved by using the GAHP performance curves to meet the demand profile of the House A model, effectively providing nearly the exact amount of heating or cooling necessary. By doing this, the performance of the GAHP can be evaluated under optimal operating conditions. The operating conditions as modelled through the control system is not necessarily how the GAHP would perform in real life, but instead if a perfect HVAC system was designed to deliver all heating and cooling provided by the GAHP into the house as needed.

Table 4.3 shows the peak heating and cooling demand of House A under the varying climate conditions along with the specific annual heating and cooling demands for the given temperature setpoints and season durations.

Table 4.3: Heating and cooling peak demands and annual demands for select Canadian cities

\begin{tabular}{|l|c|c|c|c|}
\hline \multicolumn{1}{|c|}{ Location } & $\begin{array}{c}\text { Peak } \\
\text { Heating } \\
\mathbf{( k W )}\end{array}$ & $\begin{array}{c}\text { Peak } \\
\text { Cooling } \\
\mathbf{( k W )}\end{array}$ & $\begin{array}{c}\text { Annual Heating } \\
\text { Demand } \\
\mathbf{( k W h / y e a r})\end{array}$ & $\begin{array}{c}\text { Annual Cooling } \\
\text { Demand } \\
\mathbf{( k W h} / \mathbf{y e a r})\end{array}$ \\
\hline Toronto, ON & 6.92 & 4.71 & 18582 & 1881 \\
\hline Montreal, QC & 7.57 & 4.33 & 20134 & 2056 \\
\hline Halifax, NS & 6.53 & 3.71 & 19536 & 745 \\
\hline Edmonton, AB & 8.55 & 5.82 & 24050 & 1197 \\
\hline Vancouver, BC & 5.49 & 3.44 & 14661 & 846 \\
\hline
\end{tabular}

\subsection{Operation and Sizing}

From Table 4.3, the peak demands of House A for both heating and cooling are much lower than what the full capacity of the GAHP is capable of. For this reason, the GAHP is sized down to a more appropriate capacity. The corrected heating and cooling capacity of the GAHP is $30.7 \mathrm{~kW}$ and $14.9 \mathrm{~kW}$ with the use of a $50 \% \mathrm{PG} /$ water solution. To pick a single size for the various regions comes with a limitation similar to the case with selecting the most appropriate PG/water solution. 
In the case of sizing correctly, it can be seen that the cooling peak of Edmonton is notably higher than the other cities. The peak cooling demand of Edmonton would require the sizing of the GAHP to be approximately $40 \%$ of its original. Edmonton also has the highest peak heating demand as well, with $8.55 \mathrm{~kW}$. This peak heating demand is equivalent to less than $30 \%$ of the heating capacity of the GAHP system. As evidenced, a compromise must be made to have the system perform most optimally to avoid unnecessary complications such as excessive short cycling. To select a single size, the HDD and CDD for each city was recalled through the summary in Table 4.2. It can be seen that Edmonton only has CDD of $137.2^{\circ} \mathrm{C}$-day which shows that there is a very low amount of cooling required compared to the heating as seen from the HDD. Although the peak cooling demand requires a sizing of $40 \%$, relative to the other cities, $30 \%$ of the original capacity was most reasonable, as the cooling demand was met within a reasonable deviation for all cities, and satisfactory for all other cities for peak heating demand. The new nominal capacity of the GAHP, sized to $30 \%$ of its original specifications, was $9.21 \mathrm{~kW}$ and 4.47 . The down sizing of the system was also applied to other mechanical equipment that was a part of the total HVAC system, namely the GAHP operating power and primary pump power. The GAHP has a rated electrical consumption of $750 \mathrm{~W}$, which was adjusted down to $225 \mathrm{~W}$. The system was designed to be delivered with 2 pumps that have a rated electrical consumption of $375 \mathrm{~W}$ each, resulting in a total electrical consumption of $750 \mathrm{~W}$ and sized down to $225 \mathrm{~W}$. Gas consumption is also scaled to $30 \%$ from nominal operation.

The GAHP was modelled to operate at nominal conditions as stated by the manufacturer specifications for both operating temperature and flow rate. During the heating mode operation, the GAHP is designed to have a nominal primary fluid flow rate of 13.4 GPM, and 12.8 GPM for cooling mode. During heating mode, the nominal supply temperature of the primary fluid into the GAHP is $50^{\circ} \mathrm{C}$, while the nominal return temperature for cooling mode is $7^{\circ} \mathrm{C}$. The manufacturer specifications give detailed performance maps for several other supply temperatures, namely $30^{\circ} \mathrm{C}, 45^{\circ} \mathrm{C}$ and $60^{\circ} \mathrm{C}$ for heating mode and $3^{\circ} \mathrm{C}$ and $10^{\circ} \mathrm{C}$ for cooling mode. The temperature difference of the primary fluid expected, as stated by the manufacturer specifications at nominal operation is $10^{\circ} \mathrm{C}$ for most heating mode supply temperatures, and $5^{\circ} \mathrm{C}$ for the cooling mode supply temperatures. However, due the to nature of the operation of the GAHP, the return temperature is the primary driving factor of the GAHPs control strategy. This model uses a simple heat transfer 
formula to transfer the heating or cooling energy from the GAHP to the fluid in the hydronic loop. The equation is as follows:

$\dot{Q}=\dot{m} \cdot c_{P G / \text { water }} \cdot \Delta T$

Equation 4.3

Where:

$\dot{Q}:$ is the heat or cooling energy output rate by the GAHP in $(\mathrm{kW})$

$\dot{m}$ : is the mass flow rate of the $50 \% \mathrm{PG} /$ water solution in $(\mathrm{kg} / \mathrm{s})$

$c_{P G / \text { water: }}$ is the specific heat of $50 \% \mathrm{PG} /$ eater solution, $3.55(\mathrm{~kJ} / \mathrm{kg} \cdot \mathrm{K})$ at $25^{\circ} \mathrm{C}$ (Dow Chemical, 2008)

$\Delta T:$ is the temperature difference between supply and return temperatures in $\left({ }^{\circ} \mathrm{C}\right)$

\subsection{Control Strategy}

The control strategy designed for this model was modelled after the expected control of the GAHP unit as stated by the manufacturer. The GAHP system is modelled to operate in a hydronic loop. As a result, the fluid temperature is what defines if the GAHP decided to turn on or off. However, whether the GAHP signals on or off is only one stage in the control system, included in the operational procedures is whether the primary loop pump should operate. The GAHP is designed to only turn on once the return temperature is below a certain temperature for heating or above a certain temperature for cooling. In the case of nominal operation for the conditions set in this model, these set points would be whether the return temperature is below $40^{\circ} \mathrm{C}$ in heating mode or above $12^{\circ} \mathrm{C}$ in cooling mode.

In this model, the need for heating or cooling is defined by whether there is heating or cooling demand in the generated demand profile. If there is demand in the profile, and there is no energy in the hydronic loop to meet the demand, the GAHP will turn on. As an example, if there is a heating demand, but the temperature of the primary fluid in the hydronic fluid is too low to supply the needed demand, the GAHP operates normally. However, there will be cases where the demand exists, but is too low to use the energy added into the hydronic loop for heating mode and vice versa for cooling mode. The GAHP will only consider turning on when the setpoint of the return temperature is reached. With unmet demand, the energy that is still within the primary loop, 
this residual energy, is continued to be pumped to meet the demand. As a result, the GAHP will not unnecessarily add or remove more energy than required, but consequently the pump will frequently be in use to use up the remaining cooling or heating energy in the loop. For this reason, the low time step for the simulation was crucial, as the return temperature needed to be consistently updated to check whether there was energy in the hydronic loop that had yet to be used to meet demand. Due to this strategy, sizing correctly is a key concern, as oversized equipment would result in short GAHP cycles with extended periods of pump use to bring the return temperature to the expected set points. Figure 4.4 shows a simple flow diagram to show the control strategy.

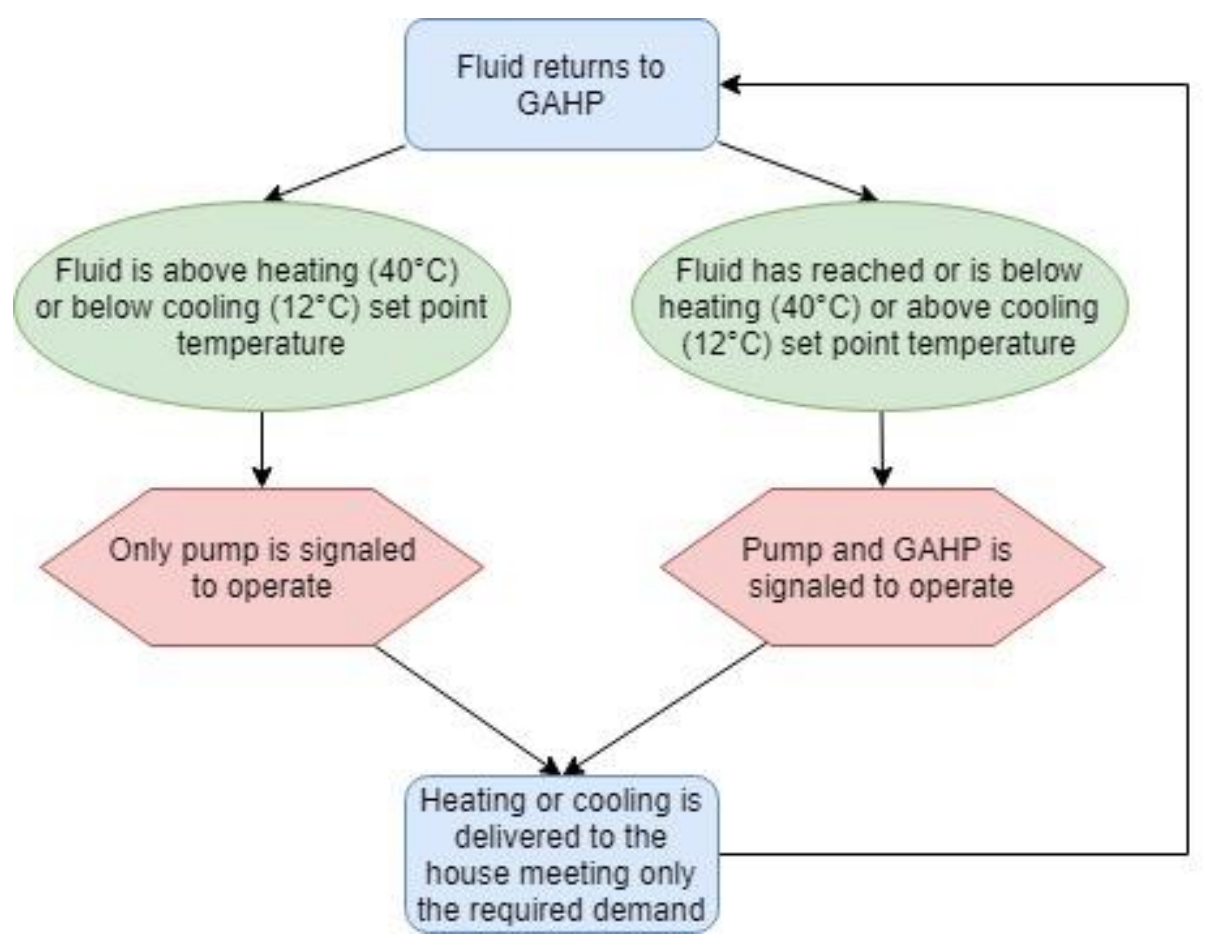

Figure 4.4: Flow diagram of the control strategy used in simplified model

The primary objective of this control strategy is to meet the demand of the house exactly with the capacity of the GAHP. This will provide estimates of the GAHP performance characteristics, although whether the House A model will maintain a thermally comfortable temperature throughout the entire year, cannot readily be discerned.

\subsection{Simulation Results}

The simplified model was used to simulate House A for the 5 separate Canadian climates listed in Table 4.1. The results found show trends that are expected of each region. As seen in 
Table 4.2, each region has different scheduling for when heating and cooling season began, as such, some regions will have naturally higher consumption for heating season or cooling season compared to other cities. This however, will allow for more realistic understanding of how the system may be applied in those regions and satisfy demand effectively. Table 4.4 shows the performance characteristics found for each city for heating season when using a 50\% PG/water solution. In the following tables, the Coefficient of Performance (COP) and Gas Utilization Efficiency (GUE) is defined by the following equations. Each unit of natural gas is assumed to have an energy density of $37 \mathrm{MJ} / \mathrm{m}^{3}$ (Statistics Canada, 2011).

$$
\begin{aligned}
G U E & =\frac{\text { GAHP Output }(k W h)}{\text { GAHP Gas Input }(k W h)} \\
C O P & =\frac{\text { GAHP Output }(k W h)}{\left(\begin{array}{c}
\text { GAHP Gas Input }(k W h) \\
+ \text { Circulation Pump Energy Consumption }(k W h) \\
+ \text { GAHP Electrical Energy Consumption }(k W h)
\end{array}\right)}
\end{aligned}
$$

Equation 4.4

Equation 4.5

Table 4.4: GAHP heating performance summary from simplified model for various Canadian cities with 50\% PG/water as the primary working fluid

\begin{tabular}{|l|c|c|c|c|c|}
\hline \multicolumn{1}{|c|}{ Location } & Toronto & Montreal & Edmonton & Vancouver & Halifax \\
\hline $\begin{array}{l}\text { GAHP Operating Hours } \\
\text { (hours) }\end{array}$ & 2301 & 2591 & 3185 & 1622 & 2355 \\
\hline Gas Input $(\mathrm{kWh})$ & 19318 & 21759 & 26746 & 13617 & 19777 \\
\hline Gas Consumed $\left(\mathrm{m}^{3}\right)$ & 1880 & 2117 & 2602 & 1325 & 1924 \\
\hline Pump Power $(\mathrm{kWh)}$ & 1368 & 1354 & 1487 & 1524 & 1534 \\
\hline GAHP Power $(\mathrm{kWh})$ & 518 & 583 & 717 & 365 & 530 \\
\hline Heating GUE & 0.96 & 0.93 & 0.90 & 1.08 & 0.99 \\
\hline Heating COP & 0.88 & 0.85 & 0.83 & 0.95 & 0.89 \\
\hline Average Cycles per hour & 3.22 & 2.74 & 2.52 & 2.83 & 3.28 \\
\hline
\end{tabular}

From the results summarized in Table 4.4, Edmonton requires the highest heating energy, while Vancouver requires the least. This is expected as Edmonton has a much higher HDD than all other cities, while Vancouver has the lowest. As a result, Vancouver has the highest seasonal heating GUE at 1.08, which is expected since the GAHP has the highest capacities at milder temperatures as seen in Figure 4.2. It should also be noted that Vancouver is the only city that obtained a GUE above 1. Edmonton has the lowest at 0.90 due to more colder days, bringing the 
overall seasonal heating GUE down significantly. Toronto and Montreal have roughly close GUE values, both of which have value equal or less than that of the most efficient furnaces available presently. Halifax has a GUE value of 0.99 , the only other city other than Vancouver that is competitive against current natural gas forced air furnaces All these GUE values are significantly lower than the rated nominal value which is $126 \%$ during heating mode when using water as the primary fluid. With the reduction of capacity due to the use of PG/water solution, the value is still expected to have been closer to $114 \%$. However, the lower GUE than expected is most likely due to the poorer performance of the GAHP at very cold temperatures as seen in Figure 4.2. The COP values for all cities are below unity, as the pump power required reduced the efficiency of the system. Table 4.5 shows the heating performance of the GAHP when using original manufacturer performance data for when water is the primary fluid.

Table 4.5: GAHP heating performance summary from simplified model for various Canadian cities with water as the primary working fluid

\begin{tabular}{|l|c|c|c|c|c|}
\hline \multicolumn{1}{|c|}{ Location } & Toronto & Montreal & Edmonton & Vancouver & Halifax \\
\hline $\begin{array}{l}\text { GAHP Operating Hours } \\
\text { (hours) }\end{array}$ & 2020 & 2278 & 2807 & 1424 & 2068 \\
\hline Gas Input $(\mathrm{kWh)}$ & 16963 & 19129 & 23573 & 11955 & 17366 \\
\hline Gas Consumed $\left(\mathrm{m}^{3}\right)$ & 1650 & 1861 & 2294 & 1163 & 1690 \\
\hline Pump Power $(\mathrm{kWh)}$ & 1368 & 1354 & 1487 & 1524 & 1534 \\
\hline GAHP Power $(\mathrm{kWh})$ & 455 & 513 & 632 & 320 & 465 \\
\hline Heating GUE & 1.10 & 1.05 & 1.02 & 1.23 & 1.12 \\
\hline Heating COP & 0.99 & 0.96 & 0.94 & 1.06 & 1.01 \\
\hline Average Cycles per hour & 3.16 & 2.97 & 2.75 & 2.51 & 3.12 \\
\hline
\end{tabular}

It is shown in Table 4.5 that the GUE values of all cities, even Edmonton is above 1 when water is the primary fluid. This suggests that the efficiency of the system can be more competitive and effective if a primary fluid that has heat transfer capabilities closer to that of water or even higher is used. Although the seasonal heating GUE for each city is still lower than that of the nominal GUE due to the colder Canadian climate.

In addition, although demand was met exactly with respect to the demand profiles, due to the nature of the simulation, the pump was operated frequently. One aspect that is of interest and provides insight into the low GUE and COP values is the amount of cycling that occurred in the 
models. When using 50\% PG/water, Halifax had the highest cycles per hour of 3.28 per hour, and with 5-minute time steps this would mean cycles did not on average last for more than 10 minutes. Edmonton had the lowest cycles per hour 2.52, which is not a significant deviation from Halifax. When using water as the primary fluid, cycling for all cities were reduced, but not significantly. This highlights the limitations of the system, even when conditions such as thermal inertia and part load performance in the GAHP are not accounted for, since only steady state manufacturer performance data is used.

Similarly. cooling mode performance of the GAHP was much more consistent for when both $50 \%$ PG/water and water alone was used as the primary working fluid. Results for cooling performance of the GAHP are shown in Table 4.6 and 4.7.

Table 4.6: GAHP cooling performance summary from simplified model for various Canadian cities with 50\% PG/water as the primary working fluid

\begin{tabular}{|l|c|c|c|c|c|}
\hline \multicolumn{1}{|c|}{ Location } & Toronto & Montreal & Edmonton & Vancouver & Halifax \\
\hline GAHP Operating Hours & 394 & 426 & 251 & 176 & 156 \\
\hline Gas Input $(\mathrm{kWh})$ & 3304 & 3580 & 2104 & 1481 & 1313 \\
\hline Gas Consumed $\left(\mathrm{m}^{3}\right)$ & 321 & 348 & 205 & 144 & 128 \\
\hline Pump Power $(\mathrm{kWh})$ & 364 & 423 & 235 & 197 & 191 \\
\hline GAHP Power $(\mathrm{kWh})$ & 89 & 96 & 56 & 40 & 35 \\
\hline Cooling GUE & 0.58 & 0.58 & 0.58 & 0.59 & 0.58 \\
\hline Cooling COP & 0.51 & 0.51 & 0.51 & 0.51 & 0.50 \\
\hline Average Cycles per hour & 2.22 & 2.19 & 2.21 & 2.18 & 1.95 \\
\hline
\end{tabular}

From Table 4.6, cooling GUE of all cities are consistent with 0.58 for all cities, with the exception of Vancouver at 0.59 . This consistency is likely due to the smaller range of outdoor temperatures that the GAHP will operate in during the cooling season. The GAHP has a higher capacity during milder temperatures, this can also be seen in the decrease in cycles per hour for cooling mode for all cities compared to the heating season. As expected, the cities with the highest CDD had the highest consumption and hours of operation, and as a result, higher energy consumption. COP is equally consistent for all cities apart from Vancouver and Halifax, this decrease however is not significant and most likely due to the longer pump operating durations to deliver cooling when demand is too low for the GAHP to operate but enough for the pump to circulate the previously cooled fluid in the hydronic loops to deliver cooling. 
Table 4.7: GAHP cooling performance summary from simplified model for various Canadian cities with water as the primary working fluid

\begin{tabular}{|l|c|c|c|c|c|}
\hline \multicolumn{1}{|c|}{ Location } & Toronto & Montreal & Edmonton & Vancouver & Halifax \\
\hline GAHP Operating Hours & 346 & 375 & 221 & 156 & 138 \\
\hline Gas Input $(\mathrm{kWh})$ & 2905 & 3152 & 1855 & 1307 & 1162 \\
\hline Gas Consumed $\left(\mathrm{m}^{3}\right)$ & 283 & 307 & 180 & 127 & 113 \\
\hline Pump Power $(\mathrm{kWh})$ & 364 & 423 & 235 & 197 & 191 \\
\hline GAHP Power $(\mathrm{kWh})$ & 78 & 84 & 50 & 35 & 31 \\
\hline Cooling GUE & 0.66 & 0.66 & 0.66 & 0.67 & 0.66 \\
\hline Cooling COP & 0.57 & 0.57 & 0.57 & 0.57 & 0.56 \\
\hline Average Cycles per hour & 2.15 & 2.09 & 2.13 & 2.03 & 1.82 \\
\hline
\end{tabular}

With water as the primary fluid, the GUE increases to 0.66 for all cities expect Vancouver where it is 0.67 . Similar to the performance due to the use of a primary fluid of 50\% PG/water compared to water alone, with water alone overall performance, including cycling, is improved to a similar degree. Tables $4.4-4.7$ all show that the GAHP has potential, but choosing an effective primary fluid is key for it to be competitive in terms of performance.

As mentioned earlier, it is more feasible to use a 30\% PG/water solution in Vancouver due to the higher minimum temperature compared to the other cities. Even with the use of 50\% PG/water solution, Vancouver still has the highest efficiencies, apart from seasonal cooling COP. This shows that Vancouver would have higher performance than that was shown in the Tables 4.4 and 4.6. This screening tool shows that there is promise for the GAHP system in these climates, but primary working fluid choice affects the feasibility significantly. Additional equipment such as thermal storage tanks would likely reduce the short cycling behaviour by having a larger volume requiring to be heated or cooled, allowing the GAHP to continue operating. This model does not account for the volume of PG/water solution in the system but instead, as stated earlier, uses simple energy balance equations to heat or cool the fluid depending on demand. This would contribute to the effects of cycling since in real life, hydronic loops in the home would contain a significant amount of fluid that would be heated and moved through the home before returning to the GAHP. Additional thermal storage would amplify this case and theoretically should allow for longer, more effective cycles. 


\subsection{Cost Analysis}

\subsubsection{Marginal Cost for Natural Gas and Electricity}

The cost of energy use due to the GAHP would differ greatly from region to region, primarily depending on natural gas and electricity prices. For each city, socioeconomic factors contribute to the pricing in each region. Edmonton, located in the province of Alberta, has its economy heavily based in the energy sector, resulting in more affordable energy rates. Unlike a city such as Halifax, located in Nova Scotia, which is not so heavily reliant on natural gas or electricity, as seen in Table 1.1, results in higher energy prices. Nova Scotia in fact, is known to have the highest natural gas prices in Canada currently (Withers, 2017). Table 4.8 summarises the marginal costs of both electricity and natural gas in each city being studied.

Table 4.8: Average marginal gas and electricity prices for various Canadian cities

\begin{tabular}{|l|c|c|c|c|c|}
\hline Location & Toronto & Montreal & Edmonton & Vancouver & Halifax \\
\hline $\begin{array}{l}\text { Marginal Electricity Price } \\
(\$ / \mathrm{kWh})\end{array}$ & 0.1122 & 0.0512 & 0.0738 & 0.0884 & 0.1533 \\
\hline $\begin{array}{l}\text { Marginal Natural Gas } \\
\text { Price* }\left(\$ / \mathrm{m}^{3}\right)\end{array}$ & 0.2443 & 0.4394 & 0.1624 & 0.2464 & 0.6951 \\
\hline
\end{tabular}

*Energy density of natural gas is assumed to be $37 \mathrm{MJ} / \mathrm{m}^{3}$ (Statistics Canada, 2011)

These costs only account for variable costs dependant on usage and not fixed costs, i.e. supply, delivery, transportation, etc. but not fixed monthly fees. Detailed tables summarising the breakdown of marginal energy cost can be found in Appendix A.

\subsubsection{Simple Cost Analysis}

To estimate potential cost savings, the GAHP will be compared to an ASHP, one that was also modelled in House A in a previous study. This will be done as an ASHP is more commonly heralded as a highly efficient technology with high performance characteristics with low energy use. Since ASHP systems only consume electricity, they can potentially have zero GHG emissions when clean renewable electricity is utilized, which is not possible for a GAHP. However, since electricity prices are high in some regions, an ASHP would not be as feasible for a typical residential homeowner, in comparison to an GAHP. The ASHP that will be compared to the GAHP is a two-stage cold climate ASHP with nominal heating capacity of $11.06 \mathrm{~kW}(38 \mathrm{MBH})$ and a cooling capacity of $9.82 \mathrm{~kW}(33.5 \mathrm{MBH})$. 


\subsubsection{Capital Cost}

It is clear that the heating capacity of the ASHP is only about a third of the capacity of the GAHP. One Robur GAHP-AR unit can provide the heating and cooling for the equivalent of 3 House A buildings. This is significant because the capital costs of both units, GAHP and ASHP, are close. The approximate cost that the ASHP system was purchased and installed for to be tested at House A was $\$ 14,500$. The cost of the GAHP that was purchased for both Houses A and B was approximately $\$ 19,000$, for both the Robur GAHP-AR unit as well as the accompanying DDC controller. With nearly equivalent costs, the GAHP unit used for this study is approximately $\$ 5,700$ (scaled to $30 \%$ of original) with respect to the energy it delivers to House A. The GAHP unit is more effective in terms of capital cost, if each unit would be utilized for multiple residential units.

\subsubsection{Operation Cost}

To estimate the saving in operational costs, ASHP consumption data from modelling House A with an ASHP will be used. From the previous study, the energy demand and ASHP consumption for the same cities is summarised in Table 4.9.

Table 4.9: ASHP thermal energy output and electricity consumption for both heating and cooling season for various Canadian cities (Safa et al., 2015c)

\begin{tabular}{|l|c|c|c|c|c|}
\hline \multicolumn{1}{|c|}{ Location } & Toronto & Montreal & Edmonton & Vancouver & Halifax \\
\hline Heating Output $(\mathrm{kWh})$ & 17,579 & 23,888 & 26,644 & 18,916 & 21,689 \\
\hline Cooling Output $(\mathrm{kWh})$ & 2,289 & 2,934 & 1,830 & 1,404 & 1,133 \\
\hline Heating Consumption $(\mathrm{kWh})$ & 5,442 & 8,031 & 10,141 & 4,236 & 6,009 \\
\hline Cooling Consumption $(\mathrm{kWh})$ & 434 & 540 & 337 & 245 & 203 \\
\hline
\end{tabular}

The values of heating and cooling output from Table 4.9 match closely with the House A annual energy demand seen in Table 4.3. The differences are most likely due to using different heat and cooling season schedules, but the values are close enough to give a qualitative estimation of expected operational cost savings for the different regions.

A summary of the total electricity and natural gas consumption for both heating and cooling season for each unit can be found in Table 4.10. Figure 4.10 compares the consumption of the ASHP to that of the GAHP that used 50\% PG/water as the primary working fluid. 
Table 4.10: Total electricity and natural gas consumption of ASHP and GAHP for various Canadian cities

\begin{tabular}{|c|c|c|c|}
\hline Location & $\begin{array}{l}\text { Energy } \\
\text { Source }\end{array}$ & $\begin{array}{c}\text { Total ASHP } \\
\text { Consumption }(\mathrm{kWh})\end{array}$ & $\begin{array}{c}\text { Total GAHP } \\
\text { Consumption }\left(\mathbf{m}^{3}\right)\end{array}$ \\
\hline \multirow[b]{2}{*}{ Toronto } & Electricity & 5,876 & 561 \\
\hline & Natural Gas & 0 & 2036 \\
\hline \multirow[b]{2}{*}{ Montreal } & Electricity & 8,571 & 629 \\
\hline & Natural Gas & 0 & 2285 \\
\hline \multirow[b]{2}{*}{ Edmonton } & Electricity & 10,478 & 706 \\
\hline & Natural Gas & 0 & 2562 \\
\hline \multirow[b]{2}{*}{ Vancouver } & Electricity & 4,481 & 387 \\
\hline & Natural Gas & 0 & 1404 \\
\hline \multirow[b]{2}{*}{ Halifax } & Electricity & 6,212 & 526 \\
\hline & Natural Gas & 0 & 1910 \\
\hline
\end{tabular}

The sum of electricity consumed in Edmonton by the ASHP is stated to be due to the use of a supplementary heater when the ASHP could not meet heating demand. This is due to the minimum temperature in the annual ambient temperature profile for Edmonton not being within the operating range of the ASHP, which is designed to provide to temperatures as low at $-25^{\circ} \mathrm{C}$. This results in a much higher energy consumption in Edmonton specifically.

The operational costs are evaluated using the total energy consumption stated in Table 4.11 for both units and the marginal energy rates found in Table 4.8. A summary of these results is shown in Table 4.11, along with the potential savings or losses of using the GAHP system using $50 \% \mathrm{PG} /$ water relative to the ASHP.

Table 4.11: Total annual operational costs for ASHP and GAHP for various Canadian cities

\begin{tabular}{|l|c|c|c|c|c|}
\hline \multicolumn{1}{|c|}{ Location } & Toronto & Montreal & Edmonton & Vancouver & Halifax \\
\hline ASHP Cost $(\$)$ & 659.48 & 438.84 & 773.28 & 396.12 & 952.36 \\
\hline GAHP Cost $\$$ ) & 605.76 & 1118.03 & 513.01 & 397.74 & 1513.02 \\
\hline Difference (\$) & 53.71 & -679.20 & 260.27 & -1.62 & -560.66 \\
\hline
\end{tabular}

Due to the high natural gas prices in Montreal and Halifax, the GAHP is not feasible as an ASHP, which would be more cost effective in both locations with the affordable electricity rates relative to natural gas. This shows that regional characteristics should be accounted for in the 
implementation of the GAHP technology. In the case of Quebec, as seen in Table 1.1, electricity is the primary heating fuel. As IESO mentioned in a report on residential heat pumps, ASHP systems are most cost effective when the primary heating fuel was already electricity (IESO, 2017). For the case of Nova Scotia, Table 1.1 also shows that natural gas is not a primary source, instead Oil and electricity have high shares as the primary heating fuel in those locations.

In locations such as Ontario, British Columbia and Alberta however, the GAHP may prove to be competitive. In Vancouver, the price difference is surprising at a loss at $-\$ 1.62$ in potential savings with the use of a GAHP compared to an ASHP. This is likely due to the high performance of the ASHP in the milder climate and affordable electricity prices, resulting in the GAHP being slightly outclassed when $50 \% \mathrm{PG} /$ water is used. This is low enough to be negligible depending on factors such as heating and cooling scheduling. However, as stated earlier, the reduced efficiency of the system due to 50\% PG/water solution can be mitigated in Vancouver with the use of a 30\% PG/water solution instead, which has higher heat transfer potential, making the GAHP more viable.

In Toronto, high electricity prices are expected to make gas appliances more competitive, especially when natural gas is the primary heating fuel in Ontario, as stated in Table 1.1. When the GAHP demonstrates higher efficiency than a traditional forced air furnace, which is the primary heating appliance in Canada (see Figure 1.4), reduced natural gas usage along with affordable pricing make the GAHP system potentially viable on a cost basis. However, due to the lower performance of the $50 \%$ PG/water solution, the GAHP in Toronto reveals potential savings of only $\$ 54$ annually, which would not be competitive on a when considering payback periods.

The GAHP however, truly has the largest impact in Edmonton, Alberta. With low natural gas prices due to an economy highly dependant on the energy sector, and electricity still being generated through the burning of fossil fuels, a GAHP system is most feasible in Alberta. Using an ASHP would primarily be best when the electricity consumed is generated through renewable resources. However, in Alberta, this is not generally the case and with reduced natural gas consumption, the GAHP can reduce GHG emission relative to standard appliances which remain affordable with savings estimates of \$260 with respect to an ASHP. A GAHP would be an optimal transitional technology to be used in Edmonton, Alberta on a cost basis, and if considering the current emissions due the use of Alberta's electrical grids. 


\subsection{GHG Reduction Potential}

For GHG reduction potential, the GAHP natural gas consumption is compared to that of a forced air furnace with an efficiency assumed to be $90 \%$ for the heating season, where natural gas is assumed to be the primary heating fuel. Table 4.12 summarizes the natural gas energy input of the forced air furnace assuming demand is met exactly, using annual heating demand values from Table 4.3.

Table 4.12: Natural gas energy consumption of $90 \%$ efficient forced air furnace for House A for various Canadian cities

\begin{tabular}{|l|c|c|}
\hline Location & $\begin{array}{c}\text { Furnace } \\
\text { Heating Output } \\
\text { (kWh) }\end{array}$ & $\begin{array}{c}\text { Gas } \\
\text { Consumption } \\
\text { (MJ) }\end{array}$ \\
\hline Toronto & 20647 & 74328 \\
\hline Montreal & 22371 & 80536 \\
\hline Halifax & 21707 & 78144 \\
\hline Edmonton & 26722 & 96200 \\
\hline Vancouver & 16290 & 58644 \\
\hline
\end{tabular}

Table 4.13 compares the natural gas energy consumption of both the forced air furnace and GAHP system and summarizes the total GHG emissions produced during the heating season. In Table 4.13, it can be seen that the most significant GUE reductions can be found in Vancouver as expected. However, Edmonton has the lowest improvement in the GHG emissions that is reduced compared to the GAHP. Since the GUE for Edmonton when the primary fluid at $50 \%$ PG/water is near the same efficiency of the furnace it is being compared to, the reduction in GHG emissions is practically negligible. All other cities however, show that the GAHP reduces the GHG emissions, showing potential for the GAHP to be a viable transitional technology in those locations when comparing to a $90 \%$ efficient forced air natural gas furnace. 
Table 4.13: GHG emissions reduction through reduced natural gas consumption of GAHP using $50 \%$ PG/water compared to $90 \%$ efficient forced air furnace in various Canadian cities

\begin{tabular}{|c|c|c|c|c|}
\hline Location & $\begin{array}{c}\text { HVAC } \\
\text { Unit }\end{array}$ & $\begin{array}{c}\text { Gas } \\
\text { Consumption } \\
(\mathrm{MJ}) \\
\end{array}$ & $\begin{array}{c}\text { GHG } \\
\text { Emissions } \\
\left(\mathrm{kg} \cdot \mathrm{CO}_{2}\right) \\
\end{array}$ & $\begin{array}{c}\text { GHG } \\
\text { Emissions } \\
(\%) \\
\end{array}$ \\
\hline \multirow{2}{*}{ Toronto } & GAHP & 69546 & 3895 & \multirow[b]{2}{*}{$-6.9 \%$} \\
\hline & Furnace & 74328 & 4162 & \\
\hline \multirow{2}{*}{ Montreal } & GAHP & 78332 & 4387 & \multirow[b]{2}{*}{$-2.8 \%$} \\
\hline & Furnace & 80536 & 4510 & \\
\hline \multirow{2}{*}{ Halifax } & GAHP & 71198 & 3987 & \multirow[b]{2}{*}{$-9.8 \%$} \\
\hline & Furnace & 78144 & 4376 & \\
\hline \multirow{2}{*}{ Edmonton } & GAHP & 96287 & 5392 & \multirow[b]{2}{*}{$0.1 \%$} \\
\hline & Furnace & 96200 & 5387 & \\
\hline \multirow{2}{*}{ Vancouver } & GAHP & 49021 & 2745 & \multirow[b]{2}{*}{$-19.6 \%$} \\
\hline & Furnace & 58644 & 3284 & \\
\hline
\end{tabular}

*Using a natural gas emissions factor of $0.056 \mathrm{~kg} \cdot \mathrm{CO}_{2} / \mathrm{MJ}(\mathrm{NRC}, 2018)$ ${ }^{*} \mathrm{GHG}$ Emissions reduction \% is solved using:

(GHG kg. $\mathrm{CO}_{2}$ of GAHP - GHG kg. $\mathrm{CO}_{2}$ of Furnace) / GHG kg. $\mathrm{CO}_{2}$ of GAHP 


\section{Experimental Methodology}

The GAHP was tested and evaluated in both House A and B located at the Kortright Center located in Vaughan, Ontario. The system was designed and tested in collaboration with the Sustainable Technology Evaluation Program (STEP) under the TRCA organization.

\subsection{Testing Plan}

The testing plan for this study was to be designed around the objective of developing a performance map for various flow rates and return, i.e., inlet (to the GAHP), temperatures. Through changing these key parameters, the capacity of the GAHP will be plotted against the ambient outdoor temperature, which can later be compared to a plot that is derived using the manufacturer performance data.

For this study, two circulations pumps were installed for the primary loop connected to the GAHP, which only allowed for three fixed flow rate settings: low, medium and high. These values are highly dependent on the temperature of the fluid due to changes in the viscosity and density of said fluid. As a result, the flow rates for both heating and cooling season are different due to the different operating temperatures of the heat transfer fluid between the heating and cooling modes.

The nominal flow rates for heating and cooling mode are 13.4 GPM and 12.8 GPM, respectively, as stated in Table 3.6. For the experimental evaluation, the system was designed to have at least one pump setting to match the nominal flow rate for each season. In the design however, due to the fixed setting of the circulation pumps the nominal cooling flow rate was not achievable, the closest possible was 12.6 GPM. This flow rate is near the nominal flowrate however, and a qualitative comparison can be done between the manufacturer cooling performance curves and ones obtained experimentally. These flow rates are all within operating range of the GAHP.

In addition to modifying flowrate values, the return temperatures that were tested varied around the nominal temperature. Similar to flow rate, one of the return temperatures for both

heating and cooling season were matched with the nominal temperatures provided by the manufacturer specifications. For heating and cooling season, the nominal return temperatures are $40^{\circ} \mathrm{C}$ and $12^{\circ} \mathrm{C}$. Table 5.1 summarises the flowrate and return temperature settings that were experimentally tested for the development of the GAHP performance map. 
Table 5.1: Return temperature and flow rate conditions used for developing experimental performance map for GAHP

\begin{tabular}{|l|c|c|}
\hline \multicolumn{1}{|c|}{ Season } & Heating & Cooling \\
\hline High Flow Rate $(\mathrm{GPM})$ & 14.8 & $\mathbf{1 2 . 6}$ \\
\hline Medium Flow Rate $(\mathrm{GPM})$ & $\mathbf{1 3 . 4}$ & 12.1 \\
\hline Low Flowrate $(\mathrm{GPM})$ & 10.1 & 10.1 \\
\hline High Inlet Temperature $\left({ }^{\circ} \mathrm{C}\right)$ & 48 & 16 \\
\hline Medium Inlet Temperature $\left({ }^{\circ} \mathrm{C}\right)$ & $\mathbf{4 0}$ & $\mathbf{1 2}$ \\
\hline Low Inlet Temperature $\left({ }^{\circ} \mathrm{C}\right)$ & 32 & 10 \\
\hline
\end{tabular}

$*$ Nominal flow rates and return temperatures are bolded

These points were primarily chosen because they were achievable with the available equipment and system. In the selected cooling temperatures seen in Table 5.1, the intervals are not the same. Originally the lowest temperature setting was to be $8^{\circ} \mathrm{C}$, however, this resulted in the GAHP shutting off due to its internal control system, mainly as it went into freeze protection mode as the supply temperatures would approach $0^{\circ} \mathrm{C}$, as since the GAHP was designed for water as the primary fluid, it is likely the feature was triggered due to this. During testing, conditions that were closest to the nominal temperature and flow rates were prioritized, this resulted in less detailed performance maps for specific conditions.

\subsection{System Schematic and Design}

As mentioned in Section 3.4 the HVAC system was designed to use 50\% PG/water, but only for the primary loop, which delivered heating and cooling directly to House A and the dump load but used a flat plate heat exchanger to deliver heating and cooling to House B. House B used a secondary loop containing only water that was fed into three thermal storage tanks totalling a volume of approximately $870 \mathrm{~L}$.

As seen in Figure 5.1, the primary loop feeds into the AHU, basement radiant floor and occasionally the DHW tank of House A. A flat plate heat exchanger is used to charge the thermal storage tanks in House B, which is then used to supply energy to the multizone AHU, all radiant floors and the inlaw suite that is connected to the hydronic system in House B. The energy in the system travels in order from House A to House B, and the remaining energy is consumed at the dump load. After which the primary fluid is returned to the GAHP. Each energy circuit is fitted with temperature sensors and flow meters for energy balancing and analysis. The system is also 
fitted with power meters and natural gas meters in order to be able to analyze the overall efficiency and performance of the system.

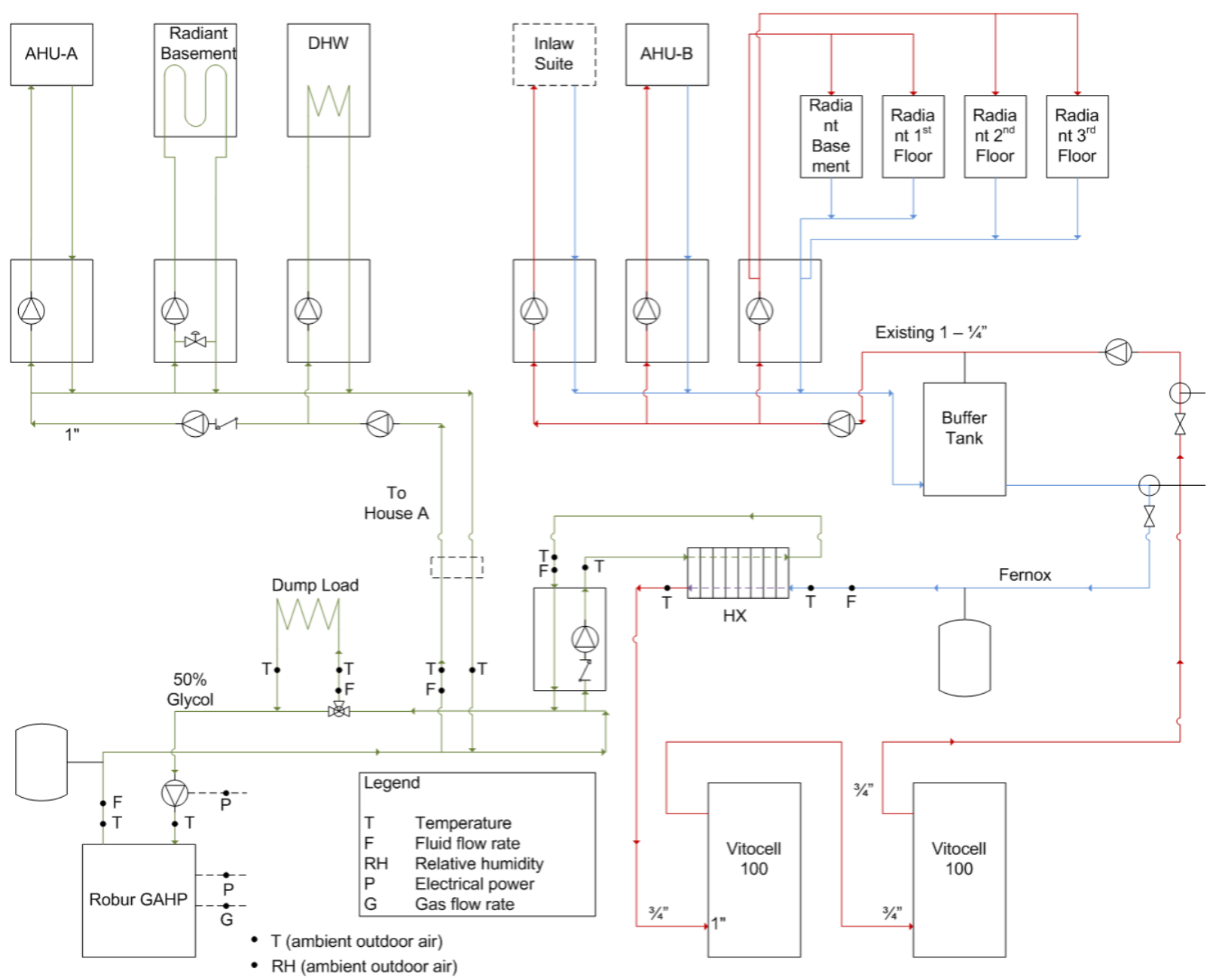

Figure 5.1: Complete combined house HVAC schematic for GAHP experimental evaluation

\subsection{Sensor Placement}

Each temperature sensor is placed in both the inlet and outlet of each energy circuit. The energy circuits being measured are the energy consumption in House A, House B, dump load and the energy provided by the GAHP. To minimize the energy loss through piping that cannot be easily accounted for, the sensors are strategically placed to minimize flow distance between each circuit. This helps to minimize error and deviation in each circuit, which would later be used to perform energy balancing to check if all units are functioning and being monitored correctly. 


\subsection{Data Acquisition System (DAQ) and Monitoring}

The monitoring system was developed using the National Instruments Measurement and Automation Explorer and LabVIEW software. Each point of interest was measured in intervals of 5 seconds or less and stored on servers located at the facility. The monitoring system located at the TRCA facility has been developed since the ASHs were built and have more than 300 sensors in use (Zhang et al., 2011). This highly adaptable monitoring system was one of the key reasons for the ASH to be chosen as the testing facility for the GAHP as it allowed for immense control on the monitoring network and to minimize error or misreading by having multiple checks through redundant sensors and alerts through the software.

\subsection{Sensor Calibration and Validation}

For this study, the main categories of sensors used were fluid temperature, fluid flow rate, outdoor air temperature, outdoor air humidity, watt meters and natural gas meters. Each were either calibrated or validated to be within manufacturer specifications. The methods of calibration are summarized in Table 5.2.

Table 5.2: Calibration and validation methods for various sensor/measurement types

\begin{tabular}{|l|l|}
\hline Sensor/Measurement Type & \multicolumn{1}{|c|}{ Calibration/Validation Method } \\
\hline Fluid Temperature RTD & $\begin{array}{l}\text { Calibrated with SIKA Precision } \\
\text { Micro-Calibration Bath: TPM 165S }\end{array}$ \\
\cline { 1 - 2 } $\begin{array}{l}\text { Ambient Outdoor } \\
\text { Temperature }\end{array}$ & $\begin{array}{l}\text { Validated with Lufft Ultrasonic } \\
\text { Weather Station: WS600-UMB }\end{array}$ \\
\cline { 1 - 2 } Ambient Outdoor Humidity & $\begin{array}{l}\text { Validated by measuring volume } \\
\text { passed through each meter }\end{array}$ \\
\cline { 1 - 2 } Fluid Flow Meter & $\begin{array}{l}\text { Verified using previously installed } \\
\text { meter from utility }\end{array}$ \\
\cline { 1 - 2 } Natural Gas Meter & $\begin{array}{l}\text { Verified using a Fluke 289 True } \\
\text { RMS Multimeter }\end{array}$ \\
\hline Watt Node Power Meter
\end{tabular}

\subsubsection{Fluid Temperature Measurements}

For this system, each energy circuit uses a pair of resistance temperature detectors (RTD) to measure the fluid inlet and outlet temperatures. Each pair of measurements would be used to solve for a temperature difference to be used in Equation 4.3. As a result, each RTD pair was 
calibrated together to minimize error between each reading. To calibrate each pair of RTDs, both were submerged into a calibration bath of mineral oil within the SIKA calibration tool. The temperatures measured ranged from $0^{\circ} \mathrm{C}$ to $70^{\circ} \mathrm{C}$ in intervals of $10^{\circ} \mathrm{C}$. This range was used to account for the temperatures that are expected to be observed during the operation of the GAHP during heating and cooling mode. To account for the electrical noise that would be present in the monitoring system, the RTD were calibrated using the National Instruments software that would $\log$ the data that would be used in the study. A LabVIEW program was developed to monitor the temperature of the RTD when in the calibrator using a graphical display to output the real-time measurements.

When the calibrator reached steady state for each of the calibration temperatures set, the measurement from the LabVIEW program were logged and averaged during the steady state. For the RTDs, the raw resistance values were recorded and matched with the temperatures of the calibrator to develop calibration curves for each sensor. The relationships observed after calibration were mostly linear in the ranges tested. Table 5.3 summarizes the correlations derived through the calibration of the RTDs using the calibration bath. The $\mathrm{R}^{2}$ value is unity for each derived equation showing strong correlation. The formulas use raw ohm values from the sensor reading to be converted into temperature readings. The equations were evaluated for the calibration temperature set points, i.e., from $0^{\circ} \mathrm{C}$ to $70^{\circ} \mathrm{C}$ at $10^{\circ} \mathrm{C}$ intervals, and the maximum temperature difference included in Table 5.3.

Table 5.3: Calibration equations of RTDs used in experimental evaluation of GAHP

\begin{tabular}{|l|c|c|}
\hline Location & Equation & Max Difference $\left({ }^{\circ} \mathbf{C}\right)$ \\
\hline House A Supply & $\mathrm{T}=5.17 \mathrm{E}-01 * \mathrm{R}-2.60 \mathrm{E}+02$ & -0.06 \\
\hline House A Return & $\mathrm{T}=5.17 \mathrm{E}-01 * \mathrm{R}-2.60 \mathrm{E}+02$ & \multirow{2}{*}{0.14} \\
\cline { 1 - 2 } House B Supply & $\mathrm{T}=-1.200 \mathrm{E}-04 * \mathrm{R} 2+6.708 \mathrm{E}-01 * \mathrm{R}-$ & \\
\cline { 1 - 2 } & $3.082 \mathrm{E}+02$ & \multirow{2}{*}{-0.03} \\
\hline House B Return & $\mathrm{T}=-1.47 \mathrm{E}-04 * \mathrm{R} 2+7.01 \mathrm{E}-01 * \mathrm{R}-$ & \multirow{2}{*}{-0.11} \\
\hline Robur Supply & $\mathrm{T}=5.19 \mathrm{E}-01 * \mathrm{R}-2.63 \mathrm{E}+02$ & \\
\hline $\begin{array}{l}\text { Dump Load } \\
\text { Supply }\end{array}$ & $\mathrm{T}=5.19 \mathrm{E}-01 * \mathrm{R}-2.63 \mathrm{E}+02$ & \\
\hline $\begin{array}{l}\text { Dump Load } \\
\text { Return }\end{array}$ & $\mathrm{T}=5.22 \mathrm{E}-01 * \mathrm{R}-2.61 \mathrm{E}+02$ & \\
\hline
\end{tabular}

$* \mathrm{~T}$ is temperature in $\left({ }^{\circ} \mathrm{C}\right)$ and $\mathrm{R}$ is resistance in $(\Omega)$ 
** Max difference evaluated using: (Supply Temperature - Return Temperature)

From Table 5.3, it can be seen that the error between each RTD pair is very minimal and within expectation. House B required a polynomial fit however to achieve an $\mathrm{R}^{2}$ value of unity. Each RTD was placed into a thermal well that was installed into the piping of the hydronic system. Within each well, the RTD was placed with a coating of thermal paste to improve conductivity.

\subsubsection{Fluid Flow Measurements}

The flow meters that were used in this study measure flow rate which created pulses to indicate volume change. Each pulse equates to a fixed volume that would pass a magnetic sensor. To measure flow rate, the volume of the fluid as measured through pulses, is divided by the time measured between each pulse. The time is monitored through the software that monitors the entire DAQ system within the home in intervals of 5 seconds or less. The flow meters nature of using pulses to measure volume introduce error in the DAQ, as some pulses may be on the edge of a fixed time interval, resulting in very high and very low flow rates for these intervals. To account for this, flow rates are averages to account for the pulses not aligning with the time intervals correctly.

To validate the flowmeter, each flow meter that would be installed on the energy loops being monitored and had 50\% PG glycol pumped through it at various speeds. The speeds that were tested were ones that were within the operating range of the GAHP. Although the flow range for the GAHP is 6.2 GPM to 22 GPM, the pumps available only allowed flow rates up to 16 GPM to be validated. All flow rates tested from about 6 GPM to 16 GPM were within manufacturer specifications. Since the range of flow rates that are being evaluated in the experimental study are within the validated range, the flow rates accuracy is sufficient for this study.

\subsubsection{Ambient Outdoor Temperature and Relative Humidity}

To measure the outdoor air temperature and humidity, a weather station was placed within close proximity to the GAHP unit to get the most accurate readings. The weather station used was shielded to prevent radiation from the sun from adding error to the outdoor air temperature measurements. Due to the shielding, there was difficulty using any typical temperature sensor to validate the temperature of the weather station in the immediate vicinity. As a result, a separate weather station, that was located approximately $200 \mathrm{~m}$ away was used to validate that the station 
used in this project was reading correctly. Both stations were logged and compared for a two-week duration for verification. Figure 5.2 shows the ambient outdoor temperature of both weather stations to see how closely the profiles and measurements agreed. Figure 5.3 shows the same but with relative humidity. Vaisala is the model of the ambient outdoor temperature and humidity sensor used for the GAHP performance evaluation and is compared to the Lufft weather station located near the testing site.

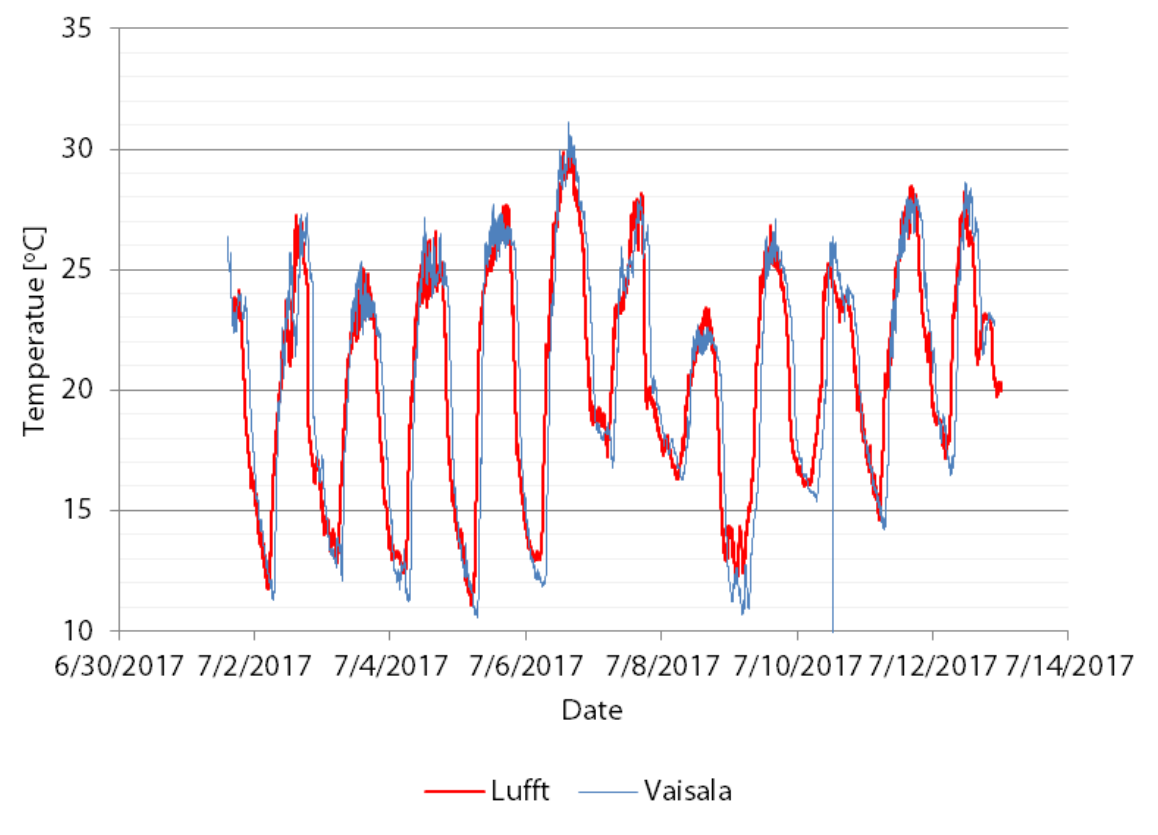

Figure 5.2: Comparison of Vaisala measured outdoor temperature against Lufft weather station over two week period (TRCA, 2018) 


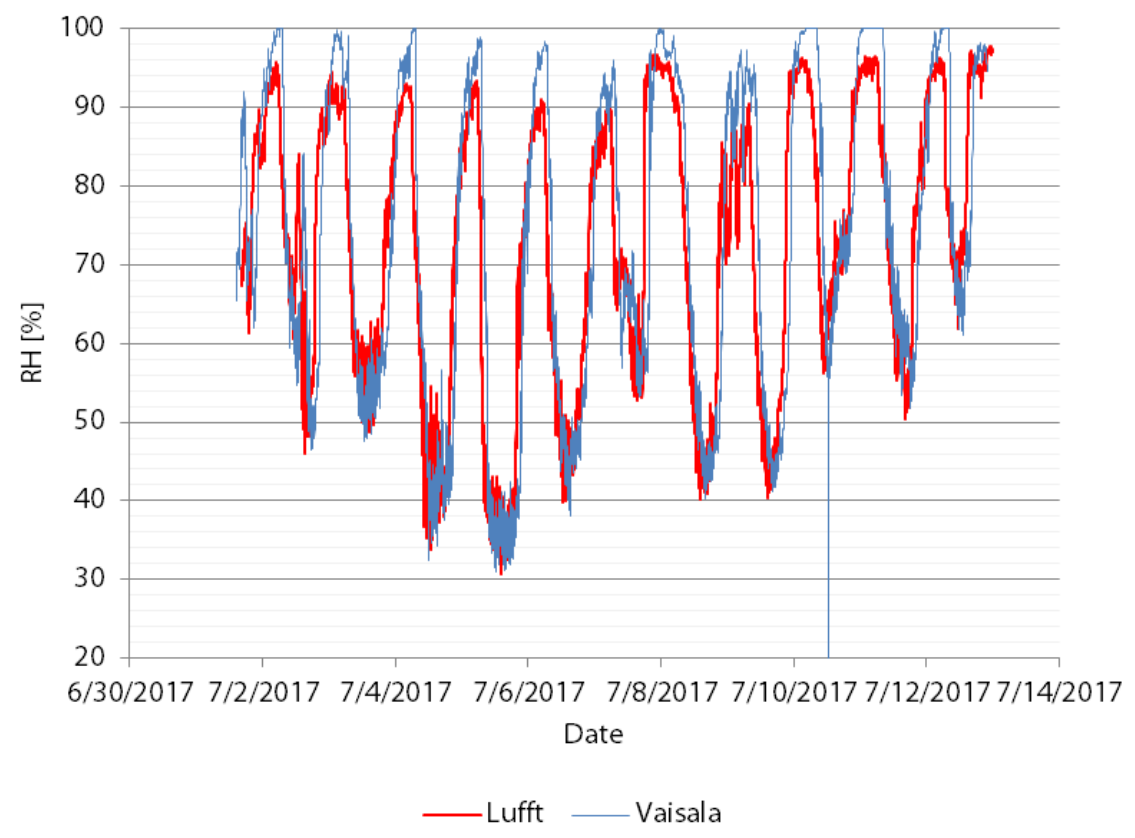

Figure 5.3: Comparison of Vaisala measured relative humidity against Lufft weather station over two week period (TRCA, 2018)

\subsubsection{Natural Gas Meter Verification}

For the natural gas meter verification, the meter installed to monitor the GAHP natural gas consumption was compared to the meters installed to monitor the natural gas consumption of both houses. The gas meter that monitors the consumption of the GAHP alone is located indoor, while the gas meters that monitor House A and House B are located outdoor. Two testing periods were done for this verification. A short-term test, which was done over a period of 4 hours and a longterm test done over a period of 3 weeks. For these periods, no appliances that would consume natural gas were used, to restrict the natural gas consumption read by the house meter to only that of the GAHP. Similar to the flow rate meters used for the hydronic loops in the ASHs, the natural gas meters measure volume primarily based on the generation of pulses. Both short and long-term verifications show that errors are less than $2 \%$ from actual consumption when comparing the volume read through DAQ system for both the indoor and outdoor meters to the pulse counters built on each respective unit (TRCA, 2018).

\subsubsection{Summary}

Table 5.4 shows a detailed summary of the sensors used and their corresponding accuracies. All sensors were monitored throughout the testing period and checked for proper 
function. LabVIEW software was used to record all raw data and converted using calibrated or manufacturer provided curves.

Table 5.4: Summary of sensor locations, operational ranges and accuracies

\begin{tabular}{|c|c|c|c|}
\hline Description/Location & $\begin{array}{c}\text { Sensor } \\
\text { Type/Model }\end{array}$ & $\begin{array}{c}\text { Calibrated/Operating } \\
\text { Range }\end{array}$ & $\begin{array}{c}\text { Manufacturer/Calibrated } \\
\text { Accuracy }\end{array}$ \\
\hline House A Flow & $\begin{array}{l}\text { MAG-VIEW } \\
\text { MVM-100-Q }\end{array}$ & $\begin{array}{c}5-100 \mathrm{LPM} \\
(1.3-26.3 \mathrm{GPM})\end{array}$ & $\pm 2 \%$ of reading \\
\hline House B Flow & $\begin{array}{l}\text { MAG-VIEW } \\
\text { MVM-100-Q }\end{array}$ & $\begin{array}{c}5-100 \text { LPM } \\
(1.3-26.3 \text { GPM })\end{array}$ & $\pm 2 \%$ of reading \\
\hline Dump Load Flow & $\begin{array}{l}\text { MAG-VIEW } \\
\text { MVM-100-Q }\end{array}$ & $\begin{array}{c}5-100 \text { LPM } \\
(1.3-26.3 \text { GPM })\end{array}$ & $\pm 2 \%$ of reading \\
\hline Primary Loop Flow & $\begin{array}{l}\text { MAG-VIEW } \\
\text { MVM-250-Q }\end{array}$ & $\begin{array}{c}12.5-250 \mathrm{LPM} \\
(3.3-65.8 \mathrm{GPM})\end{array}$ & $\pm 2 \%$ of reading \\
\hline Natural Gas Meter & $\begin{array}{l}\text { AC-250 } \\
\text { Diaphragm } \\
\text { Meter }\end{array}$ & $5.5 \mathrm{~m}^{3} / \mathrm{h}-18.8 \mathrm{~m}^{3} / \mathrm{h}$ & $\pm 2 \%$ of reading \\
\hline $\begin{array}{c}\text { House A Supply } \\
\text { Temperature }\end{array}$ & $\begin{array}{l}\text { Kamstrup } \\
\text { Pt.500 RTD }\end{array}$ & $\begin{array}{c}0^{\circ} \mathrm{C}\left(32^{\circ} \mathrm{F}\right)-70^{\circ} \mathrm{C} \\
\left(158^{\circ} \mathrm{F}\right)\end{array}$ & $\begin{array}{c} \pm 0.1^{\circ} \mathrm{C}\left( \pm 0.18^{\circ} \mathrm{F}\right) \text { of } \\
\text { reading }\end{array}$ \\
\hline $\begin{array}{l}\text { House A Return } \\
\text { Temperature }\end{array}$ & $\begin{array}{l}\text { Kamstrup } \\
\text { Pt.500 RTD }\end{array}$ & $\begin{array}{c}0^{\circ} \mathrm{C}\left(32^{\circ} \mathrm{F}\right)-70^{\circ} \mathrm{C} \\
\left(158^{\circ} \mathrm{F}\right)\end{array}$ & $\begin{array}{c} \pm 0.1^{\circ} \mathrm{C}\left( \pm 0.18^{\circ} \mathrm{F}\right) \text { of } \\
\text { reading }\end{array}$ \\
\hline $\begin{array}{l}\text { House B Supply } \\
\text { Temperature }\end{array}$ & $\begin{array}{l}\text { Kamstrup } \\
\text { Pt.500 RTD }\end{array}$ & $\begin{array}{c}0^{\circ} \mathrm{C}\left(32^{\circ} \mathrm{F}\right)-70^{\circ} \mathrm{C} \\
\left(158^{\circ} \mathrm{F}\right)\end{array}$ & $\begin{array}{c} \pm 0.1^{\circ} \mathrm{C}\left( \pm 0.18^{\circ} \mathrm{F}\right) \text { of } \\
\text { reading }\end{array}$ \\
\hline $\begin{array}{l}\text { House B Return } \\
\text { Temperature }\end{array}$ & $\begin{array}{l}\text { Kamstrup } \\
\text { Pt.500 RTD }\end{array}$ & $\begin{array}{c}0^{\circ} \mathrm{C}\left(32^{\circ} \mathrm{F}\right)-70^{\circ} \mathrm{C} \\
\left(158^{\circ} \mathrm{F}\right)\end{array}$ & $\begin{array}{c} \pm 0.1^{\circ} \mathrm{C}\left( \pm 0.18^{\circ} \mathrm{F}\right) \text { of } \\
\text { reading }\end{array}$ \\
\hline $\begin{array}{c}\text { GAHP Supply } \\
\text { Temperature }\end{array}$ & $\begin{array}{l}\text { Kamstrup } \\
\text { Pt.500 RTD }\end{array}$ & $\begin{array}{c}0^{\circ} \mathrm{C}\left(32^{\circ} \mathrm{F}\right)-70^{\circ} \mathrm{C} \\
\left(158^{\circ} \mathrm{F}\right)\end{array}$ & $\begin{array}{c} \pm 0.1^{\circ} \mathrm{C}\left( \pm 0.18^{\circ} \mathrm{F}\right) \text { of } \\
\text { reading }\end{array}$ \\
\hline $\begin{array}{c}\text { GAHP Return } \\
\text { Temperature }\end{array}$ & $\begin{array}{l}\text { Kamstrup } \\
\text { Pt.500 RTD }\end{array}$ & $\begin{array}{c}0^{\circ} \mathrm{C}\left(32^{\circ} \mathrm{F}\right)-70^{\circ} \mathrm{C} \\
\left(158^{\circ} \mathrm{F}\right)\end{array}$ & $\begin{array}{c} \pm 0.1^{\circ} \mathrm{C}\left( \pm 0.18^{\circ} \mathrm{F}\right) \text { of } \\
\text { reading }\end{array}$ \\
\hline $\begin{array}{l}\text { Dump Load Supply } \\
\text { Temperature }\end{array}$ & $\begin{array}{l}\text { Kamstrup } \\
\text { Pt.500 RTD }\end{array}$ & $\begin{array}{c}0^{\circ} \mathrm{C}\left(32^{\circ} \mathrm{F}\right)-70^{\circ} \mathrm{C} \\
\left(158^{\circ} \mathrm{F}\right)\end{array}$ & $\begin{array}{c} \pm 0.1^{\circ} \mathrm{C}\left( \pm 0.18^{\circ} \mathrm{F}\right) \text { of } \\
\text { reading }\end{array}$ \\
\hline $\begin{array}{l}\text { Dump Load Return } \\
\text { Temperature }\end{array}$ & $\begin{array}{l}\text { Kamstrup } \\
\text { Pt.500 RTD }\end{array}$ & $\begin{array}{c}0^{\circ} \mathrm{C}\left(32^{\circ} \mathrm{F}\right)-70^{\circ} \mathrm{C} \\
\left(158^{\circ} \mathrm{F}\right)\end{array}$ & $\begin{array}{c} \pm 0.1^{\circ} \mathrm{C}\left( \pm 0.18^{\circ} \mathrm{F}\right) \text { of } \\
\text { reading }\end{array}$ \\
\hline $\begin{array}{l}\text { GAHP Power } \\
\text { Consumption }\end{array}$ & $\begin{array}{l}\text { Continental } \\
\text { Control } \\
\text { Systems Watt } \\
\text { Node }\end{array}$ & $\begin{array}{l}1,2 \text {, or } 3 \text { phases with } \\
120 \text { to } 600 \mathrm{VAC} \text { and } 5 \\
\text { to } 6000 \mathrm{amps} \mathrm{CT}\end{array}$ & $\pm 0.5 \%$ of reading \\
\hline
\end{tabular}




\begin{tabular}{|c|c|c|c|}
\hline $\begin{array}{l}\text { Primary Loop Pump } \\
\text { Power Consumption }\end{array}$ & $\begin{array}{c}\text { Continental } \\
\text { Control } \\
\text { Systems Watt } \\
\text { Node }\end{array}$ & $\begin{array}{c}1,2 \text {, or } 3 \text { phases with } \\
120 \text { to } 600 \text { VAC and } 5 \\
\text { to } 6000 \text { amps CT }\end{array}$ & $\pm 0.5 \%$ of reading \\
\hline $\begin{array}{c}\text { Outdoor Air Relative } \\
\text { Humidity }\end{array}$ & $\begin{array}{c}\text { Vaisala } \\
\text { HMS82 } \\
\text { Vaisala } \\
\text { INTERCAP }\end{array}$ & $0 \%-90 \%$ RH & $\pm 3.0 \%$ of reading \\
\hline $\begin{array}{c}\text { Outdoor Air Dry Bulb } \\
\text { Temperature }\end{array}$ & $\begin{array}{c}\text { Vaisala } \\
\text { HMS82 } \\
\text { Pt1000 RTD } \\
\text { Class F0.1 IEC } \\
60751\end{array}$ & $\begin{array}{c}-40^{\circ} \mathrm{C}\left(-40^{\circ} \mathrm{F}\right)-60^{\circ} \mathrm{C} \\
\left(140^{\circ} \mathrm{F}\right)\end{array}$ & $\begin{array}{c} \pm 0.3{ }^{\circ} \mathrm{C}\left( \pm 0.54{ }^{\circ} \mathrm{F}\right) \text { of } \\
\text { reading }\end{array}$ \\
\hline
\end{tabular}

\subsection{Steady State Data Collection and Analysis}

To have a period of GAHP operation to be considered steady state, the system is required to run for a minimum of 30 minutes, as stated in other GAHP studies (Priedeman \& Garrabrant, 2001). Due to the oversizing of the GAHP for the house, dump loads were required to meet this load. Without this dump load, maintaining steady state for long durations at fixed return temperatures would not be possible. Loads needed to be maximized for the GAHP to function at full capacity. However, to collect data at fixed return temperatures, control is needed over how much cooling or heating is delivered. The GAHP specifications for heating and cooling mode is stated to have a temperature difference of $10^{\circ} \mathrm{C}$ and $5^{\circ} \mathrm{C}$ respectively by design. Leaving the dump load to operate at fully capacity, would result in over heating of the fluid in cooling mode or over cooling of the fluid during heating mode, disrupting the balance for the GAHP to maintain a fixed temperature difference for a sustained period. To address this issue, a variable controller was added to the dump load to be able to control the return temperature into the GAHP. It should be noted, the method of control that was utilized for the dump load was not to vary the fluid flow rate, since each test required to be maintained at a specified flow rate, in addition to a fixed return temperature. The heating of cooling load of the dump load was controlled through the fan speed of the dump load, to vary the air flow over the coils. This allowed control over the return temperature, while maintaining the flow rate. This control however, required a manual operator to maintain a steady return temperature. Each test was done individually depending on the weather 
conditions available at the time, this limited the obtainable steady state data to daytime. For the steady state point to be considered sufficient to be used in the performance map, the ambient outdoor range was only allowed to have a deviation of $\pm 0.5^{\circ} \mathrm{C}$. With the limitation of only testing during working hours of the facility and requiring a narrow window of opportunity with respect for the weather, steady state points collected were limited.

Each set of data was analyzed through a script developed in MATLAB, with the purpose of solving for the total capacity of the GAHP, along with the energy consumed by each energy circuit. This was solved through a simple procedure. The primary formula used to solve the energy of each circuit was Equation 4.3. However, unlike the simplified model from Chapter 4, some equations were used to describe the physical properties of the primary fluid depending on the temperature. These relations were developed by fitting the values of available property tables for $50 \%$ PG/water for both specific heat and density. The equations for density and specific heat are following (Dow Chemical, 2008):

$$
\begin{aligned}
& \rho_{P G / \text { water }}=-0.0026 T^{2}-0.4407 T+1053.9 \\
& C_{p_{P G / \text { water }}}=0.0039 T+3.4547
\end{aligned}
$$$$
\text { Equation } 5.1
$$

Where:

$T:$ is the temperature of the $50 \% \mathrm{PG} /$ water fluid in $\left({ }^{\circ} \mathrm{C}\right)$

$\rho_{P G}:$ is the density of $50 \% \mathrm{PG} /$ water in $\left(\mathrm{kg} / \mathrm{m}^{3}\right)$

$C_{p_{P G}}:$ is the specific heat capacity of $50 \% \mathrm{PG} /$ water in $(\mathrm{kJ} / \mathrm{kg} \cdot \mathrm{K})$

Once the energy of each circuit was solved for each time interval, the energy consumed or generated from each steady state period was averaged. These averaged capacity values were then compared. A quick energy balance was done to check if the energy consumed by the system matched the energy generated by the GAHP. This was done to make sure there were no errors in the monitoring system and all values obtained were consistent.

\subsection{Limitations}

The capacity of the GAHP absorption cycle is also governed by evaporator saturation temperature and entry and exit temperature of water. As mentioned in the literature review, there 
are several factors that can contribute to the performance of the GAHP, by enhancing or modifying the equipment within the AHP that drive the absorption process, but since only the hydronic system was monitored and the absorption cycle of the system was left unmodified, its effects on capacity is unknown. As a result, this limits the study primarily to the overall performance of the GAHP and not the finer optimizations that can be made through monitoring the internal system that drive the absorption cycle within the unit.

Collecting data was limited to available weather conditions during the working hours of the facility. In addition to having limited availability to collect data, experimental data that was collected needed to be sufficiently steady state to be considered a viable point to be used in the performance maps. At times the outdoor weather would deviate more than the acceptable temperature range during a steady state test, this would be only discovered once data is analyzed, and as a result the recorded data would not be usable. Other situations would also occur during steady state testing that would make the point no longer viable, such as sudden cycling or change in capacity during the duration of the test. Each steady state point needed to have at least 30 minutes of steady state operation to be viable. Due to these limitations, further testing is required to complete the performance map for both heating and cooling season. 


\section{Experimental Data Analysis}

\subsection{Cooling Mode Operation}

The cooling season data was collected in the month of August in 2017, then the months of May to July in 2018. This was due to initial time constraints in the implementation of the GAHP system and reworking the HVAC equipment and hydronic system already present in the ASH to accommodate the new HVAC system and monitoring system for the GAHP. The ambient outdoor temperature range of the data collected is from $23.3^{\circ} \mathrm{C}$ to $32.8^{\circ} \mathrm{C}$. During the testing for cooling mode, nominal flow rate, with respect to the manufacturer specifications, was not achievable due to the limitations of the available pumps. At maximum flow rate, the pumps were only able to achieve an average flow rate of 12.6 GPM although the manufacturer nominal flow rate is 12.8 GPM. Due to the inability to account for how this difference would affect the capacity, such as effects on heat exchanger the comparison of the experimental data for nominal operation should only be compared to manufacturer operation in a qualitative perspective.

\subsubsection{Performance Maps}

As mentioned in Table 5.1 in Section 5.1, there were specific variables that were used as the control to develop a performance map of the GAHP. For cooling season, a detailed performance map was developed primarily for a return temperature of $12^{\circ} \mathrm{C}$, with varying flow rates. However, issues with monitoring system resulting in the loss of controlled steady state testing during the cooling seasons limited the detail of the performance map. Figure 6.1 shows a cooling performance map with a $12^{\circ} \mathrm{C}$ return temperature with varying flow rates. 


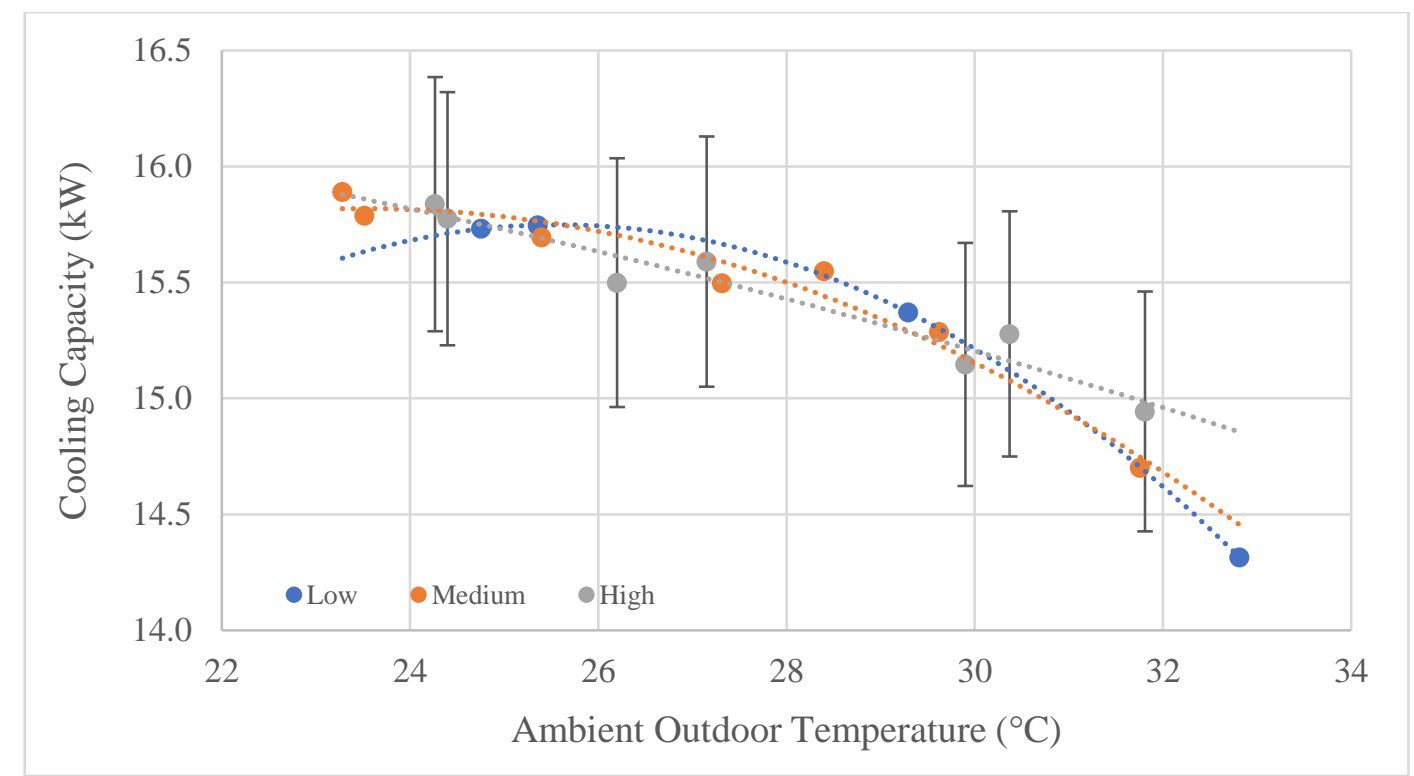

Figure 6.1: Experimental cooling capacity with respect to ambient outdoor temperature for a return temperature of $12^{\circ} \mathrm{C}$ for varying flow rates using $50 \% \mathrm{PG} /$ water

From Figure 6.1 it can be seen that the flow rate had minimal effect on the capacity for a fixed return temperature. Although it should be noted that the range of the flow rate was low, with a 2.5 GPM difference from the highest flow rate to the lowest. A $2^{\text {nd }}$ order polynomial trend line is used for the medium and high flow rates, with a linear relation for the low flow rate. With lower steady state points available for the low flow would result in a more exaggerated plot with a $2^{\text {nd }}$ order polynomial, whereas a linear relation was more appropriate. The trendlines placed showed little no significant offset from one performance curve to another to distinguish any effect on capacity due to the different flow rates used.

Table 6.1 summarizes the performance curves and their respective $\mathrm{R}^{2}$ values for those that are plotted in Figure 6.1. It should be noted that the limited data available shows that the $\mathrm{R}^{2}$ for the low flow rate is 1 , but due to the limited data available, does not accurately describe the GAHP cooling performance for the overall range in a $2^{\text {nd }}$ order polynomial fit. 
Table 6.1: Experimental cooling performance curves for varying flow rates at a fixed return temperature of $12^{\circ} \mathrm{C}$ using $50 \%$ PG/water solution

\begin{tabular}{|l|l|l|}
\hline \multicolumn{1}{|c|}{ Flow Rate } & \multicolumn{1}{c|}{ Performance Curve Formula } & \multicolumn{1}{c|}{$\mathbf{R}^{\mathbf{2}}$} \\
\hline Low $(10.1 \mathrm{GPM})$ & $-0.0273 \mathrm{~T}^{2}+1.3987 \mathrm{~T}-2.1369$ & 1.000 \\
\hline Medium $(12.1 \mathrm{GPM})$ & $-0.0157 \mathrm{~T}^{2}+0.7387 \mathrm{~T}+7.139$ & 0.9616 \\
\hline High $(12.6 \mathrm{GPM})$ & $-0.0025 \mathrm{~T}^{2}+0.0319 \mathrm{~T}+16.482$ & 0.9380 \\
\hline
\end{tabular}

*Where $\mathrm{T}$ represents the ambient outdoor temperature

In Figure 6.2, the cooling performance map is shown for a fixed flow rate of 12.6 GPM with varying return fluid temperatures.

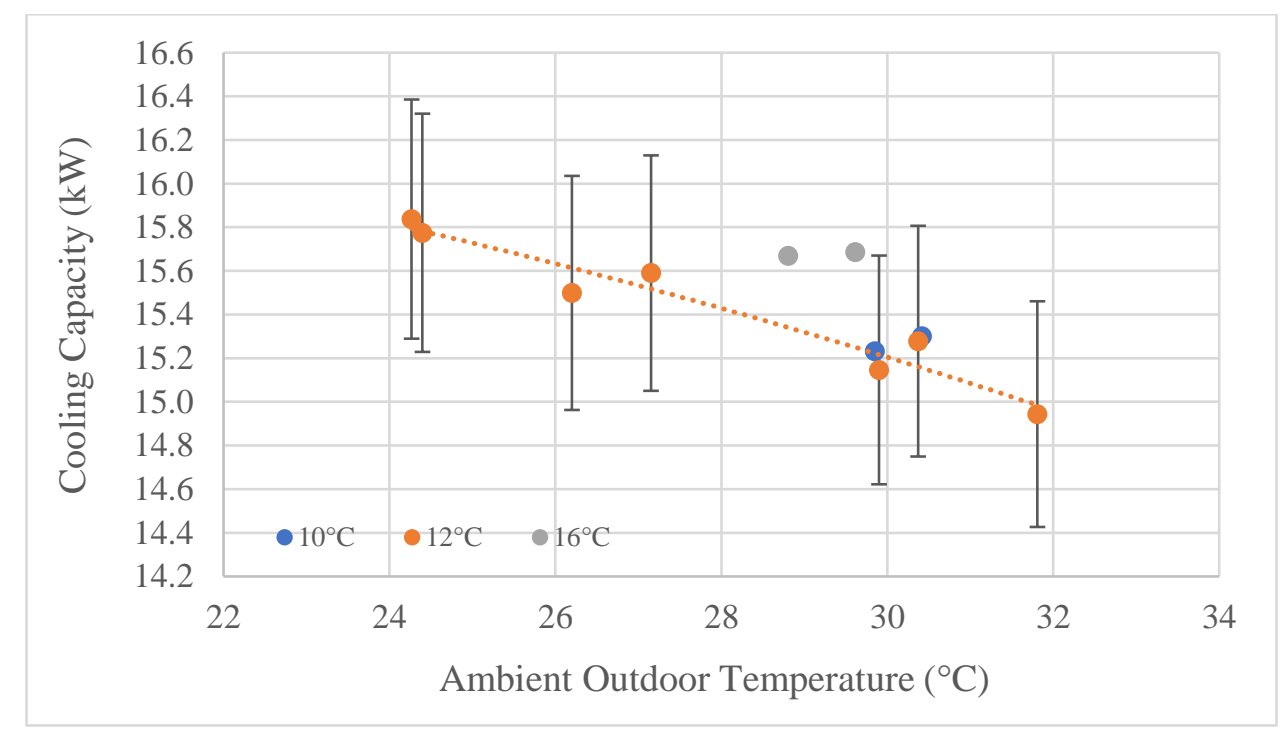

Figure 6.2: Experimental cooling capacity of GAHP with respect to ambient outdoor temperatures for varying return temperatures at a flow rate of 12.6 GPM using 50\% PG/water

The limited number of points do not allow for a sufficient representation of the correlation of capacity versus the outdoor ambient temperature for return fluid temperatures of $10^{\circ} \mathrm{C}$ and $16^{\circ} \mathrm{C}$. The trendline applied to the $12^{\circ} \mathrm{C}$ return fluid temperature is a $2^{\text {nd }}$ order polynomial. However, the relation can be linear for the range that was experimentally evaluated. This relation is comparable to that of the manufacturer performance map for water at a fixed flow rate of $12.8 \mathrm{GPM}$ at varying return temperatures as seen in Figure 6.3. 


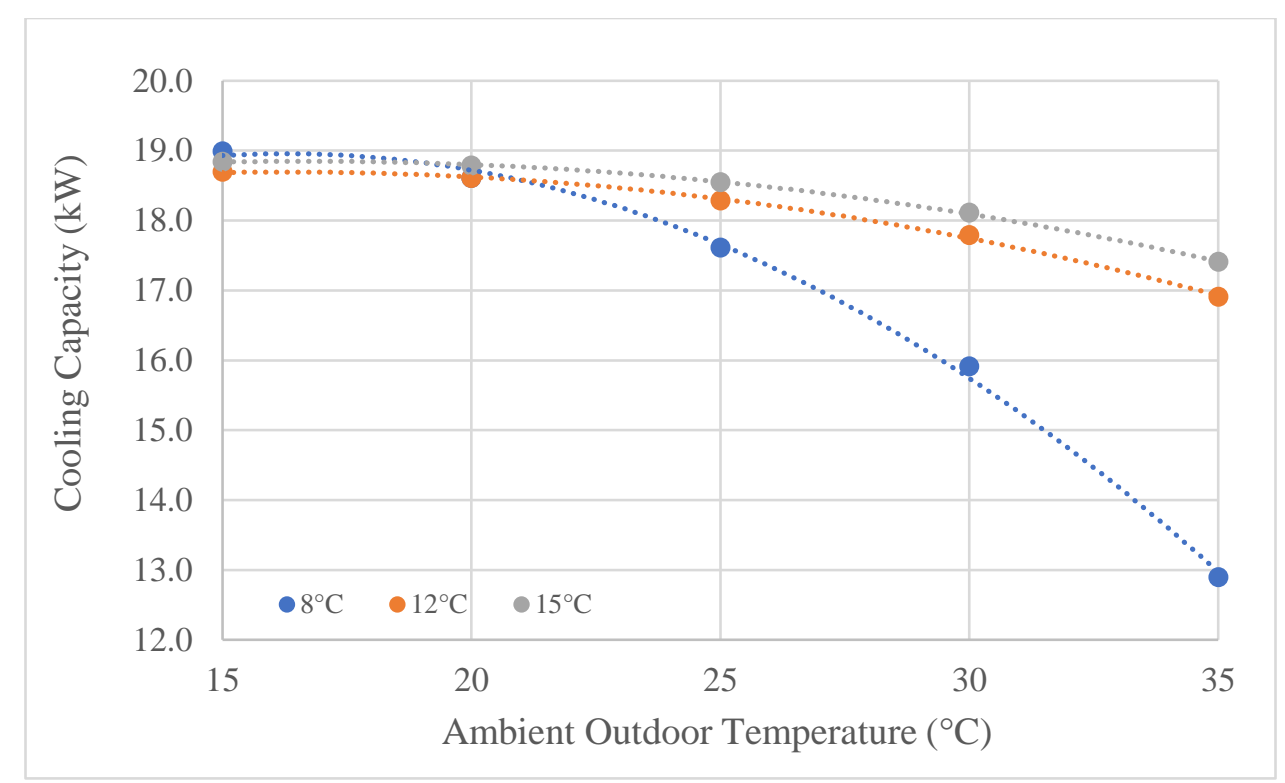

Figure 6.3: Manufacturer cooling performance curves for a working fluid of water for varying return temperatures at 12.8 GPM

The relationship for cooling capacity against ambient outdoor temperatures for both the $12^{\circ} \mathrm{C}$ and $15^{\circ} \mathrm{C}$ return have fairly linear correlations in the useful ranges. One unique aspect that needs further investigation is the higher than expected performance of the GAHP during lower return fluid temperatures with the use of $50 \% \mathrm{PG} /$ water, when compared to the manufacturer data for water alone. From the manufacturer performance map, lower return fluid temperatures should result in significantly lower performance during ambient outdoor temperatures greater than $25^{\circ} \mathrm{C}$. However, from Figure 6.2, from the 2 steady state points collected for a return temperature of $10^{\circ} \mathrm{C}$, the performance is nearly equal to that of the $12^{\circ} \mathrm{C}$ return temperature. Further investigation is required by collecting more data to develop a more complete performance map. 
Figure 6.4 shows the experimental steady state cooling performance of the GAHP with a fixed flow rate of 12.1 GPM.

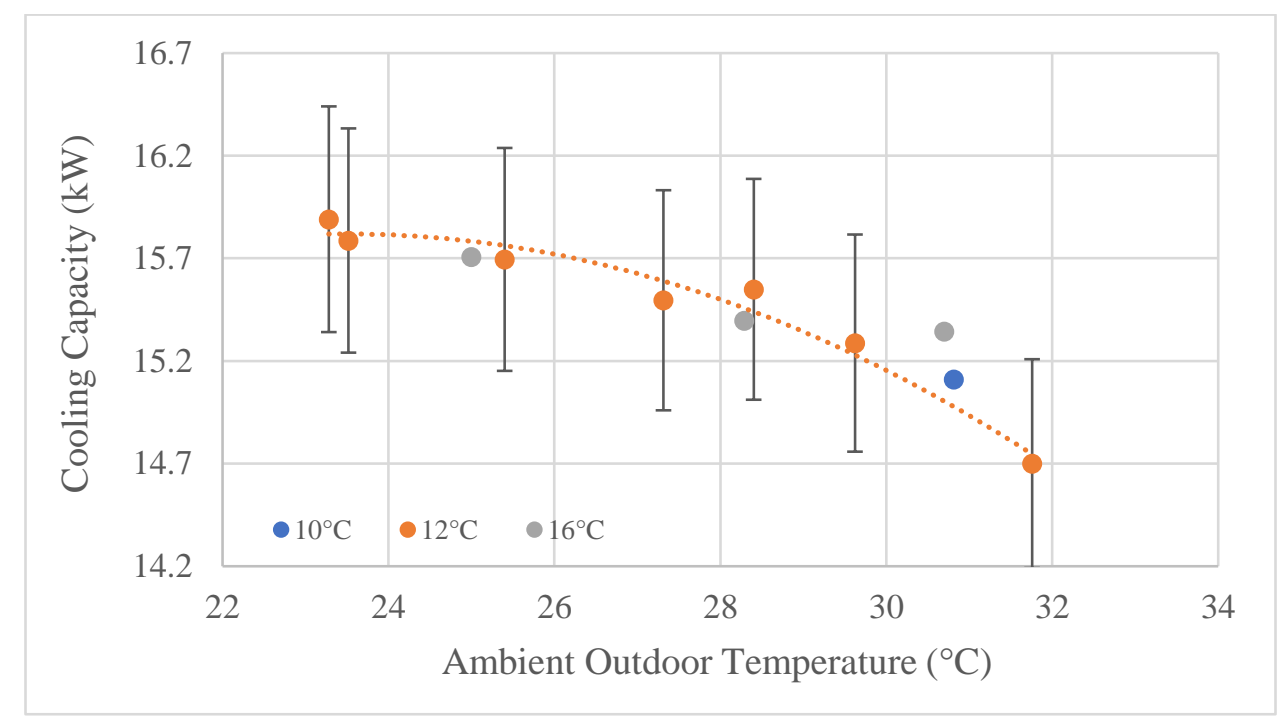

Figure 6.4: Experimental cooling capacity of GAHP with respect to ambient outdoor temperatures for varying return temperatures at a flow rate of 12.1 GPM using $50 \%$ PG/water

More steady state points are required to be collected for the cooling performance map with a fixed flow rate. However, from the trends that can be seen, and unusual occurrence is apparent. Similar to the cooling performance of when flow rates varied, at a medium flow rate of 12.1 GPM, the steady state data for all return fluid temperatures seem to have little to no discernible variation in cooling capacity. This is unusual as it does not perform as expected when compared to the variation in capacity present when water is the primary working fluid according to the manufacturer. This suggests a more consistent cooling performance regardless of whether the flow rate is varies, nor the return temperature, for the range temperature and flow rates that were tested. Figure 6.5 shows the cooling performance of the GAHP when the fixed flow rate is at its lowest at 10.1 GPM. 


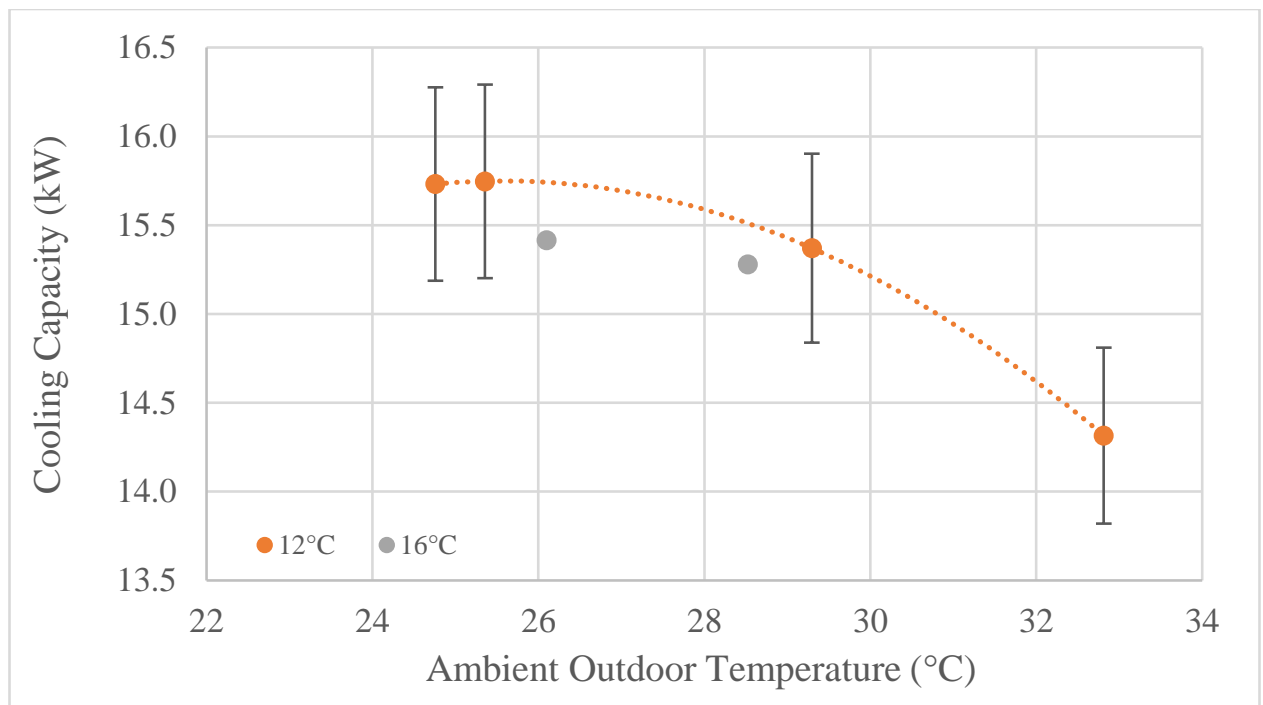

Figure 6.5: Experimental cooling capacity of GAHP with respect to ambient outdoor temperatures for varying return temperatures at a flow rate of 10.1 GPM using $50 \%$ PG/water

Similar to the earlier cooling performance plots, Figure 6.5 shows a trend where changes in return temperature seem to have minimal effect on cooling capacity. Further data requires to be collected to further investigate the lack of variation in cooling capacity of the GAHP. Manufacturer data suggests that cooling return temperatures above nominal have similar performance, which can be seen in Figure 6.3. However, the lack of variation is most notable for temperatures lower than nominal return fluid temperature.

\subsubsection{Gas Utilization Efficiency (GUE) of GAHP}

To understand the overall effectiveness of the GAHP during cooling mode operation, GUE plots are used. The rated natural gas (HHV) input for the GAHP is $28 \mathrm{~kW}(95.5 \mathrm{MBH})$. However, the natural gas input that was set when the GAHP unit was commissioned was $28.7 \mathrm{~kW}(98 \mathrm{MBH})$. This could be a factor to consider in the experimental performance evaluation, as more gas energy may have been provided than what the GAHP internal heat exchangers were designed for. However, this difference between the rated gas input compared to the gas input during the experimental evaluation is less than $2 \%$. The difference is not expected to be significant in the overall performance of the system but should be noted. Using $28.7 \mathrm{~kW}(98 \mathrm{MBH})$ as constant gas input for the GAHP, a GUE plot was derived using the steady state points previously plotted. Figure 6.6 plots the GUE of the cooling performance as derived from Figure 6.1 using a gas input 
of $28.7 \mathrm{~kW}(98 \mathrm{MBH})$. This plot only accounts for a fixed return fluid temperature with varying flow rates however. This is done as the steady state data available for the nominal return temperature of $12^{\circ} \mathrm{C}$ has the highest tested ambient outdoor temperature range, offering the most complete image of GAHP cooling performance. A summary of the maximum and minim GUE values for each flow rate and the differences can be found in Table 6.2.

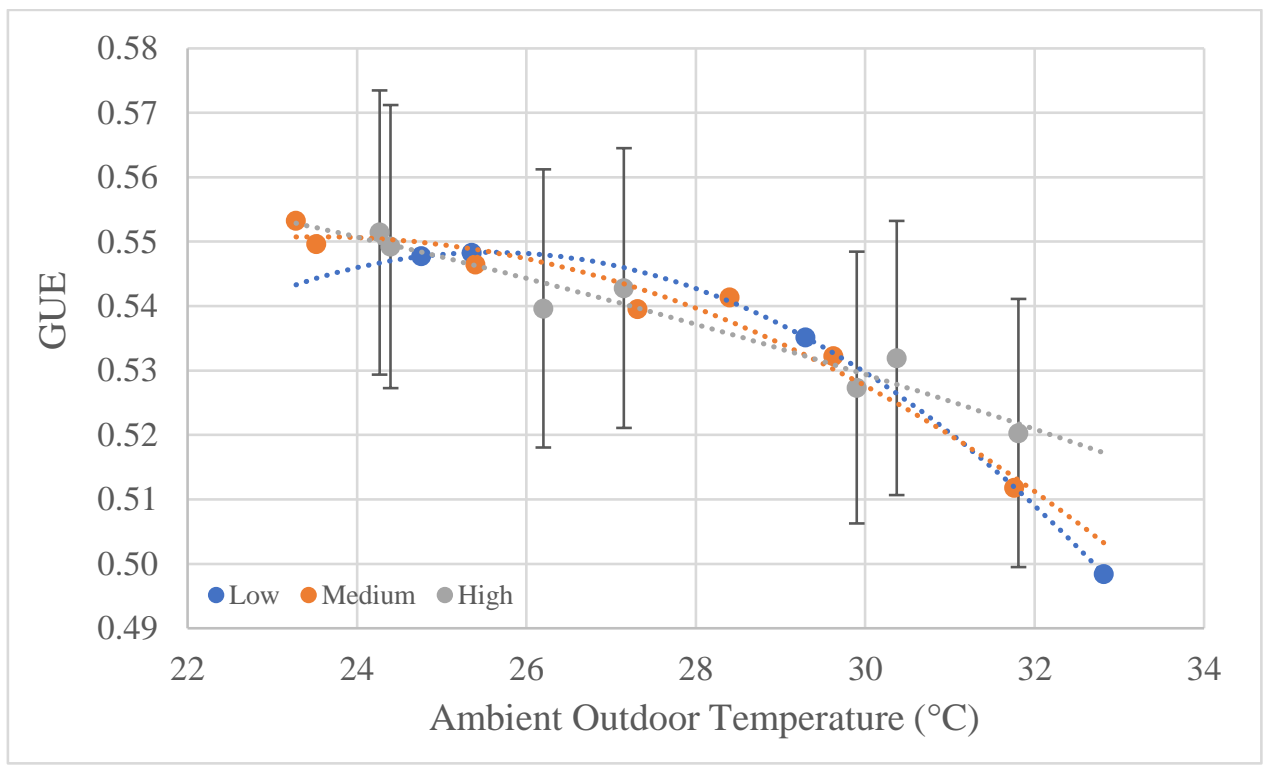

Figure 6.6: Experimental cooling GUE with respect to ambient outdoor temperature for a return temperature of $12^{\circ} \mathrm{C}$ for varying flow rates using $50 \%$ PG/water with gas input of $28.7 \mathrm{~kW}$

Table 6.2: Maximum and minimum experimental cooling GUE values of varying flow for a fixed return temperature of $12^{\circ} \mathrm{C}$ for $50 \%$ PG/water solution

\begin{tabular}{|l|c|c|c|}
\hline Flow Rate & Low & Medium & High \\
\hline Minimum & $49.8 \%$ & $51.2 \%$ & $52.0 \%$ \\
\hline Maximum & $54.8 \%$ & $55.3 \%$ & $55.1 \%$ \\
\hline Difference & $5.0 \%$ & $4.1 \%$ & $3.1 \%$ \\
\hline
\end{tabular}

The lowest GUE value was fond to be $49.8 \%$ at an outdoor temperature of $32.8^{\circ} \mathrm{C}$. The highest GUE occurs during the medium flow rate with a value of 55.3\%. The highest GUE difference is $5 \%$ which is fairly insignificant with respect the range of temperatures tested when compared to the GUE profiles of the GAHP cooling performance with water as a primary working 
fluid. This is can be seen in Figure 6.7 presenting the manufacturer cooling GUE using a gas input of $28 \mathrm{~kW}(95.5 \mathrm{MBH})$.

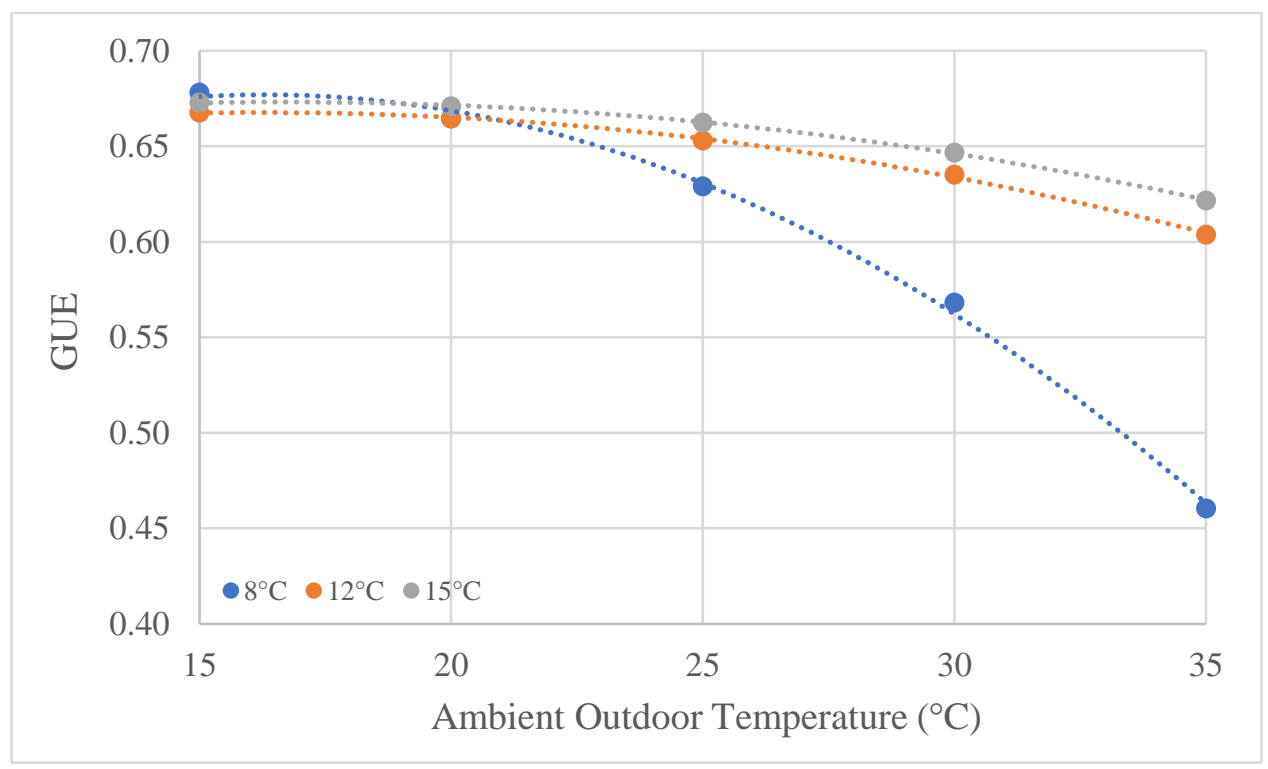

Figure 6.7: Manufacturer cooling GUE for a working fluid of water for varying return temperatures at $12.8 \mathrm{GPM}$ with gas input of $28 \mathrm{~kW}$

Table 6.3 summarizes the cooling GUE of the GAHP with a working fluid of water for various return temperatures. The highest GUE for when water is the primary working fluid is $67.8 \%$ at the lowest return temperature of $8^{\circ} \mathrm{C}$. The other return temperatures have a GUE only $1 \%$ lower at most at their best performance. However, the lowest GUE for the lowest return temperature is $46 \%$, a significant $21.8 \%$ decrease. A decrease in performance such this is not seen in the cooling performance of the GAHP when tested with glycol. It should be noted that this low performance is seen at the lowest return temperature for the GAHP when using water. From previous plots, from the few steady state points available for $10^{\circ} \mathrm{C}$, the performance is similar to that of the $12^{\circ} \mathrm{C}$ steady state operation and does not show an equivalent drop in performance. The difference in GUE for $12^{\circ} \mathrm{C}$ and $15^{\circ} \mathrm{C}$ from the entire range of available steady state points is $6.4 \%$ and $5.1 \%$ respectively. This is still a higher difference than what was observed from GAHP evaluation with 50\% PG/water. The performance decrease from the GAHP during cooling mode operation with 50\% PG/water compared to the use of water alone as the primary fluid at nearly nominal flow rate and nominal return fluid temperature is $12.2 \%$ at most and $10.2 \%$ at the least. 
This is roughly similar to what is expected when taking account, the deration of the capacity of the GAHP for 50\% PG/water. From these differences, any additional decrease due to the gas input from what was used for the manufacturer specifications relative to what was used when the GAHP was field tested, could not be easily distinguished.

Table 6.3: Maximum and minimum manufacturer cooling GUE values for a working fluid of water at a flow rate of 12.8 GPM for varying return temperatures

\begin{tabular}{|l|c|c|c|}
\hline Return Temperature & $\mathbf{8}^{\circ} \mathbf{C}$ & $\mathbf{1 2}^{\circ} \mathbf{C}$ & $\mathbf{1 5}^{\circ} \mathbf{C}$ \\
\hline Minimum & $46.1 \%$ & $60.4 \%$ & $62.2 \%$ \\
\hline Maximum & $67.8 \%$ & $66.8 \%$ & $67.3 \%$ \\
\hline Difference & $21.8 \%$ & $6.4 \%$ & $5.1 \%$ \\
\hline
\end{tabular}

Overall, the minimal change in GUE for the range of tested outdoor temperatures for the GAHP when using a primary working fluid of $50 \%$ PG/water shows that the GAHP has consistent thermal output when in cooling mode operation.

\subsubsection{Power Consumption}

Power consumption of the GAHP and primary pump was monitored to observe changes in power draw during the different flow rates and operating modes of the GAHP. The GAHP is rated to have a nominal power draw of $750 \mathrm{~W}$, and each of the two primary pumps is rated for a power draw of $375 \mathrm{~W}$, for a total of $750 \mathrm{~W}$. When monitored for cooling mode operation, average power consumption values were evaluated. Table 6.4 summarizes these average power draw rates for each flow rate that was investigated during the cooling performance evaluation. From Table 6.4, it can be seen that the average power draw of the GAHP during cooling mode is approximately $490 \mathrm{~W}$, significantly lower than the rated value by $260 \mathrm{~W}$. The circulation pump power draw however is nearer to the rated power draw, this is likely due to the increased density and lower viscosity of the $50 \% \mathrm{PG} /$ water. 
Table 6.4: Average electric power consumption of GAHP and circulation pumps at varying flow rates during cooling mode

\begin{tabular}{|l|c|c|}
\hline Flow Rate & GAHP $(\mathbf{W})$ & $\begin{array}{c}\text { Circulation } \\
\text { Pump }(\mathbf{W})\end{array}$ \\
\hline Low & 487 & 688 \\
\hline Medium & 488 & 748 \\
\hline High & 490 & 770 \\
\hline
\end{tabular}

Figure 6.8 plots the COP with respect to the experimental data from Figure 6.1, with consideration of the circulation pump power and GAHP electrical power in addition to the gas input for each flow rate for the GAHP in cooling mode operation as seen in Table 6.4.

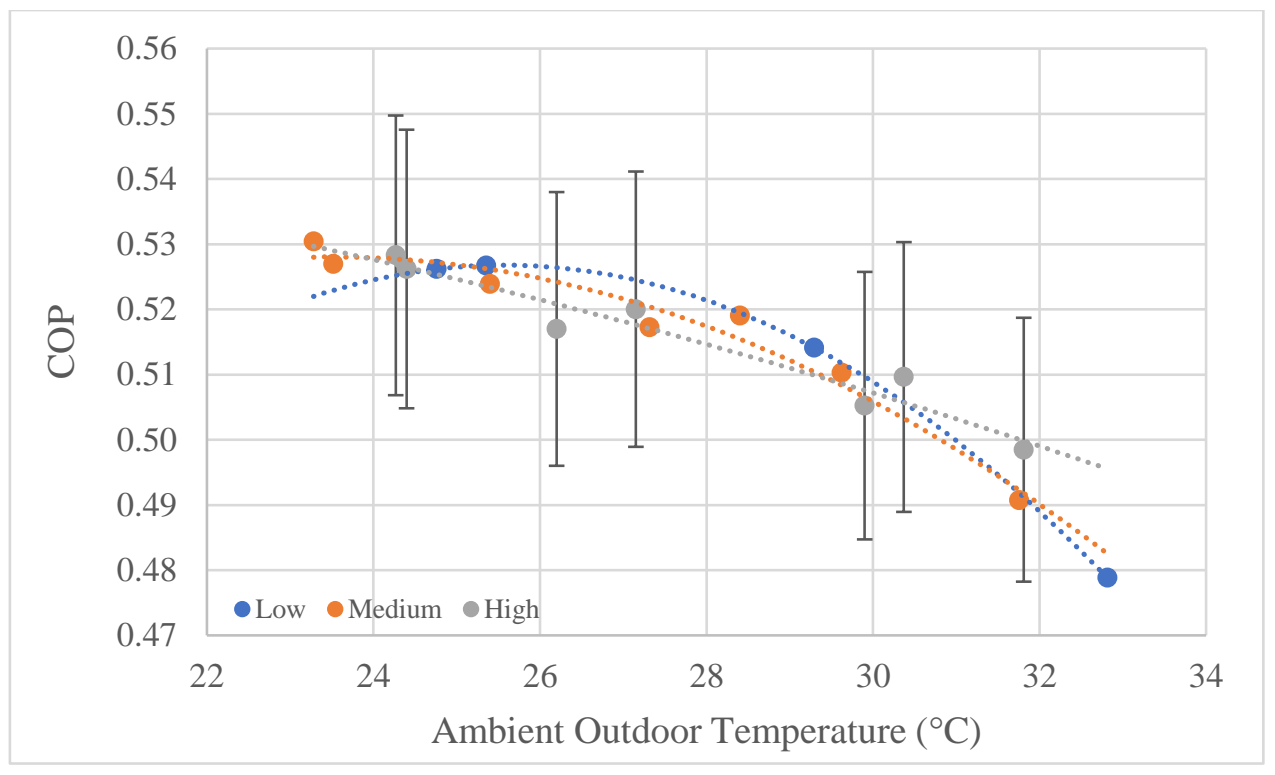

Figure 6.8: Experimental cooling COP with respect to ambient outdoor temperature for a return temperature of $12^{\circ} \mathrm{C}$ for varying flow rates using $50 \%$ PG/water

The COP decreases slightly for the GAHP during cooling mode operation but remains within a range of $5 \%$ from maximum to minimum values, similar to the GUE, as seen in Table 6.5. 
Table 6.5: Maximum and minimum experimental cooling COP values of varying flow for a fixed return temperature of $12^{\circ} \mathrm{C}$ for $50 \%$ PG/water solution

\begin{tabular}{|l|c|c|c|}
\hline Flow Rate & Low & Medium & High \\
\hline Minimum & $47.9 \%$ & $49.1 \%$ & $49.8 \%$ \\
\hline Maximum & $52.7 \%$ & $53.0 \%$ & $52.8 \%$ \\
\hline Difference & $4.8 \%$ & $4.0 \%$ & $3.0 \%$ \\
\hline
\end{tabular}

\subsubsection{Part Load Performance}

Cycling was a concern during the evaluation of the GAHP. To minimize cycling during steady state testing, thermal storage and a variable dump load was utilized. However, evaluating the GAHP only at steady state performance would not give a full understanding of the cyclic behaviour of the GAHP during its natural operation. As a result, the GAHP was left to operate normally during periods when the system was not controlled by a manual operator, but instead left to the controls built within the GAHP unit itself. This cycling data was collected and analyzed to find specific parameters to understand the cyclic behaviour of the GAHP unit for both heating and cooling mode. a cycling factor was developed to help document the loss of performance due to start-up time for each cycle and by evaluating the duration and output of the GAHP when operating for various durations. The cycling factor was derived using the following formula:

$F_{c y c}=\frac{\eta_{\text {overall }}}{\eta_{S S}}$

Equation 6.1

Where:

$F_{c y c}:$ is the cycling factor

$\eta_{\text {overall }}$ : is the overall efficiency of the cycle, steady state and start-up inclusive

$\eta_{S S}:$ is the steady state efficiency of each cycle

A nonlinear regression model was used to derive a formula to equate the cycling factor to generate a smooth nonlinear function to equate available variables to fit the typical cyclic profile of the GAHP for an individual cycle. For this fit, a Generalized Reduced Gradient (GRG) nonlinear algorithm was used to minimize the root mean sum error (RMSE) of the fit for each cycle profile. The equation that is to be applied to solve for cycling factor is as follows: 
$F_{c y c}=\frac{\dot{E}_{S S}}{\dot{E}_{\text {avg }}}\left(1+\frac{t_{\text {startup }}}{t}\left(\frac{\dot{Q}_{\text {startup }}}{\dot{Q}_{S S}}-1\right)\right)$

Equation 6.2

Where:

$\dot{E}_{\text {avg }}=\frac{\dot{E}_{\text {startup }} t_{\text {startup }}+\dot{E}_{S S}\left(t-t_{\text {startup }}\right)}{t}$

Equation 6.3

Where:

$t:$ is the total time of the cycle in minutes

$t_{\text {startup }}$ is the time during taken during the cycle to ready steady state in minutes

$\dot{E}_{S S}$ : is the gas input energy during steady state operation in $\mathrm{kW}$

$\dot{E}_{\text {avg }}$ : is the gas input energy averaged over the entire cycle in $\mathrm{kW}$

$\dot{E}_{\text {startup }}$ : is the gas input energy during the cycle start-up duration in $\mathrm{kW}$

$\dot{Q}_{\text {startup }}:$ is the thermal capacity delivered by the GAHP during the cycle start-up duration in $\mathrm{kW}$

$\dot{Q}_{S S}$ : is the thermal capacity delivered by the GAHP during steady state operation. In kW

For cooling mode, multiple cycles were analyzed. Unlike cooling mode, sufficient cycling data was available to find a cycling factor to determine the performance of a cycle depending on the duration of the total cycle. A short summary of the average cycling results can be found in Table 6.6.

Table 6.6: Average cycling parameters evaluated for part-load performance mapping during cooling mode operation of GAHP

\begin{tabular}{|l|c|}
\hline Cycle time (min) & 62.7 \\
\hline Time to reach steady state (min) & 5.9 \\
\hline Startup efficiency $(\%)$ & $33.4 \%$ \\
\hline Steady state efficiency (\%) & $53.4 \%$ \\
\hline Overall efficiency (\%) & $50.5 \%$ \\
\hline Cycling factor & 0.95 \\
\hline Capacity ratio (Start-up:SS) & 0.60 \\
\hline Gas input ratio (SS:Average) & 1.01 \\
\hline
\end{tabular}


For the fit that was plotted, several variables were fixed, the start-up time and the gas input energy ratio. Capacity ratio $\left(\frac{\dot{Q}_{s t a r t u p}}{\dot{Q}_{S S}}\right)$ had significant variance and was plotted for a cooling capacity ratio deviation of $0.6 \pm 0.1$ for cooling mode.

From Table 6.6, the average start-up time was 5.9 minutes with an average start-up efficiency of $33.4 \%$ for each cycle for the cooling season. All the cycles analyzed showed an average overall GUE of 50.5\%. The average steady state GUE of the cycles analyzed was $53.4 \%$.

Figure 6.9 shows a plot of each cycles and their respective cycling factors. The start-up time was fixed at 8.1 minutes and gas input ratio was set at 1.03 . The cycling factor function was also plotted with a heating capacity ratio deviation of $0.5 \pm 0.2$. Cooling ratio is the capacity ratio during cooling mode operation.

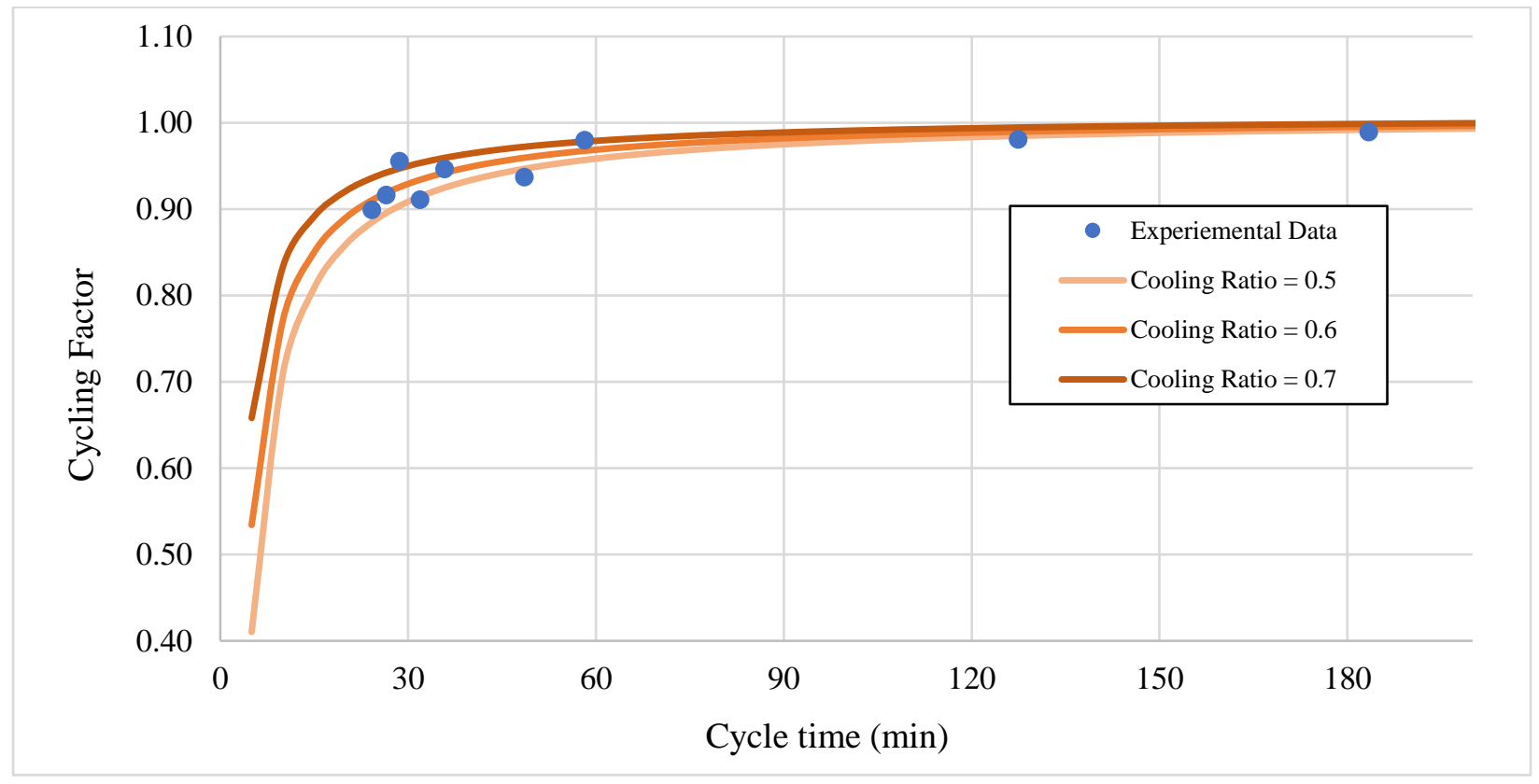

Figure 6.9: Experimental cycling factor of GAHP during cooling mode operation with respect to the duration of an entire cycle

From Figure 6.9, due to lack of usable cycle data, the correlation developed has lower deviation. However, the cycle data obtained had high quality cycles with the longest cycle remaining steady for approximately 3 hours. This, in addition to providing valuable information to evaluate the cycling performance of the GAHP in cooling mode operation, shows that the system is capable for remining in steady state operation for periods that are much longer than required, 
where 30 minutes is the minimum needed for effective steady state performance. This can be seen in Figure 6.9 where most cycles had durations of approximately 30 minutes or more and achieved cycle factors of $90 \%$ and above. This shows that the GAHP performs well in cooling mode when typical cycling behaviour is observed. What is not showed through this plot however, is that during cooling mode, large periods of short cycling can and have been seen to occur when the primary working fluid, $50 \% \mathrm{PG} /$ water in this case, reaches very low return temperatures such as $6^{\circ} \mathrm{C}$ or lower. This results the GAHP going into freeze protection regularly, resulting in numerous short cycles per hour that do not achieve steady state. This however, is more of a control issue inherent to the default controls programmed into the GAHP.

This cycling correlation seen in Figure 6.9 is only applicable once a full cycle is completed to determine the effectiveness of said cycle when normal cycling with nominal return temperatures is assumed. To model the cycling nature for cooling mode per minute during the period where the GAHP approaches steady state, the following equation was developed:

$F_{c y c}=-86.172 x^{2}+18.539 x$

Equation 6.4

Where:

$x$ : represents each minute divided by 60 , i.e., hour units. The range for this formula is from 0 to 6 minutes ( 0 hours to 0.1 hours). After which, the cycle factor is set to 1 , to represent steady state.

The formula was set to have a y-intercept of 0 , assuming at the initial moment the cycle begins, the GAHP will have cycle factor of 0 .

Each cooling cycle is assumed to take 6 minutes, from average cycle times, to reach steady state. This formula is primarily for use in simulations where each value is solved for specified time intervals, where operation time, i.e., GAHP “on" time, is in hours. Figure 6.10 shows a visual depiction of the cycle factor sum relative to the current minute of the GAHP cycle in its start-up phase for cooling mode operation. 


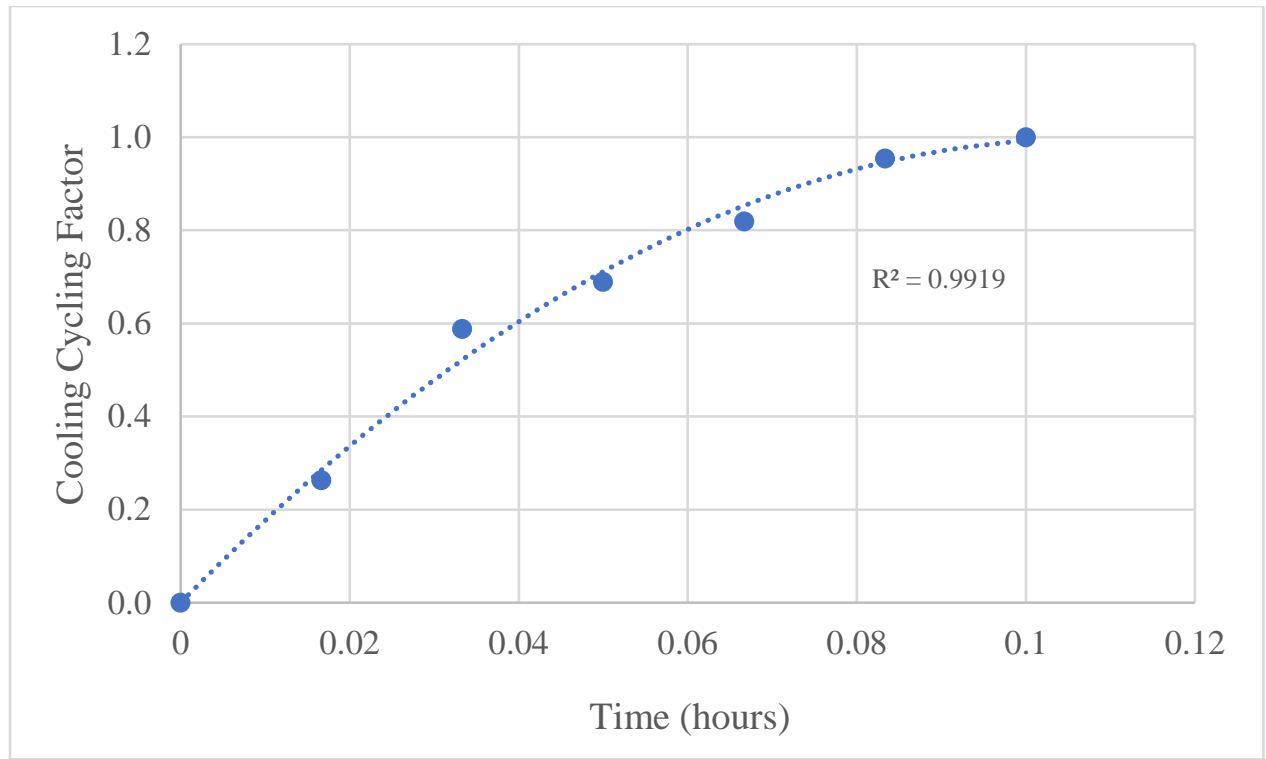

Figure 6.10: Experimental cooling mode cycle factor with respect to time for average GAHP start-up period, first 6 minutes

\subsection{Heating Mode Operation}

The heating season data was collected through the months of November 2017 up until March 2018. However, since the control for the dump load required a manual operator, not all temperatures during this period were obtainable for the steady state data collection. The lowest temperature that was obtained during this period was $-27.3^{\circ} \mathrm{C}$. However, since the GAHP can provide DHW heating, the capacity of the GAHP was also evaluated at high ambient outdoor temperatures. The highest temperature that was evaluated for the GAHP operating in heating mode was $31.9^{\circ} \mathrm{C}$. This allows a fuller picture on how the system can provide heating for the entire year, whether space heating or DHW heating. However, although this data for DHW heating was collected, it was not used for simulation development.

\subsubsection{Performance Maps}

Similar to the data collected during the cooling season, for heating season, nominal operating conditions were prioritized when developing the performance map. Due to this, the points collected for nominal flow rate and nominal return temperature provide the most detailed capacity profiles. As stated earlier in the cooling season data analysis, flow rate did not have any significant effect on the capacity profile with respect to the ambient outdoor temperature. Figure 
6.11 shows the capacity of the GAHP during heating mode for varying flow rates while a fixed return temperature of $40^{\circ} \mathrm{C}$.

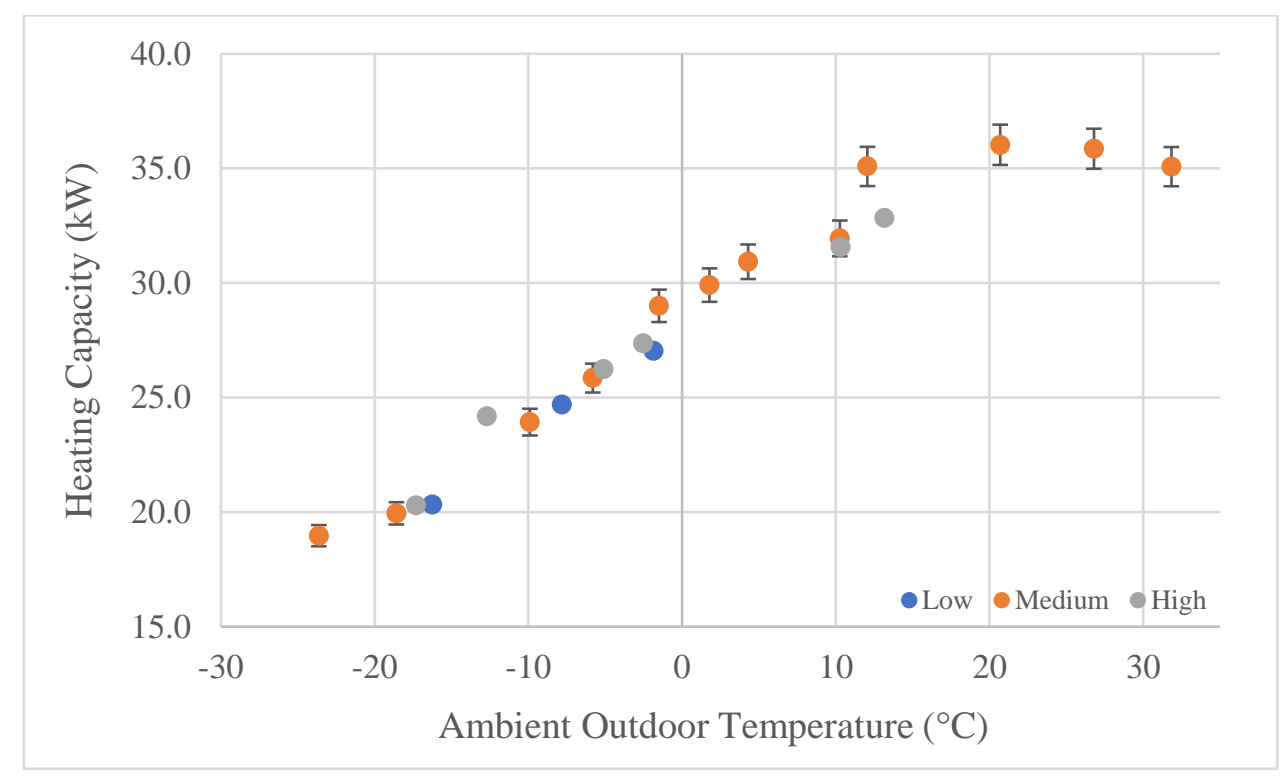

Figure 6.11:Experimental heating capacity with respect to ambient outdoor temperature for a return temperature of $40^{\circ} \mathrm{C}$ for varying flow rates using $50 \% \mathrm{PG} /$ water

Although the points available for low and high flow rates are fewer than the ones available for the nominal flow rate setting of medium, there is no discernable offset due to the varying flow rates of the GAHP for heating mode, as evidenced from the data from cooling mode operation.

However, when flow rate is fixed, and only return temperature is varied, the capacity profile is shares similarity to that of the manufacturer performance map. Figure 6.12 represents the manufacturer performance map for heating mode for varying flow return temperatures with a fixed nominal flow rate with a primary fluid of water. 


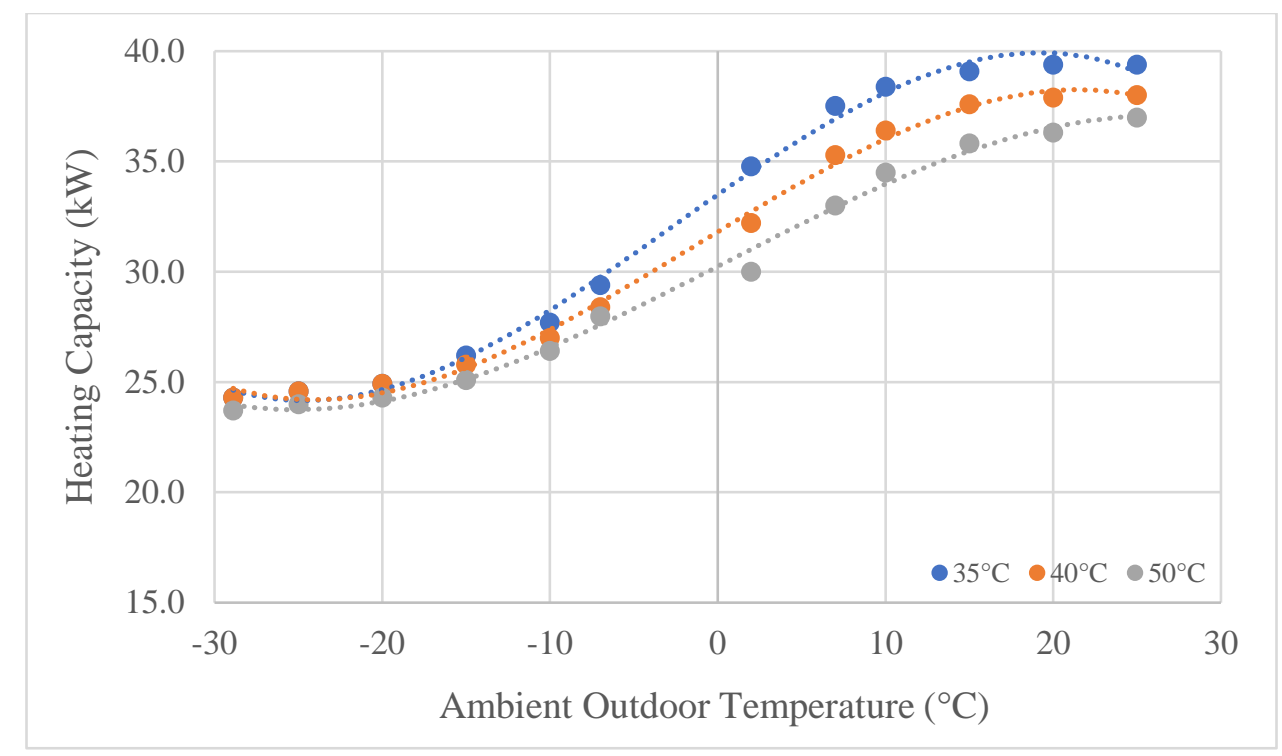

Figure 6.12: Manufacturer heating performance curves for a working fluid of water for varying return temperatures at 13.4 GPM

When compared to the experimental steady state performance map, as seen in Figure 6.13, a similar trend is seen where the capacity difference between the return temperatures is most prominent in warmer temperatures, but in colder temperatures, the capacity of the system converges. The GAHP shows poor performance during cold temperatures. The correlation between the varying temperatures show that the GAHP has the highest performance when having a lower return temperature. However, since the GAHP would be frequently used for DHW, assuming a minimum tank temperature of $50^{\circ} \mathrm{C}$, the return temperature of the GAHP would need to be above $40^{\circ} \mathrm{C}$, so the benefits of higher capacity with the use of lower return temperatures would rarely be utilized. In the case of this study, DHW heating was not considered, if the GAHP was used solely for space heating, a lower temperature would be more viable, offering a higher GUE and as a result, having reduced emissions and higher operational cost savings. Since all return temperature points converge at colder temperatures, the benefits of having lower return temperatures are nonexistent at temperatures below $-15^{\circ} \mathrm{C}$. Canadian climates generally have high CDD, and as seen in Figure 6.13, low performance in the colder temperatures limits the overall GAHP effectiveness. 


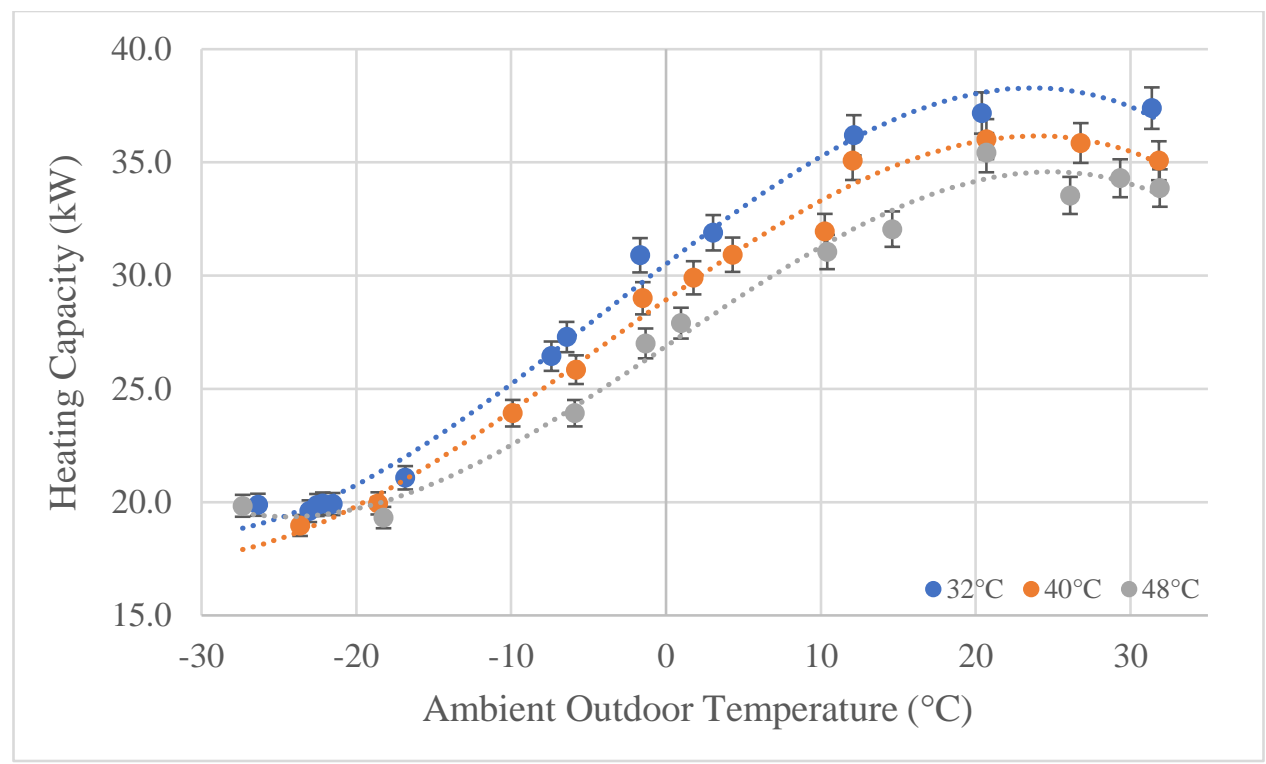

Figure 6.13: Experimental heating capacity of GAHP with respect to ambient outdoor temperatures for varying return temperatures at a flow rate of 13.4 GPM using $50 \%$ PG/water

Figure 6.13 also has temperatures measured for very high temperatures, values above the range of temperatures provided by the manufacturer $\left(25^{\circ} \mathrm{C}\right)$. This shows a trend of the GAHP achieving a steadier output of heating at higher temperatures. The fit that was used to show the correlation of GAHP capacity against ambient outdoor temperature was a $3^{\text {rd }}$ order polynomial. Table 6.7 presents the heating performance curves for those plotted in Figure 6.13 with their respective $\mathrm{R}^{2}$ values.

Table 6.7: Experimental heating performance curves for varying return temperatures at a fixed flow rate of 13.4 GPM using $50 \%$ PG/water solution

\begin{tabular}{|l|c|c|}
\hline $\begin{array}{c}\text { Return } \\
\text { Temperature }\end{array}$ & \multicolumn{1}{c|}{ Performance Curve Formula } & $\mathbf{R}^{\mathbf{2}}$ \\
\hline $32^{\circ} \mathrm{C}$ & $-0.0002 \mathrm{~T}^{3}-0.0028 \mathrm{~T}^{2}+0.525 \mathrm{~T}+30.515$ & 0.9929 \\
\hline $40^{\circ} \mathrm{C}$ & $-0.0002 \mathrm{~T}^{3}-0.0027 \mathrm{~T}^{2}+0.4851 \mathrm{~T}+28.932$ & 0.9895 \\
\hline $48^{\circ} \mathrm{C}$ & $-0.0003 \mathrm{~T}^{3}+0.0001 \mathrm{~T}^{2}+0.463 \mathrm{~T}+26.882$ & 0.9855 \\
\hline
\end{tabular}

*Where $\mathrm{T}$ represents the ambient outdoor temperature in ${ }^{\circ} \mathrm{C}$

However, the polynomial fit for the heating performance curves are within the range of operating temperatures that heating mode would be utilized for during space heating, therefore the higher temperatures downward trend would not be considered in modelling work. From Figure 
6.13 , it can be seen that the swing in potential capacity is very high for the GAHP in heating mode. Table 6.8 shows the maximum and minimum capacity values of the GAHP in heating mode.

Table 6.8: Maximum and minimum experimental heating capacity values of varying return temperatures at a flow rate of 13.4 GPM for $50 \%$ PG/water solution

\begin{tabular}{|l|l|l|l|}
\hline Return Temperature & $\mathbf{3 2}^{\circ} \mathbf{C}$ & $\mathbf{4 0}^{\circ} \mathbf{C}$ & $\mathbf{4 8}^{\circ} \mathbf{C}$ \\
\hline Minimum $(\mathrm{kW})$ & 19.60 & 18.97 & 19.32 \\
\hline Maximum $(\mathrm{kW})$ & 37.40 & 36.03 & 35.43 \\
\hline Difference \% & 17.80 & 17.06 & 16.11 \\
\hline
\end{tabular}

The difference in the capacity goes as high as $17.8 \mathrm{~kW}$, this is nearly half the capacity of the GAHP when derated for $50 \%$ PG/water solution $(30.7 \mathrm{~kW})$. This shows very poor performance during the most crucial times, i.e., during the coldest climate conditions, and can potentially be undersized if not taken into consideration.

Performance maps were also developed for the other flow rates at varying temperatures. Similar to cooling mode however, since nominal operating conditions were prioritized, data for complete performance maps could not be collected due to weather and facility availability limitations. More data can be collected to obtain a fuller map for the low and high flow rates that were evaluated. Figure 6.14 and 6.15 show the heating mode performance of the GAHP for 14.8 GPM and 10.1 GPM flow rates. 


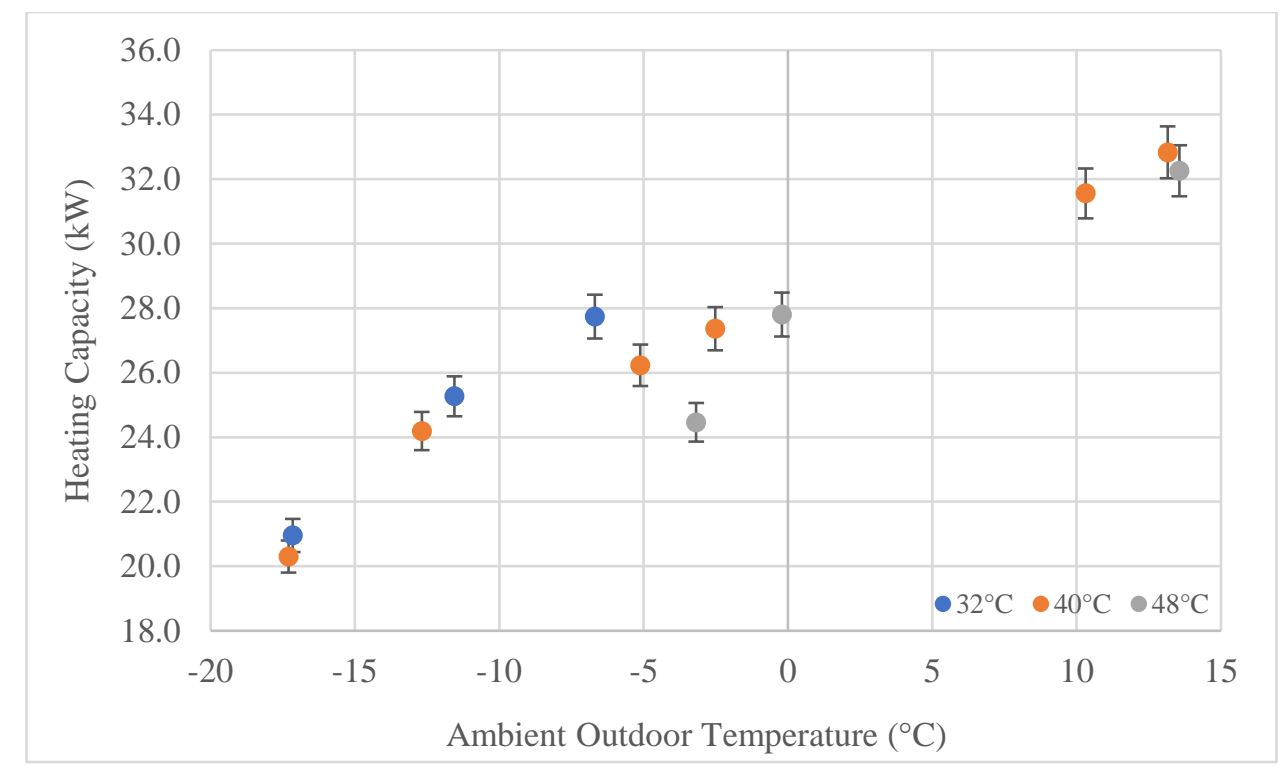

Figure 6.14: Experimental heating capacity of GAHP with respect to ambient outdoor temperatures for varying return temperatures at a flow rate of 14.8 GPM using $50 \%$ PG/water

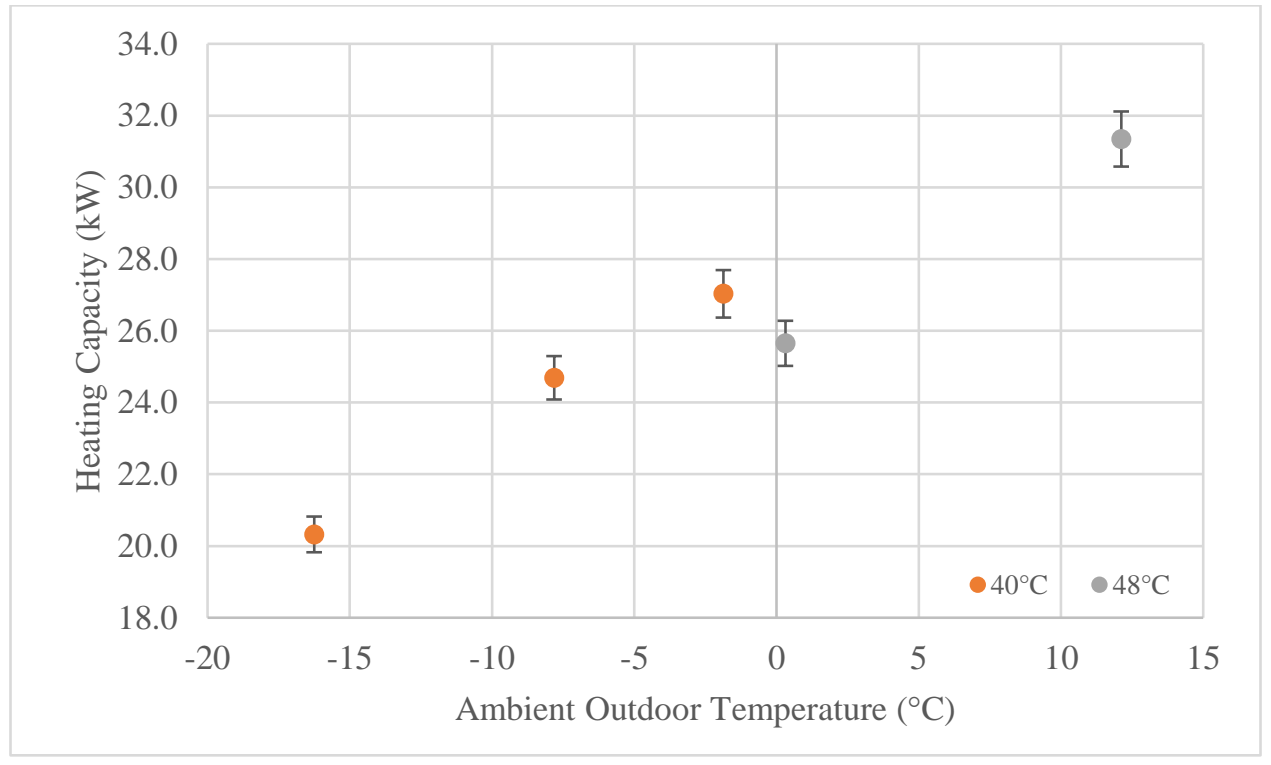

Figure 6.15: Experimental heating capacity of GAHP with respect to ambient outdoor temperatures for varying return temperatures at a flow rate of 10.1 GPM using $50 \%$ PG/water

As stated earlier however, flow rates have not shown a significant effect on the capacity of the system. As seen in Figures 6.14 and 6.15, the capacity values are comparable to those seen in the Figure 6.13 for nominal flow rate, for similar ambient outdoor temperatures. 


\subsubsection{Gas Utilization Efficiency (GUE) of GAHP}

Similar to the analysis for GAHP cooling mode operation, GUE profile during heating mode operation is investigated. Figure 6.16 shows the GUE plot derived from the data in Figure 6.13.

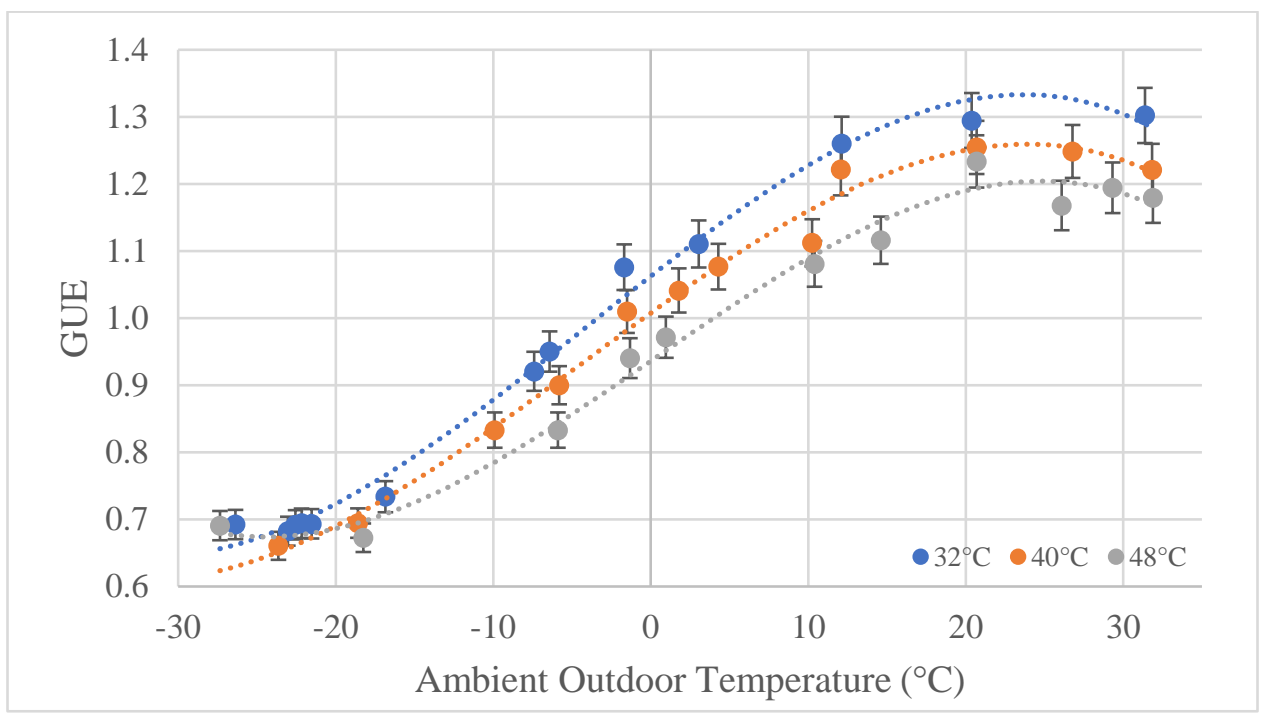

Figure 6.16: Experimental heating GUE of GAHP with respect to ambient outdoor temperatures for varying return temperatures at a flow rate of 13.4 GPM using 50\% PG/water with gas input of $28.7 \mathrm{~kW}$

From this plot, the lowest GUE is $66 \%$ evaluated at an ambient outdoor temperature of $23.6^{\circ} \mathrm{C}$ for a fixed return temperature of $40^{\circ} \mathrm{C}$. The lowest GUE for a fixed return temperature of $32^{\circ} \mathrm{C}$ and $48^{\circ} \mathrm{C}$ were only approximately $2 \%$ higher than that for the $40^{\circ} \mathrm{C}$ return temperature. A summary of the maximum and minimum heating GUE values for each return temperatures can be found in Table 6.9. A GUE value of $100 \%$ for the nominal flow rate and return temperature only occurs when the ambient outdoor temperature is $-1.5^{\circ} \mathrm{C}$ or above.

Table 6.9: Maximum and minimum experimental heating GUE values of varying return temperatures at a flow rate of 13.4 GPM for $50 \%$ PG/water solution

\begin{tabular}{|l|r|r|r|}
\hline Return Temperature & \multicolumn{1}{|c|}{$\mathbf{3 2}^{\circ} \mathbf{C}$} & \multicolumn{1}{|c|}{$\mathbf{4 0}^{\circ} \mathbf{C}$} & \multicolumn{1}{c|}{$\mathbf{4 8}^{\circ} \mathbf{C}$} \\
\hline Minimum & $68.2 \%$ & $66.1 \%$ & $67.3 \%$ \\
\hline Maximum & $130.2 \%$ & $125.4 \%$ & $123.4 \%$ \\
\hline Difference & $62.0 \%$ & $59.4 \%$ & $56.1 \%$ \\
\hline
\end{tabular}


The differences in GUE from the highest to lowest for each return temperature is significant however, ranging from $56 \%$ to $62 \%$. The outdoor temperature range that was tested was far larger than that that was done for the cooling performance however, and a larger difference is expected.

Comparatively, the GUE plot of the manufacturer specifications for a gas input of $28 \mathrm{~kW}$ (95.5 MBH) are shown in Figure 6.17, derived similarly from the data in Figure 6.12 earlier. Table 6.10 also summarizes the maximum and minimum GUE that is found in the heating performance of the GUE using water as the primary working fluid.

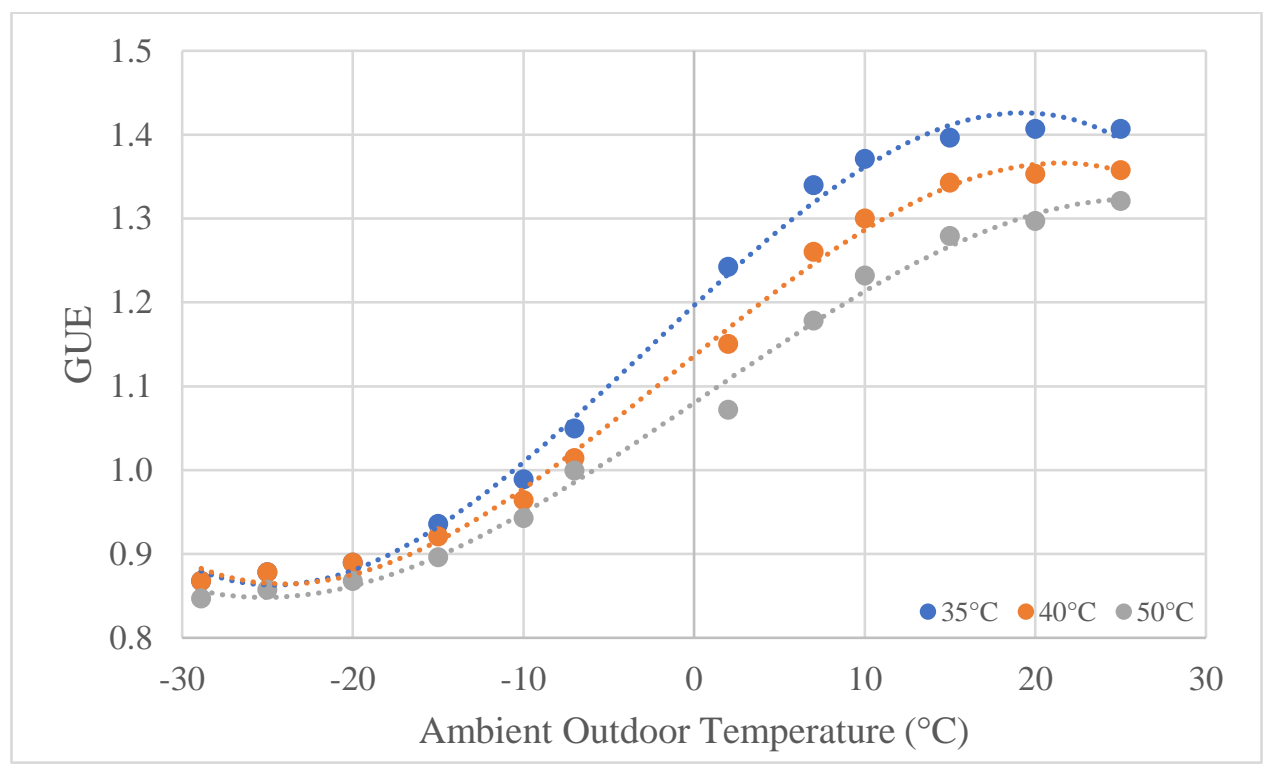

Figure 6.17: Manufacturer heating GUE for a working fluid of water for varying return temperatures at 13.4 GPM with gas input of $28 \mathrm{~kW}$

Table 6.10: Maximum and minimum manufacturer heating GUE values for a working fluid of water at a flow rate of 13.4 GPM for varying return temperatures

\begin{tabular}{|l|r|r|r|}
\hline Return Temperature & \multicolumn{1}{|c|}{$\mathbf{3 5}^{\circ} \mathbf{C}$} & \multicolumn{1}{|c|}{$\mathbf{4 0}^{\circ} \mathbf{C}$} & \multicolumn{1}{|c|}{$\mathbf{5 0}^{\circ} \mathbf{C}$} \\
\hline Minimum & $86.8 \%$ & $86.8 \%$ & $84.7 \%$ \\
\hline Maximum & $140.7 \%$ & $135.8 \%$ & $132.1 \%$ \\
\hline Difference & $53.9 \%$ & $49.0 \%$ & $47.4 \%$ \\
\hline
\end{tabular}

From Table 6.10, it can be seen that the differences in maximum and minimum efficiencies is significantly lower when compared to that of the GAHP heating mode operation using 50\% PG/water, with approximately $10 \%$. This shows that the experimentally tested GAHP is higher 
efficiency losses throughout the range of tested temperatures in comparison to a when using water alone.

The lowest GUE when the GAHP was operated under nominal flow rate and return temperature conditions was $86.6 \%$. This is a $20.7 \%$ lower than the lowest GUE that was found for a similar flow rate and return temperature as seen in Table 6.9. A 20.7\% decrease in GUE is far greater than what can be explained through simply derating for 50\% PG/water and even if accounting for a possible $2 \%$ loss of efficiency due to higher gas input than designed for the GAHP. The loss of efficiency is most likely due to factors introduced through the experimental testing being done in an actual home and not through the lab, which the manufacturer data is mostly likely derived through. In addition to this, it is likely that 50\% PG/water solution loses heat transfer effectiveness the more extreme cold weather conditions. This is not feasible in the Canadian climate since the fluid was selected explicitly for it low freezing point in the more extreme cold weather conditions. Lower effectiveness of the $50 \%$ PG/water solution brings the effectiveness of the GAHP down to levels that is not cost effective in comparison to other heating appliances. This higher than expected difference for the GUE of the 50\% PG/water experimental evaluation may also be attributed to the physical climate, such as snow or ice build up on the unit itself since it is located outdoors. This may have prevented airflow into the unit itself, possibly affecting the performance of the system internally, which could not be monitored. This is a natural consequence of using the GAHP unit in the Canadian climate as snow and ice is a regular occurrence and in addition to the reduced effectiveness of the $50 \%$ PG/water solution, the poor GAHP performance would affect its cost and energy saving potential during a season where higher heating efficiencies is the norm.

Assuming a forced-air furnace to have an efficiency of $95 \%$, the GAHP only has better performance at temperatures of approximately $-5^{\circ} \mathrm{C}$ and higher. This is far from the average temperatures seen during the winter season in Toronto. As a result, the GAHP operating with a GUE higher than that of a typical household forced-air furnace would only be for a shorter duration and most effective during transitional seasons such as fall or spring, when the use of heating and cooling appliances is already minimized compared to the winter season. At an ambient temperature of $-10^{\circ} \mathrm{C}$, at the nominal flow rate and return temperature, the experimental performance curve has a roughly $80 \%$ efficiency, equivalent to that of a typical boiler. With standard heating appliances 
for residential and multi-unit units having efficiencies much higher, the GAHP does not show, simply from the performance map, to have any benefit over existing appliances already in use when using 50\% PG/water. At an equivalent ambient outdoor temperature, with water as the primary working fluid, the GUE is approximately that of a $95 \%$ forced-air furnace.

With a fixed return temperature of $40^{\circ} \mathrm{C}$, the highest GUE of the water based GAHP performance was found to be $135.8 \%$, compared to the experimental results this shows a difference of $10.4 \%$. This shows that the performance difference is not as significant during warmer temperatures than at colder temperatures. A $10.4 \%$ difference is an improvement from the expected $50 \%$ PG/water derate, showing that that GAHP had higher than expected performance. The range where the GAHP has its highest performance however, is at its mildest temperatures, where heating is not required as often, as such, the benefits of the high GUE during these ranges would not be experienced to counteract the low performance of the GAHP during the ranges where it would most often be utilized.

\subsubsection{Power Consumption}

During the Heating mode, both the GAHP and pumps consumed power at a rate different to the cooling season. Table 6.11 summarizes the average power consumption for both the GAHP and pump at the various flow rate settings used in this study. The GAHP had a steady power consumption that averaged at $570 \mathrm{~W}$ when in heating mode operation, which is $180 \mathrm{~W}$ lower than the manufacturer rated power consumption. As expected, the circulation power required for heating mode is lower than the total rated power consumption of $750 \mathrm{~W}$, likely due to the reduced fluid density and lower viscosity resulted from higher fluid temperatures. The circulation power is also notably lower for heating mode in comparison to that of the cooling mode operation.

Table 6.11: Average electric power consumption of GAHP and circulation pumps at varying flow rates during heating mode

\begin{tabular}{|l|c|c|}
\hline Flow Rate & GAHP $(\mathbf{W})$ & $\begin{array}{l}\text { Circulation } \\
\text { Pump }(\mathbf{W})\end{array}$ \\
\hline Low & 569 & 534 \\
\hline Medium & 571 & 631 \\
\hline High & 566 & 694 \\
\hline
\end{tabular}


Figure 6.18 plots the COP with respect to the experimental data from Figure 6.13, using circulation power and GAHP electrical power in addition to the gas input for the medium flow rate as seen in Table 6.11.

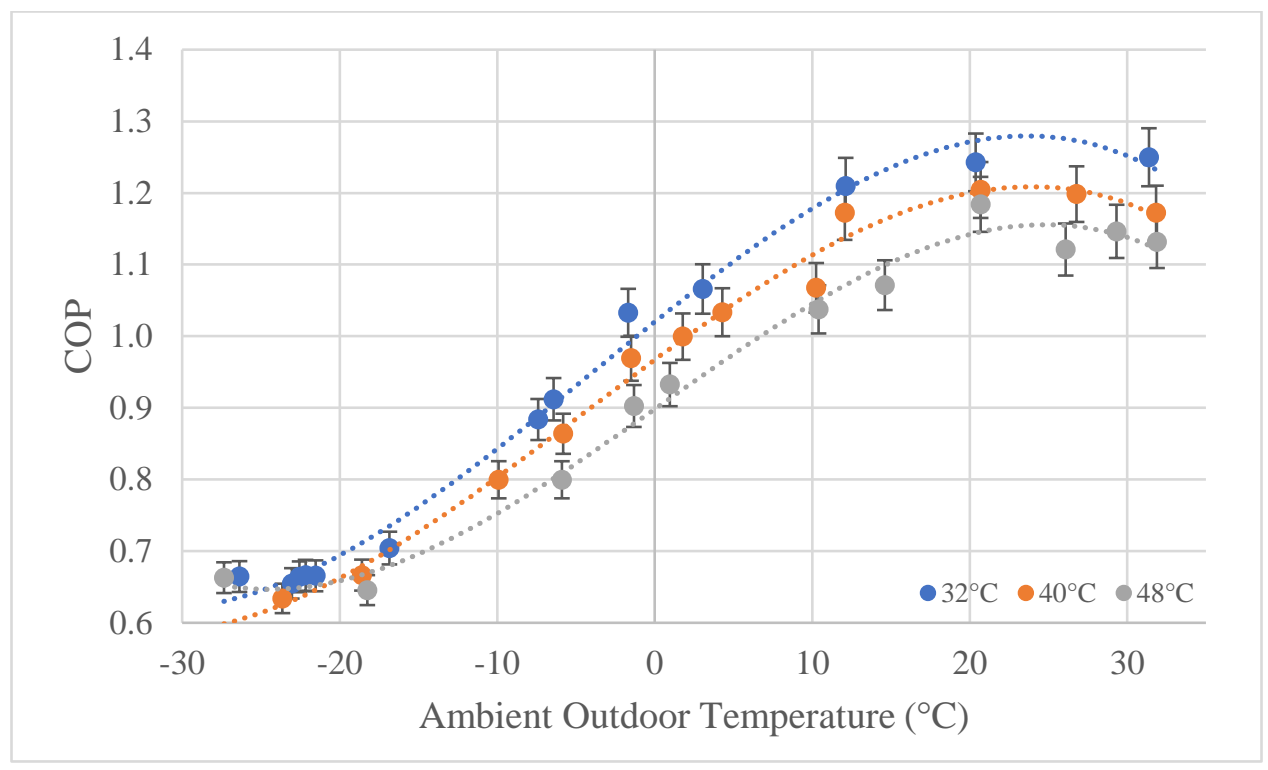

Figure 6.18: Experimental heating COP of GAHP with respect to ambient outdoor temperatures for varying return temperatures at a flow rate of 13.4 GPM using 50\% PG/water

From Figure 6.18, the COP of the system is only above $100 \%$ for nominal return temperature and flow rate when the ambient outdoor temperature is above $1.8^{\circ} \mathrm{C}$. This shows that the GAHP would be more suitable to milder climates. Table 6.12 summarizes the maximum and minimum COP for each return temperature.

Table 6.12: Maximum and minimum experimental heating COP values of varying return temperatures at a flow rate of 13.4 GPM for $50 \%$ PG/water solution

\begin{tabular}{|l|c|c|c|}
\hline Return Temperature & $\mathbf{3 2}^{\circ} \mathbf{C}$ & $\mathbf{4 0}^{\circ} \mathbf{C}$ & $\mathbf{4 8}^{\circ} \mathbf{C}$ \\
\hline Minimum & $65.5 \%$ & $63.4 \%$ & $64.6 \%$ \\
\hline Maximum & $125.0 \%$ & $120.4 \%$ & $118.4 \%$ \\
\hline Difference & $59.5 \%$ & $54.9 \%$ & $53.8 \%$ \\
\hline
\end{tabular}




\subsubsection{Cycling and Part Load Performance}

For heating mode, multiple cycles were analyzed. Unlike cooling mode, sufficient cycling data was available to find a cycling factor to determine the performance of a cycle depending on the duration of the total cycle. A short summary of the cycling results can be found in Table 6.13.

Table 6.13: Average cycling parameters evaluated for part-load performance mapping during heating mode operation of GAHP

\begin{tabular}{|l|c|}
\hline Cycle time (min) & 40.3 \\
\hline Time to reach steady state (min) & 8.1 \\
\hline Startup GUE (\%) & $49.4 \%$ \\
\hline Steady state GUE (\%) & $83.0 \%$ \\
\hline Overall GUE (\%) & $74.4 \%$ \\
\hline Cycling factor & 0.89 \\
\hline Capacity ratio (Start-up:SS) & 0.52 \\
\hline Gas Input ratio (SS:Average) & 1.04 \\
\hline
\end{tabular}

As seen in Table 6.13, the average start-up time was 8.1 minutes with a GUE of $49.4 \%$ during this period for the during heating season. All the cycles analyzed showed an average overall GUE of $74 \%$. The average steady state GUE of the cycles analyzed was only $83 \%$ however.

Figure 6.19 shows a plot of each cycles and their respective cycling factors. The start-up time was fixed at 8.1 minutes and gas input ratio was set at 1.03. The cycling factor function was also plotted with a heating capacity ratio deviation of $0.5 \pm 0.2$. 


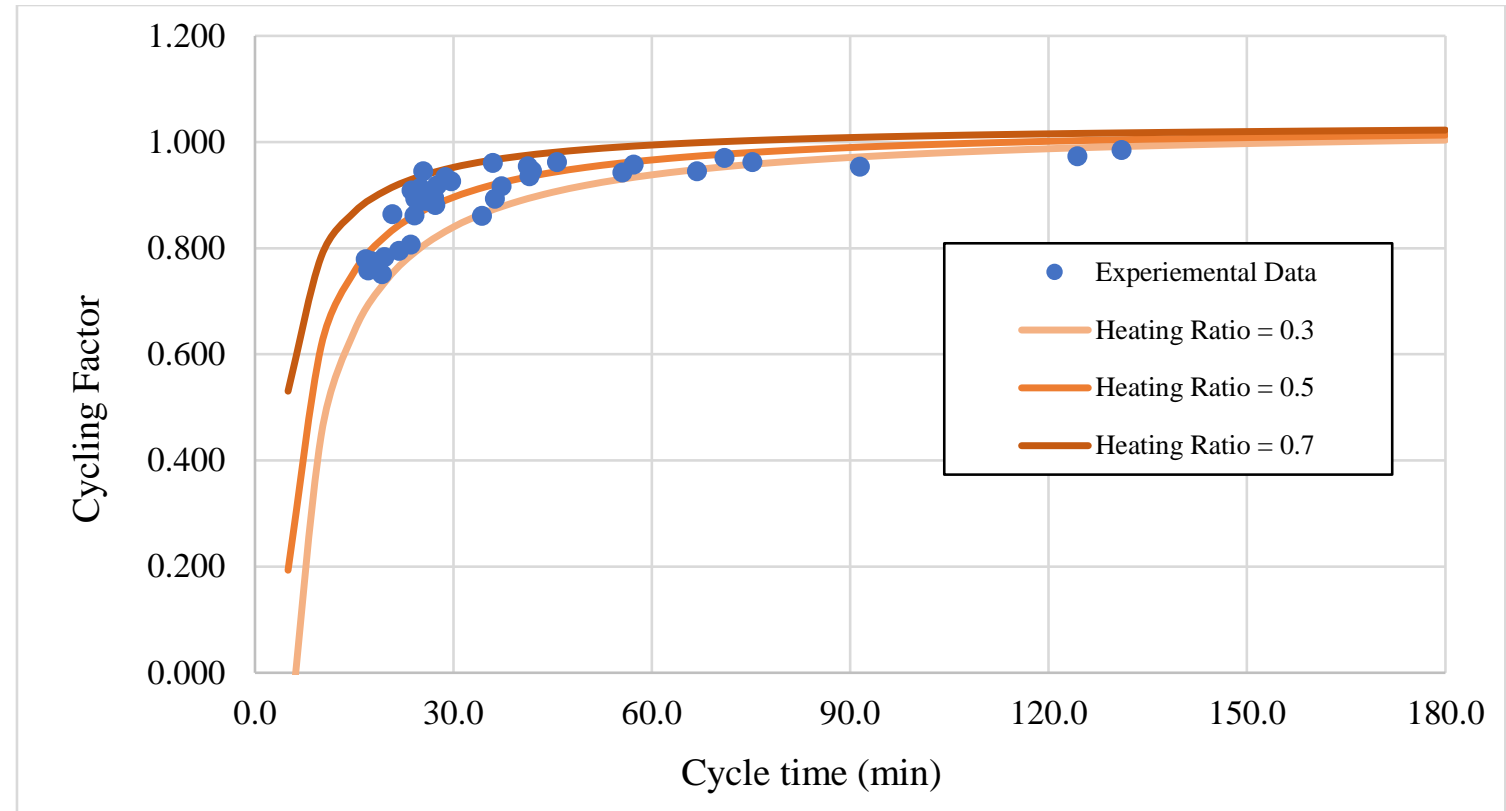

Figure 6.19: Experimental cycling factor of GAHP during heating mode operation with respect to the duration of an entire cycle

From Figure 6.19, cycles that had durations of more than 30 minutes in total, achieved cycle factors of $90 \%$ and above. When cycle durations were below 30 minutes, i.e., less than 30 minutes of steady state when start-up time is accounted for, the cycle capacity would be approximately $80 \%$ of the steady state capacity. This shows that the GAHP has a reasonable performance when cycling is accounted for.

To model the cycling nature for heating mode per minute during the period where the GAHP approaches steady state, the following equation was developed:

$F_{c y c}=-10130 x^{4}+2404.5 x^{3}-176.31 x^{2}+12.209 x$

Equation 6.5

Where:

$x$ : represents each minute, where the range is from 0 to 8 minutes ( 0 hours to 0.133 hours). A start up time of 8 minutes is assumed given the average start up time of the cycles analyzed. After 8 minutes, the cycling factor is set 1 unity to distinguish steady state operation. 
This formula is primarily for use in simulations where each value is solved for specified time intervals. Figure 6.20 shows a visual depiction of the cycle factor sum relative to the current minute of the GAHP cycle in its start-up phase for heating mode operation.

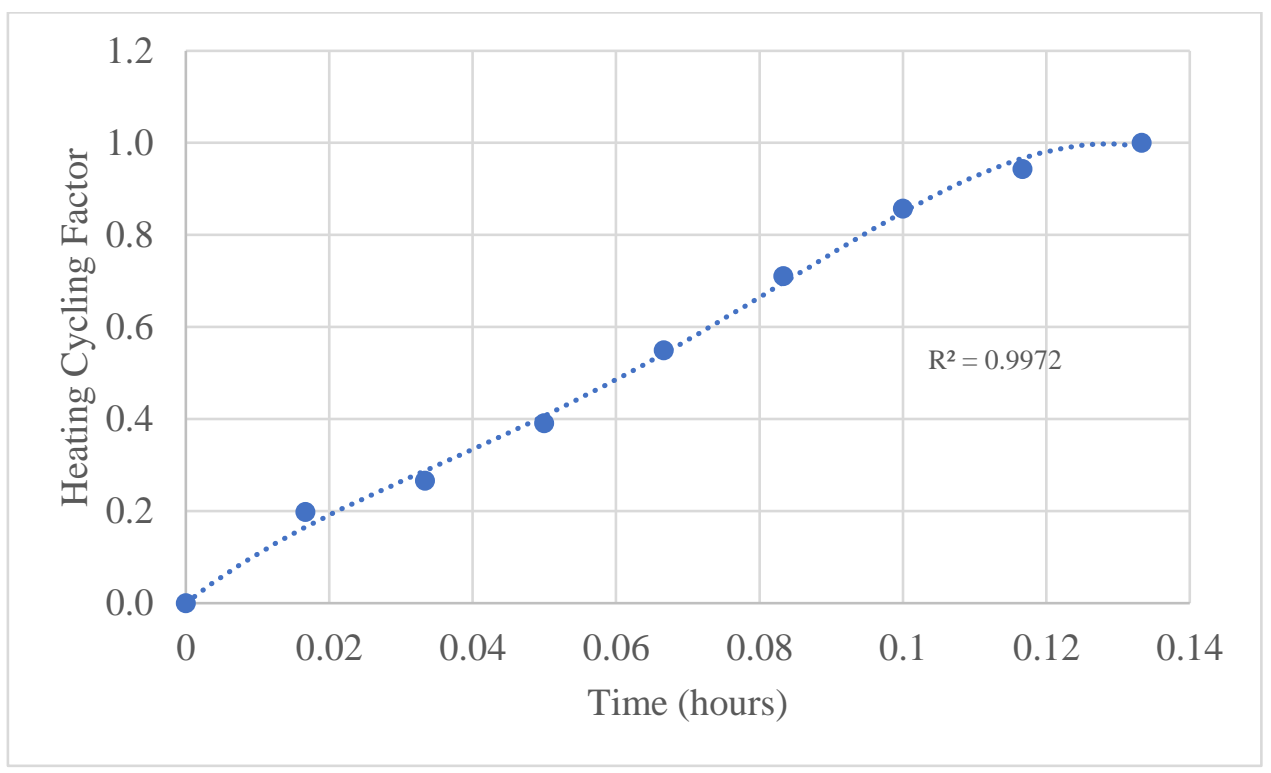

Figure 6.20: Experimental heating mode cycle factor with respect to time for average GAHP start-up period, first 8 minutes 


\section{Integrated GAHP Modelling and Simulation}

\subsection{House Model Design}

To model the GAHP in TRNSYS, a combined House A and B model was developed. Previous experimental studies have been done in the ASH, primarily for the performance evaluation of the GSHP in House B and ASHP in House A. However, both systems were independent of each other and did not require an integrated house model. For the GAHP, since both House A and B were combined into a single unified HVAC system, an upgraded combined model was developed. Previous TRNSYS models for House A and B were developed originally in TRNSYS 16 (Safa et. Al, 2015b; Safa et al., 2015c). In the previous version of the software, 3D modelling of the software was not easily available. Porting house models from previous version also run the risk of losing information due to obsolete features in updated versions of the software.

As a result, the combined house model for House A and B was developed as a 3D model using measurements from the original ASH construction blueprints and schematics. This house model only took measurements of the air nodes and did not account for wall measurements to define zone boundaries. This is due to the nature of the modelling software accounting for varying wall thicknesses when inputting envelope characteristics. Previous house models were only capable of modelling the house in terms of primary details, such as window, wall and floor surface area and slope angles provided. With the option to build a 3D model allows more refined positioning of the walls, and windows, but also gives the added option to include other fenestration devices such as doorways. Building the model in 3D also allows for the addition of shading devices such as facades and surrounding structures.

The previous house models also assumed that the connecting wall between House A and B would be exposed to the sun, which is accounted for and corrected in the 3D model. Figure 7.1 and 7.2 show the 3D model of House A and B combined from the front and back. For this model, the inlaw suite was not included as a conditioned zone due to its minimal thermal load on the system to simplify the model but was included as a shading item along with the garage for House B due to its notable size. House A garage was included as a zone since its thermal zone is adjacent to the first floor of the House A, to account for any loss of heat from the first floor into the garage, although expected to be minimal. The garage $\mathrm{A}$ is not a conditioned zone however. The atrium in House $\mathrm{B}$ is also a new addition due to the use of 3D modelling. In the House B located at the 
TRCA facility, the second floor has an open connection to the first floor. To model a zone with an atrium, walls had to be created to define the boundaries of the first and second floor. However, the adjacent walls between the zones for the first and second floor were defined as having no thermal mass and were set to allow coupling air flow. This allowed for air to flow more freely through the first and second floor, recreating a more realistic depiction of House B.

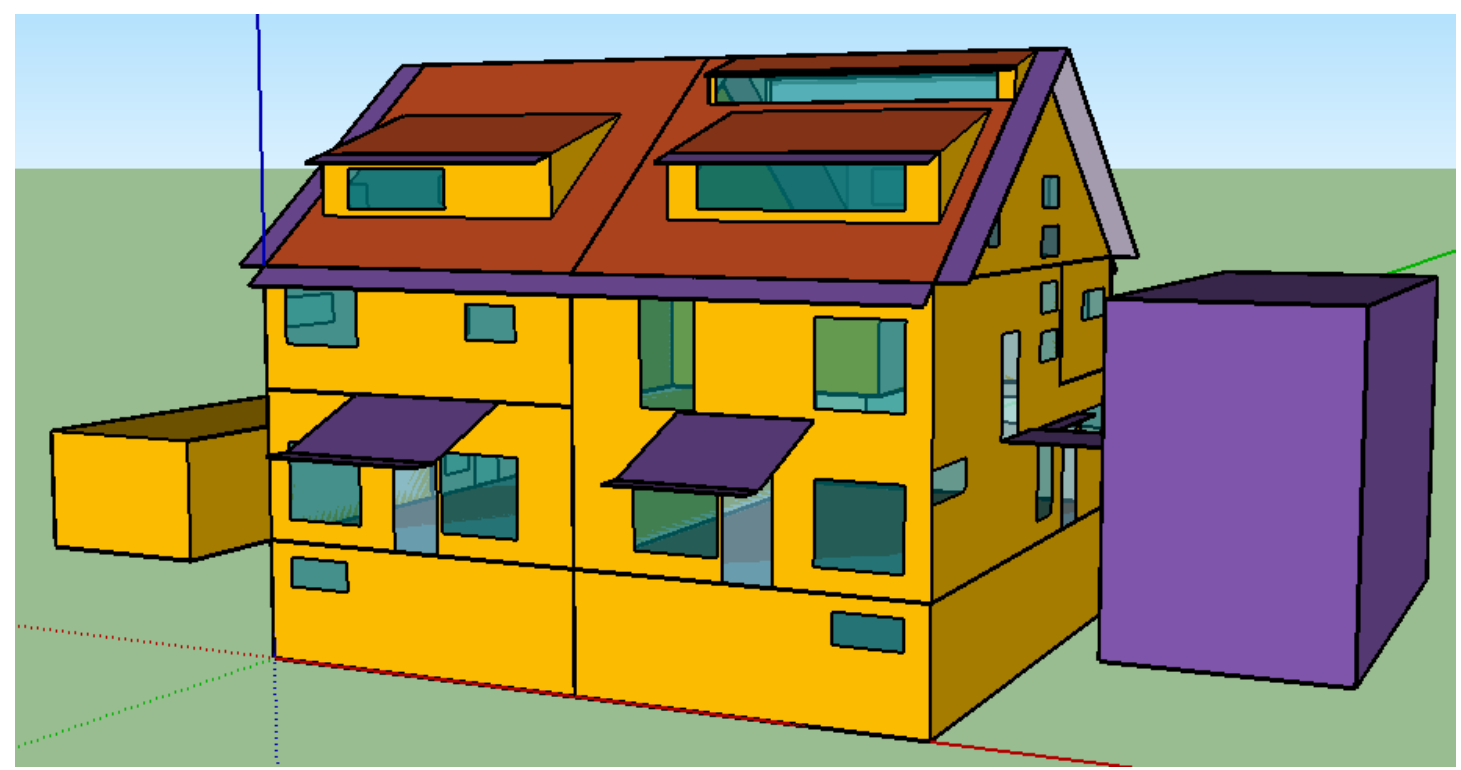

Figure 7.1: South facing side of TRNSYS 3D ASH model, House A on left and House B on right

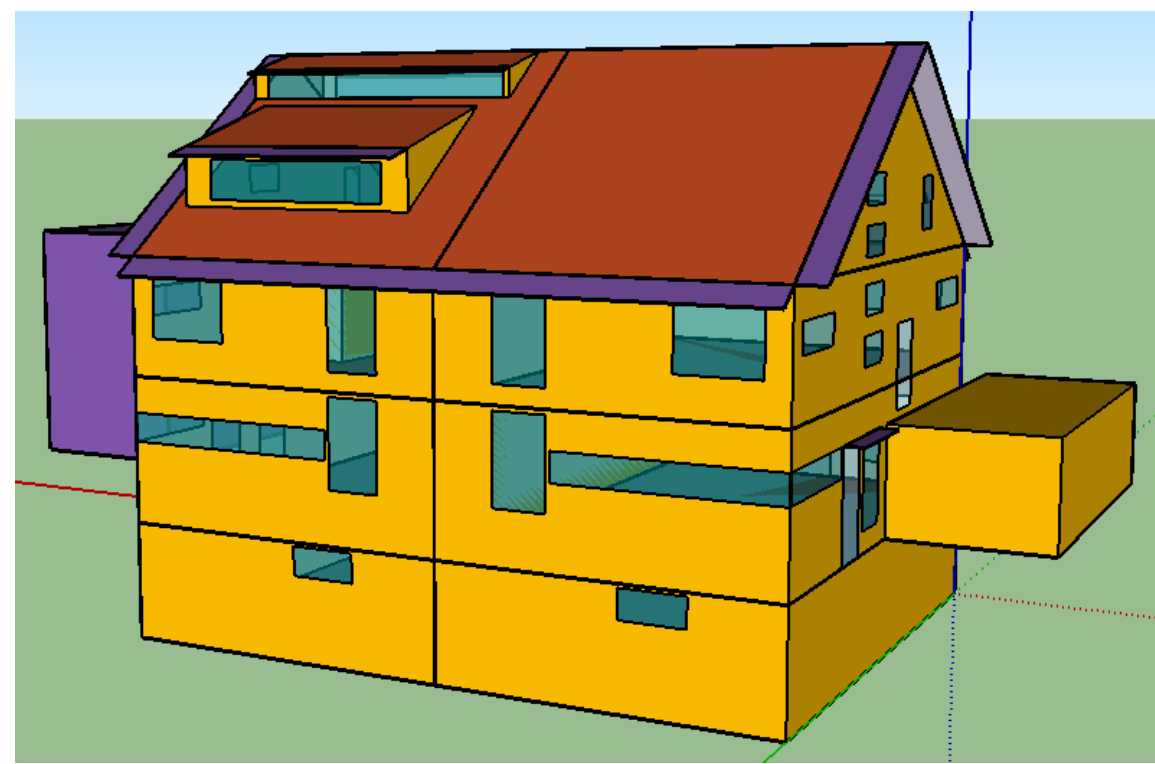

Figure 7.2: North facing side of TRNSYS 3D ASH model, House A on right and House B on left 


\subsection{House Model Validation}

The House A and B 3D model was exported into TRNBuild of version 17 of TRNSYS, where known envelope characteristics, internal gains, scheduling, ventilation and infiltration were input (Dembo et al., 2010; Safa et al., 2015c) The combined house model was validated through the comparisons of peak loads and annual demand of the originally validated individual House A and House B models. The house model was simulated under unlimited heating and cooling conditions, i.e., simulated to have an HVAC system designed to provide the ideal amount of heating or cooling depending on demand for the house. The conditions for simulation were matched to the original validated house models from previous studies. The cooling season is set to begin on May $22^{\text {nd }}\left(3408^{\text {th }}\right.$ hour $)$ to September $30^{\text {th }}\left(6575^{\text {th }}\right.$ hour $)$ with a zone setpoint of $23^{\circ} \mathrm{C}$ for each conditioned zone. The heating season was set to start October $1^{\text {st }}\left(6576^{\text {th }}\right.$ hour) to May $21^{\text {st }}$ $\left(3407^{\text {th }}\right.$ hour) at a zone set point of $21^{\circ} \mathrm{C}$ for each conditioned zone. The climate that both the validated house models and the combined house model was simulated for was for the Metropolitan Toronto area, where the temperature profile is shown earlier in Figure 4.1. To help the combined model closely match the demands of the validated model, adjustments where made to the shading devices and internal gains to reasonably match the peak loads and annual energy demand of the houses. For the case of internal gains, occupancy was added to House B, three adults, to match the higher use in House B due to staff using it for meetings and office space. This brought down the peak values of the heating demand. Minor adjustments were made to the shading schedule to better match the cooling peaks during cooling season and annual demand for both seasons. Figure 7.3 and 7.4 show the annual heating and cooling demand profiles for both House A and B. Table 7.1 and 7.2 summarizes the differences between peak heating and cooling demands and the differences between annual energy demand for House A and B of the validated model and combined model. 


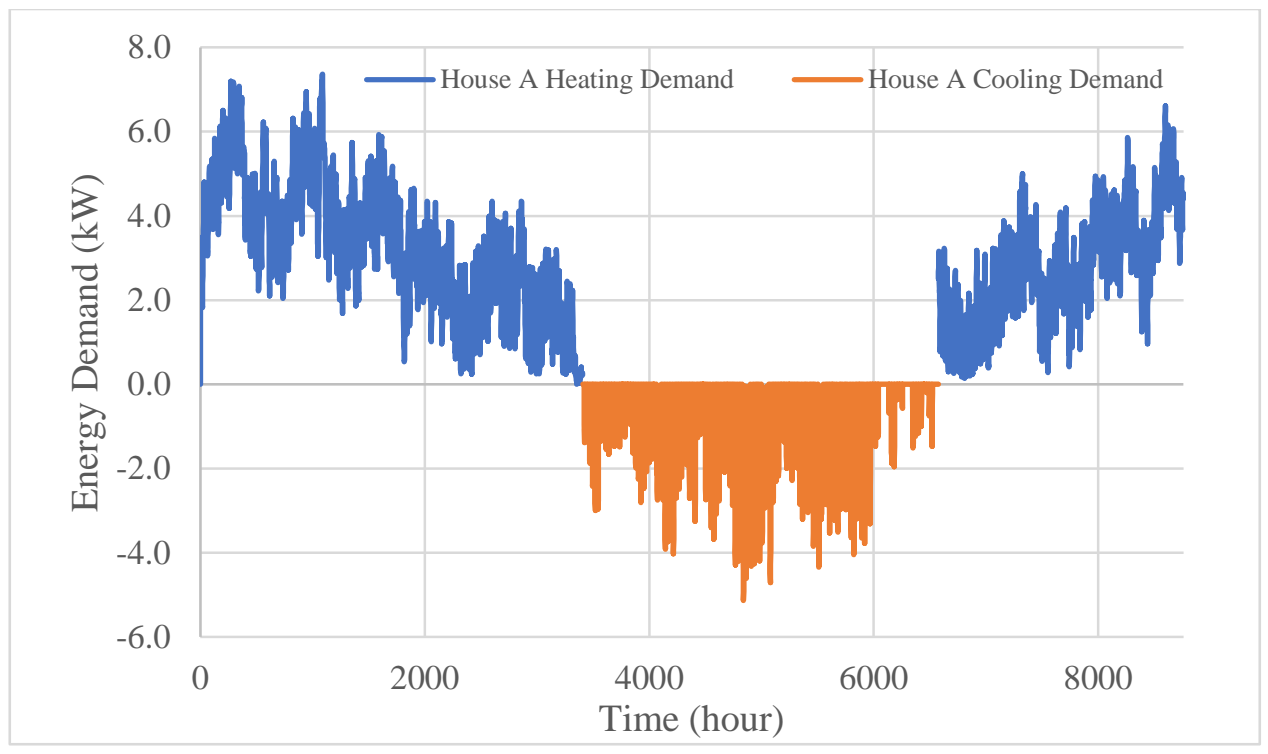

Figure 7.3: House A annual energy demand profile for identical setpoints and season durations used in validated model

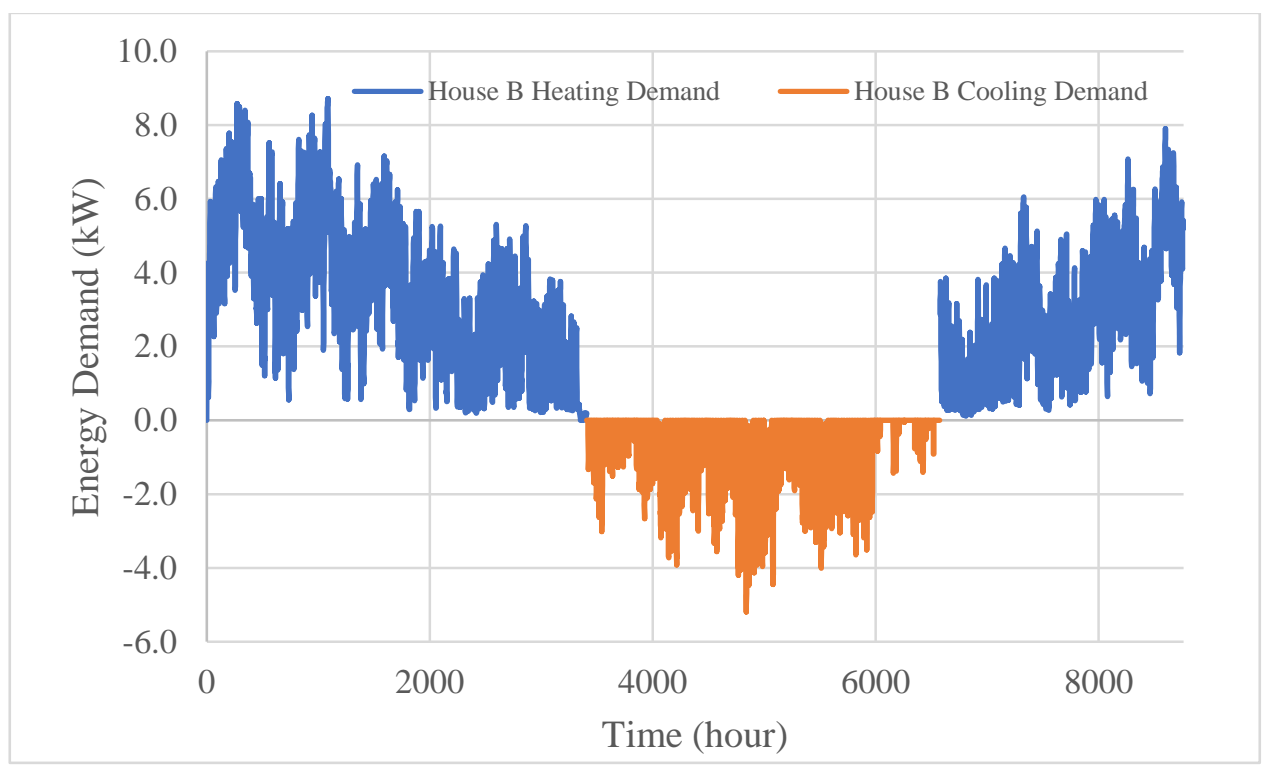

Figure 7.4: House B annual energy demand profile for identical setpoints and season durations used in validated model

From Table 7.1, the differences in peak values are significantly high compared to the validated model, the differences are all lower than $9 \%$ however. This high peak values are likely a result of 3D geometry, difference in volume and increased number of windows. The increased detail in geometry allows for more wall area in contact with the ambient environment and total 
volume, especially for the $3^{\text {rd }}$ floor, which was found to have the highest heating demand for both houses. Previous validated models were restricted in wall and roof placement due to limited available angles orientations in previous versions. However, the annual heating and cooling demand for the combined house model is close to those of the validated model with less than $2 \%$ difference, showing good agreement, as seen in Table 7.2.

Table 7.1: Peak heating and cooling demand of each house of validated house models compared to combined house model

\begin{tabular}{|l|c|c|c|c|}
\hline \multirow{2}{*}{ House Model } & \multicolumn{2}{|c|}{ Peak Heating Demand (kW) } & \multicolumn{2}{c|}{ Peak Cooling Demand (kW) } \\
\cline { 2 - 5 } & House A & House B & House A & House B \\
\hline $\begin{array}{l}\text { Validated Model (Safa } \\
\text { et al., 2015c) }\end{array}$ & 6.76 & 8.02 & 5.08 & 4.86 \\
\hline Combined Model & 7.37 & 8.72 & 5.13 & 5.19 \\
\hline Percent Difference (\%) & $-8.99 \%$ & $-8.70 \%$ & $-1.05 \%$ & $-6.81 \%$ \\
\hline
\end{tabular}

$*$ Percent Difference $(\%)=($ Combined Model - Validated Model $) /$ Validated Model

Table 7.2: Annual heating and cooling demand of each house of validated house models compared to combined house model

\begin{tabular}{|l|c|c|c|c|}
\hline \multirow{2}{*}{ House Model } & \multicolumn{2}{|c|}{$\begin{array}{c}\text { Annual Heating Demand } \\
(\mathbf{k W h} / \mathbf{y} \text { ear })\end{array}$} & \multicolumn{2}{c|}{$\begin{array}{c}\text { Annual Cooling Demand } \\
(\mathbf{k W h} / \text { year }\end{array}$} \\
\cline { 2 - 5 } & House A & House B & House A & House B \\
\hline $\begin{array}{l}\text { Validated Model (Safa } \\
\text { et al., 2015c) }\end{array}$ & 17557 & 18701 & 2313 & 2440 \\
\hline Combined Model & 17473 & 18596 & 2348 & 2469 \\
\hline Percent Difference (\%) & $0.48 \%$ & $0.56 \%$ & $-1.50 \%$ & $-1.18 \%$ \\
\hline
\end{tabular}

*Percent Difference $(\%)=($ Combined Model - Validated Model $) /$ Validated Model

However, these differences are justified due to the nature of the model and the differences in modelling techniques used. Due to the more refined placement of windows, the radiation modelling of the 3D house design is likely contributing to the higher peak. This can result in higher cooling demand peaks during the summer and higher heating demand peaks during the winter due to a higher window to wall ratio, i.e. reduced insulation, especially for the $3^{\text {rd }}$ floor of each house as some windows were not accounted in previous model due to implementation issues in previous software. Matching the cooling and heating demands would've resulted in much lower annual thermal demand. The combined model only used measurements to define the boundaries air nodes and neglected wall thicknesses in the 3D model, the total volume of each zone is lower than each 
respective zone in the validated model. This lower volume requires less total thermal energy to condition the spaces. As s result, the annual demands were matched, at the cost of higher peak loads.

\subsection{Simplification of House Model}

To simplify the HVAC system that is to be implemented in the TRNSYS house model, only a single primary hydronic loop was used. Unlike the original ASHs, where only House A and the dump load use the primary loop that contains the 50\% PG/water solution and House B used a hydronic loop with only water, the TRNSYS model uses 50\% PG/water solution to deliver heating/cooling to both houses. The use of a single hydronic loop prevents the loss of heating or cooling capacity through the flat plate heat exchanger that would occur in the actual HVAC design. The TRNSYS model uses a single hydronic loop that heats or cools the 50\% PG/water solution through operation of the GAHP. This heated or chilled fluid is then pumped into a single thermal storage tank with a total volume of $870 \mathrm{~L}$, a combination of the 3 thermal storage tanks in House B. From the thermal storage tank, the fluid is pumped through a single AHU that is designed to deliver heating or cooling to either House A or B depending on demand. The working fluid is then returned to the GAHP where the loop is completed.

This is simplified from the original ASHs, in where House A uses a radiant floor system to heat the basement and House B uses a radiant floor system to heat all 4 floors. House B also uses a multizone AHU to deliver cooling to each floor individually depending on demand. Since the simplified model only uses a single AHU to deliver both heating and cooling to either House A or B individually, the level of control possible in House B is not utilized. The single AHU used in the TRNSYS model, although not multizone in the same sense as the one originally implemented in House B where each floor is individually controlled. It is instead multizone in the sense that both House A and B are treated as separate zones, and heating and cooling can be delivered to either house individually or both at the same time. This is done by manipulating the division of energy that is output from the heating or cooling coil in the AHU.

As stated in Table 7.1, the peak values of House A and B for both heating and cooling are used to find the optimal division of energy distributed through both House A and B depending on demand. Once the division of the AHU output energy is split for House A and B, the energy for 
House A and B is again split to match the peak demand of each floor for both heating and cooling. Table 7.3 show peak heating and cooling values for each floor for both houses.

Table 7.3: Peak heating and cooling demand for each floor of each house in combined house model

\begin{tabular}{|l|c|c|c|c|}
\hline \multirow{2}{*}{ Zone } & \multicolumn{2}{|c|}{ House A } & \multicolumn{2}{c|}{ House B } \\
\cline { 2 - 5 } & $\begin{array}{c}\text { Peak Heating } \\
\text { Demand (kW) }\end{array}$ & $\begin{array}{c}\text { Peak Cooling } \\
\text { Demand (kW) }\end{array}$ & $\begin{array}{c}\text { Peak Heating } \\
\text { Demand (kW) }\end{array}$ & $\begin{array}{c}\text { Peak Cooling } \\
\text { Demand (kW) }\end{array}$ \\
\hline Basement & 0.77 & 0.00 & 0.84 & 0.00 \\
\hline First Floor & 1.97 & -0.95 & 2.67 & -1.14 \\
\hline Second Floor & 1.66 & -1.33 & 0.80 & -0.60 \\
\hline Third Floor & 2.97 & -3.16 & 4.41 & -3.62 \\
\hline
\end{tabular}

Using these peak demands, the ratios of how much heat is to be delivered to each zone relative to the entire house for both House A and B is evaluated and can be found in Table 7.4.

Table 7.4: Heating and cooling ratio for each floor for both houses with respect to total heating or cooling energy input into each house

\begin{tabular}{|l|c|c|c|c|}
\hline \multirow{2}{*}{ Zone } & \multicolumn{2}{|c|}{ House A } & \multicolumn{2}{c|}{ House B } \\
\cline { 2 - 5 } & $\begin{array}{c}\text { Heating } \\
\text { Ratio }\end{array}$ & $\begin{array}{c}\text { Cooling } \\
\text { Ratio }\end{array}$ & $\begin{array}{c}\text { Heating } \\
\text { Ratio }\end{array}$ & $\begin{array}{c}\text { Cooling } \\
\text { Ratio }\end{array}$ \\
\hline Basement & $10 \%$ & $0 \%$ & $10 \%$ & $0 \%$ \\
\hline First Floor & $27 \%$ & $18 \%$ & $31 \%$ & $21 \%$ \\
\hline Second Floor & $23 \%$ & $24 \%$ & $9 \%$ & $11 \%$ \\
\hline Third Floor & $40 \%$ & $58 \%$ & $51 \%$ & $68 \%$ \\
\hline
\end{tabular}

The basement shows to have no need for cooling for both House A and B as the annual temperature is consistently below the temperature setpoint of $24^{\circ} \mathrm{C}$ for cooling season. As expected, the third floor for house $\mathrm{B}$ requires the most heating and cooling, due to its larger volume and larger window/wall ratio compared to House A.

When combining the demand profile of both House A and B from the combined model, the peak heating demand is found to be $16.08 \mathrm{~kW}$ and the peak cooling demand to be $10.37 \mathrm{~kW}$. This combined house demand profile can be found in Figure 7.5. The annual thermal demand for heating and cooling was $35899 \mathrm{kWh}$ and $4847 \mathrm{kWh}$ respectively. 


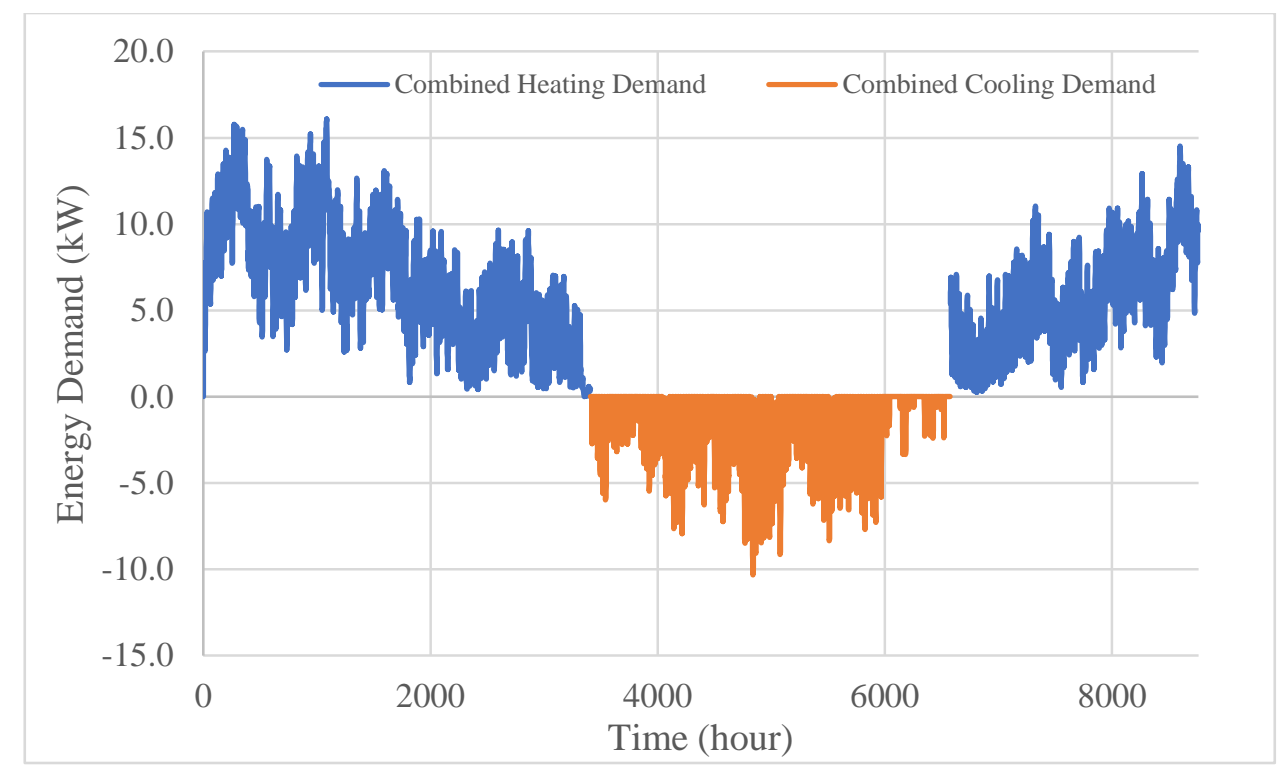

Figure 7.5: Combined house model annual energy demand profile for identical setpoints and season durations used in validated model

\subsection{Gas Absorption Heat Pump Model}

The GAHP model that was developed for both heating and cooling mode used only the performance curves observed through experimental evaluation. The TRNSYS model used to simulate the GAHP used a fixed flow rate, 13.4 GPM for heating mode and 12.6 GPM for cooling mode and used a control system designed to have a return temperature of $40^{\circ} \mathrm{C}$ in heating mode and $12^{\circ} \mathrm{C}$ in cooling mode. With these conditions, only the appropriate performance curve was used. Since some flow rate conditions do not have enough steady state data for the entire range of operating ambient outdoor temperatures for varying return fluid temperatures, further testing would be required to get a complete performance map at different operating conditions. Once a fuller performance map is acquired, interpolation between these conditions can be done.

The equations used to describe the performance curves of the GAHP in the TRNSYS models are the following.

For heating mode operation with a return temperature of $40^{\circ} \mathrm{C}$ and flow rate of $13.4 \mathrm{GPM}$ :

$\dot{Q}_{\text {Heating }}=-0.000207 T^{3}-0.00267 T^{2}+0.485 T+28.9$

Equation 7.1

For cooling mode operation with a return temperature of $12^{\circ} \mathrm{C}$ and flow rate of $12.6 \mathrm{GPM}$ : 
$\dot{Q}_{\text {Cooling }}=-0.0157 T^{2}+0.7387 T+7.139$

Equation 7.2

Where:

$T:$ is the ambient outdoor temperature in $\left({ }^{\circ} \mathrm{C}\right)$

$\dot{Q}_{\text {Mode }}:$ is the capacity of the GAHP for heating or cooling mode operation in $(\mathrm{kW})$

\subsubsection{Part Load Performance Modelling}

For part load performance modelling, Equations 6.4 and 6.5 would be used for both cooling and heating mode operation of the GAHP respectively. These formulas would evaluate the capacity of the cycles for each time step, modifying the capacity of the GAHP appropriately. However, this modelling does not account for the time from after the cycle is completed to when another cycle begins as this was assumed to turn off immediately at the end of each cycle. To model the part load performance effectively, a 1 minute time step was used in all simulations.

\subsection{Operation and Equipment Sizing}

For the sizing of the GAHP, the rated GAHP capacity corrected for $50 \% \mathrm{PG} /$ water is 30.7 $\mathrm{kW}$ for heating and $14.9 \mathrm{~kW}$ for cooling. However, these derated capacity values are through manufacturer data. Using the experimental performance curve seen in Equations 7.1 and 7.2 to solve for the GAHP heating and cooling capacity ratings at $7^{\circ} \mathrm{C}$ and $35^{\circ} \mathrm{C}$ respectively give a clearer perspective of the GAHP potential. The heating and cooling capacity solved at these temperatures are $32.1 \mathrm{~kW}$ and $13.8 \mathrm{~kW}$ respectively. From the temperatures that are used to rate the capacity of the GAHP it is clear that the system is inherently designed for milder climates, as it uses a fairly high temperature to rate the heating and cooling mode capacity. For the simulation however, these rating will be used to size the equipment appropriately with the locations being simulated.

In the model developed in TRNSYS, the dump load is not included to account for the excessive capacity, but instead the system is sized down to meet the demand. It should be noted, that he reasons that the GAHP provide much more heating capacity than cooling capacity for the house, is likely due to the fact that the GAHP was designed to provide both space heating and cooling, along with domestic water heating. This additional capacity is likely allotted for the DHW heating, which is not studied in detail in this project. The sizing will be done to meet the peak 
demands of the house for either heating or cooling season, whichever season peak load requires the highest sizing, as this will be the minimum required. This sizing will be applied to the GAHP and circulation pump power and GAHP operational power for heating and cooling season respectively. The GAHP and circulation pump power consumption can be found in Table 6.3 and 6.9, which will be sized down for each respective climate.

\subsection{Control Strategy}

The control strategy of the GAHP is designed to reduce potential for cycling with the use of the thermal storage tank in addition to the control built into the GAHP. The control system is designed to provide heating or cooling to either house depending on a multizone thermostat that monitors both houses. When either house calls for heating or cooling, a conditioning signal is sent to the GAHP to operate. This heated or cooled fluid is fed into a thermal storage tank. This thermal storage tank also sends a conditioning signal, one to turn the GAHP off when the temperature in the tank reaches a specified set point. For heating season, this set point is $48^{\circ} \mathrm{C}$ and $10^{\circ} \mathrm{C}$ for the cooling season. While this temperature is not met, the aquastat sends a signal to request the GAHP to charge the thermal storage tank. Finally, the GAHP has a control to turn off if the temperature of the fluid return to the GAHP is not at the specified value, which for the case of a return temperature of $40^{\circ} \mathrm{C}$ for heating or $12^{\circ} \mathrm{C}$ for cooling, the temperature must below or above these set points before the GAHP will consider operating. However, all three of the signals sent by the aquastat and thermostat can be contradictory. For this reason, the signals are multiplied to avoid charging the thermal storage tank when there is no actual demand and avoid operating the GAHP when the return temperature condition is not satisfied. If the thermal storage tank is completely charged but demand still exists, the GAHP is set to turn off, but the pump used to move the fluid through the AHU would still operate. This effectively will provide demand when needed while reducing the tendency for short cycling and remaining consistent with the designed control of the GAHP.

During the heating or cooling of each house, it should be noted that sometimes House A may need conditioning when House B does not and vice versa. For this reason, the energy of the GAHP is distributed among the houses based on peak demands. For heating season, $46 \%$ of the energy is sent to House A and 54\% to House B. For cooling season, the split is more even at 50\% for each house. Any unused energy is expected to be returned to the GAHP hydronic loop. 


\subsection{System Parameters and Effects}

During the modelling of the GAHP system, it was found that the thermal storage tank set point and dead band had a significant effect on the overall performance. For heating, a high aquastat set point allowed for the thermal storage tank to contain more energy which in turn helped maintain zone temperatures closer to the set points. Lower set points for the thermal storage however, resulted in less energy available for the zones, resulting in more unstable zone temperatures. Lower set points also run the risk of having the fluid return temperature be below the GAHP aquastat set point. Typically, this would only trigger the GAHP to operate, but along with requesting the GAHP to operate for longer periods thus increasing gas consumption, it also results in the return temperature diverging far below the range that the performance curve would be viable for. As such, there is a lower limit for the thermal storage set point for the heating model, which was approximately $48^{\circ} \mathrm{C}$. This case is similar with cooling mode, with the upper limit of approximately $10^{\circ} \mathrm{C}$. For both heating and cooling mode, increasing the dead band was also found to be beneficial for the system performance. High aquastat temperature dead bands resulted in more stable zone temperatures, but higher natural gas consumption, while lower dead bands results in times when zone set point is not reached for long periods due to constant fluctuation of tank temperature, resulting is more cycling of the system. For this heating model, a 30 second time step was used, whereas for the cooling model, a 1 minute time step was used. Due to the nature of the GAHP, using a hydronic system, lowering the time step improves the overall accuracy of the model. However, beyond 30 seconds resulted in unreasonable simulation times and no longer showed significant difference in the overall results.

The tank model that was used in the TRNSYS model is Type 534, which is a stratified thermal storage tank with no heat exchanger. However, this tank model allows for mixing to obtain uniform tank temperature. Mixing in the tank improved the zone temperatures of the model slightly. Higher tank volume similarly improved zone temperatures and also reduced natural as consumption. To account for heat loss through the tank, insulation was made ideal to prevent loss when the system was not operating. The zone thermostat dead band similarly had a significant effect. Higher dead bands allowed for more stable zone temperatures but resulted in significantly higher natural gas consumption. A dead band that was too low was found to cause a more unstable temperature, resulting in the GAHP trying to compensate and providing a slightly higher output (increased 
natural gas consumption) than required. A $1^{\circ} \mathrm{C}$ dead band was found to keep the system functioning at relatively uniform zone temperatures, while minimizing excessive thermal output. 


\section{TRNSYS Simulation Results and Analysis}

In this study, the GAHP performance will be evaluated using TRNSYS building simulations of the combined House A and House B model. A sensitivity analysis will be performed for a few key Canadian cities where the GAHP has the most potential as determined in Chapter 4 . The cities that the GAHP will be evaluated with the TRNSYS simulation are Toronto, Edmonton, Vancouver, Halifax and Montreal. Halifax and Montreal, although have high natural gas prices as they do not have a strong natural gas economy, are included in the analysis to see the effects of the GAHP in their respective climates.

\subsection{Locations and Sizing}

The combined house model used a set point temperature of $22^{\circ} \mathrm{C}$ during the heating season and $24^{\circ} \mathrm{C}$ for the cooling season. The seasons beginning and end times are stated in Table 4.2 in Section 4.2. Using these periods to define when the heating and cooling season begin and end, the peak demands and annual thermal demands of the combined houses at the desired setpoints for each location was simulated. These values are summarized in Table 8.1. As expected, Edmonton has the highest peak heating demand at $20.21 \mathrm{~kW}$, with Vancouver having the lowest at $10.21 \mathrm{~kW}$. Toronto has the highest peak cooling demand at $9.78 \mathrm{~kW}$ with Vancouver again having the lowest at $6.31 \mathrm{~kW}$. The sizing of the equipment would be done to match the peaks heating or cooling demands of the combined house, whichever has highest required size as this would be the minimum to meet demand. However, referring to Table 6.6 from earlier, it can be seen immediately that the peak heating demand seen in Table 8.1 of the combined house in the Edmonton climate is too high for the GAHP to provide for, even at full capacity. At the lowest temperature that the GAHP was experimentally evaluated, the heating capacity of the system is $18.97 \mathrm{~kW}$ for a return temperature of $40^{\circ} \mathrm{C}$ and a flow rate of $13.4 \mathrm{GPM}$. It should also be noted that the peak heating demand in Edmonton occurs when the outdoor ambient temperature is below $-30^{\circ} \mathrm{C}$, where as none of the experimentally evaluated data points were obtained lower than $-27.3^{\circ} \mathrm{C}$, as such, the extrapolated value during the simulation would be even lower at full capacity due the $3^{\text {rd }}$ order polynomial fit. 
Table 8.1: Heating and cooling peak demands and annual demands for combined house model in various Canadian cities

\begin{tabular}{|l|c|c|c|c|}
\hline Location & $\begin{array}{c}\text { Peak Heating } \\
(\mathbf{k W})\end{array}$ & $\begin{array}{c}\text { Annual Heating } \\
\text { Demand (kWh/year) }\end{array}$ & $\begin{array}{c}\text { Peak Cooling } \\
(\mathbf{k W})\end{array}$ & $\begin{array}{c}\text { Annual Cooling } \\
\text { Demand (kWh/year) }\end{array}$ \\
\hline Toronto & 16.59 & 40447 & 9.78 & 3843 \\
\hline Edmonton & 20.21 & 53357 & 8.71 & 2588 \\
\hline Vancouver & 10.21 & 30562 & 6.31 & 1731 \\
\hline Montreal & 18.11 & 44241 & 9.12 & 4223 \\
\hline Halifax & 15.72 & 41903 & 6.46 & 1594 \\
\hline
\end{tabular}

A similar case can be seen for Toronto, with its peak heating demand at 16.59 when sized down with respect to the peak demands, would reduce the capacity of the GAHP at its lowest outdoor operating temperatures below that of the peak heating demand. To size the GAHP for each location, new derated nominal values were solved. Using the conditions used by the manufacturer to rate for the nominal performance, the derated rated capacity was solved for the GAHP that was experimentally evaluated. At $7^{\circ} \mathrm{C}$, the heating capacity was evaluated to be $32.1 \mathrm{~kW}$ and at $35^{\circ} \mathrm{C}$ the cooling capacity was evaluated to be $13.8 \mathrm{~kW}$. Although it should be noted that the cooling capacity was extrapolated. Using these capacity values, the sizing was checked for each location. For all locations with the exception of Halifax, peak cooling demand is what required the highest sizing of the GAHP, where final sizing is listed in Table 8.2. As mentioned earlier in Chapter 4, the GAHP was designed for water heating and space heating, and as such has a much higher heating capacity relative to its cooling capacity.

Along with the heating capacity rating being defined by the GAHP operation during mild outdoor temperature, the capacity of the GAHP is not described well by the rating for the GAHP operation during very cold outdoor temperatures. However, since the GAHP is designed for small commercial buildings, using it at full capacity would add to its capital cost in analyzing the cost effectiveness of the GAHP. In addition, sizing to meet the demand at the lowest temperatures would result in oversizing for the GAHP during cooling mode operation. However, when simulated, the thermal storage tank was found to help accommodate for the lower thermal capacity and maintain the temperature setpoint of the building for the heating season for Toronto, Halifax and Vancouver. This was not the case for Edmonton and Montreal however, as supplementary heating was required to maintain thermally comfortable temperatures. The supplementary heater was controlled by the thermostat and only turned on when the zone temperatures fell below $20^{\circ} \mathrm{C}$. 
The supplementary heater is assumed to by a $90 \%$ efficient forced air furnace using natural gas as its primary fuel.

\subsection{Performance Analysis}

From the simulation results, it was found that the swing in capacity was significant for the heating mode operation of the GAHP. Figure 8.1 plots the GAHP output for Toronto for both heating and cooling season. In the plot, it can be seen that there is approximately a $10 \mathrm{~kW}$ difference from the highest potential capacity to the lowest. At its lowest, the GAHP was able to provide just enough heating output to meet the demand of the combined houses, as no supplementary heater was needed. As seen in Figure 8.1, the cooling capacity is nearly constant as the outdoor temperatures stay primarily within a range where the cooling capacity performance curve is shows linear characteristics. In the heating season, the loss of capacity during the coldest temperatures is significant. The GAHP for both seasons however, provide more heating and cooling than the actual demand of the combined house. This is primarily due to the fact that the GAHP does not have variable gas input, and at milder temperatures produces more capacity, capacity that is not necessarily needed. This extra capacity was designed to be used for DHW heating in addition to space heating, which shows that the GAHP may be better suited for different applications than that of residential. The thermal storage did have a noticeable effect by decreasing the overall GAHP output, but due to the control of the system, there is may still be potential for it to be further optimized. 


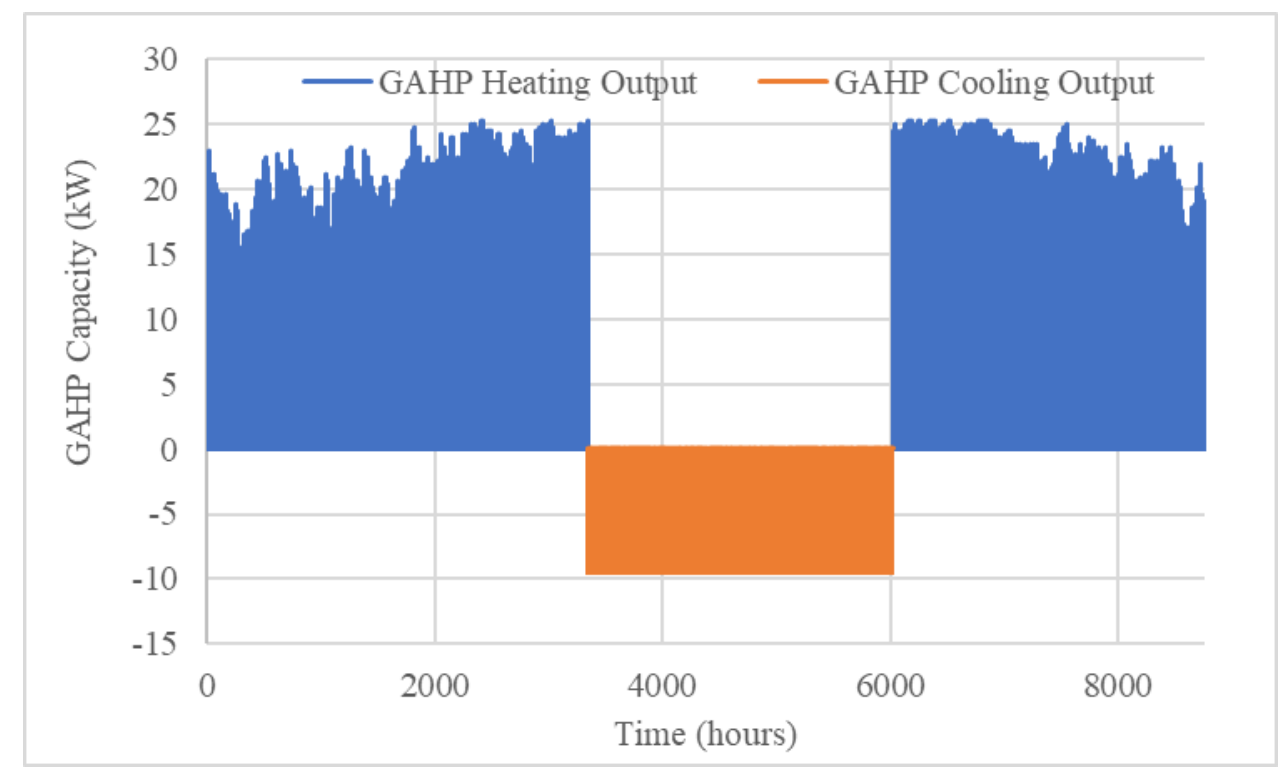

Figure 8.1: TRNSYS simulation GAHP output profile for heating and cooling season in the city of Toronto

Table 8.2 summarizes the heating performance characteristics of the GAHP in the five locations simulated for the sensitivity analysis. For Edmonton specifically, a supplementary heater was required, since the locations being studied were chosen due to their lower natural gas price and relatively high GHG emission factor from power generation, and to keep consistent with the primary heating fuel that is used, the auxiliary heater is assumed to be a forced air furnace with an efficiency of $90 \%$. The GUE for Edmonton is solved with the addition of the auxiliary heater output with the GAHP output, and the auxiliary gas consumption is included with the GAHP gas consumption. The GUE is significantly lower than expected for all cities for heating mode. The primary cause of this reduction is the incorporation of the part load performance. Due to the excessive cycling initiated by the control system the performance of the GAHP is dramatically decreased. Although the demand is met, along with the poorer performance of the GAHP during the coldest temperatures compared to the derated 50\% PG/water performance curves, part load performance is a significant factor that can only be minimized by decreasing the cycling by optimizing the control system.

With the addition of part load performance and the reduced heat transfer of the working fluid, the heating GUE is significantly lower than that of a typical furnace that would be used in a residential home. The circulation pump was on for most of the heating season for all five cities, resulting in high power consumption in that regard. The model will need to be more optimized to 
find a system that can fully utilize the GAHP potential to minimize the excessive cycling and thus consumption of natural gas, when the primary objective is to improve natural gas consumption.

Table 8.2: GAHP heating performance simulation results for various Canadian cities with part load performance

\begin{tabular}{|l|c|c|c|c|c|}
\hline \multicolumn{1}{|c|}{ Location } & \multicolumn{1}{l|}{$\begin{array}{l}\text { Toront } \\
\text { o }\end{array}$} & Edmonton & Vancouver & Montreal & Halifax \\
\hline Sizing Factor (-) & 0.70 & 0.63 & 0.45 & 0.66 & 0.49 \\
\hline $\begin{array}{l}\text { GAHP Heating Operating } \\
\text { Hours (hour) }\end{array}$ & 3884 & 4649 & 3888 & 4056 & 4582 \\
\hline GAHP Output (kWh) & 41706 & 50986 & 29906 & 44000 & 41247 \\
\hline $\begin{array}{l}\text { Auxiliary Heating Output } \\
\text { (kWh) }\end{array}$ & 0 & 1862 & 0 & 662 & 0 \\
\hline $\begin{array}{l}\text { Auxiliary Gas Input } \\
\text { (kWh) }\end{array}$ & 0 & 2069 & 0 & 736 & 0 \\
\hline Total Gas Input (kWh) & 78039 & 84062 & 50216 & 76827 & 64437 \\
\hline Gas Consumed (m $\left.{ }^{3}\right)$ & 7593 & 8179 & 4886 & 7475 & 6270 \\
\hline Pump Power (kWh) & 1722 & 1850 & 1104 & 1692 & 1416 \\
\hline GAHP Power (kWh) & 1552 & 1671 & 998 & 1528 & 1281 \\
\hline Heating GUE & 0.53 & 0.61 & 0.60 & 0.57 & 0.64 \\
\hline Heating COP & 0.51 & 0.59 & 0.57 & 0.55 & 0.61 \\
\hline
\end{tabular}

*Energy density of natural gas of is assumed to be $37 \mathrm{MJ} / \mathrm{m}^{3}$ (Statistics Canada, 2011)

Table 8.3 summarizes the GAHP cooling performance characteristics for the various locations. Due to the higher consumption during the cooling season, the GAHP in Montreal has the lowest cooling GUE among the cities. The GUE of all cities was consistently around 0.40, similarly to the heating performance, is exceptionally low due to excessive cycling and inherently poor performance during cooling mode operation. The cycles in both modes would be exceptionally short as to not operate at steady state enough to significantly show feasible use of the GAHP. The GAHP does not show to be a feasible technology under the current setup using $50 \%$ PG/water as the primary fluid, as the heat transfer effectiveness is far too reduced, in cycling is still a key issue, due to the interaction of the control signals in the system. An effective GAHP should have a high GUE during the heating season, high enough that it could potential offset the high natural gas consumption of the GAHP during the cooling season. Programs such as carbon cap and trade would not be effective with the GAHP under these conditions, as there are other technologies readily available with higher overall efficiencies. 
Table 8.3: GAHP cooling performance simulation results for various Canadian cities with part load performance

\begin{tabular}{|l|c|c|c|c|c|}
\hline \multicolumn{1}{|c|}{ Location } & Toronto & Edmonton & Vancouver & Montreal & Halifax \\
\hline Sizing Factor (-) & 0.70 & 0.63 & 0.45 & 0.66 & 0.49 \\
\hline $\begin{array}{l}\text { GAHP Cooling } \\
\text { Operating Hours (hour) }\end{array}$ & 595 & 396 & 371 & 670 & 316 \\
\hline GAHP Output $(\mathrm{kWh})$ & 3857 & 2545 & 1822 & 4090 & 1659 \\
\hline Total Gas Input $(\mathrm{kWh})$ & 11948 & 7155 & 4787 & 12687 & 4446 \\
\hline Gas Consumed $\left(\mathrm{m}^{3}\right)$ & 1162 & 696 & 466 & 1234 & 433 \\
\hline Pump Power $(\mathrm{kWh})$ & 359 & 230 & 132 & 373 & 125 \\
\hline GAHP Power $(\mathrm{kWh})$ & 204 & 122 & 82 & 217 & 76 \\
\hline Cooling GUE & 0.32 & 0.36 & 0.38 & 0.32 & 0.37 \\
\hline Cooling COP & 0.31 & 0.34 & 0.36 & 0.31 & 0.36 \\
\hline
\end{tabular}

*Density of natural gas of is assumed to be $37 \mathrm{MJ} / \mathrm{m}^{3}$ (Statistics Canada, 2011)

However, when part load performance is not considered in the TRNSYS model, the GAHP model shows performance similar to that which was found in the screening tool in Chapter 4. Tables 8.4 and 8.5 summarize the performance of the GAHP for both heating and cooling season without part load performance. From both tables, the heating and cooling GUEs were found to be close to that which was found in the screening tool developed in Excel. It should be noted that the Excel tool only evaluates the GAHP performance of House A, while the TRNSYS model evaluates the performance for both House A and B. However, the overall performance for the houses, which are fairly identical in terms of building envelope and structure, have shown to have GUE values as expected, below 100\% for all cities except Vancouver. 
Table 8.4: GAHP heating performance simulation results for various Canadian cities with no part load performance

\begin{tabular}{|l|c|c|c|c|c|}
\hline \multicolumn{1}{|c|}{ Location } & Toronto & Edmonton & Vancouver & Montreal & Halifax \\
\hline Sizing Factor (-) & 0.70 & 0.63 & 0.45 & 0.66 & 0.49 \\
\hline $\begin{array}{l}\text { GAHP Heating } \\
\text { Operating Hours (hour) }\end{array}$ & 2091 & 3187 & 2063 & 2499 & 2940 \\
\hline GAHP Output (kWh) & 39652 & 49723 & 28933 & 42413 & 40461 \\
\hline $\begin{array}{l}\text { Auxiliary Heating } \\
\text { Output (kWh) }\end{array}$ & 0 & 1981 & 0 & 651 & 0 \\
\hline $\begin{array}{l}\text { Auxiliary Gas Input } \\
\text { (kWh) }\end{array}$ & 0 & 2201 & 0 & 723 & 0 \\
\hline Total Gas Input (kWh) & 42000 & 57619 & 26644 & 47330 & 41341 \\
\hline Gas Consumed (m $\left.{ }^{3}\right)$ & 4086 & 5606 & 2592 & 4605 & 4022 \\
\hline Pump Power (kWh) & 1441 & 1617 & 769 & 1450 & 1112 \\
\hline GAHP Power (kWh) & 835 & 1146 & 530 & 941 & 822 \\
\hline Heating GUE & 0.94 & 0.86 & 1.09 & 0.90 & 0.98 \\
\hline Heating COP & 0.90 & 0.83 & 1.04 & 0.85 & 0.93 \\
\hline
\end{tabular}

This suggests that part load performance has a significant impact. Although thermal storage was incorporated in the overall system, the control algorithm that was used resulted in the thermal storage fluid temperature fluctuating near the set point, which was one of the main sources of short cycling. With the similar performance of the TRNSYS model and the screening tool, this suggests that even if part load performance as a result of cycling is reduced, the fluid choice still brings the efficiency of the GAHP down to a point where it is marginally competitive against a forced-air furnace, performance wise. From Table 8.5, the consistency of the performance of the GAHP during cooling mode is similar to that of the screening tool. However, the performance is slightly reduced, similar to the heating performance when no part load is included. In addition to modelling different buildings, it is possible that the lower performance of the experimental curves results in slightly lower GUE values. 
Table 8.5: GAHP cooling performance simulation results for various Canadian cities with no part load performance

\begin{tabular}{|l|l|l|l|l|l|}
\hline \multicolumn{1}{|c|}{ Location } & Toronto & Edmonton & Vancouver & Montreal & Halifax \\
\hline Sizing Factor $(-)$ & 0.70 & 0.63 & 0.45 & 0.66 & 0.49 \\
\hline $\begin{array}{l}\text { GAHP Cooling } \\
\text { Operating Hours (hour) }\end{array}$ & 352 & 257 & 258 & 394 & 215 \\
\hline GAHP Output $(\mathrm{kWh})$ & 3860 & 2543 & 1819 & 4092 & 1660 \\
\hline Total Gas Input $(\mathrm{kWh})$ & 7077 & 4647 & 3328 & 7472 & 3024 \\
\hline Gas Consumed $\left(\mathrm{m}^{3}\right)$ & 689 & 452 & 324 & 727 & 294 \\
\hline Pump Power $(\mathrm{kWh})$ & 314 & 211 & 118 & 317 & 107 \\
\hline GAHP Power $(\mathrm{kWh})$ & 121 & 79 & 57 & 128 & 52 \\
\hline Cooling GUE & 0.55 & 0.55 & 0.55 & 0.55 & 0.55 \\
\hline Cooling COP & 0.51 & 0.52 & 0.52 & 0.52 & 0.52 \\
\hline
\end{tabular}

\subsection{Operational Cost Comparison with Forced Air Furnace}

For the cost analysis, the consumption of the GAHP (GAHP and auxiliary heater in Edmonton's case) during heating mode is compared to 3 cases. These 3 cases will represent that of a forced air furnace with an $85 \%, 90 \%$ and $95 \%$ efficiency. The natural gas consumption of the forced air furnaces is solved by assuming the furnaces meet the thermal demand of the house for heating exactly. The annual demand values from Table 8.1 are divided by the respective furnace case efficiencies to obtain the energy of the natural gas input, which is then converted into LNG volume to evaluate the pricing estimate when comparing to the GAHP. During the cooling season, electric air conditioners are more established, and since natural gas is not commonly used as a primary fuel during the cooling season, cooling season is excluded. Table 8.4 summarizes the natural gas consumption of the forced air furnace with respect to the annual heating demand of the combined home. 
Table 8.6: Annual thermal demand and respective natural gas consumption for 2 cases of forced air furnaces with different efficiencies in various Canadian cities

\begin{tabular}{|l|c|c|c|c|}
\hline Location & $\begin{array}{c}\text { Annual } \\
\text { Heating } \\
\text { Demand } \\
(\mathbf{k W h} / \mathbf{y e a r})\end{array}$ & $\begin{array}{c}\text { Gas } \\
\text { Consumption } \\
\left.\text { Case 1 } \mathbf{( m}^{\mathbf{3}}\right)\end{array}$ & $\begin{array}{c}\text { Gas } \\
\text { Consumption } \\
\left.\text { Case 2 } \mathbf{( m}^{\mathbf{3}}\right)\end{array}$ & $\begin{array}{c}\text { Gas } \\
\text { Consumption } \\
\left.\text { Case 3 } \mathbf{( m}^{\mathbf{3}}\right)\end{array}$ \\
\hline Toronto & 40447 & 4630 & 4373 & 4143 \\
\hline Edmonton & 53357 & 6108 & 5768 & 5465 \\
\hline Vancouver & 30562 & 3498 & 3304 & 3130 \\
\hline Montreal & 44241 & 5064 & 4783 & 4531 \\
\hline Halifax & 41903 & 4797 & 4530 & 4292 \\
\hline
\end{tabular}

*Density of natural gas of is assumed to be $37 \mathrm{MJ} / \mathrm{m}^{3}$ (Statistics Canada, 2011)

Tables 8.7 - 8.9 compare the cost of natural gas in each region using marginal cost rates from Table 4.8, for the GAHP without part load against all three cases of forced air natural gas furnaces during the heating season. It should be noted that the GAHP with part load performance was not compared in the following tables, since the furnace cases considered do not account for part load performance. When GAHP performance with part load performance is compared to furnaces with no part load however, even at the lowest furnace efficiency (85\% GUE), Edmonton, which has the most affordable natural gas economy, has an operational cost difference of $-\$ 146$. Suggesting more expensive operation when using the GAHP, due to the lower performance that resulted from part load operation due to short cycling.

Table 8.7: Operational cost comparison of GAHP during heating season and forced air furnace with efficiency of $85 \%$ in various Canadian cities

\begin{tabular}{|l|c|c|c|c|c|}
\hline \multicolumn{1}{|c|}{ Location } & Toronto & Edmonton & Vancouver & Montreal & Halifax \\
\hline Furnace Heating Cost $(\$)$ & 1131.08 & 992.06 & 862.06 & 2225.07 & 3334.17 \\
\hline GAHP Heating Cost $\$$ ) & 998.21 & 910.58 & 638.72 & 2023.34 & 2795.77 \\
\hline Difference (\$) & 132.87 & 81.48 & 223.34 & 201.73 & 538.40 \\
\hline
\end{tabular}

Table 8.8: Operational cost comparison of GAHP during heating season and forced air furnace with efficiency of $90 \%$ in various Canadian cities

\begin{tabular}{|l|c|c|c|c|c|}
\hline \multicolumn{1}{|c|}{ Location } & Toronto & Edmonton & Vancouver & Montreal & Halifax \\
\hline Furnace Heating Cost (\$) & 1068.24 & 936.95 & 814.17 & 2101.46 & 3148.94 \\
\hline GAHP Heating Cost (\$) & 998.21 & 910.58 & 638.72 & 2023.34 & 2795.77 \\
\hline Difference (\$) & 70.03 & 26.36 & 175.45 & 78.11 & 353.17 \\
\hline
\end{tabular}


Table 8.9: Operational cost comparison of GAHP during heating season and forced air furnace with efficiency of $95 \%$ in various Canadian cities

\begin{tabular}{|l|c|c|c|c|c|}
\hline \multicolumn{1}{|c|}{ Location } & Toronto & Edmonton & Vancouver & Montreal & Halifax \\
\hline Furnace Heating Cost (\$) & 1012.02 & 887.63 & 771.32 & 1990.85 & 2983.20 \\
\hline GAHP Heating Cost (\$) & 998.21 & 910.58 & 638.72 & 2023.34 & 2795.77 \\
\hline Difference (\$) & 13.81 & -22.95 & 132.60 & -32.49 & 187.44 \\
\hline
\end{tabular}

As it can be seen the cost difference of natural gas during heating mode of the GAHP becomes increasingly lower as the efficiency of the forced air furnace approaches the values closer to the most efficient furnaces available. Due to the lower performance of the GAHP in Edmonton, when part load is not included, operational cost benefits of the GAHP are minimal when compared to the natural gas furnaces. Interestingly, the highest potential cost savings when comparing the GAHP to the forced air furnaces occur in regions where natural gas is not a primary heating fuel, and as such would not have common application due to higher natural gas prices to start with.

Improving the performance of the HVAC system so that it would allow the GAHP to provide heating and cooling with the optimization of the control system and thermal storage should be investigated, as there is potential as seen in Chapter 4. But due to the lower GUE values as seen through the experimentally collected data, improvements on capacity must be significant before such a system may be more widely feasible in the Canadian climate.

\subsection{Model Limitations}

The GAHP TRNSYS model has several areas for improvement and further investigation to improve the simulation results to better match with expected performance. Some key issues that arose in the model are found in the control system, tank model, available data, and GAHP model.

For the control system, it was found that the aquastat that controlled the tank temperature resulted in a lot of cycling signals. The aquastat that was connected to the thermal storage tank was set to read the average tank temperature and request heating (or cooling) as long as the temperature in the tank was below (or above for cooling) the setpoint temperature of the aquastat. The temperatures set for the aquastat were similar to that which was set for the thermal storage tanks at the experimental site, the ASHs. However, the pump was signalled to be on for a majority of the time. Due to the nature of the designed control system, all three signals: the aquastat of the thermal storage tank, the aquastat for the fluid returning to the GAHP and the thermostat calling 
for heating or cooling into the zones of the houses, needed to be on for the GAHP to operate. With the aquastat of the thermal storage tank being the bottleneck in this simulation, it created a situation where the thermal storage tank was kept fluctuating near the aquastat setpoint. This was a result of the tank being heated quickly and discharged just as quickly even with a $4^{\circ} \mathrm{C}$ dead band. This also requires further investigation of the TRNSYS tank model that was used. Type 534 thermal storage tank was used with a volume of $870 \mathrm{~L}$ to be the thermal storage for both House A and House B. Since the thermal storage tank had an average tank temperature that was fluctuating enough to trigger cycling in the control system; a new control method that would optimize the tank for long term thermal storage potential needs to be investigated. This cycling behaviour was also seen during the experimental evaluation of the GAHP, showing that this issue also exists during the experimental evaluation at times as well.

Nevertheless, the most significant limitation in the model is the lack of experimental data points to complete the performance curves of the cooling performance map for varying return temperatures. During cooling mode modelling, there were periods where the set point was not maintained. This occurrence was a result of the fluid flowing through the AHU diverging from the range for the performance curve before being corrected. This issue was not as prevalent during heating mode. To account for this, a more detailed GAHP model will need to be developed using more experimental data to complete the performance map. With additional data, interpolation between the curve would be more effective and changes in capacity due to varying return temperatures can be better reflected in the simulation. A detailed parametric model should be developed to account for direct capacity that can be delivered to the house for varying flow rates and return temperatures. However, the current model gives an understanding of finding key limitations that need to be optimized to improve the performance of the GAHP for the heating and cooling season. 


\section{Conclusions and Recommendations}

The objective of this research was to investigate the performance of an outdoor GAHP unit in the cold Canadian climate using 50\% PG/water solution as the working fluid, to develop a performance map. The experimental evaluation was carried out in a testing facility known as the Archetype Sustainable Houses (ASH) located in the Kortright center in Vaughan, Ontario. The $\mathrm{ASH}$ is a twin house that was designed for the evaluation of different technologies and building methods. For this study, the experimental testing was carried out by reworking the HVAC and hydronic system of both houses to create a unified system to deliver heating and cooling to both House A and House B. A 50\% PG/water working fluid was used due to its low freezing point, allowing the GAHP to operate in the Canadian climate.

\subsection{Simplified Screening Model}

An Excel tool was developed to simulate the performance of the GAHP by derating the manufacturer data, originally rated for a working fluid of water, for $50 \% \mathrm{PG} /$ water. At nominal flow rates and return temperatures, the model simulates the GAHP performance for any building model demand profile over an entire year for both heating and cooling seasons. The model uses a 5 minute time step since the GAHP control that was implemented in the tool is controlled by the return temperature of the primary working fluid in a hydronic closed loop. A small time step provided the opportunity to identify more precisely the extent of cycling that would occur in the operation of the GAHP. The building model demand profile that was simulated was that of a validated model of House A. House A however, was oversized and as such the GAHP was sized appropriately to meet the peak demand of the building model. The GAHP simulation tool was designed to meet the load of the building model demand profile exactly, presenting a case where the GAHP provides the ideal amount of heating and cooling.

This derated GAHP model was simulated in 5 different Canadian cities to investigate its potential in their respective climates. The cities that the simulation tool was used to investigate were Toronto, Montreal, Edmonton, Vancouver and Halifax. The city that showed to have the highest heating GUE was found to be Vancouver. This is expected since the GAHP had its highest performance in milder temperatures. The heating GUE in Vancouver was found to be $108 \%$ with Edmonton was found to have the lowest heating GUE with $90 \%$ efficiency. Only Vancouver had a GUE above $100 \%$ when using 50\% PG/water. The lower GUE for all other cities are primarily 
due to the colder temperatures in their respective climates. The lowest GUE from the derated nominal performance curve is approximately 74\%. Due to the GAHP operating at the lowest end of the performance curve more frequently in Montreal and Edmonton especially, the overall heating GUE is decreased. Halifax, with a GUE of 99\%, in addition to Vancouver were the only cities to achieve a GUE that was higher than the most efficient furnaces available currently. When compared to a $90 \%$ efficient forced air furnace, a GHG emission reduction analysis found that the GAHP had reduced emission relative to a forced air furnace during the heating season for all cities but Edmonton, when using 50\% PG/water. However, when using the screening tool for original manufacturer performance data for water, the GAHP showed exceptional performance. This demonstrates that a working fluid with more effective heat transfer is required for the GAHP to be viable in most Canadian climates.

For cooling the season, the GUE of all cities were consistent at around 58\%, this is likely due to the milder temperatures during the cooling season for Canadian climates. From the performance curve provided by the manufacturer, it can be seen that performance remains fairly linear in relation to nominal flow and return temperature, even through hotter temperatures. Along with cooling and heating performance of the GAHP, the system was compared to that of an ASHP, which was experimentally evaluated in House A as well. This ASHP performance was evaluated in a different study and a sensitivity study was similarly performed for the same Canadian cities. An operational cost analysis was done for both units, investigating the potential cost savings of the GAHP due to a more affordable primary fuel, relative to the ASHP which uses only electricity as its primary fuel. It was found that in regions where natural gas was a primary heating fuel: Toronto, Edmonton and Vancouver, there were cost savings. Toronto and Edmonton had the most significant cost savings with $\$ 260$ for Edmonton and $\$ 54$ for Toronto when using the GAHP compared to the ASHP. However, Vancouver actually showed to have a alight loss of about \$-2. This is a result of the milder climate in Vancouver which resulted in highly efficient performance of the ASHP which, in addition to more affordable electricity prices, was also more cost effective than the GAHP. Although it should be noted that the capital cost of the GAHP was significantly lower than the ASHP, if used for more than a single residential unit and cost is divided among each unit. Overall, the tool suggests that the GAHP has potential in regions where natural gas is a primary fuel through reduced operational cost, reduced GHG emissions compared to standard heating appliances and higher efficiency during the heating season under certain conditions. The 
primary condition is when the GAHP uses fluids with heat transfer potential that is closer to or better than water, which is what the unit was originally rated for.

\subsection{Experimental Performance Evaluation}

During the experimental performance evaluation of the GAHP, it was found that the GAHP had some significant draw backs, primarily due to the use of a 50\% PG/water solution as the primary working fluid during the heating season. When evaluated during the heating season, it was found that the GUE of the GAHP was significantly reduced during the coldest ambient outdoor temperatures, below what is expected from the derating of the 50\% PG/water. The GUE, at its lowest temperature was found to have a $20.7 \%$ decrease in GUE compared to the manufacturer performance data for a primary fluid of water. The derate factor provided by the manufacturer would suggest a decrease in performance of $12.2 \%$ by using a $50 \% \mathrm{PG} /$ water fluid. This decrease in performance has several possible factors. The gas input that was used in the experimental evaluation was 98 BTU $(28.7 \mathrm{~kW})$ which was above the GAHP rated gas input of $95.5 \mathrm{BTU}$ (28 $\mathrm{kW})$. Due to this, more energy could have been input into the internal GAHP heat exchangers than was originally designed for, potentially not utilizing the extra energy. Another source of error was the fact that the GAHP was being field tested and not under strict lab conditions, as such weather had the potential to decrease the performance of the GAHP even further. Since the lowest performing data points were collected at temperatures below $-25^{\circ} \mathrm{C}$, snow and ice buildup obstructing the flow of ambient air into the GAHP could possibly also reduce the performance of the system. However, since there was no monitoring of the internal system of the GAHP, this can not be confirmed. Another factor that likely results in the reduction of the GAHP performance is the properties of the $50 \% \mathrm{PG} /$ water being affected by the ambient outdoor temperature, resulting in lower heat transfer potential of the GAHP.

Although during the coldest temperatures, the GAHP shows to have lower performance than expected, at higher ambient outdoor temperatures, the GAHP was found to have slightly higher performance than suggested by the PG/water derate factors. At its highest heating GUE during experimental evaluation, it was found to only be lower than manufacturer heating GUE by $10 \%$, when the expected decrease in performance was $12 \%$. This also neglects any effect on how the increased gas input was utilized in the GAHP. However, in the perspective of using the GAHP in the cold Canadian climate, the system does not show to be promising due to very low performance 
during heating season. It was found that the GAHP was only capable of having a heating GUE of above $100 \%$ when the ambient temperatures were above $-1.5^{\circ} \mathrm{C}$. With current forced air furnaces operating at efficiency greater than 66\%, the lowest GUE of the GAHP, the GAHP may not be capable of sufficiently providing heating at efficient standards with the current HVAC system that was implemented without further optimization and improvements.

During the cooling season, the performance of the GAHP operated to have a GUE value that was fairly consistent with expected derating of the GAHP performance. However, from the experimental work it was noticed that neither flow rate or return temperature had a significant effect on the cooling performance of the system. Due to limited data, further experimentation is required to collect more steady state points to complete the performance map of the cooling mode operation of the GAHP to distinguish any differences in performance from changing return temperature, as it was seen that flow rate had minimal effect on the performance for both heating and cooling mode operation of the GAHP.

\subsection{TRNSYS Simulation Results}

The TRNSYS simulation had limitations due to the control that was implemented, which resulted in excessive cycling. This control was modelled to be as similar as possible to the experimental set up. It was found that due to the cycling, the performance was significantly reduced. The decreased capacity of the GAHP for both heating and cooling season also played a factor in the reduced overall seasonal GUEs of the GAHP. From the simulation the heating GUE values ranged from 0.53 to 0.64 , and cooling GUEs ranged from 0.32 to 0.38 . These GUE values are significantly lower than those found using the screening tool that was discussed in Chapter 4. The Excel simulation did not consider part load performance and used a standard derate factor, however. It is clear that the control requires to be optimized to minimize the part load operation of the GAHP. Identifying solutions that reduce the interaction of the control signals should be investigated, as all three signals add sources of cycling, the effect which is compounded when each signal is not in agreement. Thermal storage should also be investigated to find methods to allow the tanks to discharge for longer periods and have a control that is not entirely focused on maintaining a tank temperature, but to charge the tank instead. When the simulation was run without part load, the values were similar to that of the screening tool, showing that the tool shows close agreement with 3D TRNSYS simulations in similar regions. 


\subsection{Future work and Recommendations}

The model that was developed was limited to the application of a single performance curve due to the limited data available to develop a full performance map, especially for the cooling season. Further investigation is required to develop a more detailed GAHP model, including investigating different control methods to optimize GAHP control. Thermal storage requires further investigation to identify how long term thermal storage can be implemented. It is clear that the aquastat of the thermal storage tank had significant cycling due to how it is implemented in the model. Finding different methods to incorporate the thermal storage, whilst remaining within the GAHP operating range should be investigated. In addition to improving the control aspect of the GAHP to optimize its performance, investigation should also be made to improve the overall efficiency of the system at low ambient temperatures. From experimental work, the heat transfer potential sacrificed with the use of $50 \%$ PG/water is significant and methods to limit the losses should be investigated.

One such method would be to increase the insulation of the piping outdoors in order to reduce the required PG ratio needed to prevent freezing. This may be done by evaluating how much insulation thickness is required to reduce the heat loss of the outdoor pipes, allowing the freezing point of the working fluid to be raised, improving the heat transfer potential. Another option is to use a different working fluid that will have similar properties to prevent freezing but maintain high heat transfer potential. Investigating options to use nanoparticle slurries that are compatible with HVAC equipment with antifreeze additives could improve the GAHP to operate efficiently in the Canadian climate. Another suggestion is to evaluate if exhaust air from the building can be used to improve the temperature of air going through the GAHP, improving the overall GUE of the system. The possibility of reusing the flue gases can also be investigated to further improve the efficiency of the GAHP. However, whether or not all these options are cost effective and provide enough enhancement to the GAHP to make it a viable HVAC unit to be used in cold climate requires further research. 


\section{Appendices}

\section{Appendix A - Marginal Cost Breakdown for Natural Gas and Electricity}

For all cost breakdowns, fixed costs such as monthly customer cost is not included in the marginal pricing for both natural gas or electricity rates.

Table A - 1: Cost breakdown used to evaluate marginal natural gas prices for various Canadian cities (EnergyShop, 2018; Heritage Gas, 2017; Energir, 2017)

\begin{tabular}{|c|c|c|}
\hline Location & Cost Description & Rate $(\$ / \mathbf{m 3})$ \\
\hline \multirow{5}{*}{ Toronto } & Gas Supply Cost & 0.0945 \\
\hline & Cost Adjustment & 0.0021 \\
\hline & Delivery & 0.1002 \\
\hline & Transportation & 0.0475 \\
\hline & Total Marginal Cost & 0.2443 \\
\hline \multirow{8}{*}{ Montreal** } & Gas Supply Cost & 0.1300 \\
\hline & Transportation & 0.0344 \\
\hline & Load Balancing & 0.0547 \\
\hline & Distribution (first $30 \mathrm{~m}^{3}$ ) & 0.2710 \\
\hline & Distribution $\left(\right.$ next $\left.70 \mathrm{~m}^{3}\right)$ & 0.1850 \\
\hline & Distribution (next $200 \mathrm{~m}^{3}$ ) & 0.1599 \\
\hline & $\begin{array}{l}\text { Cap and Trade Emission } \\
\text { Allowances System } \\
\text { (CTEAS) Service Rate }\end{array}$ & 0.0350 \\
\hline & Total Marginal Cost & 0.4394 \\
\hline \multirow{4}{*}{ Edmonton* } & Gas Supply Cost & 0.1191 \\
\hline & Delivery & 0.0377 \\
\hline & Transportation & 0.0052 \\
\hline & Total Marginal Cost & 0.1624 \\
\hline \multirow{4}{*}{ Vancouver* } & Gas Supply Cost & 0.0574 \\
\hline & Delivery & 0.1613 \\
\hline & Transportation & 0.0281 \\
\hline & Total Marginal Cost & 0.2464 \\
\hline \multirow{4}{*}{ Halifax* } & Gas Supply Cost & 0.3213 \\
\hline & Gas Cost Recovery Rate & 0.3571 \\
\hline & Municipal Tax & 0.0167 \\
\hline & Total Marginal Cost & 0.6951 \\
\hline
\end{tabular}

*Cities gas rates converted from $\$ / \mathrm{GJ}$ to $\$ / \mathrm{m}^{3}$ assuming $37 \mathrm{MJ} / \mathrm{m}^{3}$ (Statistics Canada, 2011)

**Assuming average of $200 \mathrm{~m}^{3}$ natural gas consumption per billing period 
Table A - 2: Cost breakdown used to evaluate marginal electricity prices for various Canadian cities (EnergyShop 2018; Nova Scotia Power, 2017; Hydro Québec, 2018)

\begin{tabular}{|l|l|c|}
\hline Location & Cost Description & Rate $\mathbf{( \$ / k W h )}$ \\
\hline \multirow{5}{*}{ Toronto* } & Distribution & 0.0140 \\
\cline { 2 - 3 } & Transmission & 0.0100 \\
\cline { 2 - 3 } & $\begin{array}{l}\text { System Operation and } \\
\text { Regulation }\end{array}$ & 0.0060 \\
\cline { 2 - 3 } & Supply On-Peak (6 hours) & 0.1320 \\
\cline { 2 - 3 } & Supply Mid-Peak (6 hours) & 0.0945 \\
\cline { 2 - 3 } & Supply Off-Peak (12 hours) & 0.0650 \\
\cline { 2 - 3 } Montreal & Total Marginal Cost & 0.1122 \\
\hline \multirow{4}{*}{ Edmonton } & $\begin{array}{l}\text { Supply (first 1080 kWh per } \\
\text { billing period) }\end{array}$ & 0.0512 \\
\cline { 2 - 3 } & Supply & 0.0680 \\
\cline { 2 - 3 } & Delivery & 0.0058 \\
\hline Vancouver & Sotal Marginal Cost & 0.0738 \\
\hline Halifax & Supply & 0.0884 \\
\hline
\end{tabular}

*Time-of-Use (TOU) energy use considers weekend to be at off-peak pricing 


\section{Appendix B - 50\% PG/Water Solution Thermal Properties}

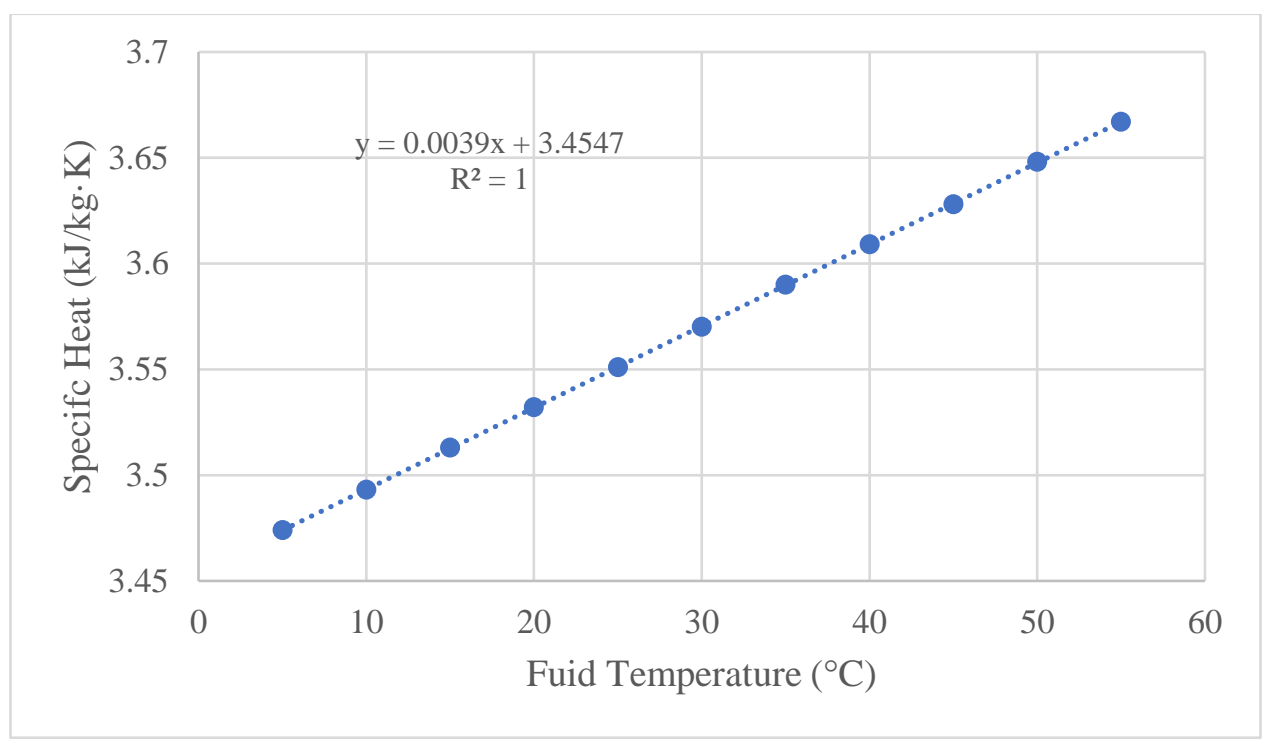

Figure B - 1: Correlation of fluid specific heat and fluid temperature for 50\% PG/water solution (Dow Chemical, 2008)

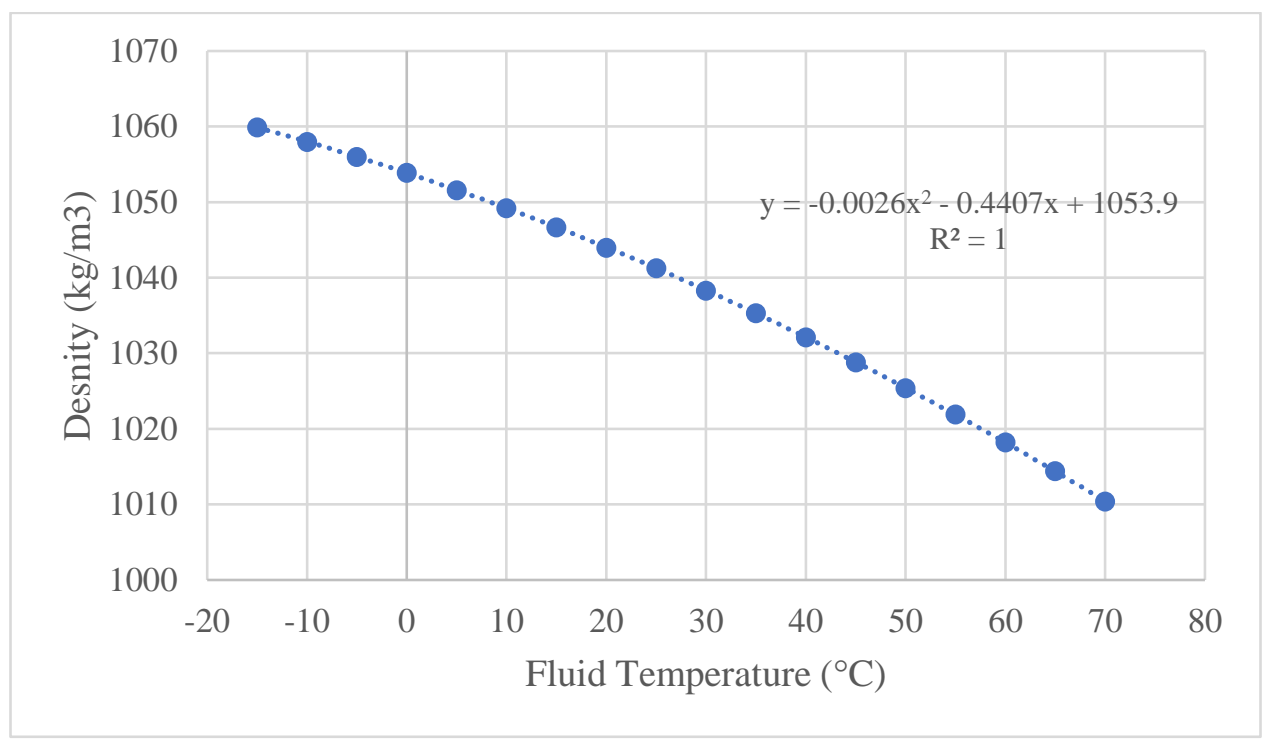

Figure B - 2: Correlation of fluid density and fluid temperature for 50\% PG/water solution (Dow Chemical, 2008) 
Table B - 1: Propylene glycol correction factors provided by GAHP Manufacturer (Robur Corporation, 2017)

\begin{tabular}{|l|c|c|c|c|c|c|c|}
\hline Percent Propylene Glycol $(\boldsymbol{\%})$ & $\mathbf{1 5 \%}$ & $\mathbf{2 0 \%}$ & $\mathbf{2 5 \%}$ & $\mathbf{3 0 \%}$ & $\mathbf{3 5 \%}$ & $\mathbf{4 0 \%}$ & $\mathbf{5 0 \%}$ \\
\hline Approximate Freezing Point $\left({ }^{\circ} \mathrm{F}\right)$ & $24^{\circ}$ & $18^{\circ}$ & $15^{\circ}$ & $9^{\circ}$ & $5^{\circ}$ & $-5^{\circ}$ & $-30^{\circ}$ \\
\hline Capacity Factor Multiplier* & 0.992 & 0.986 & 0.972 & 0.960 & 0.950 & 0.928 & 0.878 \\
\hline
\end{tabular}

*Evaluated at Standard ARI 590 conditions: 54 entering fluid temperature, 44 leaving fluid temperature, 95 ambient temperature, 0.0005 Fouling (Robur Corporation, 2017) 


\section{Appendix C - Sample GAHP Heating and Cooling Cycles}

The following cycles were used in the cycle derate analysis. These cycles are shown here to give a visual representation of the cycle profiles for both heating and cooling. In each figure, the start of the cycle, the start of the steady state period of the cycle, and the end of the cycle is distinguished. Cycle begins when natural gas is input into the GAHP. Steady state is assumed to start at $90 \%$ of steady state value. Cycle ends once natural gas input in the GAHP ends. Natural gas is scaled to visually present when gas input begins and ends.

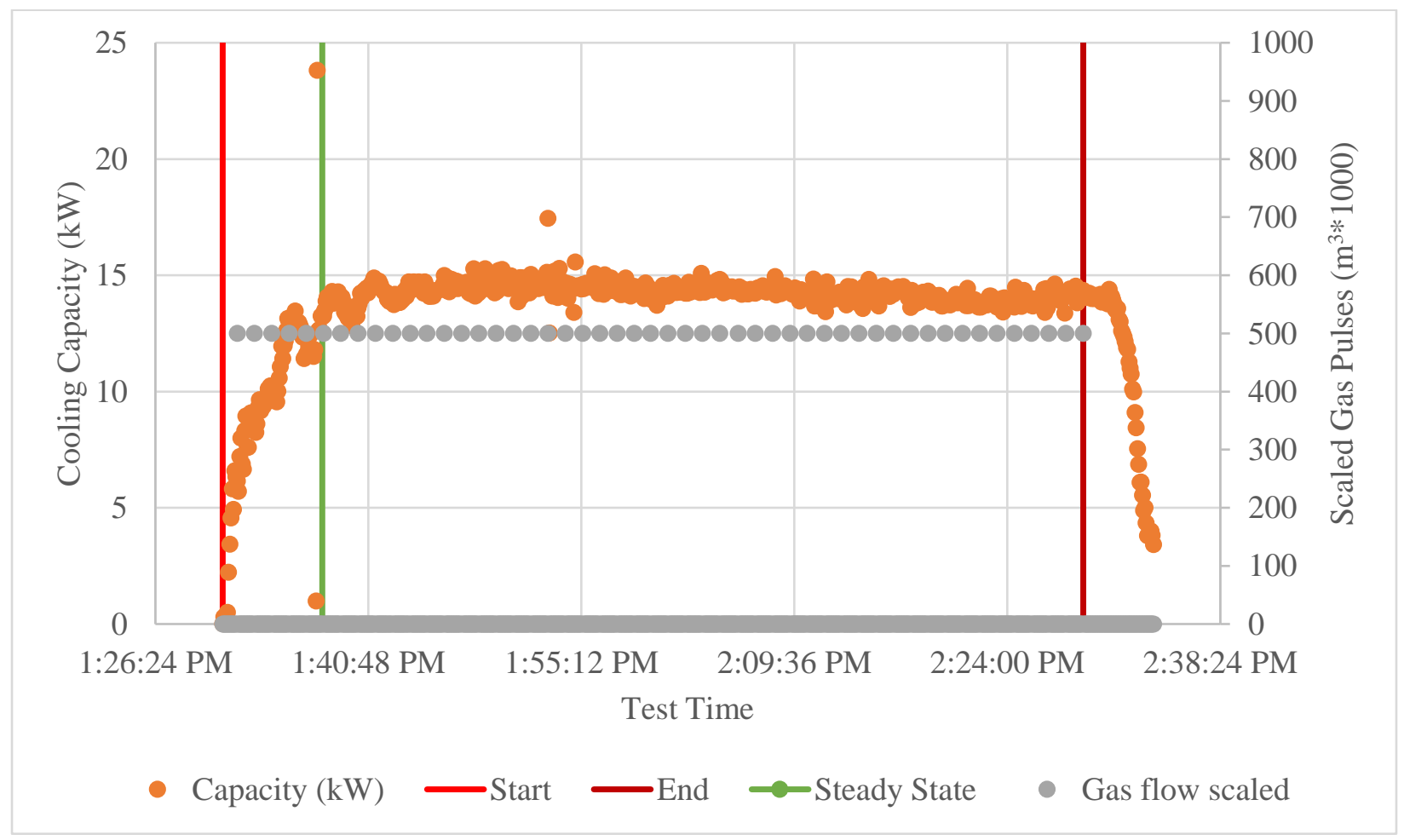

Table C - 1: Sample GAHP cooling cycle showing GAHP start-up and steady state profiles 


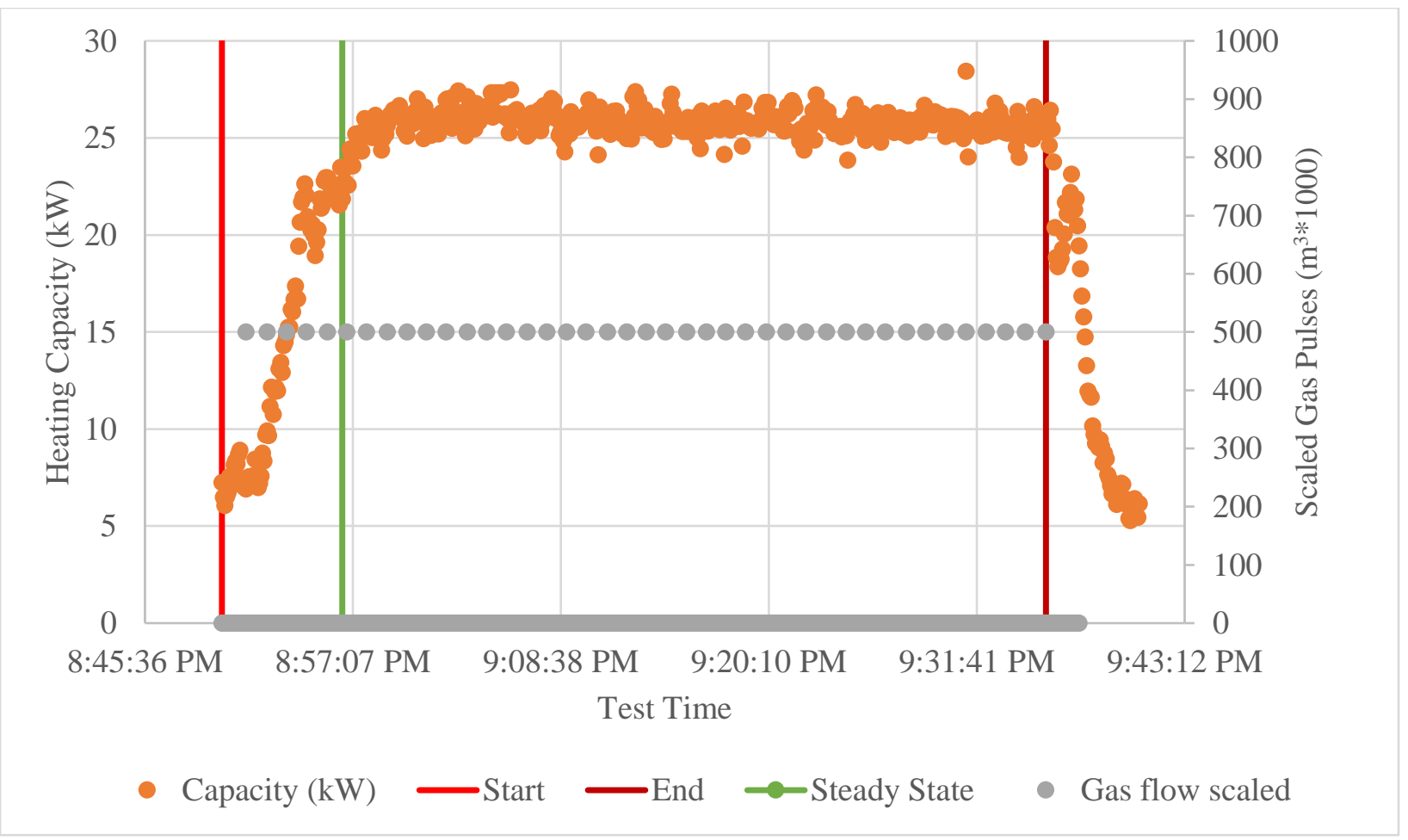

Table C - 2: Sample GAHP heating cycle showing GAHP start-up and steady state profiles 


\section{Appendix D - Uncertainty Analysis}

Uncertainty for experimental data was solved for Equations $4.3-4.5$ which were used in the experimental data analysis. The accuracies used to solve said uncertainties are found listed for each measurement in Table 5.4.

Equations 5.1 and 5.2 for density and specific heat are a function of fluid temperature, which are then in turn used to solve for the heat transfer (capacity) as stated in Equation 4.3. The fluid temperature used to solve for density and specific heat are the average of the supply and return temperatures. The uncertainties of the density and specific heat are incorporated into the uncertainty of the thermal capacity solved using Equation 4.3.

The gas input that was used to solve for the GUE and COP was 98 BTU $(28.7 \mathrm{~kW})$. The power consumption used to solve for the uncertainty of the COP was found in 6.4 and 6.11. The uncertainty for the GUE and COP however, had minimal variance for different flow rates and return temperatures values plotted for heating season and cooling season respectively. As such, are summarized as uncertainties for their respective seasons. A similar case for capacity was found, as varying temperatures showed little variance in uncertainty, whereas flow rate was the most significant factor.

Table D-1 and D-2 summarize the absolute uncertainty of the heating and cooling capacity of the GAHP solved using equation 4.3. Table D-3 summarizes the relative uncertainty of the GUE and COP respectively.

Propagation of uncertainty was calculated for addition according to the formula $\delta Z=$ $\sqrt{(\delta A)^{2}+(\delta B)^{2}+(\delta C)^{2}}$ and for multiplication according to the formula $\delta Z=$ $|Z| \sqrt{\left(\frac{\delta X}{X}\right)^{2}+\left(\frac{\delta Y}{Y}\right)^{2}+\left(\frac{\delta Z}{Z}\right)^{2}}$ where $\delta Z$ represents the combined uncertainty and $\delta \mathrm{A}, \delta \mathrm{B}$, and $\delta \mathrm{C}$ are the uncertainties of the component measurements (Bell, 1999). 
Table D - 1: Uncertainty of heating and cooling capacity from experimental data collection for varying flow rates for respective return temperature range

\begin{tabular}{|c|c|c|c|}
\hline Season & Flow rate (GPM) & $\begin{array}{c}\text { Return temperature } \\
\text { range }\left({ }^{\circ} \mathbf{C}\right)\end{array}$ & $\begin{array}{c}\text { Uncertainty } \\
\mathbf{( \% )}\end{array}$ \\
\hline Heating & $14.8-10.1$ & $32-48$ & \pm 2.45 \\
\hline Cooling & $12.6-10.1$ & $32-48$ & \pm 3.46 \\
\hline
\end{tabular}

Table D - 2: Uncertainty of experimental GUE and COP values for each respective mode of operation

\begin{tabular}{|l|c|c|}
\hline GAHP Operating Mode & Heating & Cooling \\
\hline GUE Uncertainty (\%) & \pm 3.16 & \pm 4.00 \\
\hline COP Uncertainty (\%) & \pm 3.24 & \pm 4.06 \\
\hline
\end{tabular}




\section{Appendix E - MATLAB Scripts}

MATLAB scripts developed in conjunction with STEP at the ASH facility.

\section{MATLAB Robur energy balance script:}

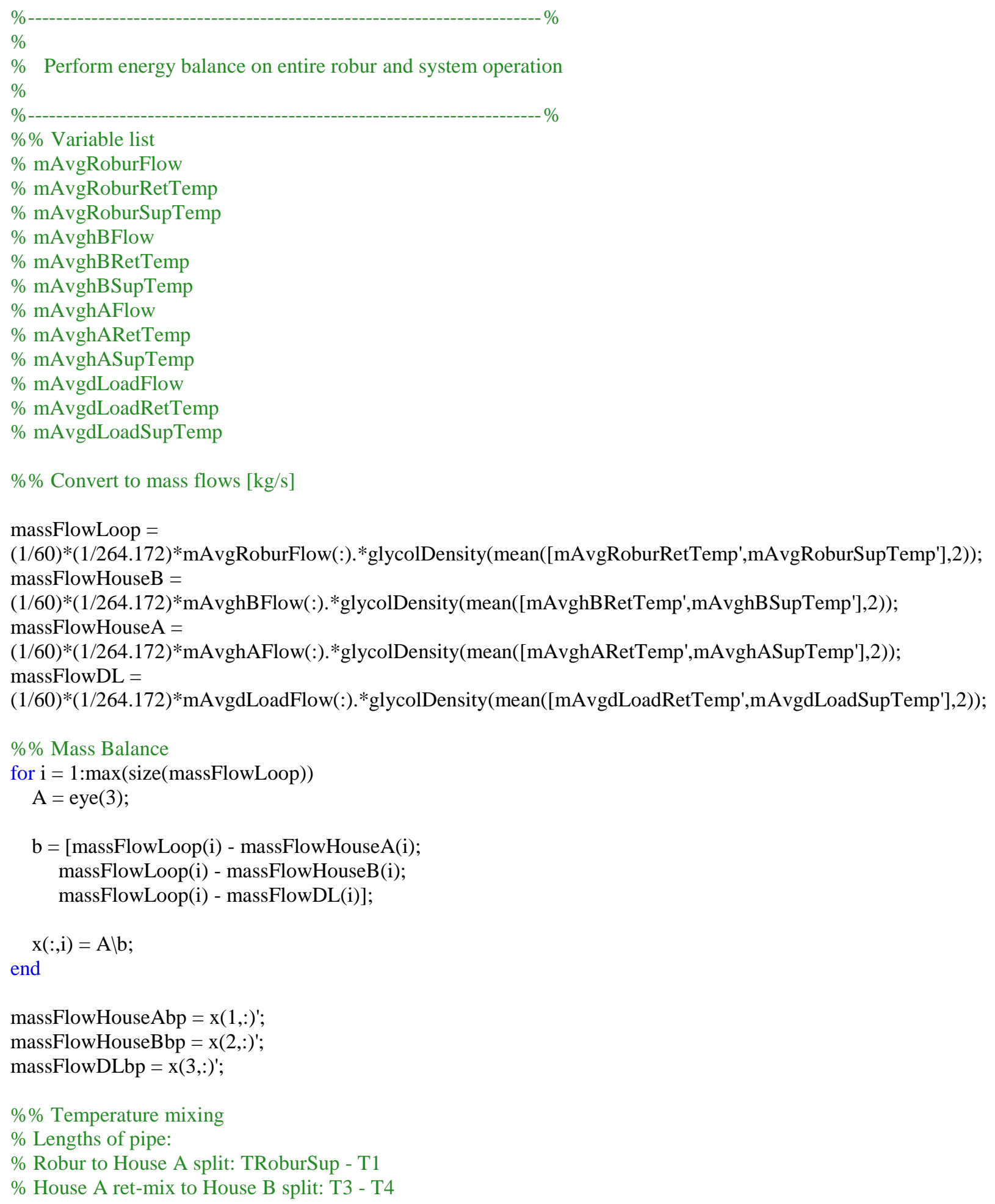




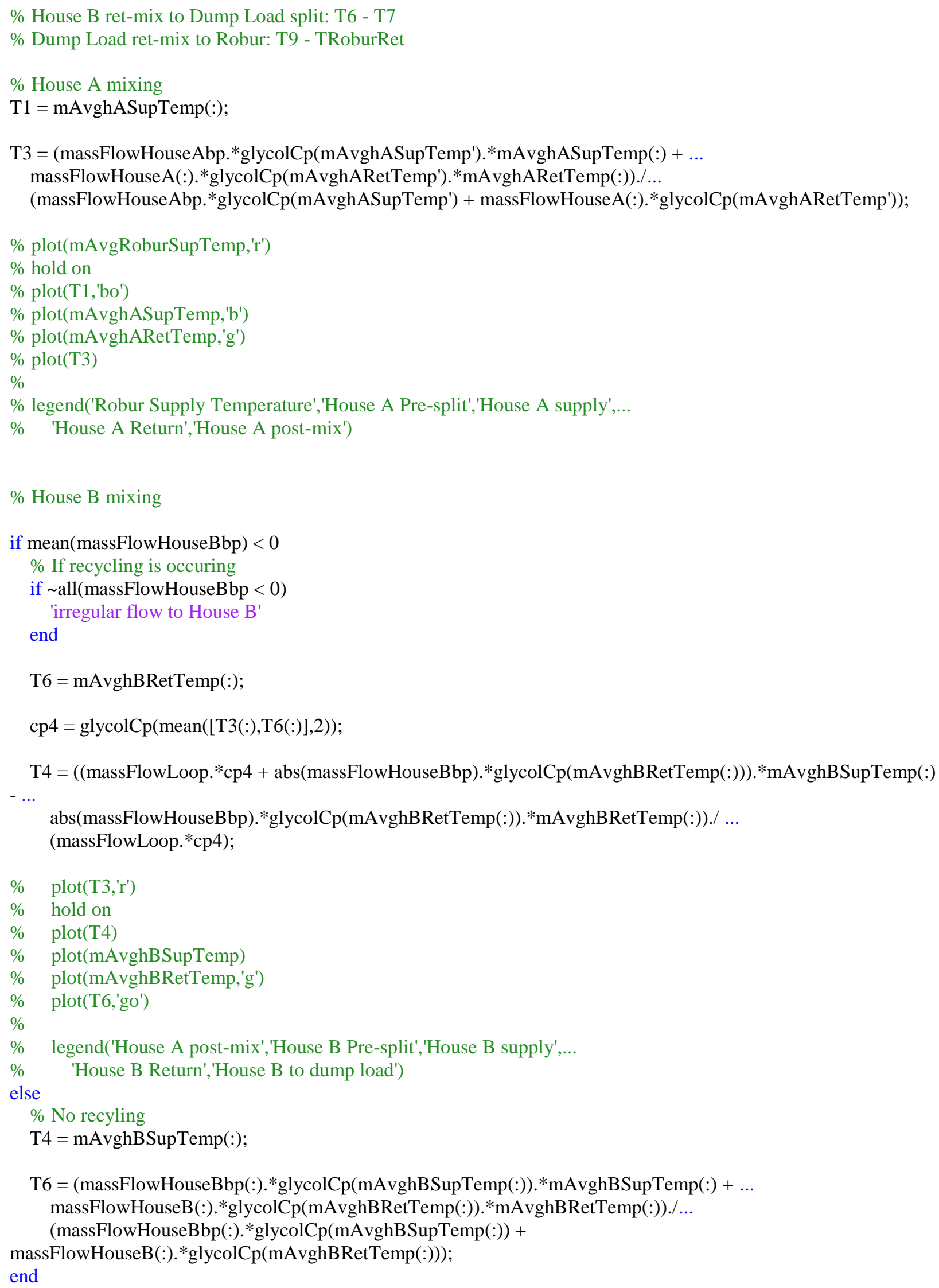




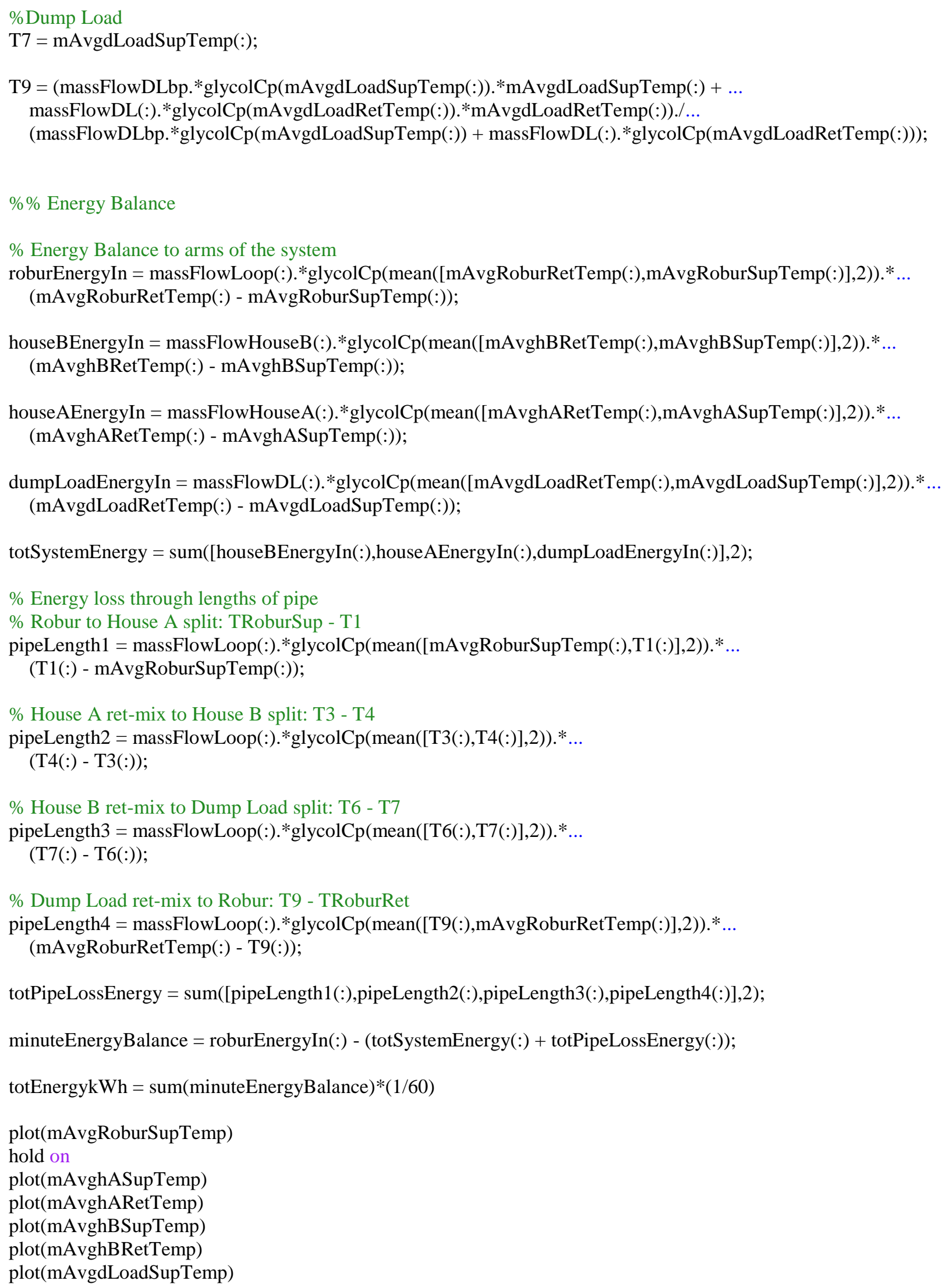


plot(mAvgdLoadRetTemp)

plot(mAvgRoburRetTemp)

legend('Robur Supply Temperature','Inlet to House A','Outlet of House A',...

'Inlet to House B','Outlet of House B','Inlet to Dump Load','Outlet of DumpLoad',...

'Robur Return Temperature') 


\section{References}

Aprile, M., Scoccia, R., Toppi, T., Guerra, M., \& Motta, M. (2016). Modelling and experimental

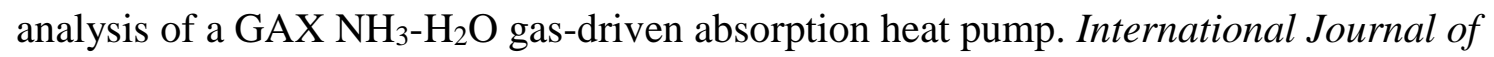
Refrigeration, 66, 145-155.

ASHRAE. (2009). ASHRAE Handbook-Fundamentals. ASHRAE Handbook-Fundamentals. https://doi.org/10.1017/CBO9781107415324.004

Ayadi, O., Mauro, A., Aprile, M., \& Motta, M. (2012). Performance assessment for solar heating and cooling system for office building in Italy. Energy Procedia, 30, 490-494.

Bakhtiari, B., Fradette, L., Legros, R., \& Paris, J. (2011). A model for analysis and design of $\mathrm{H} 2 \mathrm{O}-\mathrm{LiBr}$ absorption heat pumps. Energy Conversion Management, 52(2), 1439-1448.

Bell, S. (1999). A Beginner's Guide to Uncertainty of Measurement. Middlesex, United Kingdom: National Physical Laboratory.

Canadian Gas Association. (2014, December). Renewable Natural Gas Technology Roadmap for Canada.

Casals, X. G. (2006). Solar absorption cooling in Spain: Perspectives and outcomes from the simulation of recent installations. Renewable Energy, 31(9), 1371-1389.

Ciganda, J. L. C., Graf, R., Kühn, A., Schmitt-Gehrke, P., \& Ziegler, F. (2015, April). Operational Experiences and System Improvment Measures for Gas Absorption Heat Pump Systems. IIR Conference: Ammonia and CO2 Refrigeration Technologies.

Colosimo, D. D. (1987). Introduction to Engine-driven Heat Pumps - Concepts, Approach and Economics. ASHRAE Transactions, 93(2), 987-996.

Cruickshank, C. A., \& Harrison, S. J. (2008). Experimental evaluation of a multi-tank thermal storage under variable charge conditions. Joint Conference of the Canadian Solar Building Research Network and the Solar Energy Society of Canada, 1-9.

Dembo, A., Fung, A., NG, K. R., and Pyrka, A. (2010). The Archetype Sustainable House: Investigating Its Potentials To Achieving The Net-Zero Energy Status Based On The Results Of A Detailed Energy Audit, 1st International High Performance buildings conference Purdue University, Purdue.

Dieckmann, J., Zogg, B., Westphalen, D., Roth, K., \& Brodrick, J. (2005). Heat-Only, HeatActivated Heat Pumps. ASHRAE Journal, 47(1), 40-41.

Dincer, I. (2002). On thermal energy storage systems and applications in buildings. Energy and Buildings, 34(4), 377-388. 
Dow Chemical. (2008). Engineering and Operating Guide for DOWFROCT and DOWFROST HD inhibited propylene glycol-based heat transfer fluids, 31.1-31.13.

Eicker, U., \& Pietruschka, D. (2009). Design and performance of solar powered absorption cooling systems in office buildings. Energy and Buildings, 41(1), 81-91.

Energir. (2017). Conditions of Service and Tariff. https://www.energir.com/ /media/Files/Affaires/Tarif/conditionsservicetarif_an.pdf?la=en

EnergyShop. (2018). Natural Gas Choices for Your Home. https://www.energyshop.com/es/homes/default.cfm

Engler, M., Grossman, G., \& Hellmann, H. M. (1997). Comparative simulation and investigation of ammonia-water: absorption cycles for heat pump applications. International Journal of Refrigeration, 20(7), 504-516.

Fan, Y., Luo, L., \& Souyri, B. (2007). Review of solar sorption refrigeration technologies: Development and applications. Renewable and Sustainable Energy Reviews, 11(8), 17581775 .

Fumagalli, M., Sivieri, A., Aprile, M., Motta, M., \& Zanchi, M. Monitoring of gas driven absorption heat pumps and comparing energy efficiency on primary energy. Renewable Energy, 1-11.

Garimella, S., Keinath, C. M., Delahanty, J. C., Hoysall, D. C., Staedter, M. A., Goyal, A., \& Garrabrant, M. A. (2016). Development and demonstration of a compact ammonia-water absorption heat pump prototype with microscale features for space-conditioning applications. Applied Thermal Engineering, 102, 557-564.

Grossman, G. (1991). Absorption heat transformer for process heat generation from solar ponds. ASHRAE Transactions, 97, 420-427.

Heritage Gas. (2017). Rates. http://www.heritagegas.com/rates/

Hydro Québec. (2018). Residential Rates | Rate D.

http://www.hydroquebec.com/residential/customer-space/account-and-billing/understandingbill/residential-rates/rate-d.html

IESO. (2017). An Examination of the Opportunity for Residential Heat Pumps in Ontario.

Ikeuchi, M., Yumikura, T., Ozaki, E., \& Yamanaka, G. (1985). Design and performance of a high-temperature- boost absorption heat pump. ASHRAE Transactions, 90, 2081-94. 
Januševičius, K., Streckienè, G., \& Misevičiūtè, V. (2015). Simulation and Analysis of SmallScale Solar Adsorption Cooling System for Cold Climate. International Journal of Environmental Science and Development, 6(1), 54-60.

Kang, Y., Kunugi, Y., \& Kashiwagi, T. (2000). Review of advanced absorption cycles: performance improvement and temperature lift enhancement. International Journal of Refrigeration, 23(5), 388-401.

Karamangil, M. I., Coskun, S., Kaynakli, O., \& Yamankaradeniz, N. (2010). A simulation study of performance evaluation of single-stage absorption refrigeration system using conventional working fluids and alternatives. Renewable and Sustainable Energy Review, 14(7), 19691978.

Klein, S. A. (2010). TRNSYS 17: A Transient System Simulation Program. Solar Energy Laboratory University of Wisconsin, Madison, USA, 1, 1-5.

Kummert, M., \& Bernier, M. (2008). Analysis of a combined photovoltaic-geothermal gas-fired absorption heat pump system in a Canadian climate. Journal of Building Performance Simulation, 1(4), 245-256.

Kummert, M., Bernier, M., Costa, A., \& Paris, J. (2007). A comparison between geothermal absorption and compression heat pumps for space conditioning. International Journal of Environmental Studies, 64(4), 467-487.

Lostec, B. L., Galanis, N., \& Millette, J. (2013). Simulation of an ammonia-water absorption chiller. Renewable Energy, 60, 269-283.

Macía, A., Bujedo, L. A., Magraner, T., \& Chamorro, C. R. (2013). Influence parameters on the performance of an experimental solar-assisted ground-coupled absorption heat pump in cooling operation. Energy and Buildings, 66, 282-288.

Marc, O., Lucas, F., Sinama, F., \& Monceyron, E. (2010). Experimental investigation of a solar cooling absorption system operating without any backup system under tropical climate. Energy and Buildings, 42(6), 774-782.

Mateus, T., \& Oliveira, A. C. (2009). Energy and economic analysis of an integrated solar absorption cooling and heating system in different building types and climates. Applied Energy, 86(6), 949-957.

Mattinen, M. K., Nissinen, A., Hyysalo, S., \& Juntunen, J. K. (2015). Energy Use and Greenhouse Gas Emissions of Air-Source Heat Pump and Innovative Ground-Source Air Heat Pump in a Cold Climate. Journal of Indoor Ecology, 19(1), 61-70. 
Mendes, L. F., Collares-Pereira, M., \& Ziegler, F. (1998). Supply of cooling and heating with solar assisted heat pumps: an energetic approach. International Journal of Refrigeration, 21(2), 116-125.

Ministry of the Environment and Climate Change. (2016). Ontario's Five Year Climate Change Action Plan 2016-2020, 86.

Murphy, K. P., \& Phillips, B. A. (1984). Development of a residential gas absorption heat pump. International Journal of Refrigeration, 7(1), 123-125.

Nakanishi, T., Furukawa, T., \& Sato, N. (1981). Industrial high-temperature heat pump. Hitachi Zosen Tech Review, 42(1), 7-12.

Natural Resources Canada. (2016). Energy Fact Book: 2015-2016, 1-124.

Natural Resources Canada. (2018). Appendix B - CO2 Emission Factors. Retrieved from http://www.nrcan.gc.ca/energy/efficiency/industry/technical-info/benchmarking/canadiansteel-industry/5193

Navigant Consulting. (2016, September). Fuels Technical Report.

Nova Scotia Power. (2017). Domestic Service Tariff. Retrieved from https://www.nspower.ca/en/home/about-us/electricity-rates-and-regulations/rates/domesticservice-tariff.aspx

Phillips, B. A. (1990). Development of a High-Efficiency, Gas-Fired, Absorption Heat Pump for Residential and Small-Commercial Applications: Phase I Final Report--Analysis of Advanced Cycles. Oak Ridge National Labratory.

Priedeman, D. K., Garrabrant, M. A., Mathias, J. A., Stout, R. E., \& Christensen, R. N. (2001). Performance of a Residential-Sized GAX Absorption Chiller. Journal of Energy Resources Technology, 123(3), 236.

Qin, C., Lu, H., Liu, X., \& Schmitz, G. (2009). Engine-driven hybrid air-conditioning system. Frontiers of Energy and Power Engineering in China, 3(1), 109-116.

Qu, M., Yin, H., \& Archer, D. H. (2010). A solar thermal cooling and heating system for a building: Experimental and model based performance analysis and design. Solar Energy, 84(2), 166-182.

Rameshkumar, A., Udayakumar, M., \& Saravanan, R. (2009). Energy Analysis of a 1-Ton Absorption-Compression (GAXAC) Cooler. ASHRAE Transactions, 115(1), 405-415.

Robur Corporation, (2014). GAHP Line AR Series -Installation, Use and Maintenance Manual. 
Robur Corporation. (2017). Glycol factor tables, 1.

Rosato, A., Sibilio, S., \& Scorpio, M. (2013). A Review of Gas Engine Driven Heat Pumps for Residential Applications. CLIMA 2013.

Rosiek, S., \& Batlles, F. J. (2009). Integration of the solar thermal energy in the construction: Analysis of the solar-assisted air-conditioning system installed in CIESOL building. Renewable Energy, 34(6), 1423-1431.

Safa, A. A., Fung, A. S., \& Kumar, R. (2015a). Performance of two-stage variable capacity air source heat pump: Field performance results and TRNSYS simulation. Energy and Buildings, 94, 80-90.

Safa, A. A., Fung, A. S., \& Kumar, R. (2015b). Heating and cooling performance characterisation of ground source heat pump system by testing and TRNSYS simulation. Renewable Energy, 83, 565-575.

Safa, A. A., Fung, A. S., \& Kumar, R. (2015c). Comparative thermal performances of a ground source heat pump and a variable capacity air source heat pump system for sustainable houses. Applied Thermal Engineering, 81, 279-287.

Sanaye, S., \& Chahartaghi, M. (2010). Thermal modeling and operating tests for the gas enginedriven heat pump systems. Energy, 35(1), 351-363.

Srikhirin, P., Aphornratana, S., \& Chungpaibulpatana, S. (2000). A review of absorption refrigeration technologies. Renewable and Sustainable Energy Review, 5(4), 343-372.

Statistics Canada. (2011). Households and the Environment: Energy Use, 11, 40.

Thomas, S., \& Andre, P. (2012). Numerical simulation and performance assessment of an absorption solar air-conditioning system coupled with an office building. Building Simulation, $5(3), 243-255$.

Toppi, T., Aprile, M., Guerra, M., \& Motta, M. (2016). Numerical investigation on semi-GAX NH3-H2O absorption cycles. International Journal of Refrigeration, 66, 169-180.

Toronto and Region Conservation Authority. (2018). Performance Evaluation of a Gas Abosrption Heat Pump Operating in a Cold Climate. Vaughan.

Velázquez, N., \& Best, R. (2002). Methodology for the energy analysis of an air cooled GAX absorption heat pump operated by natural gas and solar energy. Applied Thermal Engineering, 22(10), 1089-1103. 
Wang, F., Feng, H., Zhao, J., Li, W., Zhang, F., \& Liu, R. (2015). Performance Assessment of Solar Assisted Absorption Heat Pump System with Parabolic Trough Collectors. Energy Procedia, 70, 529-536.

Wang, M., \& Infante Ferreira, C. A. (2017). Absorption heat pump cycles with NH 3 - ionic liquid working pairs. Applied Energy, 204 (December 2016), 819-830. https://doi.org/10.1016/j.apenergy.2017.07.074

Wei, M., Yuan, W., Song, Z., Fu, L., \& Zhang, S. (2015). Simulation of a heat pump system for total heat recovery from flue gas. Applied Thermal Engineering, 86, 326-332.

Withers, P. (2017). Will a huge Irving Oil pipeline discount trigger natural gas price shock in Nova Scotia? | CBC News. Retrieved from https://www.cbc.ca/news/canada/novascotia/irving-oil-natural-gas-price-new-brunswick-nova-scotia-1.4365195

Wu, R. (2009). Energy Efficiency Technologies - Air Source Heat Pump vs. Ground Source Heat Pump. Journal of Sustainable Development, 2(2), 14-23.

Wu, W., Wang, B., Shi, W., \& Li, X. (2014). An overview of ammonia-based absorption chillers and heat pumps. Renewable and Sustainable Energy Review, 31, 681-707.

Wu, W., Wang, B., Shi, W., \& Li, X. (2014). Performance improvement of ammonia/absorbent air source absorption heat pump in cold regions. Building Services Engineering Research and Technology, 35(5), 451-464.

Wu, W., Zhang, X., Li, X., Shi, W., \& Wang, B. (2012). Comparisons of different working pairs and cycles on the performance of absorption heat pump for heating and domestic hot water in cold regions. Applied Thermal Engineering, 48, 349-358.

Wu, W., Zhang, X., Li, X., Shi, W., \& Wang, B. (2012). Energy saving potential of low temperature hot water system based on air source absorption heat pump. Applied Thermal Engineering, 48, 317-324.

Yu, S. W., Jung, Y. J., Kim, S. H., Jo, J. H., Kim, Y. S., \& Cho, Y. H. (2014). A study on the optimized control strategies of geothermal heat pump system and absorption chiller-heater. International Journal of Energy Research, 38(8), 1083-1098.

Zhang, D., Barua, R., and Fung, A. (2011). TRCA-BILD Archetype Sustainable House Overview of Monitoring System and Preliminary Results for Mechanical Systems", ASHRAE Transactions, vol. 117, no. 2, pp. 597-612. 